\title{
A STUDY ON THE VIBRATIONAL PERFORMANCE CHARACTERISTICS OF AN E22 ISOLATOR AFTER OUTGASSING AND BAKE-OUT
}

\author{
A Thesis \\ presented to \\ the Faculty of California Polytechnic State University, \\ San Luis Obispo
}

In Partial Fulfillment

of the Requirements for the Degree

Master of Science in Aerospace Engineering

\author{
by \\ Alma Melendez \\ May 2014
}


(C) 2014

Alma Melendez

ALL RIGHTS RESERVED 
TITLE:

AUTHOR:

DATE SUBMITTED:

COMMITTEE CHAIR:

COMMITTEE MEMBER:

COMMITTEE MEMBER:

COMMITTEE MEMBER:
A Study on the Vibrational Performance Characteristics of an E22 Isolator After Outgassing and Bake-out

Alma Melendez

May 2014

Faysal Kolkailah, PhD, Professor Aerospace Engineering Department California Polytechnic State University, San Luis Obispo

Eltahry Elghandour, PhD, Lecturer Aerospace Engineering Department California Polytechnic State University, San Luis Obispo

Kira J. Abercromby, PhD, Assistant Professor Aerospace Engineering Department California Polytechnic State University, San Luis Obispo

Philip Costanzo, PhD, Associate Professor Chemistry and Biochemistry Department California Polytechnic State University, San Luis Obispo 


\begin{abstract}
A Study on the Vibrational Performance Characteristics of an E22 Isolator After Outgassing and Bake-Out
\end{abstract}

By: Alma Melendez

The launch environment experiences many vibration, shock, and acoustic loads. A great concern is the high random vibration levels that can damage components and spacecraft structures, which can cause a mission failure. An effective method of reducing high frequency energy is using isolators. Overall, the need for vibration isolation has been increasing because there has been an increase in the use of mechanisms in which vibrations are prevalent. In addition, there has not been extensive research on the effects of isolators that are outgassed and cured. Therefore, it is important to investigate and understand the vibrational effects on isolators. It is convenient to outgas and cure isolators for the benefit of some components because that eliminates contamination, but outgassing and bake-out could potentially affect the frequency response of the isolator system in a negative way. It is valuable to investigate how much outgassing and bake-out might affect the performance, if any, of the vibration isolator in order to benefit companies who may need that kind of information. The vibration isolators used for the purpose of this research were twenty E22-02-40 isolators provided by Barry Controls, a Hutchinson Group Company. The E22-02-40 isolators were outgassed and cured (heated at high temperatures) in order to be turned from grade $\mathrm{C}$ into grade $\mathrm{A}$ level for outgassing. Then the vibrational performance of those isolators were tested and compared to the isolators that were not outgassed and not cured. Vibration tests were run in the flat frequency spectrum and high frequency spectrum. The maximum percent difference occurred in the grade A level isolators, in which the first frequency mode increased by $33.3 \%$ in the $\mathrm{z}$ direction from the grade $\mathrm{C}$ isolators. A numerical finite element analysis was performed on Abaqus/CAE in order to verify the experimental results. In addition, a swelling test was conducted on the isolators to test their physical characteristics change after they were outgassed and cured. 


\section{ACKNOWLEDGMENTS}

The support of many people was involved in making this thesis a success. I would like to thank my thesis advisors Dr. Faysal Kolkailah and Dr. Eltahry Elghandour for their support and advice throughout my journey in the completion of this thesis. I would also like to thank Dr. Kira Abercromby and Dr. Philip Costanzo, whose help was vital for the success of this thesis. All of my advisors and committee members took time off their busy schedules to help me and I feel eternally thankful. I am also grateful for the help and knowledge Dr. Eric Kasper provided on Abaqus/CAE, which made it possible to complete my numerical finite element analysis. In addition, Cody Thompson's help with machining the aluminum plate and guidance with some of the vibration tests was essential.

Also, the support of Barry Controls in donating the E22-02-40 isolators was crucial and an enormous encouragement. I am thankful to Jennifer Stanick, from Barry Controls, who was a tremendous support and liaison. She worked really hard to help me and direct me to the right people to answer specific questions.

I would like to thank God, my family and friends because they have been my main cheerleaders throughout my college career. My mother, Hilda Rivera, has been my greatest motivation to complete my thesis and my educational career; she has been my greatest inspiration. Also, the invaluable support, friendship, and love from Gabriel Sanchez was fundamental. I would also like to thank my sister, Estela, for her support 
and inspiring words especially during hard times. Without everyone's love and encouragement it would have been very difficult to stay motivated. I am very grateful for the opportunity to complete this thesis and to all those people who have helped me. 


\section{TABLE OF CONTENTS}

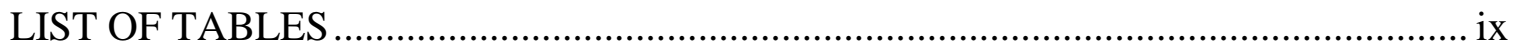

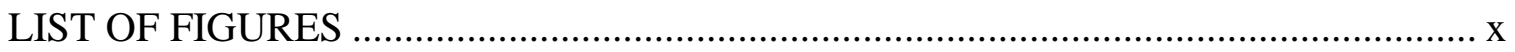

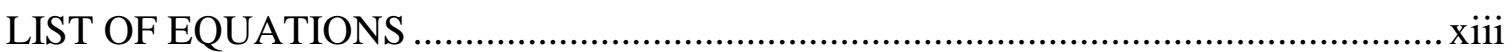

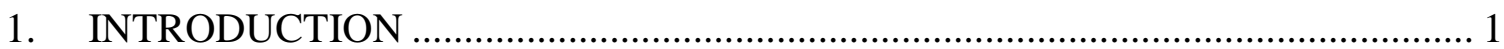

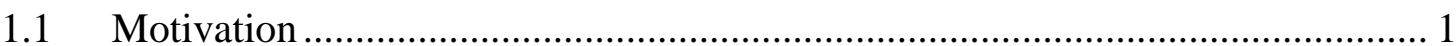

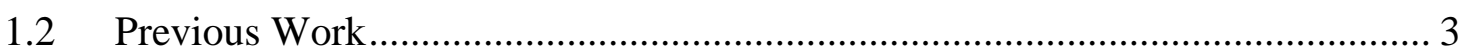

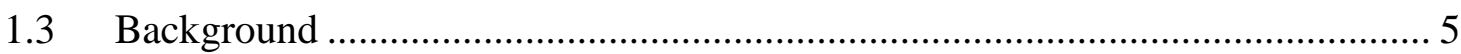

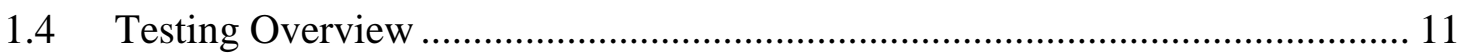

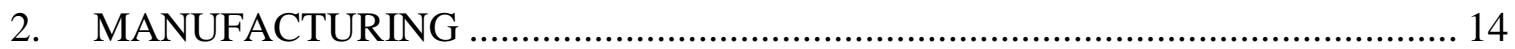

2.1 Carbon fiber composite plate manufactured for vibration tests in order to observe the vibrational performance characteristics of the E22-02-40 isolators for each group .............................................................................. 14

2.2 Tensile testing manufacturing and procedure ................................................ 16

2.3 Aluminum plate development ................................................................. 19

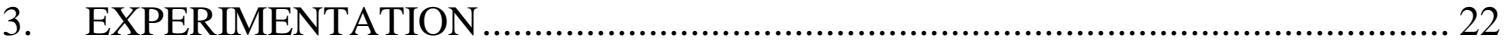

3.1 Acquiring Poisson's Ratio using the Instron machine ...................................... 22

3.2 Experimental Setup and Procedure for outgassing and curing isolators ............ 26

3.3 Experimental Setup and Procedures for vibration table....................................... 32

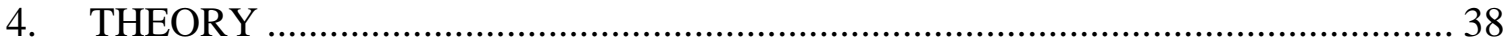

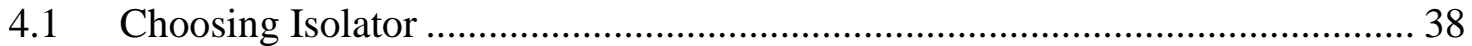

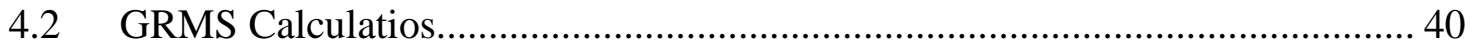

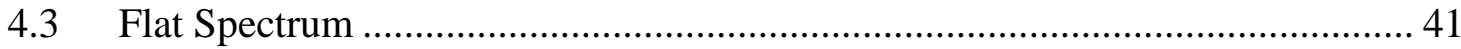

4.4 High Frequency Energy Power Spectral Density Spectrum ............................. 42

5. MATERIAL PROPERTIES RESULTS …………............................................... 44

$5.1 \quad$ Material properties of the carbon fiber.......................................................... 44

6. VIBRATIONAL RESULTS ............................................................................ 47

6.1 Vibrational results from 24 hour outgassed and cured isolator groups with

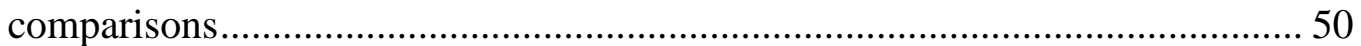

6.2 Comparisons between 24 hours and 36 hours outgassing and bake-out tests.... 55

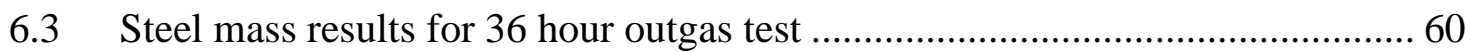

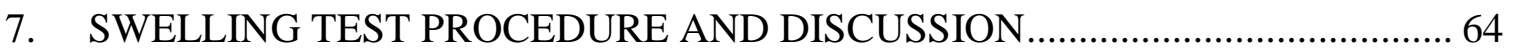

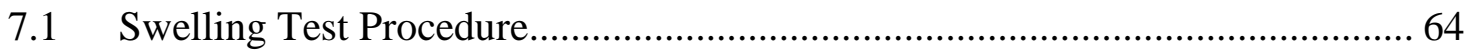

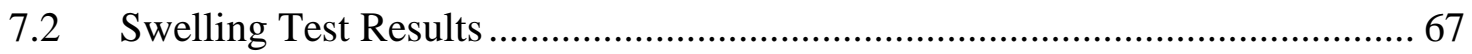


8. NUMERICAL FINITE ELEMENT ANALYSIS ……………………………...... 70

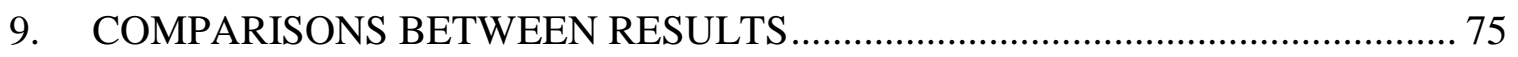

9.1 First and second frequency mode comparison of numerical and experimental

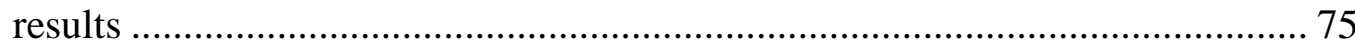

9.2 A comparison in the high frequency spectrum for groups 3,4 , and 6 ............ 76

9.3 A comparison between the experimental and input GRMS values for groups

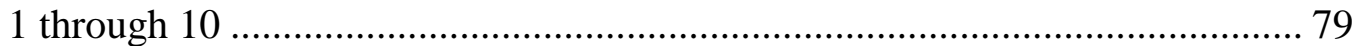

9.4 Comparison of the in-line axes and cross axes in the vibrated $\mathrm{x}, \mathrm{y}$, and $\mathrm{z}$ directions for group 4 in the high frequency spectrum ............................... 81

9.5 A comparison between the maximum frequency values of the cross axes for the vibrated $\mathrm{x}, \mathrm{y}$, and $\mathrm{z}$ orientations belonging to group 3,4 , and 6 ............. 89

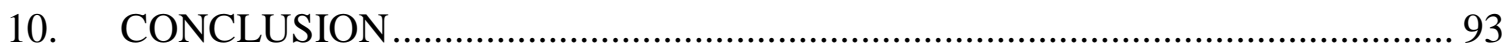

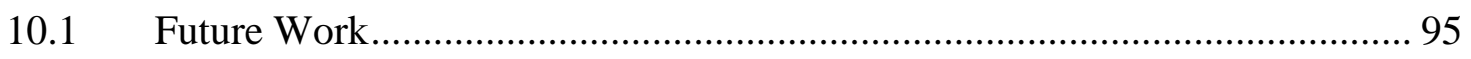

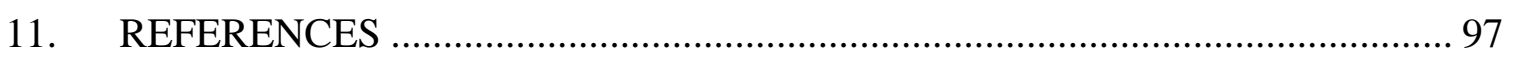

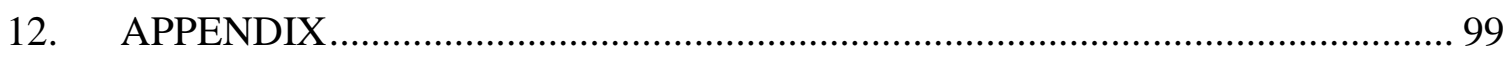

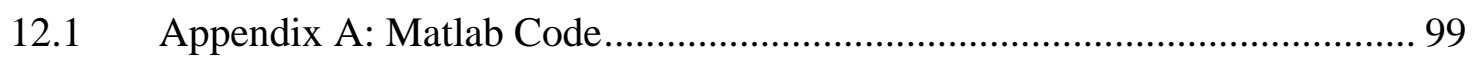

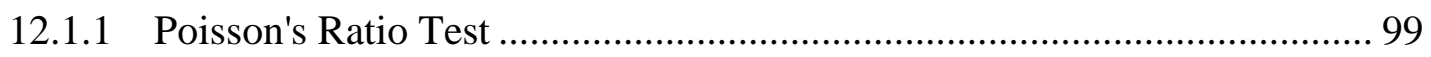

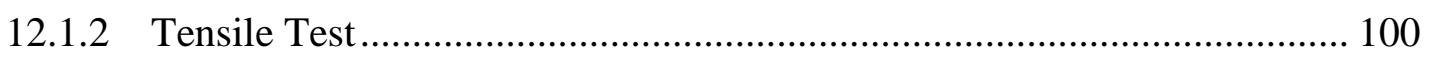

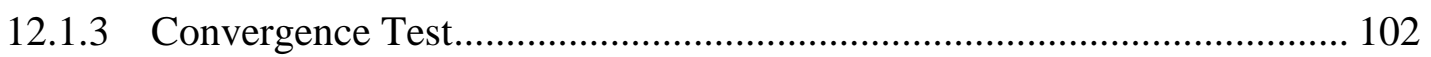

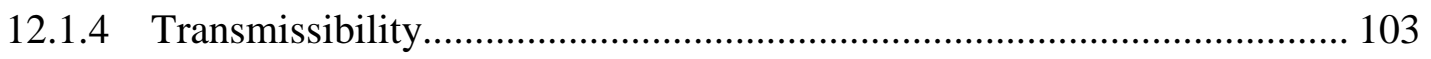

12.1.5 Vibration Tests: Flat and High Frequency Spectrums ........................... 103

12.1.6 GRMS Results and Comparisons...................................................... 116

12.1.7 Swelling Test ............................................................................ 120

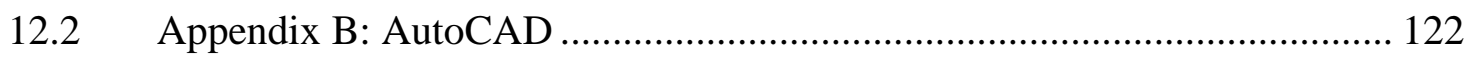

12.3 Appendix C: Triaxial accelerometer information and calibration

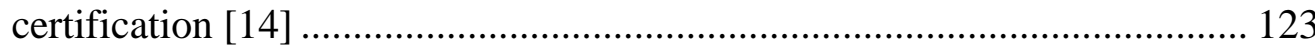

12.4 Appendix D: Raw Data............................................................... 128

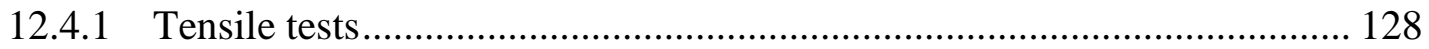

12.5 Appendix E: Curing Cycle for Carbon Fiber Composite Plates.................. 129 


\section{LIST OF TABLES}

Table 1: List of Isolator groups with corresponding time outgassed, temperatures, and spectra.......

Table 2: Comparison between the initial mass and the mass after the post-cure inside the vacuum chamber of the E22-02-40 isolators.

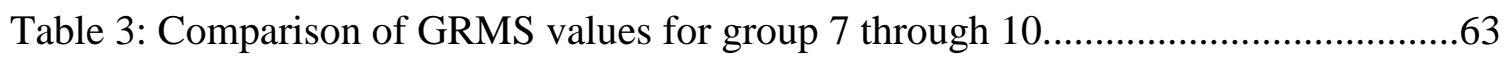

Table 4: Average mass values for the silicone material during the swelling test with the average percent mass increase standard deviation of each group................68

Table 5: Experimental GRMS values of the frequency response in the three vibrated axes for each isolator group.

Table 6: Percent difference and GRMS of the maximum $\mathrm{x}, \mathrm{y}$, and $\mathrm{z}$ axis response for groups $3,4, \& 6$. 


\section{LIST OF FIGURES}

Figure 1: E22-02-40 isolator provided by Barry Controls with upper and lower

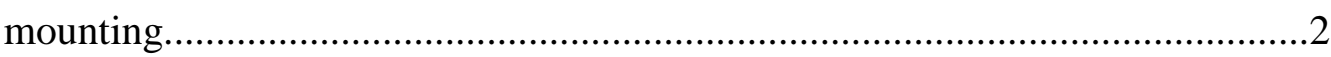

Figure 2: Amplitude and time history of sinusoidal vibration. [8] ............................... 7

Figure 3: Example of amplitude versus time for random vibration. [8] ........................... 8

Figure 4: Schematic on how a passive vibration isolation system works [11] ............... 10

Figure 5: Press table where composite plate was cured............................................. 15

Figure 6: Lay-up for the pre-curing process of the composite plate............................. 16

Figure 7: Instron machine utilized to acquire material properties of the carbon fiber

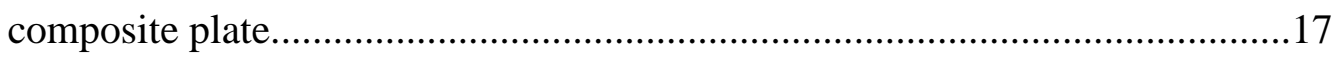

Figure 8: Front view (left) and side view (right) of a carbon fiber composite coupon

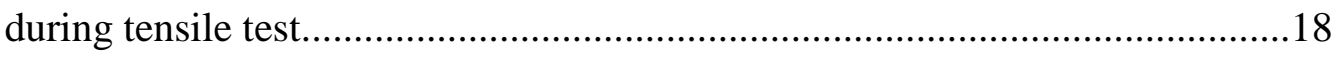

Figure 9: Aluminum plate fixture for mounting onto the vibration table. ...................... 19

Figure 10: Vibration test setup with lead mass.......................................................... 20

Figure 11: Test setup of vibration testing with steel mass...................................... 21

Figure 12: Chemical components used to connect strain gages to carbon fiber test

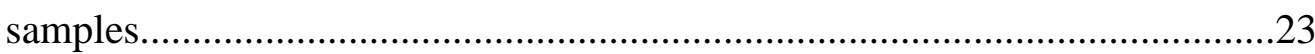

Figure 13: Longitudinal and transverse strain gages mounted on coupons for

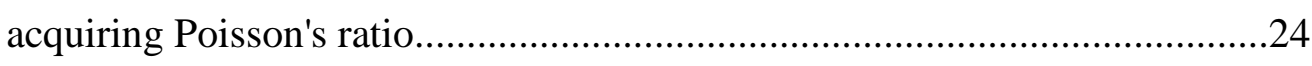

Figure 14: Poisson's ratio test with coupons, strain gages, and strain indicators............. 25

Figure 15: Test setup in the $\mathrm{Z}$ direction for the preliminary consistency flat spectrum

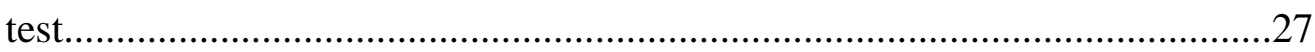

Figure 16: Main components of the student vacuum chamber and test......................... 28

Figure 17: Simple schematic of the vacuum chamber used for outgassing some of the E22-02-40 isolators.

Figure 18: Strip heater setup inside the vacuum chamber with isolators and thermocouple (Top); schematic of the wiring for the bake-out process inside the vacuum chamber (Bottom) ...................................................... 30

Figure 19: Vibration system used for the flat and high frequency energy spectrum tests.33

Figure 20: High frequency energy spectrum and flat spectrum programmed on VWINII...... 


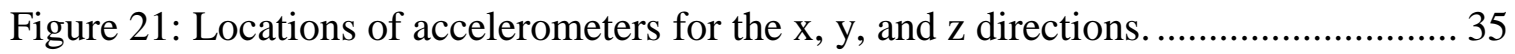

Figure 22: The $\mathrm{x}$ direction orientation for all isolator groups.................................... 35

Figure 23: The y direction orientation for all isolator groups.................................... 36

Figure 24: The $\mathrm{z}$ direction orientation for all isolator groups and test setup. .................. 36

Figure 25: Buttons that operate the amplifier for the vibration table and experiments. ... 37

Figure 26: Minimum workmanship used as a guideline for high frequency spectrum. ... 42

Figure 27: High frequency spectrum programmed for vibration tests.......................... 43

Figure 28: Stress and strain curve used to determine Young's modulus. ........................ 44

Figure 29: Data from longitudinal and transverse strain gages acquired from

Poisson's ratio.

Figure 30: Transverse strain gage and longitudinal strain gage data with error bars for four specimen

Figure 31: Two non-calibrated accelerometers vibrated next to calibrated accelerometer to compare deviation of accuracy in the flat frequency spectrum.

Figure 32: Log of the ASD vs. frequency responses of all the isolator groups for the break-in process in the flat frequency spectrum.....

Figure 33: Comparison of the frequency response of each primary axis (x, y, and z) between group 1 and group 2 in the flat frequency spectrum.......................51

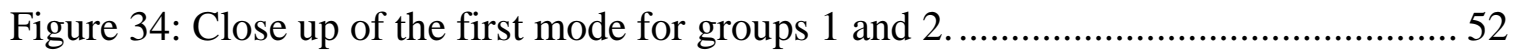

Figure 35: Comparison between group 3 and group 4 in the high frequency energy spectrum

Figure 36: Close up of the first mode for groups 3 and 4 in the high frequency energy spectrum .55

Figure 37: Comparison between groups 5 and 6 in order to see how the isolators performed in the different spectrums......

Figure 38: Comparison between group 2 and 5 in flat spectrum. 58

Figure 39: Comparison between group 4 and 6 in the high frequency energy spectrum. 59 Figure 40: Comparison between group 7 and group 9 in the flat frequency spectrum..... 61 Figure 41: Comparison in the high frequency spectrum for group 8 and group 10........ 62 Figure 42: Individual parts of an E22-02-40 isolator. 64 
Figure 43: Representation of silicone material of the E22-02-40 isolators cut into 1/4

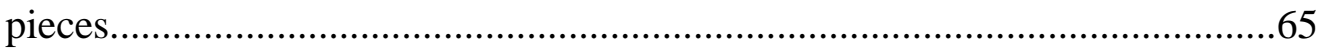

Figure 44: Twelve glass jars for different outgassing cases with silicone materials....... 66

Figure 45: Sartorius high precision scale used to weight the silicone samples for

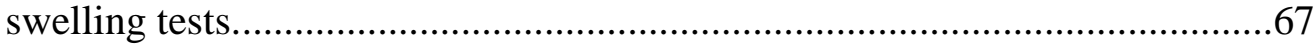

Figure 46: Percent mass increase of silicone material over time for 3 outgassing cases.. 69

Figure 47: Boundary conditions of finite element analysis model. .............................. 70

Figure 48: Side view of boundary conditions representing vibrational experiments. ...... 71

Figure 49: Numerical finite element analysis results of first mode and displacements.... 72

Figure 50: Numerical finite element analysis results of second mode and

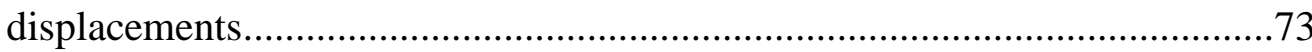

Figure 51: Convergence study of the number of degrees of freedom versus numerical frequency results.

Figure 52: Comparison between numerical and experimental results of 1st and second modes. .76

Figure 53: Comparison in the high frequency spectrum for groups 3,4 , and 6 ............ 77

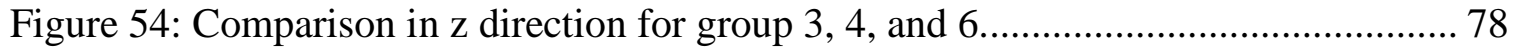

Figure 55: Frequency response of the $\mathrm{x}$ axis and cross axes ( $\mathrm{y}$ and $\mathrm{z}$ ) for the vibrated $\mathrm{x}$ direction of group 4

Figure 56: Frequency response of the y axis and cross axes ( $x$ and $z$ ) in the vibrated $y$ direction of group 4 . .83

Figure 57: Frequency response of the vibrated $\mathrm{z}$ direction and its y cross axis of group 4 84

Figure 58: The $\mathrm{x}$ axis results from vibrating in the $\mathrm{x}$ and $\mathrm{y}$ directions for group 4......... 85

Figure 59: The $\mathrm{y}$ axis results from vibrating in the $\mathrm{x}, \mathrm{y}$ and $\mathrm{z}$ directions for group 4. .... 86

Figure 60: The $\mathrm{z}$ axis results from vibrating in the $\mathrm{x}, \mathrm{y}$ and $\mathrm{z}$ directions for group $4 \ldots \ldots .87$

Figure 61: Maximum data results in the $\mathrm{x}, \mathrm{y}$, and $\mathrm{z}$ axes responses of group 4.............. 88

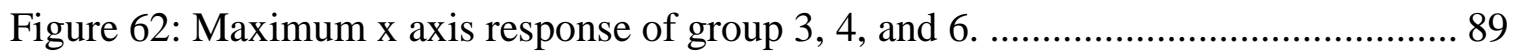

Figure 63: Maximum y axis response of group 3, 4, and 6..................................... 90

Figure 64: Maximum $\mathrm{z}$ axis response of group 3, 4, and 6..................................... 91 


\section{LIST OF EQUATIONS}

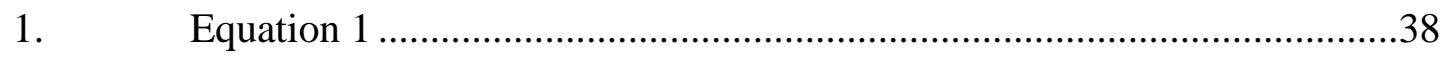

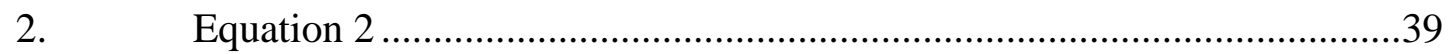

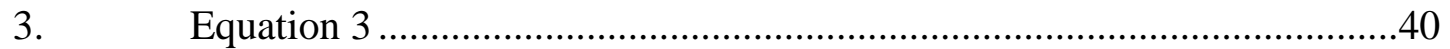

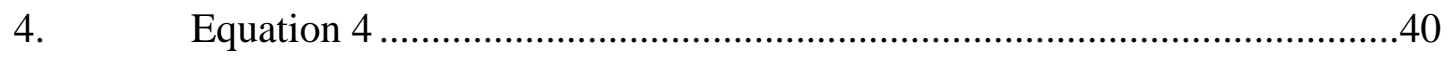

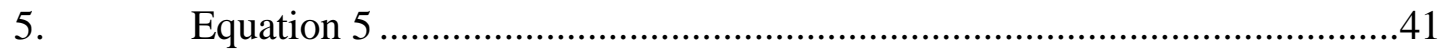




\section{INTRODUCTION}

\subsection{Motivation}

In space and during launch, there are many environments that affect a spacecraft's physical behavior. For the purpose of this thesis the focus will be on the launch environment. In the launch environment, a spacecraft experiences many random vibration levels that may reach $20 \mathrm{~g}$ 's, or more over a short period of time. One of the biggest concerns in this environment is the high random vibration levels that can damage components and spacecraft structure, which can be one of the main causes of a mission failure. One of the most effective methods of reducing outrageous levels is using isolators because they isolate the vibration away from a desired component and absorbs the energy from the oscillation. There are different types of vibration isolator systems used throughout history, but with more rapid technology advancements, vibration is becoming more prevalent and in need of using technology that is up to par with new technological advancements [3].

The knowledge regarding the effects of outgassing and curing isolators is not well known, which is the main purpose of this report. The vibration isolators that will be used for the purposes of this thesis are E22-02-40 isolators provided by Barry Controls. These isolators were chosen because they are economic, rated at a low isolation frequency, triaxial, and used in the aerospace industry, which made them the most appropriate in aiding the investigation of this thesis. Based on a previous study, which will be explained in section 1.2, that converted high damp silicone isolators from grade $\mathrm{C}$ to grade A for 
outgassing helped inspire this thesis. Also, this thesis observed if there were any changes after converting the isolators to a presumed grade A by testing the vibrational performance characteristics of the E22-02-40 isolator before and after outgassing and curing. Figure 1 shows an E22-02-40 isolator that was used in the experiments of this research.

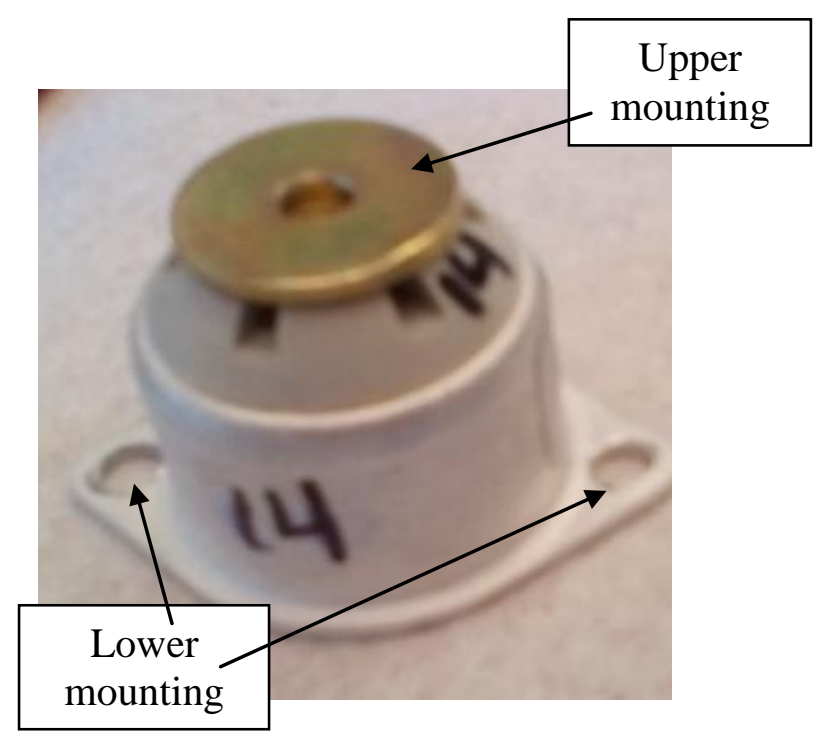

Figure 1: E22-02-40 isolator provided by Barry Controls with upper and lower mounting.

This research utilized the E22-02-40 vibration isolation device to test if the performance of the isolator changed after outgassing and curing. The E22-02-40 isolators were chosen due to their economic costs and performance characteristics. The low profile E22-02-40 series isolator for vibration is good to protect from shock, random vibration, and used on electronic equipment [1]. Its small size is useful for mounting on cramped spaces and it is lightweight, which is beneficial for military and aerospace applications [2]. The E22-0240 vibration isolator has a reliable structure, can survive 30g's and 11 millisecond shock input [2]. 


\subsection{Previous Work}

The study of identifying the characteristics and performance of vibration isolators after baking and outgassing is not well known and established. The most relevant research studies to this thesis are very few.

A study on two different vibration isolation systems and the importance of reducing vibration and shock were explored in the research paper "Protecting Satellites From the Dynamics of the Launch Environment [4]." An excessive amount of dynamic loads and shock loads can cause permanent damage to a spacecraft and sensitive equipment. Therefore, reducing the launch dynamic loads through the use of a whole-spacecraft passive isolation system is a great solution[4]. A whole-spacecraft isolation system is designed to isolate the entire spacecraft from the dynamics experienced by the launch vehicle [4]. The study discussed two types of whole-spacecraft vibration isolation systems: SoftRide system and ShockRing system. Both systems reduced vibrations, but each had a focus that varied on the type of space mission, space vehicle, and launch vehicle. The SoftRide system is a lower frequency isolation system and the ShockRing system works in the higher frequency range. The SoftRide isolation system is mounted by connecting the payload, or structure to the launch vehicle. The ShockRing system is a ring with highly-damped flexures and can be located above, below, or integrated within the payload attach fairing (PAF). Both types of vibration isolation systems have been designed, tested, analyzed, and under development. A patented SoftRide isolation device that was integrated in the mission with a Taurus 2 launch vehicle and spacecraft GFO significantly reduced the vibration level to the payload by $50 \%$ for all the load events [4]. 
An experimental flight program called VALPE (Vibro-Acoustic Launch Protection Experiment) was sponsored by the Air Force Research Laboratory and Air Force Space Test Program in order to test the ShockRing system [4]. The flight data showed that the ShockRing system reduced the acceleration levels and protected the sensitive equipment inside the spacecraft. The significance of this report proved that vibration isolators are very essential to reducing the launch environment risks and increasing the survivability of the spacecraft and mission, especially during launch.

Another study conducted on isolators was performed on Barry Controls' Hi-Damp silicone isolators, named the CP6004 and CP6015 [5]. The study was performed to determine possible outgassing characteristics of the Hi-Damp isolators to meet NASA's specifications for acceptable outgassing limits [5]. The isolators were considered to be a grade $\mathrm{C}$ level for outgassing and required an additional curing and outgassing cycle in order to be used in space. Barry Controls tested the Hi-Damp isolators to determine the post cure that would meet NASA's standards for acceptable outgassing limits. Once the post cure was determined the isolators were tested to verify that they met the outgassing requirements. The Hi-damp isolators were post cured at a pressure of $10^{-3}$ Torr, or less for 12 hours and a temperature of $149{ }^{\circ} \mathrm{C}$ and outgassed for an additional 24 hours at a temperature of $204{ }^{\circ} \mathrm{C}$. The cure was performed in order to convert an off-the-shelf isolator, grade $\mathrm{C}$, to grade $\mathrm{A}$ for outgassing. The results proved that the post cure met the ASTM E-595-84 criteria with a maximum volatile condensable material content (VCM) of $0.1 \%$ and a total mass loss (TML) of $1.0 \%$ maximum [5]. 
Both studies are important because one shows the importance of vibration isolation devices and the other shows the importance of meeting outgassing requirements to reduce contamination. This thesis will combine both studies by outgassing E22-02-40 isolators at the specified post cures and testing the performance characteristics of the isolators before and after the post cures.

\subsection{Background}

In the aerospace, automobile, and construction industry, composites have become very popular due to its weight to strength ratio. Composites provide needed properties that the combined materials offer. Composites exhibit desirable physical and chemical properties that include lightweight properties with high stiffness and strength along the direction of the reinforcing fiber. The aerospace industry frequently uses composites because they reduce mass and still provide the required structural strength for spacecraft. A common type of composite is the fiber-matrix type. Fiber is the material that improves the stiffness of the composite, and the matrix is usually a resin that further holds the fibers together. The carbon fibers can be oriented in different angles to withstand buckling and/or shear. Composites are made from embedding the fibers, or particles in a continuous matrix of a polymer, metal, or ceramic. Composite structures can become very complicated and are analyzed in computer programs such as Abaqus/CAE, GeoStar/COSMOS, Patran/Nastran, which can perform structural analysis and modal analysis.

To simplify and better understand complex structures, plates can be modeled to represent complex airplane wings, bridges, spacecraft antennae, and other plate-like structures. Therefore, analyzing the theoretical and experimental structural plates under certain 
loading conditions will help to understand the behavior of actual structures with similar conditions. A recurring problem in spacecraft design, is determining the dimensions of plate elements in order to prevent harmful deformations due to buckling [6]. In spacevehicles, buckling can cause undesirable degradation in the aerodynamic profile, failure, fatigue, or aeroelasticity phenomena [6]. Natural frequency of plates must also be determined to better understand the vibrational considerations when designing its structure.

The natural frequency and resonance of a system can be desirable or undesirable. The frequency a system oscillates at is its natural frequency after disturbed. In musical instruments, the natural frequency is desirable because it provides the operational vibrations for musical instruments to create musical notes. In comparison, undesirable vibrations are in the form of wasted energy and noise in most mechanical systems. Natural frequency can be obtained by free or forced vibrations. Free vibration occurs when a mechanical system is set off with an initial input and allowed to vibrate freely [7]. In contrast, forced vibration occurs when an external force or motion is purposely applied. Resonance is the buildup of large vibration amplitude that occurs when a structure or system is excited at its natural frequency, which can be desirable or undesirable depending on the system [7].

In musical instruments, resonance is a desirable result when played or tuned at its natural frequency. Undesirable mechanical resonances can be extremely harmful to mechanical systems, such as, buildings, bridges, spacecraft, aircraft, and other machinery. If a 
structure is forced to oscillate at its natural frequency, the system could fracture or fatigue during the time of resonance.

A very realistic method of simulating a dynamic environment is random vibration. Some examples of random vibration are experienced during a spacecraft launch, ocean waves, driving a car on a bumpy road or bicycle, or flying in an airplane [8]. Random vibration occurs at unpredictable points in time with small or large amplitudes [8]. A different frequency dependent loading function is sinusoidal vibration, which is the simplest motion because it is cyclic and repetitive. Figure 2 shows the amplitude and time plot of a sinusoidal vibration. The figure illustrates that the motion can be predicted as long as time and amplitude, or frequency and amplitude are defined [8].

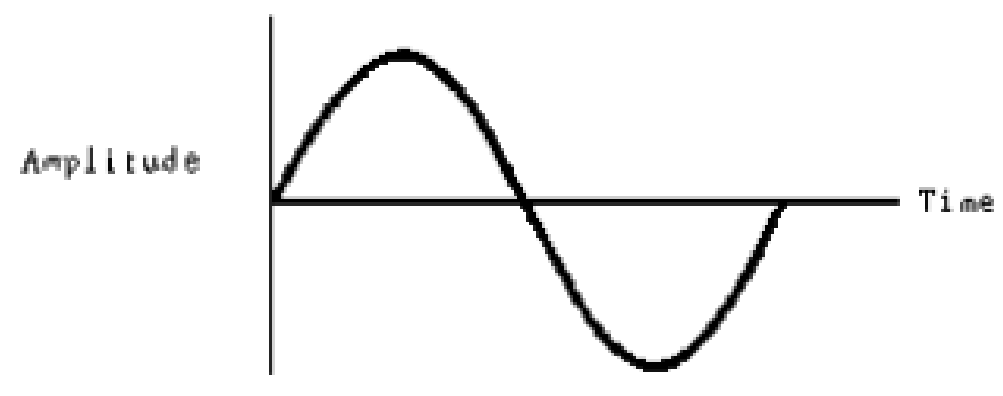

Figure 2: Amplitude and time history of sinusoidal vibration. [8]

Unlike periodic/sinusoidal vibrations, random vibrations cannot be predicted and numerous frequencies can be excited at the same time [9]. Figure 3 below shows an example of random vibration. 


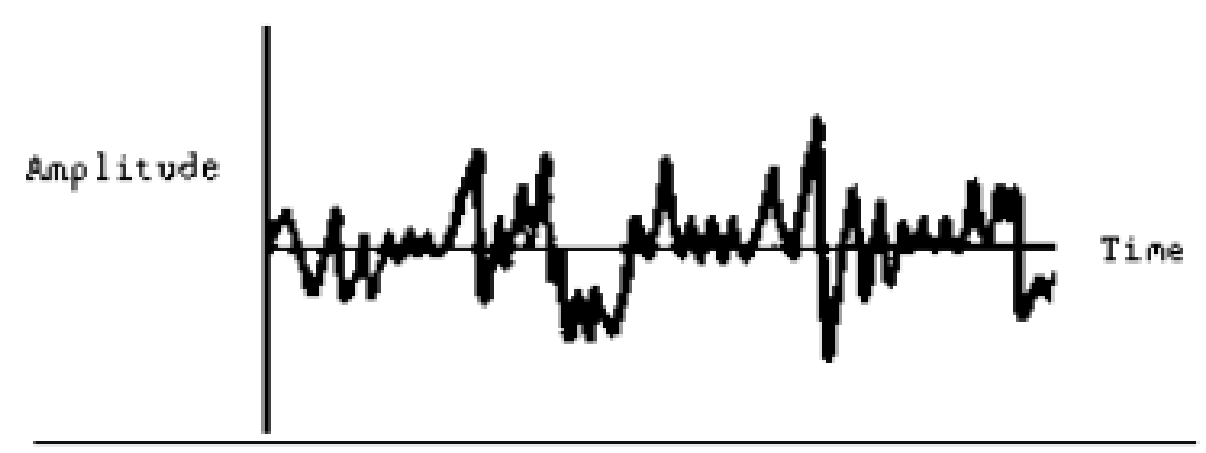

Figure 3: Example of amplitude versus time for random vibration. [8]

Figure 3 shows a multiple number of high peaks during a period of time with no evident pattern [8]. Since random vibration cannot be predicted, a probabilistic or statistical approach is used to treat the structural response of random vibration systems. The acceleration spectral density (ASD) and power spectral density (PSD) are used to specify random vibration. Power spectral density is defined by the distribution of power over the frequency range of excitation [8]. The GRMS (G force Root Mean Square) values is important in random vibration because it is the square root of the area under the ASD versus frequency curve. The GRMS value usually expresses the overall energy of a random vibration frequency response.

A widely used standard for random vibration is SMC-S-016, or commonly known as MIL-STD-1540. The purpose of the MIL-STD-1540 is to establish the environmental and structural requirements for any type of launch vehicles, space vehicles, and their components [9]. The standard contains different type of test categories such as development, qualification, acceptance, flight proof and proto-qualification, and prelaunch validation and follow-on operational and evaluations [9]. In this report, the 
acceptance test from MIL-STD-1540 version C was followed for the high frequency spectrum and the amplitude was increased in the higher frequency range.

The main purpose of an isolator is to protect components from damaging vibrations that can reach very high frequencies. The vibration isolator is defined as a device that absorbs the energy of oscillations from a component of working machinery, or electrical equipment. The ultimate goal of vibration isolators is to create vibration isolation between a body transferring mechanical vibrations and a supporting body or structure [10]. The common structure of a vibration isolator contains a rubber envelope that is internally reinforced by a spring. When the isolator is manufactured, the rubber material and the spring are connected permanently [10]. When weight is applied on the machine or body, the rubber material deforms as it absorbs the vibration and the spring compresses or stretches [10]. Therefore, the design of the isolator must take into account the amount of elastic deformation of the rubber material, the spring, the potential to shock loadings, the daily vibration exposure, the long-term durability, and the convenient integration into the applied environment [10].

In addition to vibration isolators, there are passive and active approaches to isolating sensitive equipment from the effects of vibration [3]. Each approach has its benefits and weaknesses. The traditional approach is the passive system that uses springs and dampers. Figure 4 shows a basic diagram on how a passive vibration isolation system works. 

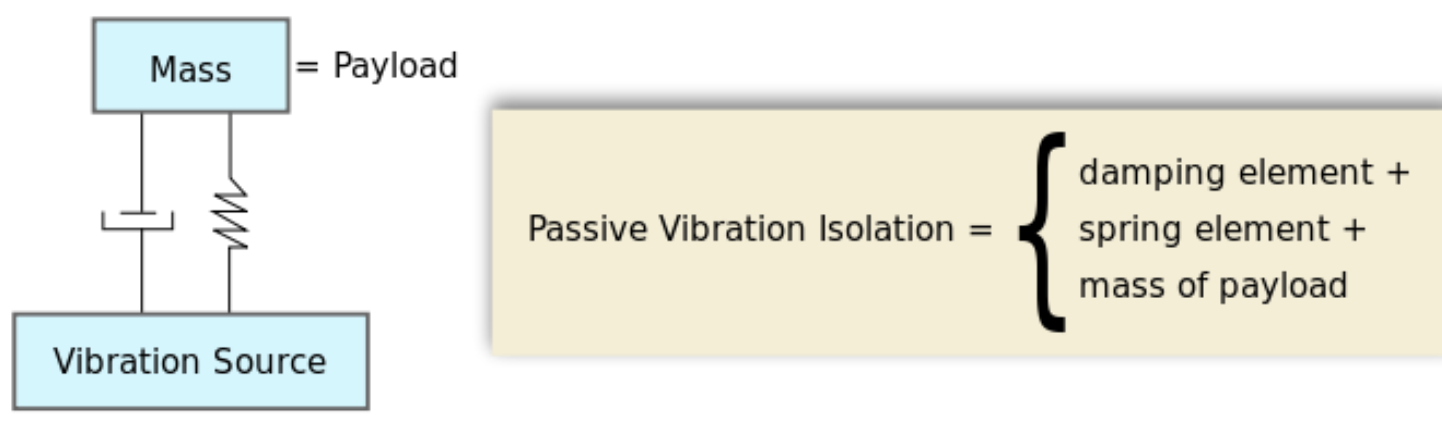

Figure 4: Schematic on how a passive vibration isolation system works [11].

As the spring resists the movement of the vibration, the damper removes kinetic energy[3]. However, the spring can become an amplifier if the frequency of the vibration reaches the natural frequency of the spring. Some examples of passive systems include air tables, mechanical springs and spring-dampers, pads or sheets of flexible materials such as elastomers, rubber, cork, wire rope isolators, base isolators for seismic isolation of buildings and bridges, and much more [10].

In contrast, active vibration isolation systems contain a spring, a feedback circuit that consists of a sensor, controller, and actuator. A control circuit and an amplifier process the vibration signal, and then the electromagnetic actuator is fed through and amplifies the signal [3]. The feedback system creates a stronger suppression of the vibrations than a damper. Active isolator systems are typically used in structures smaller than a micrometer [10]. Some examples of companies and industries that make active vibration isolator systems include Halcyonics $\mathrm{GmbH}$, Technical Manufacturing Corporation, metrology, lithography, medical systems, and microchips [10]. 


\subsection{Testing Overview}

This project investigated the performance characteristics of E22-02-40 isolators before and after outgassed and cured. Twenty E22-02-40 isolators were donated by Barry Controls. They were numbered 1 through 20 and separated into five groups of four isolators. Each group was vibrated, one group at a time, in the $\mathrm{z}$ direction in a flat spectrum of $0.1 \mathrm{~g}^{2} / \mathrm{Hz}$ in order to demonstrate that the isolators had similar response values. After the frequency responses of each group were compared, one group (isolator numbers 13-16) proved to be inconsistent from the others, and was removed (Explained in section 6.0). The remaining 16 isolators were then separated into four groups of four. Two groups of isolators were outgassed and cured for 24 hours and the other two groups were not outgassed and not cured. A total of ten isolator groups were tested and shown in Table 1. Groups one (isolator numbers 1-4) and three (isolator numbers 5-8) were outgassed and cured for 24 hours, where group one was vibrated in the flat spectrum and group three vibrated in the high frequency spectrum. Out of the two groups that were not outgassed and not cured, group two (isolator numbers 9-12) was vibrated in the flat spectrum and group four (isolator numbers 17-20) vibrated in the high frequency spectrum. A fifth group was created out of the original 16 isolators in order to perform more tests. The fifth group was taken from group two and outgassed for a total of 36 hours at a temperature of $149{ }^{\circ} \mathrm{C}$ for the first 12 hours and $204{ }^{\circ} \mathrm{C}$ for the remaining 24 hours. Group five was vibrated in the flat spectrum. Group five will also be vibrated in the high frequency spectrum, but from now on will be labeled as group six. The numbering and details of the isolator groups will be explained with more detail throughout this report. The six groups were vibrated in the flat and high frequency 
spectra with a 10 pound lead mass. Isolator groups 7 through 10 were vibrated with a 10 pound steel mass. Group 7 and 8 used the isolators from group 5 and vibrated in the different spectrums shown in Table 1.

Table 1: List of Isolator groups with corresponding time outgassed, temperatures, and spectra.

\begin{tabular}{|c|c|c|c|c|}
\hline $\begin{array}{c}\text { Group } \\
\#\end{array}$ & $\begin{array}{c}\text { Time } \\
\text { outgassed } \\
\text { (hours) }\end{array}$ & $\begin{array}{c}\text { Temperature } \\
\left({ }^{\circ} \mathbf{C}\right)\end{array}$ & $\begin{array}{c}\text { Frequency } \\
\text { Spectrum }\end{array}$ & $\begin{array}{c}\text { Material of } \\
\mathbf{1 0} \pm .01 \quad \mathbf{l b} \\
\text { Mass }\end{array}$ \\
\hline 1 & 24 & $125 \pm 5^{\circ} \mathrm{C}$ & Flat & Lead \\
\hline 2 & 0 & 0 & Flat & Lead \\
\hline 3 & 24 & $125 \pm 5^{\circ} \mathrm{C}$ & High & Lead \\
\hline 4 & 0 & 0 & High & Lead \\
\hline \multirow{2}{*}{5} & 12 & $149 \pm 10^{\circ} \mathrm{C}$ & \multirow{2}{*}{ Flat } & \multirow{2}{*}{ Lead } \\
\hline & 24 & $204 \pm 10^{\circ} \mathrm{C}$ & & \\
\hline \multirow{2}{*}{6} & 12 & $149 \pm 10^{\circ} \mathrm{C}$ & \multirow{2}{*}{ High } & \multirow{2}{*}{ Lead } \\
\hline & 24 & $204 \pm 10^{\circ} \mathrm{C}$ & & \\
\hline \multirow{2}{*}{7} & 12 & $149 \pm 10^{\circ} \mathrm{C}$ & \multirow{2}{*}{ Flat } & \multirow{2}{*}{ Steel } \\
\hline & 24 & $204 \pm 10^{\circ} \mathrm{C}$ & & \\
\hline \multirow{2}{*}{8} & 12 & $149 \pm 10^{\circ} \mathrm{C}$ & \multirow{2}{*}{ High } & \multirow{2}{*}{ Steel } \\
\hline & 24 & $204 \pm 10^{\circ} \mathrm{C}$ & & \\
\hline 9 & 0 & 0 & Flat & Steel \\
\hline 10 & 0 & 0 & High & Steel \\
\hline
\end{tabular}

Lastly, groups 9 and 10 used the four isolators from group 4 because they were the only isolators left that were not outgassed and not cured. The setup and procedure of the vibration tests are explained in section 3. After vibrating the different isolator groups, twelve isolators were taken apart and placed in a solvent for a total of 11 days and measured throughout that time in order to perform a swelling test. These experiments helped to further investigate the performance characteristics of the E22-02-40 isolators. 
The swelling test also confirmed the physical changes of the silicone damping material from each isolator, which applied to the groups that were not outgassed and not cured, the groups that were outgassed and cured for 24 hours, and the groups outgassed and cured for 36 hours. 


\section{MANUFACTURING}

\subsection{Carbon fiber composite plate manufactured for vibration tests in order to observe the vibrational performance characteristics of the E22-02-40 isolators for each group}

The carbon fiber composite material (T3001K5H/M74 bidirectional woven carbon fiber) was donated by Hexcel and manufactured in the Structures Laboratory at California polytechnic State University in San Luis Obispo. This carbon fiber composite plate was a pre-preg and a bidirectional matrix. The symmetrical carbon fiber composite plate was cured in the press table, as seen in Figure 5. Each composite plate was constructed with sixteen layers of bio direction woven carbon fibers. The curing cycle was a 2 hour cure at a temperature of $350{ }^{\circ} \mathrm{F}$ at a force of $244 \mathrm{lbs}$ (see Appendix E for the curing cycle figure). The number of layers was used to ensure that the carbon fiber composite plate would be very stiff during the vibration tests and to decrease the chances of fracturing. 


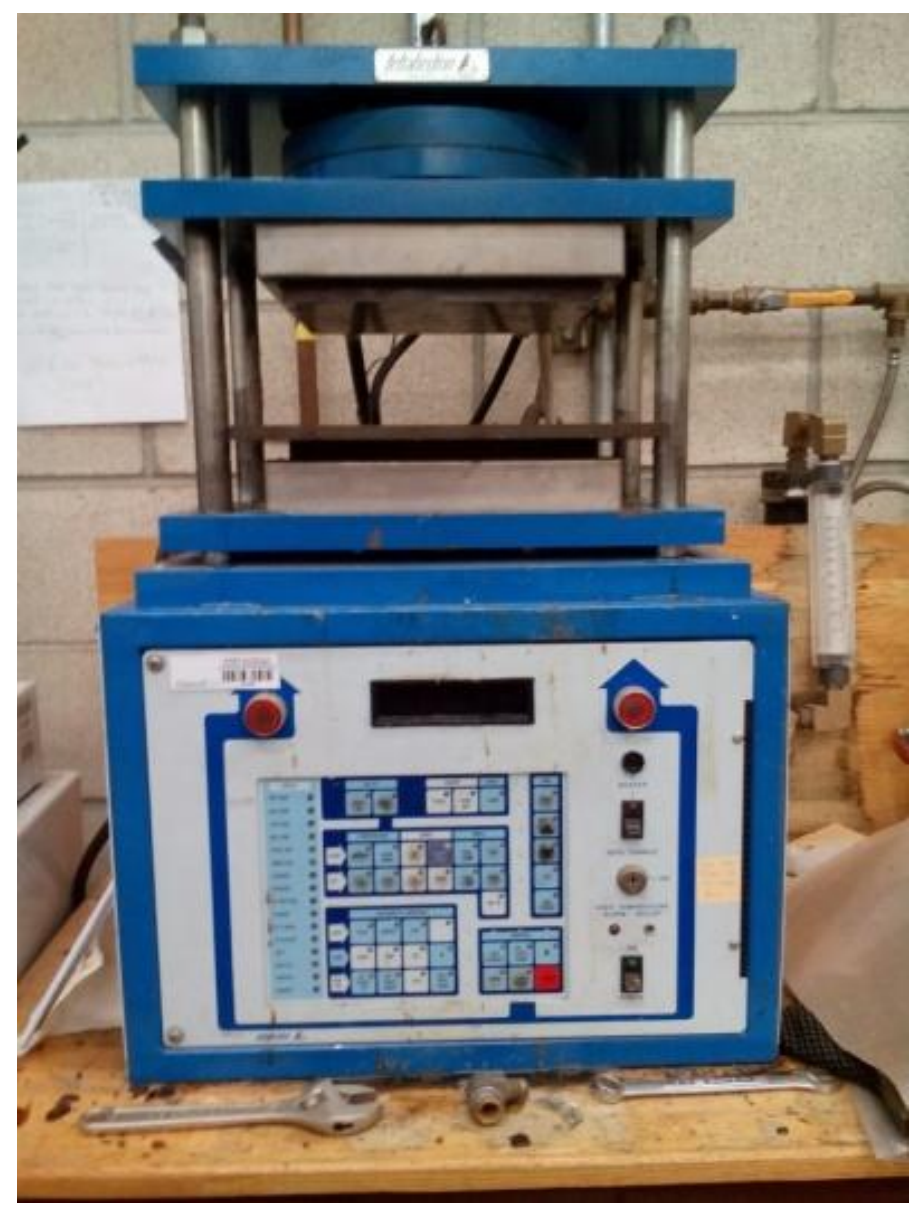

Figure 5: Press table where composite plate was cured.

Figure 6 shows the lay-up that went into the steel plates of the press table, which included two non-porous sheets (11 inch by 11 inch sheets), two porous sheets (11 inch by 11 inch sheets), the sixteen layer plate that measured 11 inches by 12 inches and the steel plates that helped cure the carbon fiber composite plate. 

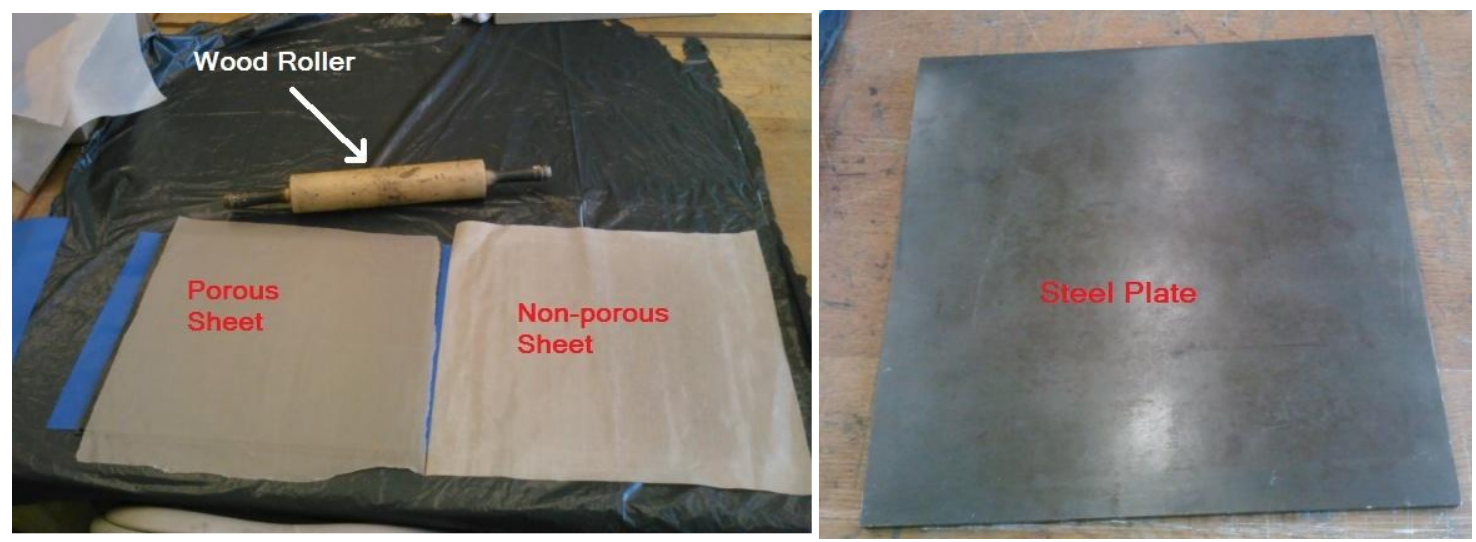

Figure 6: Lay-up for the pre-curing process of the composite plate.

The layers consisted of the carbon fiber composite plate in the middle with a porous sheet on the top and bottom of the composite plate, followed by a non-porous sheet on the top of the porous sheet and a non-porous sheet on the bottom of the bottom porous sheet. While applying the layers on the carbon fiber composite plate and the setup for the press table the wood roller was used to remove any air bubbles. Then a steel plate was placed on the top and bottom of the non-porous sheets. The carbon fiber composite plate was made with larger dimensions in order to have extra material when cut to 0.254 meters by 0.254 meters (10 inches by 10 inches) in the tile saw. A total of two carbon fiber composite plates were manufactured. One plate was utilized to determine the material properties with an Instron 8801 servo-hydraulic testing system machine and the other composite plate was used during the vibration tests.

\subsection{Tensile testing manufacturing and procedure}

The material properties of the carbon fiber plate were determined by performing a tensile test on the Instron machine, as seen in Figure 7, set inside the Aerospace Structures Laboratory. The Instron machine can record all testing data such as, stress, strain, load, 
elongation, and ultimate stress. The data for each sample was recorded on the Instron's computer, and analyzed to obtain the Young's modulus of the composite plate.

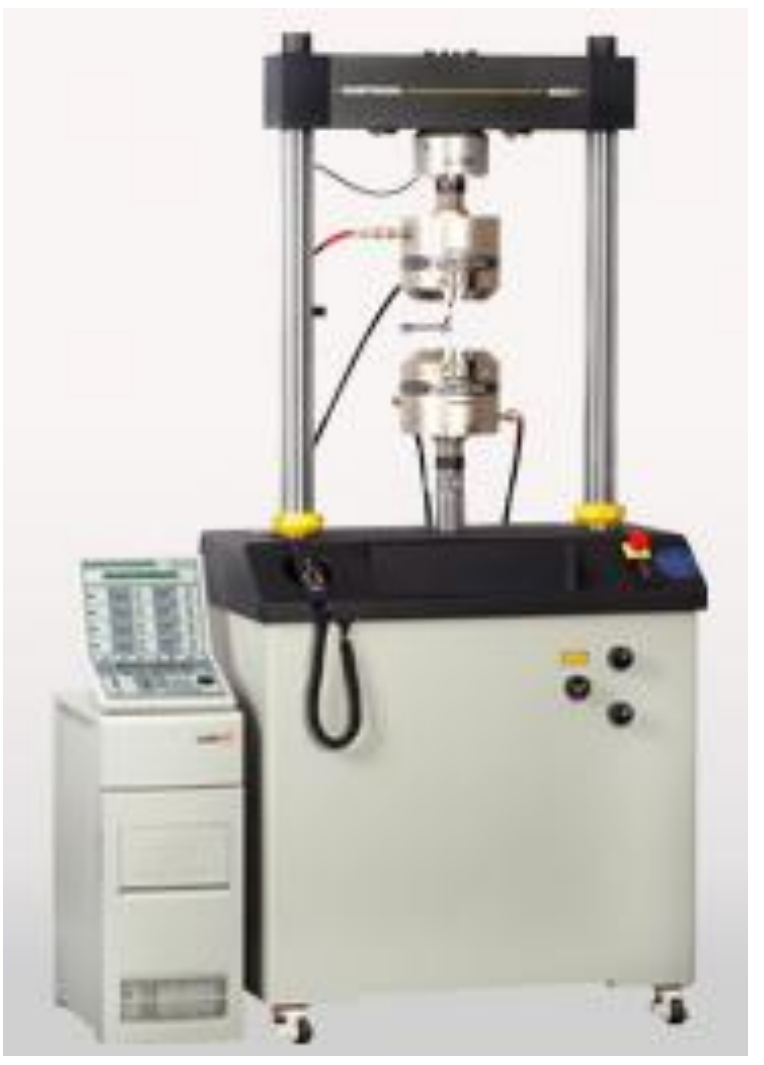

Figure 7: Instron machine utilized to acquire material properties of the carbon fiber composite plate.

Prior to testing on the Instron machine, the 10 inch by 10 inch carbon fiber plate had to be prepared. The plate was cut on a tile saw machine into 10 inch long by 1 inch wide strips, with a thickness of .107 inches. The coupon dimensions met the ASTM D3039 tension test standards for acquiring the material properties of the carbon fiber composite plate. Six coupons were tested in the Instron machine to acquire the material properties of the carbon fiber composite. Prior to placing a coupon to the Instron grips, tabs were attached at the ends of each coupon. The material of the tabs was emery cloth with a measurement of 1 inch by 1 inch. 
At the beginning of the test, the Instron machine was programmed in order for each sample to be tested the same way. Once programmed each coupon was clamped, one at a time, parallel to the grips and perpendicular to the floor, as seen in Figure 8. Then the program loaded the coupon under tension until it broke, or until the load dropped by 40 percent.
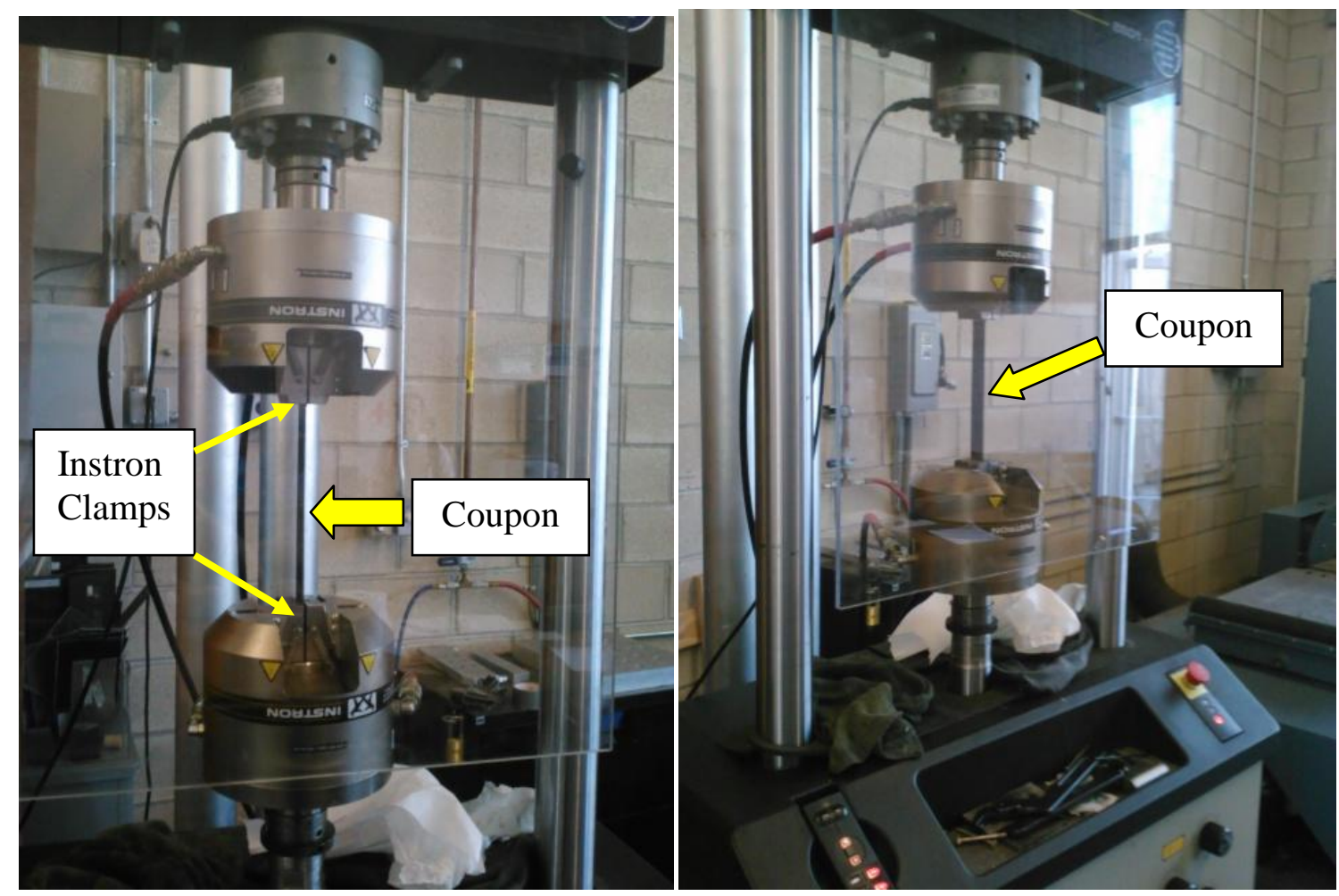

Figure 8: Front view (left) and side view (right) of a carbon fiber composite coupon during tensile

test.

The Instron machine recorded a strain and stress graph, extension and load graph, stress, strain, elongation, maximum and average loads, and ultimate stress. The material properties were acquired from the recorded data. A total of six coupons were used to 
acquire an average of the material properties. The Young's modulus was obtained by finding the slope from the strain and stress graph programmed in Matlab.

\subsection{Aluminum plate development}

In order to perform the vibrational tests on the vibe table, a base needed to be built in order to hold the test setup. A multipurpose aluminum alloy 6061 block with the dimensions of 11 inches by 11 inches and a thickness of 0.75 inches was designed to fit on the vibration table. The thicknes of 0.75 inches was chosen to make the aluminum fixture sturdy enough for the vibration tests. The aluminum material was chosen because it had a high bending stiffness and that would help resist high bending modes during testing. The design of the aluminum block was modeled in AutoCad and then machined by the aerospace technician Cody Thompson (refer to the Appendix B for more detailed description of the dimensions). The machined aluminum plate is shown in Figure 9.
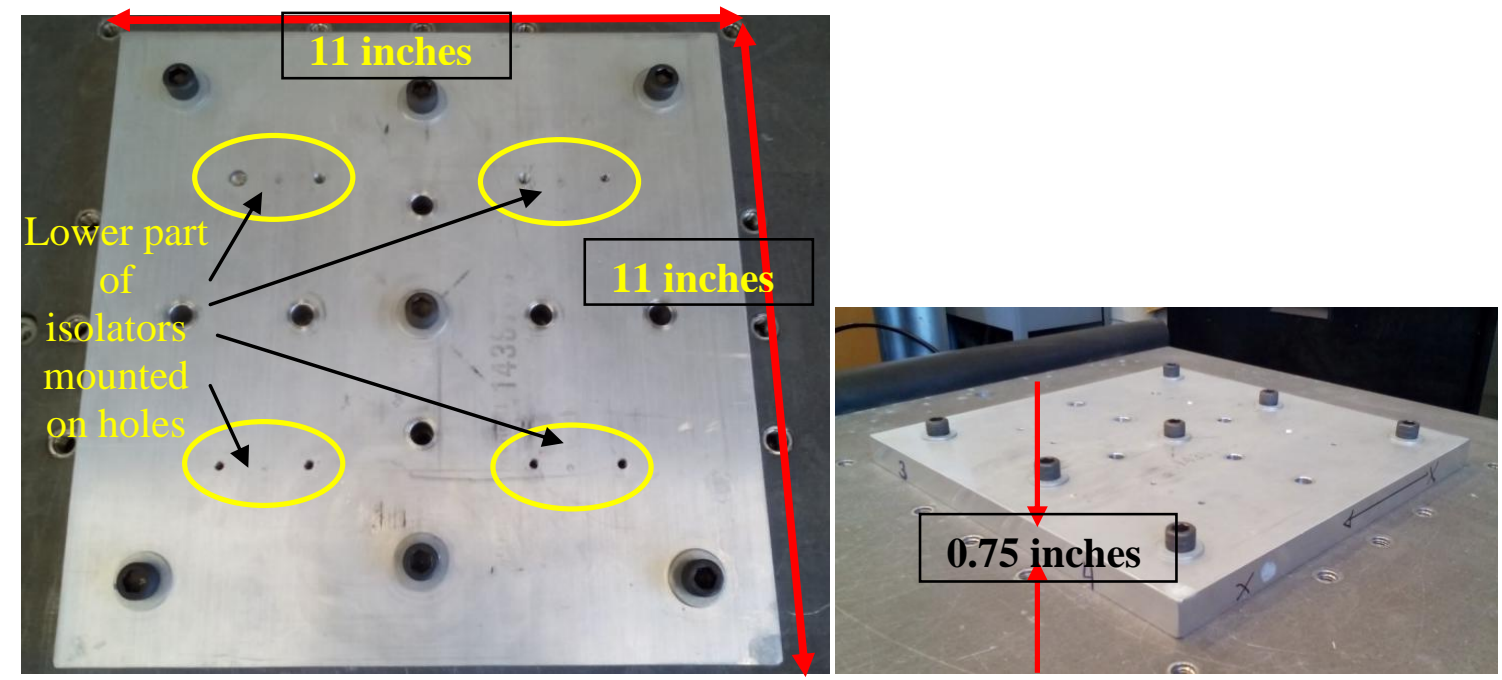

Figure 9: Aluminum plate fixture for mounting onto the vibration table. 
The screws that attached the aluminum block to the vibration table when it was in the vertical position were applied with a torque wrench at $25 \mathrm{ft}-\mathrm{lbs}$. When the aluminum block was screwed to the magnesium table the applied torque was $16 \mathrm{ft}-\mathrm{lbs}$. The zinc screws that attached the isolators to the aluminum block and the steel screws that attached to the composite plate were applied with a torque wrench at 12 in-lbs. The lead mass was screwed on top of the composite plate with a steel screw and torque wrench at 12 in-lbs. The screws were all torqued in order to ensure a safe vibration test and get the best results. An illustration of the vibration test setup with the lead mass is shown in Figure 10.

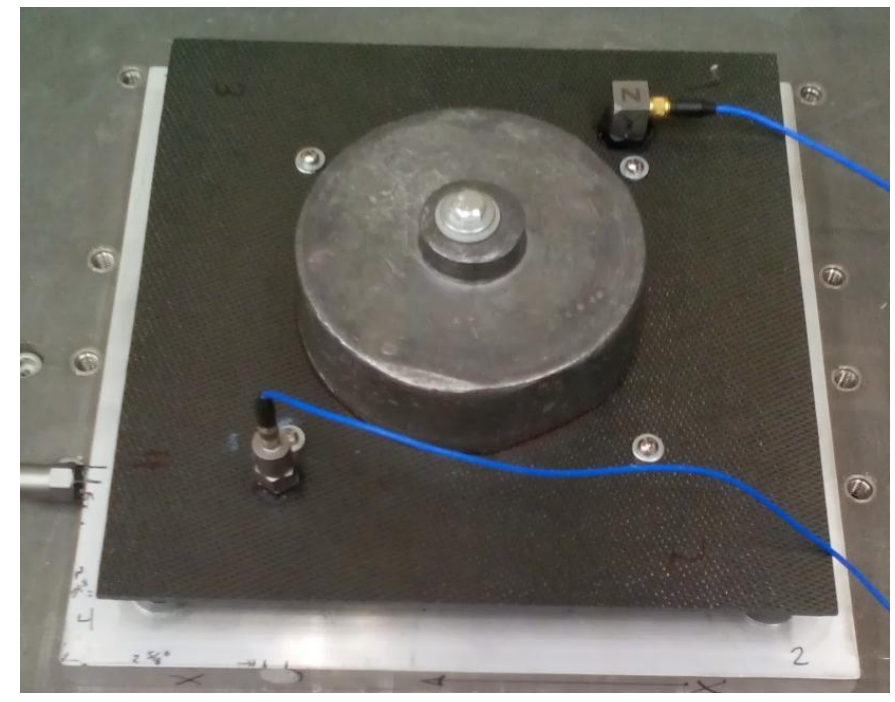

Figure 10: Vibration test setup with lead mass.

The $10 \mathrm{lb}$ lead mass (with a tolerance of $-0.01 \mathrm{lbs}$ ) was screwed on top of the carbon fiber composite plate and underneath four isolators were screwed as seen in Figure 10. Each isolator was screwed on top of the aluminum plate by two zinc (a total of eight 8-32 
x $3 / 8$ inch screws) screws and underneath the carbon fiber composite plate by one stainless steel (a total of four 8-32 x 3/4 inch screws) screw. The aluminum plate was screwed onto the vibration table.

Another vibration test was conducted with a steel mass instead of a lead mass, as seen in Figure 11. The vibration test with the steel mass utilized the same setup and components as the test with the lead mass.

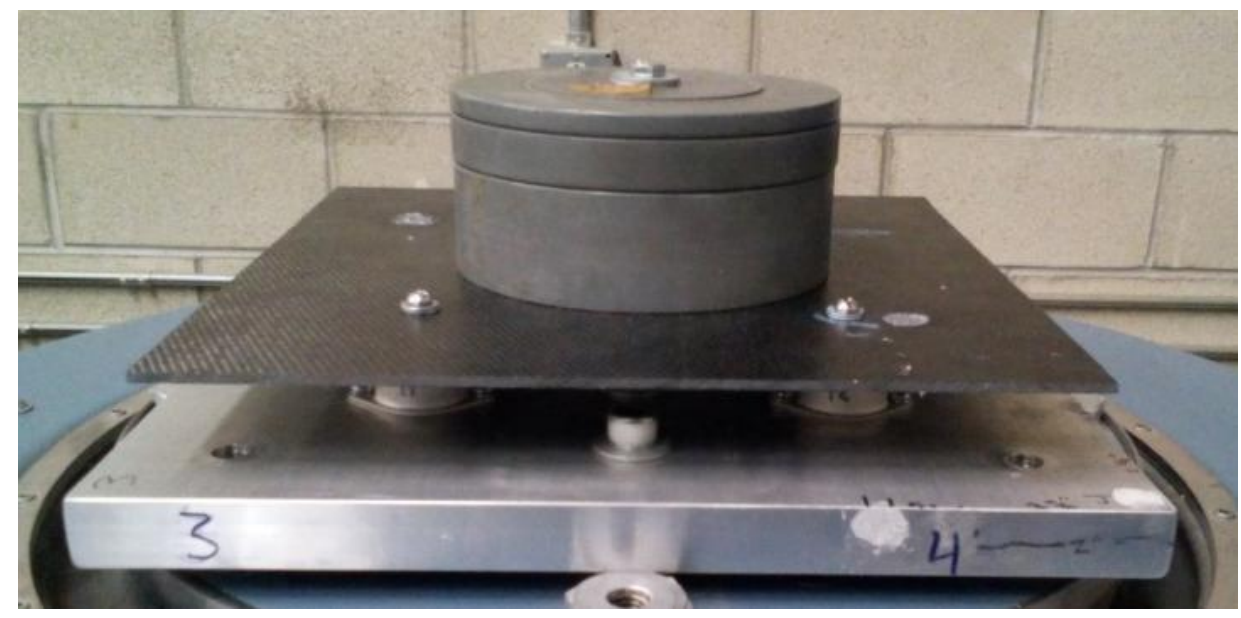

Figure 11: Test setup of vibration testing with steel mass.

The steel mass weighed $10 \mathrm{lbs}$, which was the same weight as the lead mass. Figure 12 shows the setup of the vibration test with the steel mass screwed on top of the carbon fiber plate. The three aforementioned accelerometers were also used in the same way as the vibration test with the lead mass. 


\section{EXPERIMENTATION}

\subsection{Acquiring Poisson's Ratio using the Instron machine}

In order to obtain the Poisson's ratio of the carbon fiber composite plate, strain gages needed to be applied on 10 inch by 1 inch coupons. A total of four coupons were used to acquire the Poisson's ratio of the carbon fiber composite plate. Before the coupons were

placed in the Instron machine to acquire the Poisson's ratio, the longitudinal and transverse strain gages were applied. The preparation before attaching the longitudinal and transverse strains on each coupon included several supplies. The coupons needed to be sanded with sandpaper of a 150 grade, or finer on the area where the strain gages would be applied. The strain gages used in this research are Vishay Micromeasurements $120 \Omega$ resistance gages with a model number of C2A-13-250-W-120. The area where the strain gages were applied was cleaned with the alkaline base cleaner provided by Vishay Micromeasurements. The placement of the strain gages was drawn on the coupon using a pencil and a ruler. It was very important that the pencil marking was exactly 0 degrees for the transverse strain gage and 90 degrees for the longitudinal strain gage. The strain gages were applied one at a time on scotch tape in order to place the strain gage along the marking for the respective strain gage and to avoid contaminating the strain gage with fingerprints. As each strain gage was taped on the scotch tape, an M-Bond 200 adhesive was used to apply strain gages to the test specimens. The adhesive consists of a two-part epoxy as shown in Figure 12. 


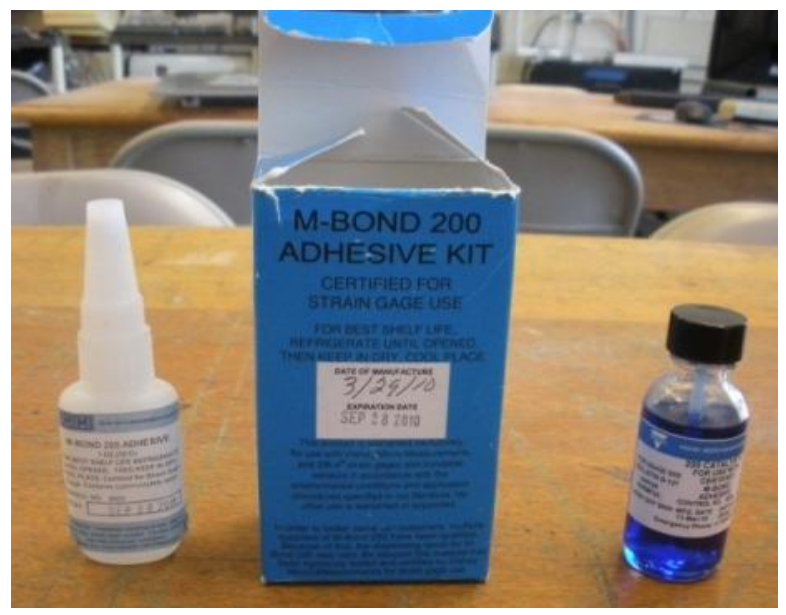

Figure 12: Chemical components used to connect strain gages to carbon fiber test samples.

The two-part epoxy was applied on the coupon and strain gage. Then manual pressure was applied on the strain gage for 2 minutes to bond the strain gage onto the coupon. A paper towel was placed on top of the strain gage covered by the scotch tape in order to avoid gluing fingers to the coupon. Prior to bonding the strain gage to the coupon, the application area was cleaned with the alkaline base cleaner provided by Vishay Micromeasurements. Once the strain gages were bonded to each coupon, the soldering process followed. Each strain gage was soldered to a bonding pad with wires. Figure 13 shows the soldered strain gages. 


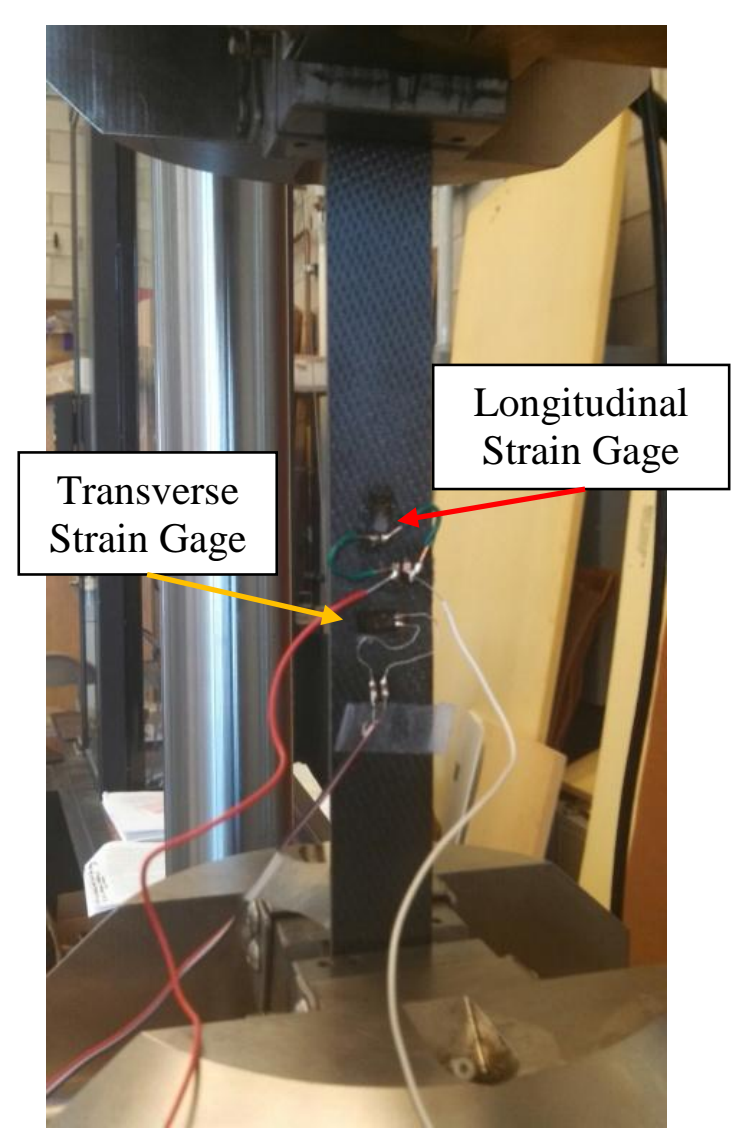

Figure 13: Longitudinal and transverse strain gages mounted on coupons for acquiring Poisson's ratio.

Once the soldering process was complete, the wires were connected to the P-3500 Strain Indicator in a quarter bridge circuit. Figure 14 shows the connection of the strain gages to the P-3500 Strain Indicator. Two P-3500 Strain Indicators were used because each coupon had a transverse strain and longitudinal strain. Each coupon was applied vertically in the Instron 8801 wedge grips. The Bluehill 2 computer software was used to record the longitudinal and transverse strain gage data along with the P-3500 Strain Indicator. The strain data was read from the P-3500 Strain Indicator of each corresponding strain gage for each coupon tested. 


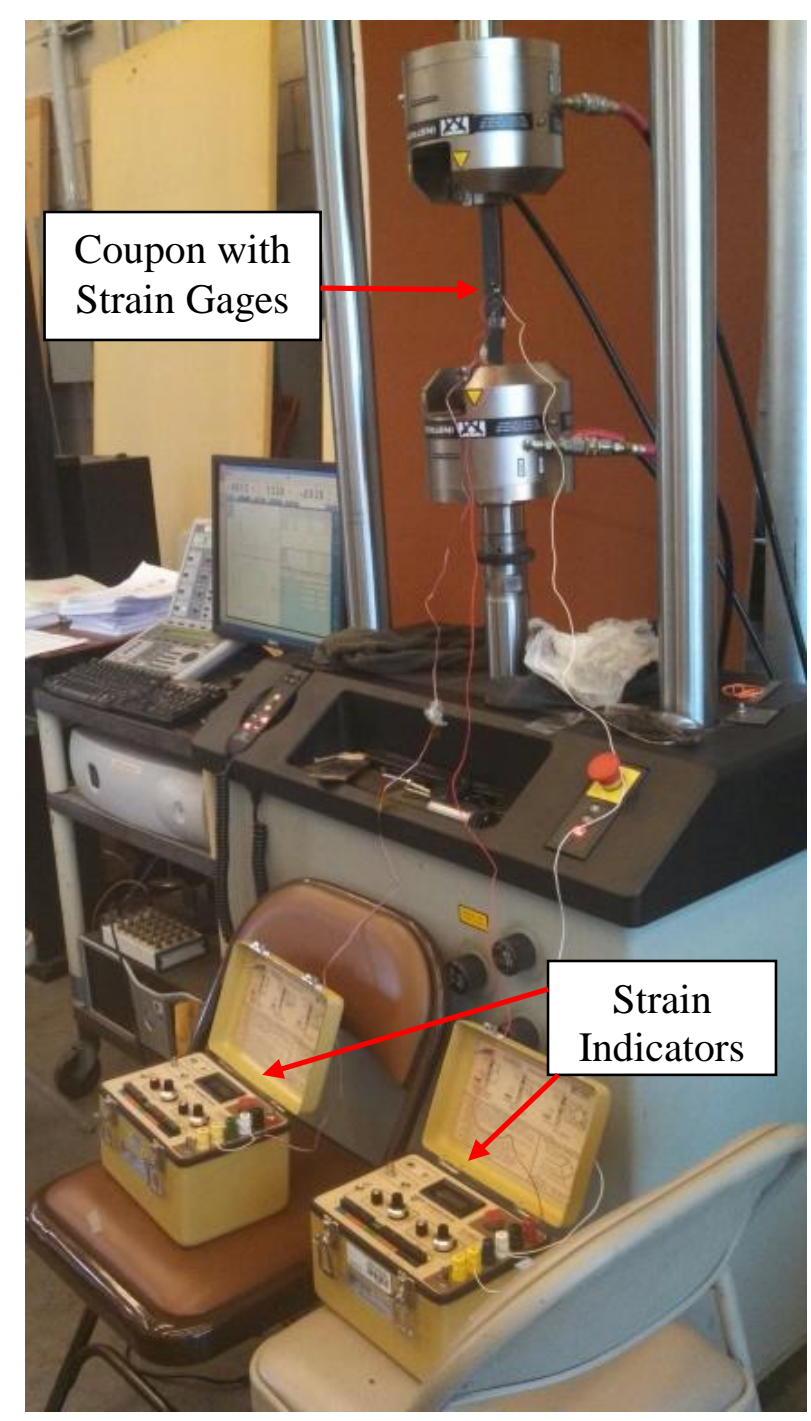

Figure 14: Poisson's ratio test with coupons, strain gages, and strain indicators.

The method used to acquire the Poisson's ratio of the composite material was in accordance with ASTM E132 testing standard. This test procedure was similar to the tensile testing procedure to acquire the Young's Modulus except for the strain gages and P-3500 Strain Indicator. 


\subsection{Experimental Setup and Procedure for outgassing and curing isolators}

The main goal of the vibration test was to determine the frequency response of each group and compare them to find out if a change in the vibrational performance characteristics of each isolator group was apparent. The duration of each vibration test was programmed for one minute and the frequency ranged from 20 to $2000 \mathrm{~Hz}$. Each isolator group was either vibrated in the flat frequency spectrum or high frequency spectrum, as explained in section 1.4 of this document. The vibration tests with the applied lead mass consisted of groups 1 through 6, while groups 7 through 10 were vibrated with the steel mass.

The test setup and accelerometers that were used for the vibrational experiments are shown in Figure 15. The orientation of the shaker was changed for the $\mathrm{x}, \mathrm{y}$, and $\mathrm{z}$ axes. The two accelerometers (353B04-SN101985 and 353B04-101984) to the right of the lead mass in Figure 15 were single axis accelerometers and were not calibrated. The 353B04SN101985 accelerometer was used as the control due to limited calibrated accelerometers and was connected to channel 1 . The other single axis accelerometer (353B04SN101984) was used to acquire the frequency response and connceted to channel 2 . The third accelerometer to the left of the mass was a calibrated triaxial accelerometer (T356A02) and the schematic and calibration certificates of the triaxial accelerometer can be seen in the Appendix C. The T356A02 accelerometer was rented from the Modal Shop to utilize a calibrated accelerometer that could provide accurate data during the vibration tests in three axes. The vibration table computer program was limilted to 4 channels and the T356A02 accelerometer had 1 cable for each axis direction. Therefore, the cables for 
the T356A02 accelerometer were switched for each vibration test with its corresponding direction.

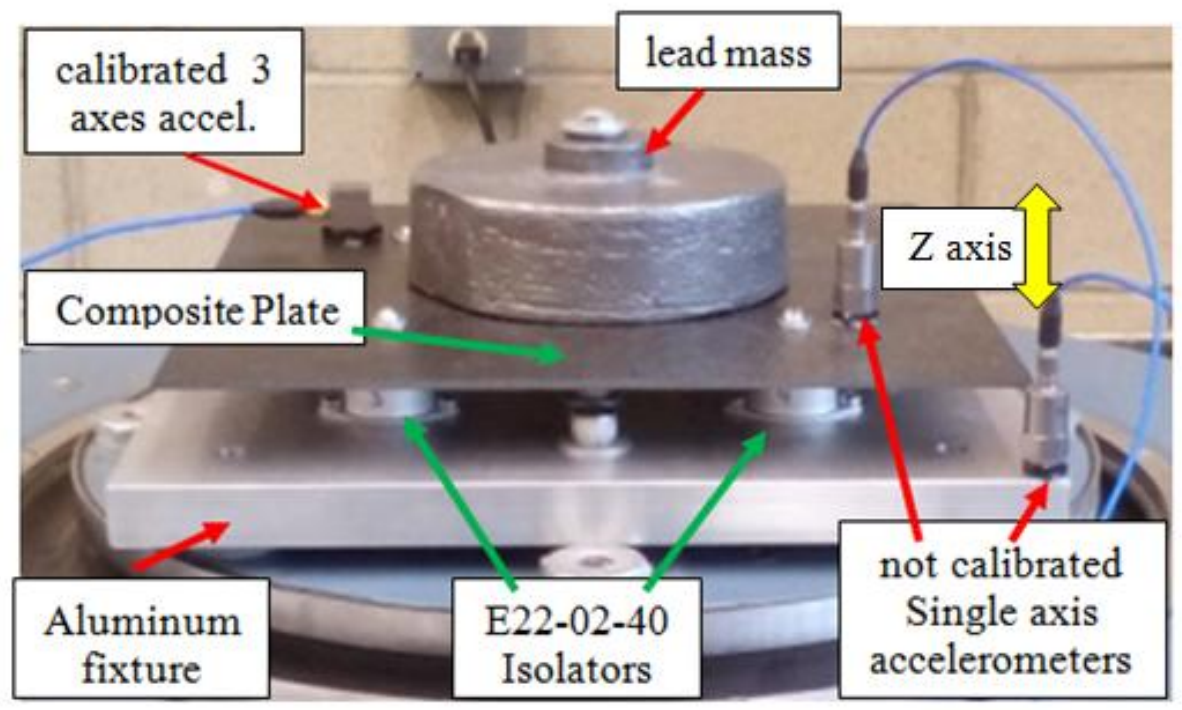

Figure 15: Test setup in the $Z$ direction for the preliminary consistency flat spectrum test.

All twenty isolators were vibrated in groups of four. The results showed that sixteen out of the twenty isolators had a consistent flat spectrum. Therefore, the sixteen consistent isolators were used in the experiments conducted for this research. Eight isolators were outgassed and cured and the remaining eight isolators (numbered 9-12 and 17-20) were not outgassed. The isolators numbered one through eight were outgassed for 24 hours and cured. Another four isolators (groups 5 and 6, as previously discussed) were outgassed for a total of 36 hours and cured at different temperatures in one of the student vacuum chambers (seen in Figure 16) in the space environments laboratory at California Polytechnic State University. 


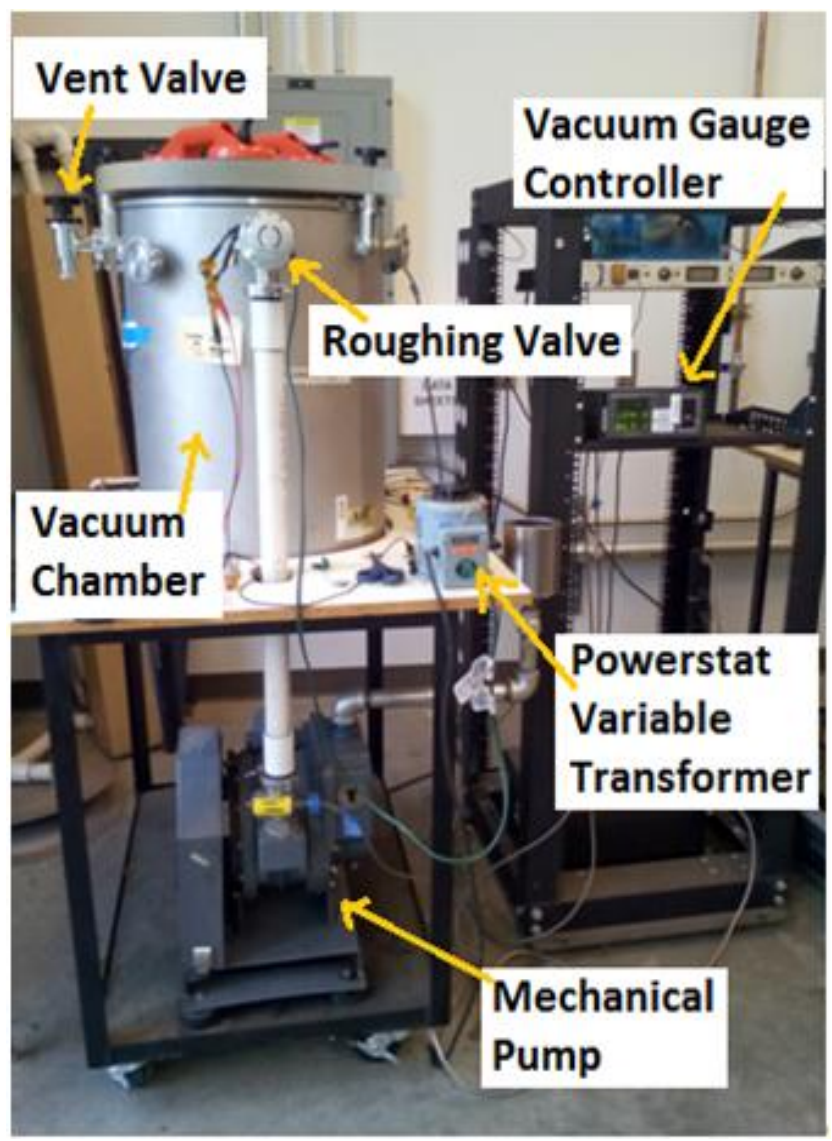

Figure 16: Main components of the student vacuum chamber and test.

A schematic of the vacuum chamber (Laco Tech LVC 1824-3113-VHX) used for the outgassing procedure is shown in Figure 17. The vacuum chamber's main components consisted of a mechanical pump (Welch 1397), venting valve, roughing valve, and two thermocouple pressure gages. 


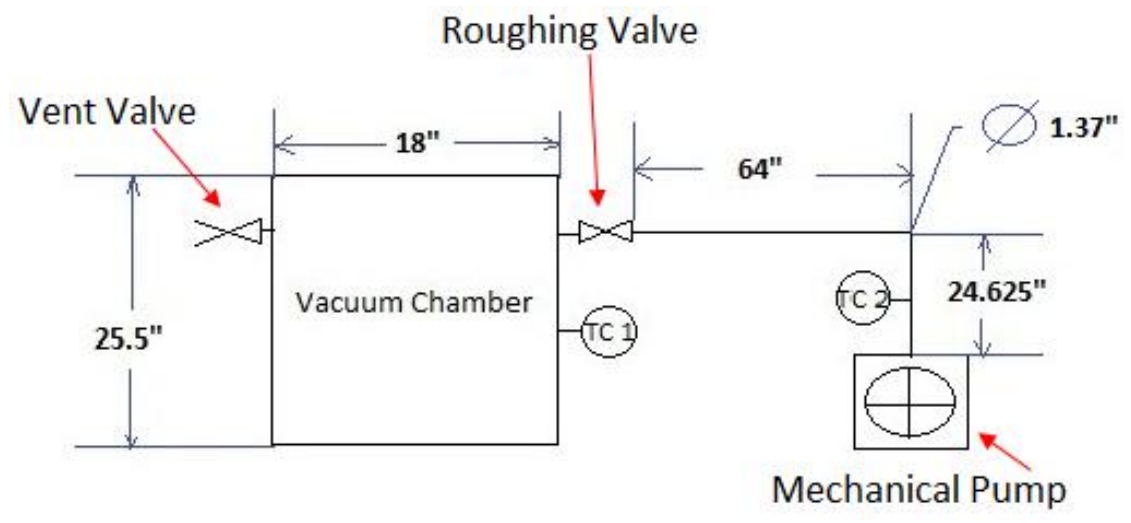

Figure 17: Simple schematic of the vacuum chamber used for outgassing some of the E22-02-40 isolators.

A Chromalox strip heater model S-1202 with 120 Volts and 250 Watts was placed inside the vacuum chamber to provide the heat for baking the isolators, as seen in Figure 18. A Powerstat variable autotransformer type 116B was connected to both ends of the Chromalox strip heater in order to provide the voltage. A thermocouple was attached with kapton tape to the surface that was in contact with the Chromalox strip heater and isolators. Before applying the kapton tape, the contacting surface was cleaned with acetone to allow a better adhesion. The opposite end of the thermocouple was attached to a digital thermometer to read the temperature of the metal plate in contact with the eight isolators. The eight isolators and thermocouple were placed one inch away from the Chromalox strip heater, as seen in Figure 18. 


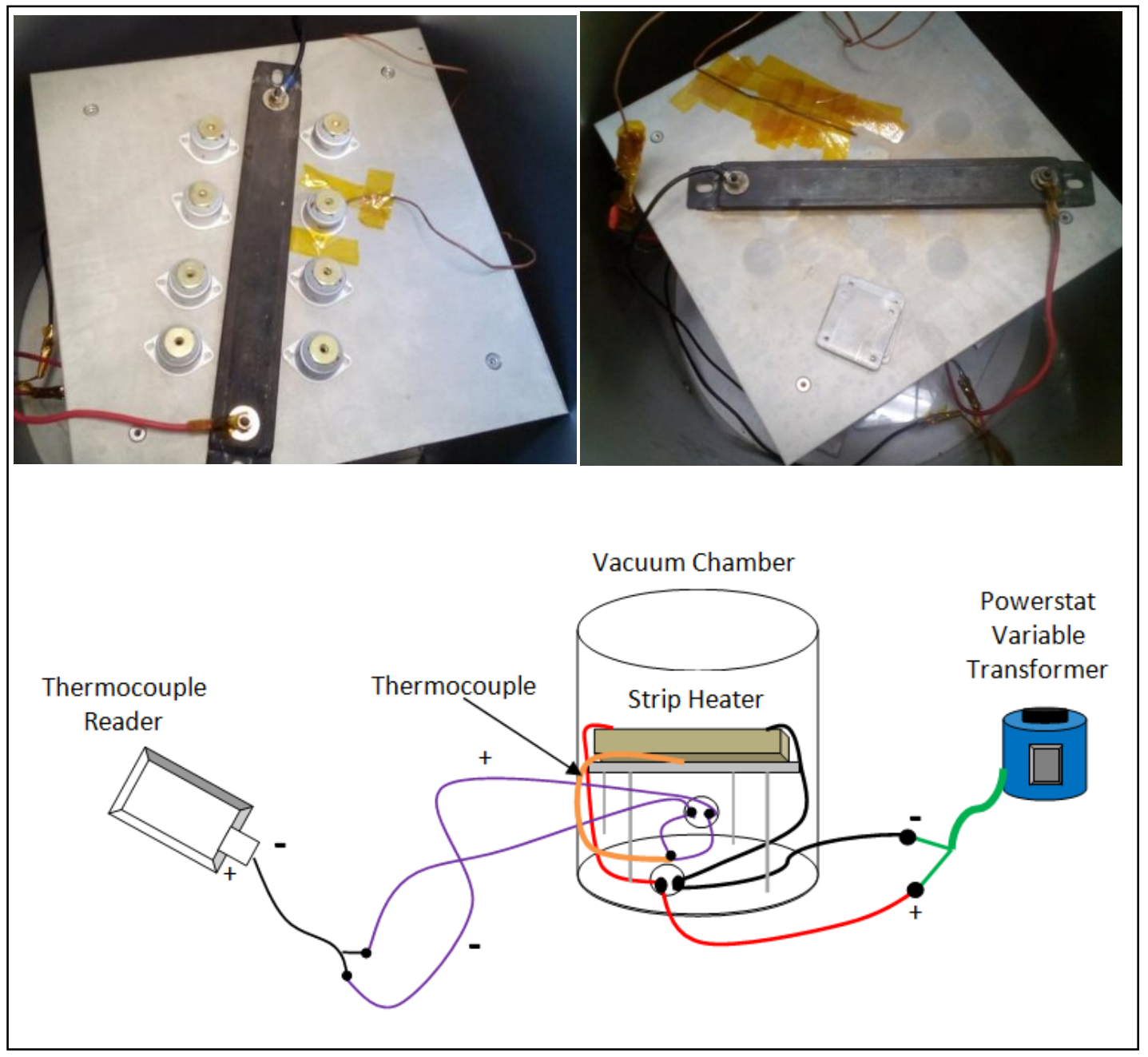

Figure 18: Strip heater setup inside the vacuum chamber with isolators and thermocouple (Top); schematic of the wiring for the bake-out process inside the vacuum chamber (Bottom).

The outgassing and baking procedure commenced once the eight isolators and thermocouple were placed inside the vacuum chamber. A grease (DOW Corning high vacuum grease) was added to the rim on the top of the vacuum chamber, where the lid was placed in order to seal the vacuum chamber. Once the lid was placed, the vent valve and roughing valve were closed. Then the mechanical pump cable was plugged into an outlet to turn it on. Then the roughing valve was fully opened, once the mechanical pump was turned on. Then the Powerstat Variable Autotransformer was turned on once the 
pressure began to decrease. The Powerstat Variable Autotransformer was turned to the desired voltage to provide the desired temperature.

The vacuum chamber's mechanical pump was turned off by unplugging its cable. Then the vent valve was opened, the heater was turned off, and the vacuum chamber lid was removed once the pressure reached atmospheric pressure. Isolators numbered 1 through 8 were weighed within 5 to 10 minutes on a precision balance scale, as well as isolators numbered 9 through 12. Table 2 lists the initial masses of the isolators numbered 1 through 12 and their masses after they were outgassed and cured.

Table 2: Comparison between the initial mass and the mass after the post-cure inside the vacuum chamber of the E22-02-40 isolators.

\begin{tabular}{|c|c|c|c|}
\hline Isolator \# & $\begin{array}{c}\text { Initial } \\
\text { Mass } \\
\text { (lbs) }\end{array}$ & $\begin{array}{c}\text { Mass After } \\
\text { Outgassing } \\
\text { and Bake-out } \\
(\mathbf{l b s})\end{array}$ & $\begin{array}{c}\text { Percent } \\
\text { Difference } \\
(\mathbf{\%})\end{array}$ \\
\hline $\mathbf{1}$ & 0.04238 & 0.04212 & 0.615 \\
\hline $\mathbf{2}$ & 0.04236 & 0.04206 & 0.711 \\
\hline $\mathbf{3}$ & 0.0422 & 0.04188 & 0.761 \\
\hline $\mathbf{4}$ & 0.0426 & 0.04238 & 0.518 \\
\hline $\mathbf{5}$ & 0.04228 & 0.04196 & 0.760 \\
\hline $\mathbf{6}$ & 0.04238 & 0.04206 & 0.758 \\
\hline $\mathbf{7}$ & 0.04238 & 0.04212 & 0.615 \\
\hline $\mathbf{8}$ & 0.04232 & 0.04206 & 0.616 \\
\hline $\mathbf{9}$ & 0.0421 & 0.04176 & 0.811 \\
\hline $\mathbf{1 0}$ & 0.04222 & 0.04178 & 1.048 \\
\hline $\mathbf{1 1}$ & 0.04214 & 0.04178 & 0.858 \\
\hline $\mathbf{1 2}$ & 0.04248 & 0.04214 & 0.804 \\
\hline
\end{tabular}


Groups 1 and 3 were outgassed for 24 hours at a temperature of $125{ }^{\circ} \mathrm{C} \pm 5{ }^{\circ} \mathrm{C}$ at a pressure of 20.9 E-3 \pm 10 E-3 Torr, which was the capacity of the vacuum chamber. Isolators numbered 1 through 4 were referred as group 1 and vibrated in the flat spectrum. Isolators 5 through 8 were designated as group 3 and vibrated in the high frequency energy spectrum. Group 2 belonged to isolators numbered 9 through 12, which were not outgassed and vibrated in the flat spectrum. Group 4 belonged to isolators 17 through 20, which were not outgassed and vibrated in the high frequency energy spectrum. Lastly groups 5 and 6 were outgassed for a total of 36 hours, the first 12 hours were at a temperature of $149{ }^{\circ} \mathrm{C} \pm 10^{\circ} \mathrm{C}$ and the remaining 24 hours at a temperature of $204{ }^{\circ} \mathrm{C} \pm 10{ }^{\circ} \mathrm{C}$, all at a pressure of $21.9 \mathrm{E}-3 \pm 10 \mathrm{E}-3$ Torr. Group 5 were vibrated in the flat spectrum and group 6 in the high frequency energy spectrum.

\subsection{Experimental Setup and Procedures for vibration table}

The vibration system model number is SAB15F-S202/ST, as seen in Figure 19, and utilized to run a high frequency energy spectrum and flat spectrum, which gathered information about the performance characteristics of the isolators. Two tests were conducted, one was with a lead mass and another test was done with a steel mass in order to have more data and comparisons. 


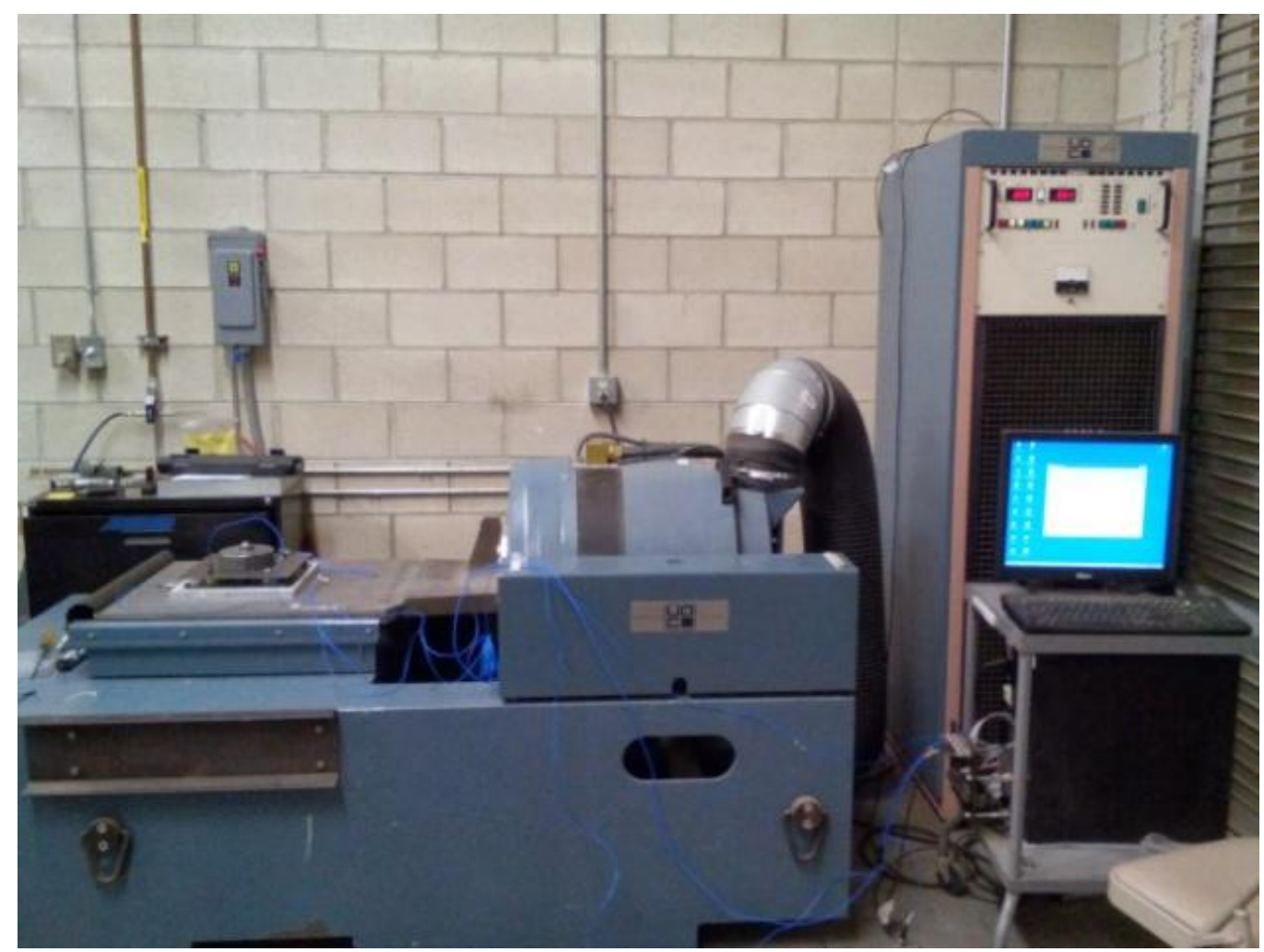

Figure 19: Vibration system used for the flat and high frequency energy spectrum tests.

A flat spectrum with amplitude of $0.1 \mathrm{~g}^{2} / \mathrm{Hz}$ was programmed on VWINII vibration controller program. A high frequency energy spectrum was programmed in the VWINII computer software for the vibration table to follow. Figure 20 illustrates the flat spectrum and high frequency energy spectrum that were programmed on VWINII and run on the vibration table. 

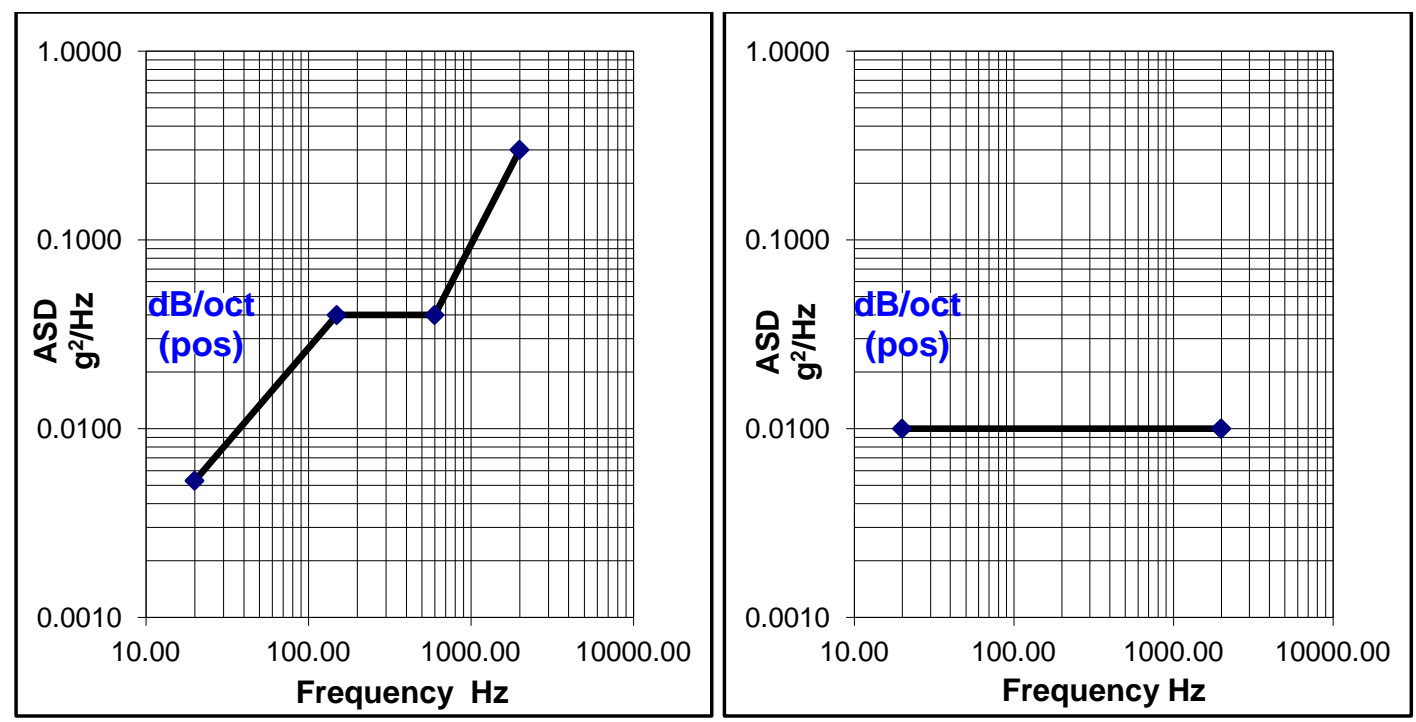

Figure 20: High frequency energy spectrum and flat spectrum programmed on VWINII.

Once the flat spectrum and high frequency energy spectrum were programmed, the isolator groups were ready to be tested. The setup consisted of an aluminum plate, composite plate, mass, accelerometers, and isolators. The lead weight of the mass was approximately $4.535 \mathrm{~kg}(10 \mathrm{lbs})$ and the mass of the steel weight was also $10 \mathrm{lbs}$. The accelerometers were placed on the same locations when vibrating in the $\mathrm{x}, \mathrm{y}$, and $\mathrm{z}$ axes in order to be consistent. An invisible quadrant was drawn in the aluminum plate and composite plate in order to designate where to place the accelerometers. Figure 21 shows the locations of the accelerometers for each axis. The orientation of the $\mathrm{x}$ direction for all four isolator groups is shown in Figure 22. 


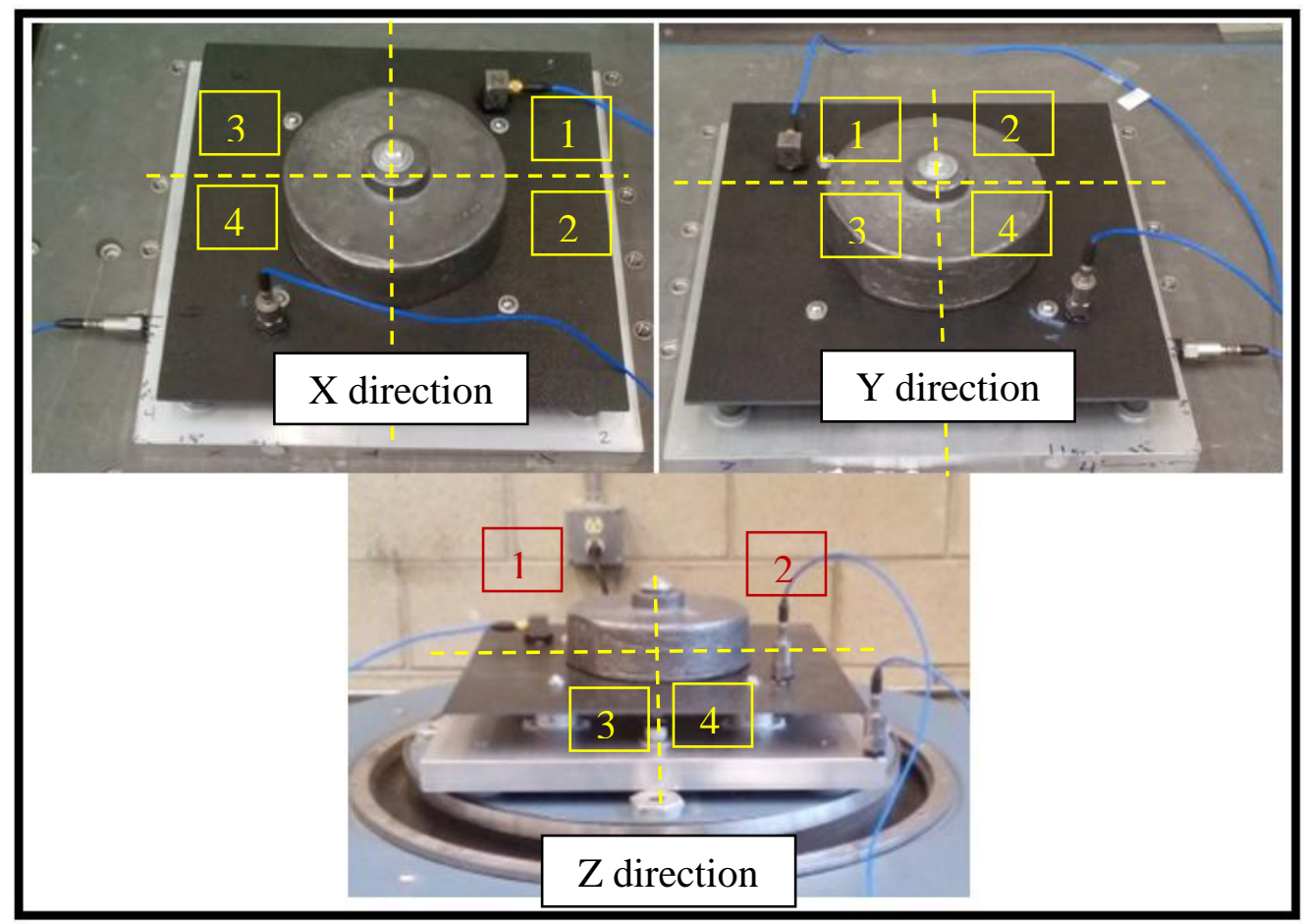

Figure 21: Locations of accelerometers for the $\mathrm{x}, \mathrm{y}$, and $\mathrm{z}$ directions.

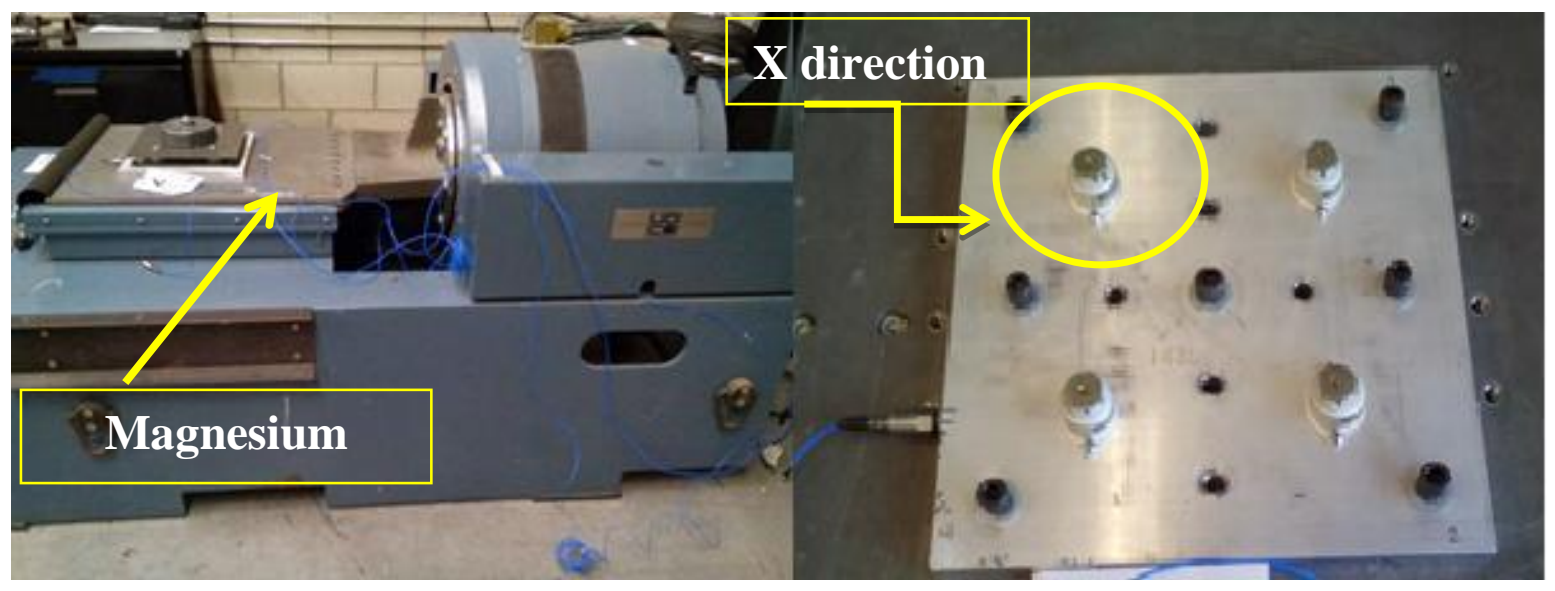

Figure 22: The $x$ direction orientation for all isolator groups.

Figure 23 shows the orientation of the isolators in the y direction for all four groups. For the $\mathrm{x}$ and $\mathrm{y}$ direction the bolts were torqued to $21.69 \mathrm{~N}-\mathrm{m}$, or $16 \mathrm{ft}-\mathrm{lbs}$ because the magnesium table was the interface. The bolts applied to the isolators were torqued to 1.36 $\mathrm{N}-\mathrm{m}$, or $1 \mathrm{ft}-\mathrm{lbs}$. 


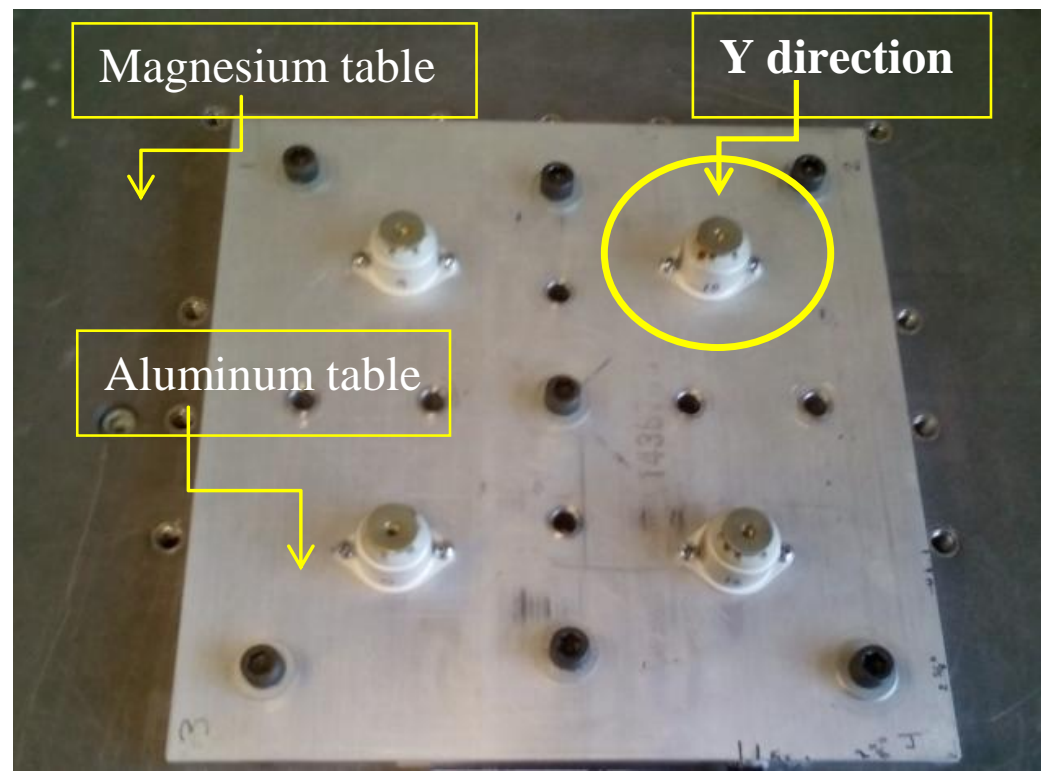

Figure 23: The y direction orientation for all isolator groups.

The isolator groups were also vibed in the $\mathrm{z}$ direction, as seen in Figure 24. The vibration table had to be rotated vertically for the $\mathrm{z}$ direction. The bolts connecting to the vibration table were torqued to $33.90 \mathrm{~N}-\mathrm{m}$, or $25 \mathrm{ft}-\mathrm{lbs}$.

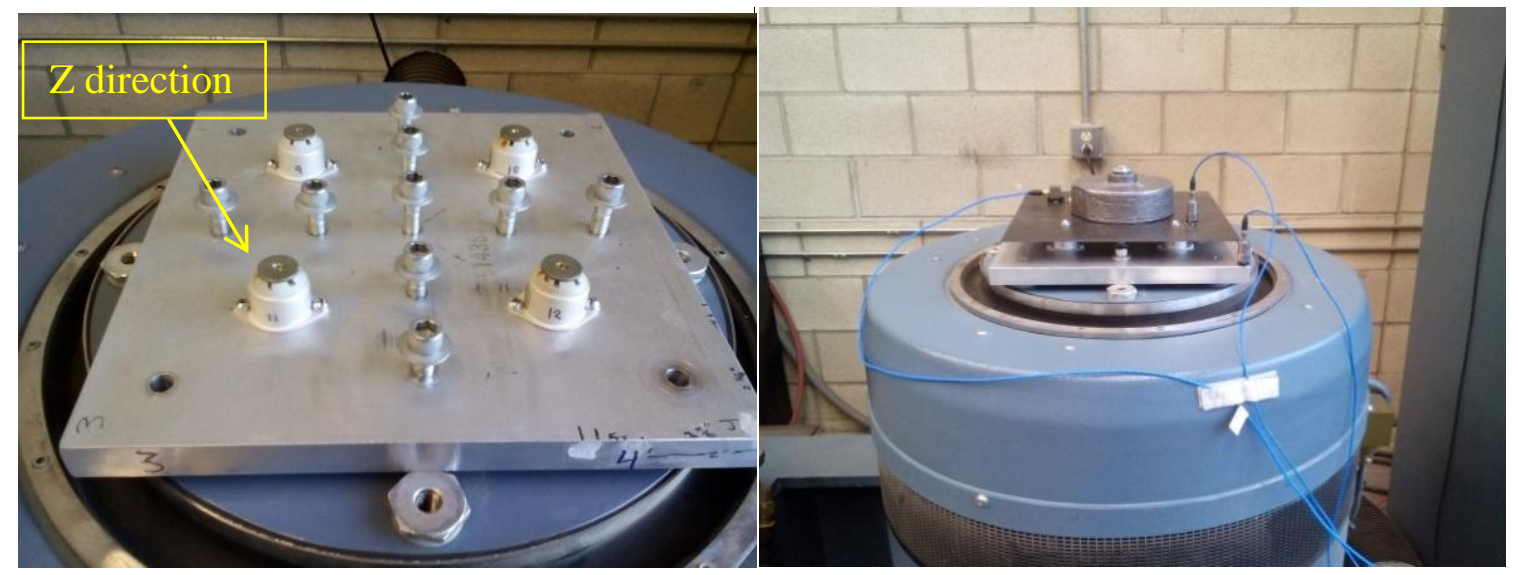

Figure 24: The $\mathrm{z}$ direction orientation for all isolator groups and test setup.

The vibration table was run by turning on the air and power as well as the computer software WINII. Then the desired pre-programed flat spectrum or high frequency energy 
spectrum was selected. The aluminum plate, isolators, composite plate, mass, accelerometers were setup on the vibration table. Then the system power button was pressed for 2 seconds, then the operate button, the gain was raised to about $75 \%$, and the auto button on the WINII program was clicked to commence the vibration table. Figure 25 shows the buttons that operated the amplifier of the vibration table.

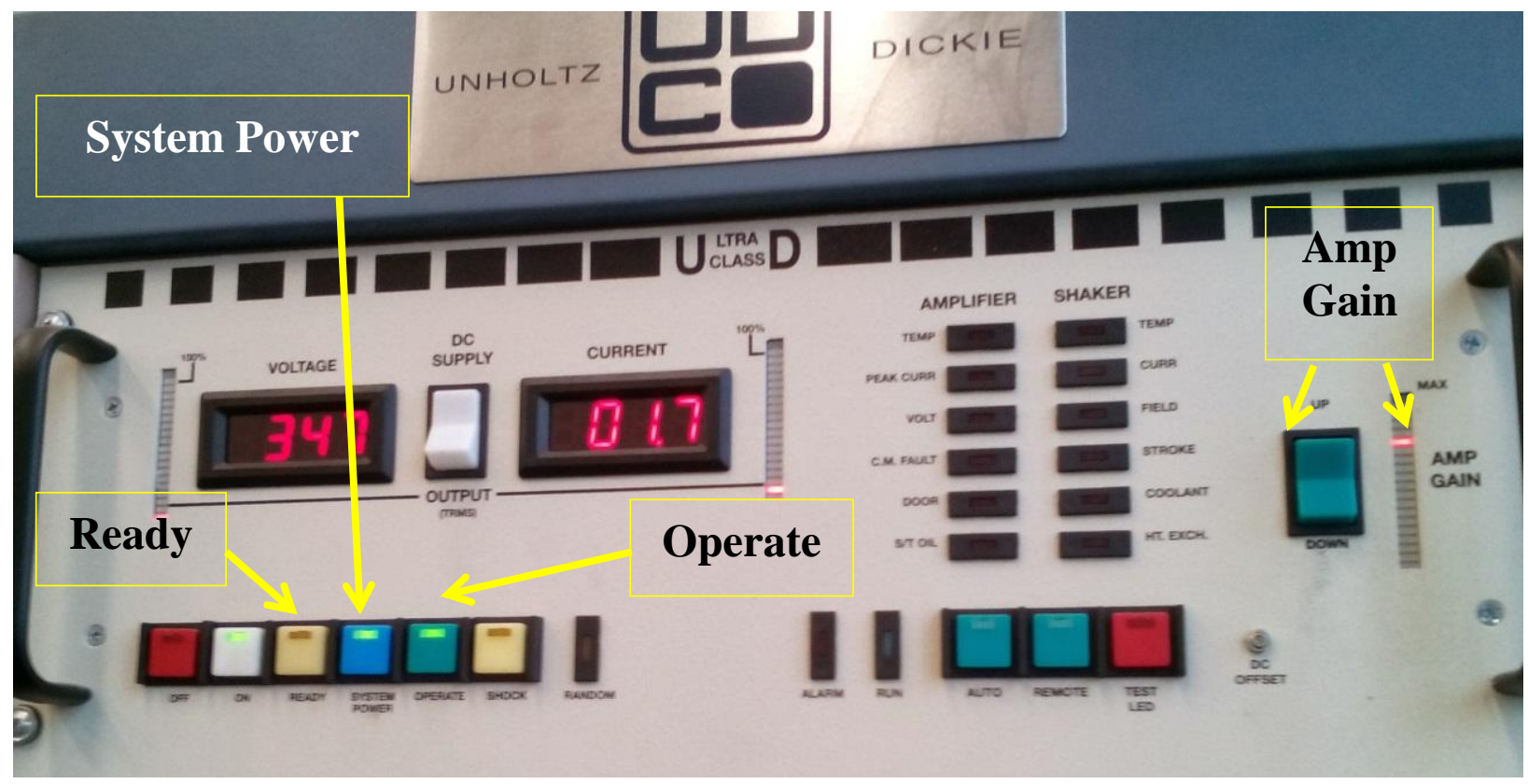

Figure 25: Buttons that operate the amplifier for the vibration table and experiments.

Once all the testing was completed the vibration table was turned off by lowering the gain to zero, pressing ready, pressing the off button, and turning off the air. 


\section{THEORY}

\subsection{Choosing Isolator}

The analysis that went into choosing the isolator was aided by the Barry Controls Isolator Guide and Lord Isolator Guide. One of the first steps to determining the type of isolator was calculating the required dynamic spring rate, which is seen in the Eqn. 1.

$$
K^{\prime}=\frac{\left(f_{n}\right)^{2}(W)}{9.8}
$$

In the above equation $K^{\prime}$ is the total system dynamic stiffness (lb/in) at a specified vibration input, $f_{n}$ is the selected system natural frequency $(\mathrm{Hz})$, and $W$ is the isolated equipment weight (lb). The individual isolator spring rate was determined by dividing the system spring rate by the desired number of isolators that will be used. The remaining criteria for choosing an isolator depended on the required dynamic spring rate, specified vibration input at the desired natural frequency of the system, static load supported per isolator, allowable system transmissibility, and environmental conditions. The determining factors for choosing the E22-02-40 isolators from Barry Controls was due to their silicone high damping material, low isolation frequency, and because they could isolate in all the primary axes. Also the study conducted by Barry Controls on the high damp isolators was an inspiration for determining the vibrational performance of those isolators before and after they were outgassed and cured. The study provided the postcure necessary to make the high damp silicone isolators a presumed grade A for outgassing, which made the E22-02-40 isolators the ideal ones to use for this research. 
For the system used in this thesis, the weight was 10 pounds, the system natural frequency was $27.4 \mathrm{~Hz}$, and the total system dynamic stiffness was $766.1 \mathrm{lb} / \mathrm{in}$. The system natural frequency was determined by Eqn. 2 .

$$
f_{n}=f_{n n} \sqrt{\frac{P_{R}}{P_{A}}}
$$

where $P_{R}$ is the rated load (lb), $P_{A}$ is the actual load, $f_{n}$ is the natural frequency at the actual load, and $f_{n n}$ is the nominal natural frequency. The actual load was $10 \mathrm{lb}$ divided by 4 isolators, which resulted in $2.5 \mathrm{lb} /$ isolator. The rated load of the E22-02-40 isolator was $3 \mathrm{lb}$ and the nominal natural frequency of the system was $25 \mathrm{~Hz}$ [2].

The transmissibility of the isolator also needed to be determined to verify that the E2202-40 isolator was right choice to perform the vibration tests. The transmissibility is the ratio of the dynamic output to the dynamic input [12]. The transmissibility provides the percentage of vibrational energy that is transmitted through a structure [12]. Usually the transmissibility is plotted in the $\mathrm{y}$ axis in decibels and the frequency in the $\mathrm{x}$ axis to understand the isolation, damping ratio, and frequency of the material [12]. The plotted curve shows that in the higher frequency range, the amount of energy transmitted from vibrations is reduced, which is an example of how isolation performance increases. The maximum transmissibility at resonance of the isolator was 4.0. Knowing the nominal natural frequency of the system, natural frequency, and $\mathrm{Q}$ factor, the absolute transmissibility was 3.05, which was under the maximum resonant transmissibility (See Appendix A for Matlab code). 


\subsection{GRMS Calculatios}

Calculating the GRMS or the root mean square of the accelerometer output was essential for the high energy spectrum portion of the vibration tests. To commence acquiring the maximum GRMS several masses needed to be weighed. Equation 3 was used to calculate the necessary acceleration that the shaker table could take

$$
F * .80=M A
$$

where, the .80 is a safety factor and $\mathrm{F}$ is the maximum force (lb) of the shaker table, $\mathrm{M}$ is the total mass (lb) of the system, and $\mathrm{A}$ is the acceleration. The GRMS is the root mean square acceleration from a random vibration ASD curve [13]. The total mass included the mass of the shaker plate, aluminum plate, carbon fiber plate, isolators, armature assembly, and 10 pound mass. The force of the shaker table was 2200 pounds and was multiplied by 80 percent as a safety factor to prevent damaging the shaker or the amplifier with high voltage and current outputs. Keeping the shaker table functioning during the entire vibration testing duration was very important. The maximum GRMS value with the 0.80 safety factor was calculated to 20.9. Equation 4 was used to calculate the envelope of the high energy spectrum

$$
A=10 * \log (2) * \frac{A S D_{H}}{10 * \log (2)+m}\left[F_{H}-F_{L}\left(\frac{F_{L}}{F_{H}}\right)^{\frac{m}{10 * \log (2)}}\right]
$$

where $\mathrm{m}$ is the slope $(\mathrm{dB} / \mathrm{OCT})$ of each trend line in the envelope, $F_{H}(\mathrm{~Hz})$ is the high frequency between the slope, $F_{L}(\mathrm{~Hz})$ is the low frequency between the slope, and $A S D_{H}$ 
is the high Acceleration Spectral Density in $\frac{g^{2}}{H z}$. If the slope is negative then the area can be determined by Eqn. 5 [13].

$$
A=A S D_{L} * F_{L} * \ln \left(\frac{F_{L}}{F_{H}}\right)
$$

The term $A S D_{L}$ is the low Acceleration Spectral Density in units of $\frac{g^{2}}{H z}$. Once the area is determined, the GRMS can be calculated [13].

\subsection{Flat Spectrum}

Since the flat spectrum has a constant amplitude throughout a certain frequency range, it was used as a baseline for the vibration experiment in this spectrum. The flat spectrum was used for two purposes. The first, was to vibrate all the isolators in the $\mathrm{z}$ direction to verify that they had the same and/or similar frequency responses. This test had an amplitude of $0.01 \mathrm{~g}^{2} / \mathrm{Hz}$ and confirmed any dissimilarities between the isolators. The second purpose of the flat spectrum was used as a test parameter for isolators prior to being outgassed and cured inside the vacuum chamber and afterwards. Four isolators were vibrated at an amplitude of $0.01 \mathrm{~g}^{2} / \mathrm{Hz}$ and called the untreated group. Another set of four isolators, which was the treated group, was outgassed for 24 hours and cured at a temperature of $125{ }^{\circ} \mathrm{C}$. A third group of treated isolators was outgassed for 36 hours and cured at different temperatures. The treated, or outgassed and cured isolators were vibrated at an amplitude of $0.01 \mathrm{~g}^{2} / \mathrm{Hz}$. The frequency responses of the treated and untreated isolators were compared and analyzed. 


\subsection{High Frequency Energy Power Spectral Density Spectrum}

The MIL-STD-1540 version C was used to test for the minimum workmanship for ensuring acceptance of the vibration test. The minimum workmanship had two options for the acceptance test of the minimum random vibration spectrum. The first option applied for test units that did not exceed fifty pounds, as seen in Figure 26, and was chosen to determine the high frequency energy envelope for the vibration tests.

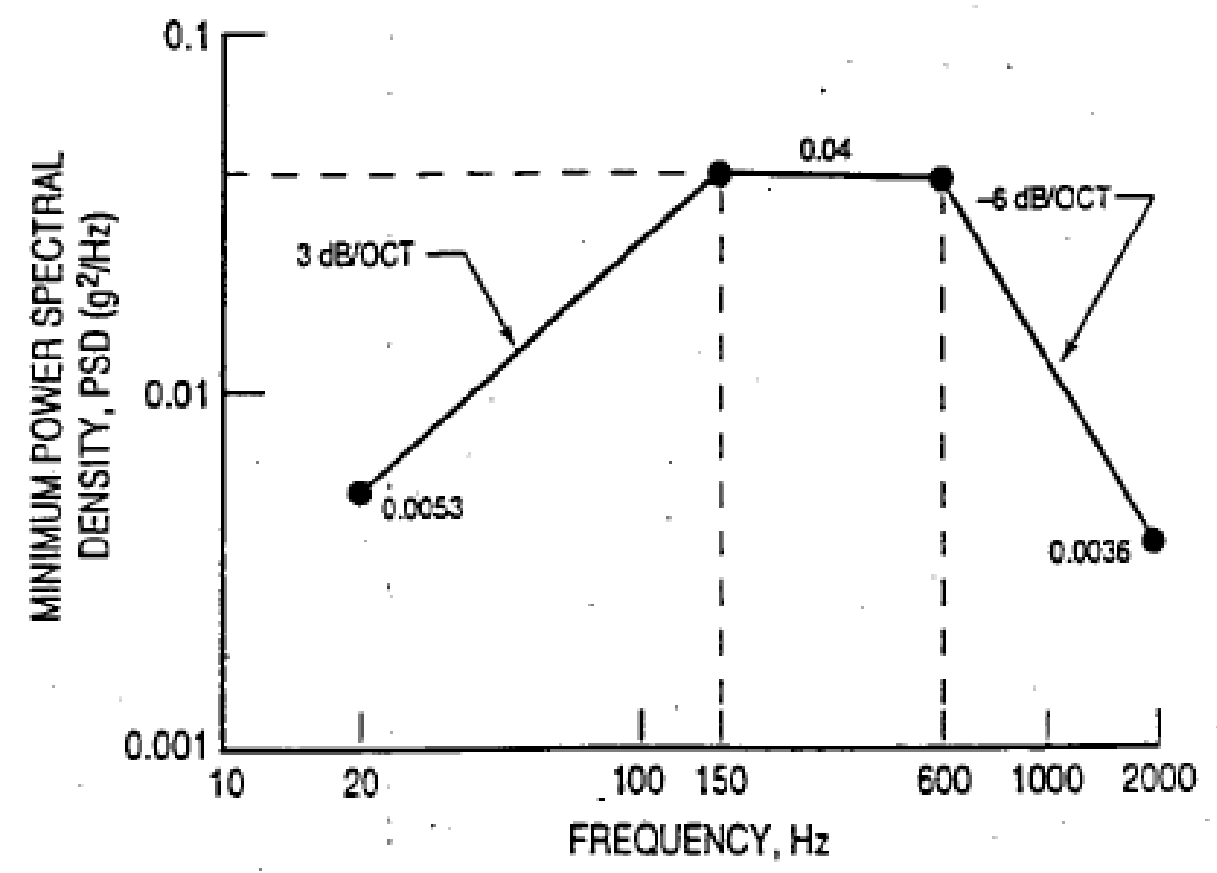

Figure 26: Minimum workmanship used as a guideline for high frequency spectrum.

The frequency envelope seen in Figure 26 was modified in the higher frequency range by increasing the amplitude to add more energy into the system. The finalized frequency envelope for the high frequency spectrum is seen in Figure 27. The total GRMS for the high frequency spectrum was 15.37 , which did not exceed the maximum GRMS allowed 
by the vibration table limits. The high frequency envelope took the maximum allowable GRMS into account in order to prevent any harm to the vibration table.

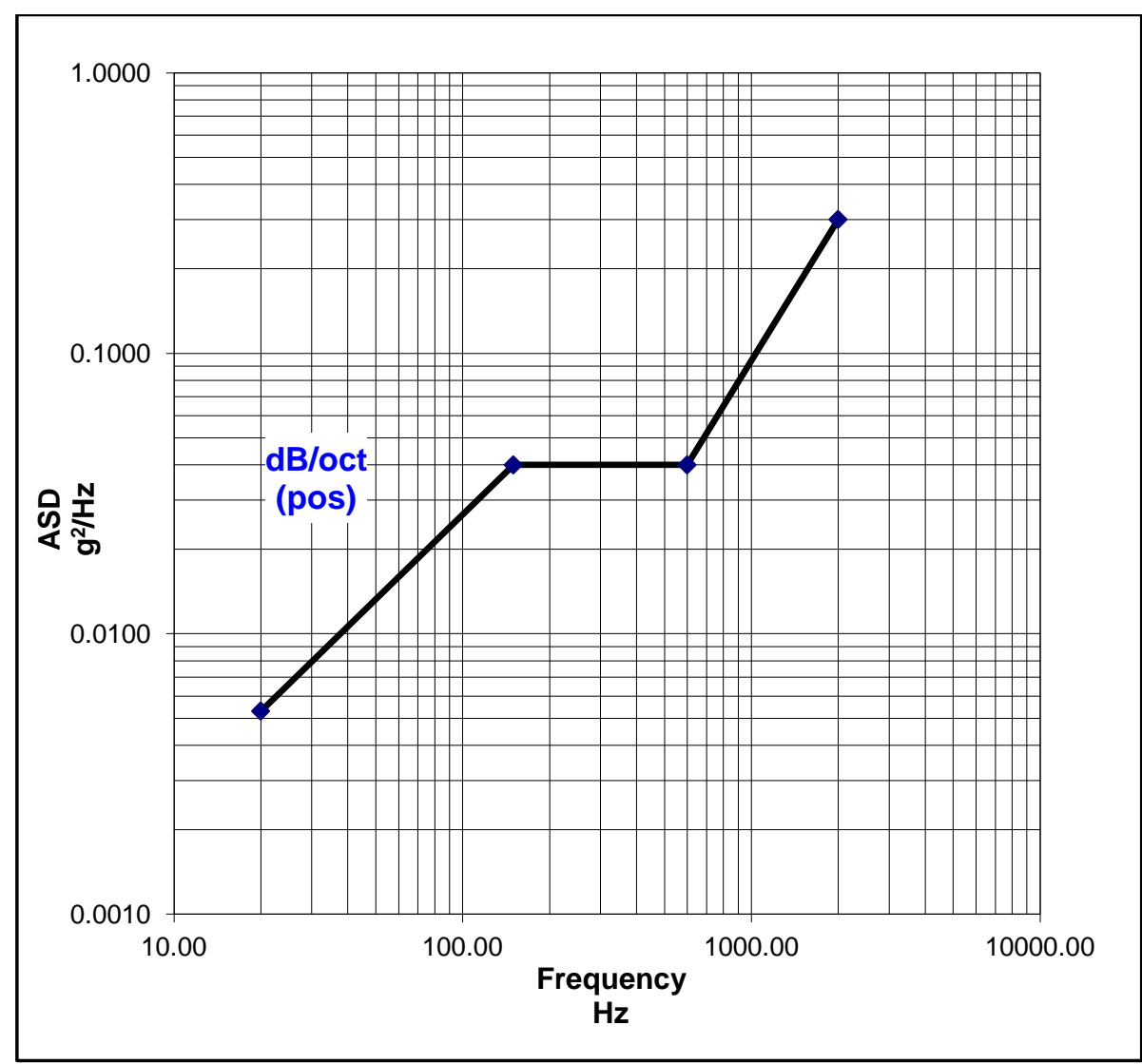

Figure 27: High frequency spectrum programmed for vibration tests. 


\section{MATERIAL PROPERTIES RESULTS}

\subsection{Material properties of the carbon fiber}

This section contains the results from the tensile test and Poisson's ratio test performed on the Instron machine. Figure 28 shows the results from the tensile tests in which six specimens were tested to acquire the Young's modulus. The average value of the Young's modulus of the carbon fiber composite plate was $6982.7 \mathrm{ksi}$. The Young's modulus was determined by using the stress and strain curve on Figure 28.

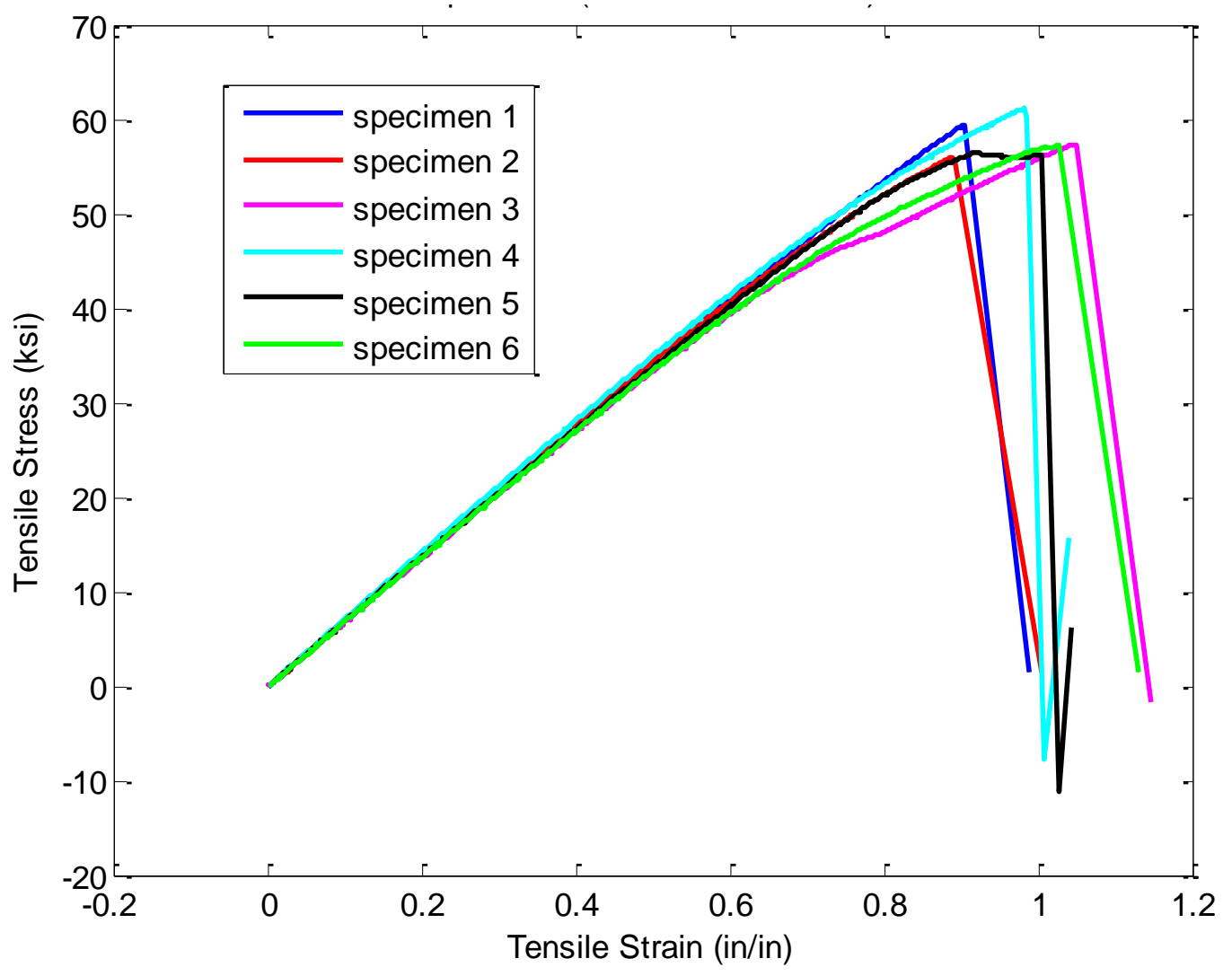

Figure 28: Stress and strain curve used to determine Young's modulus. 
Figure 29 shows the experimental results from the Poisson's ratio tests. Four specimen were tested to acquire a decent average for the Poisson's ratio. A transverse strain and longitudinal strain were attached to a coupon that pulled by the Instron machine.

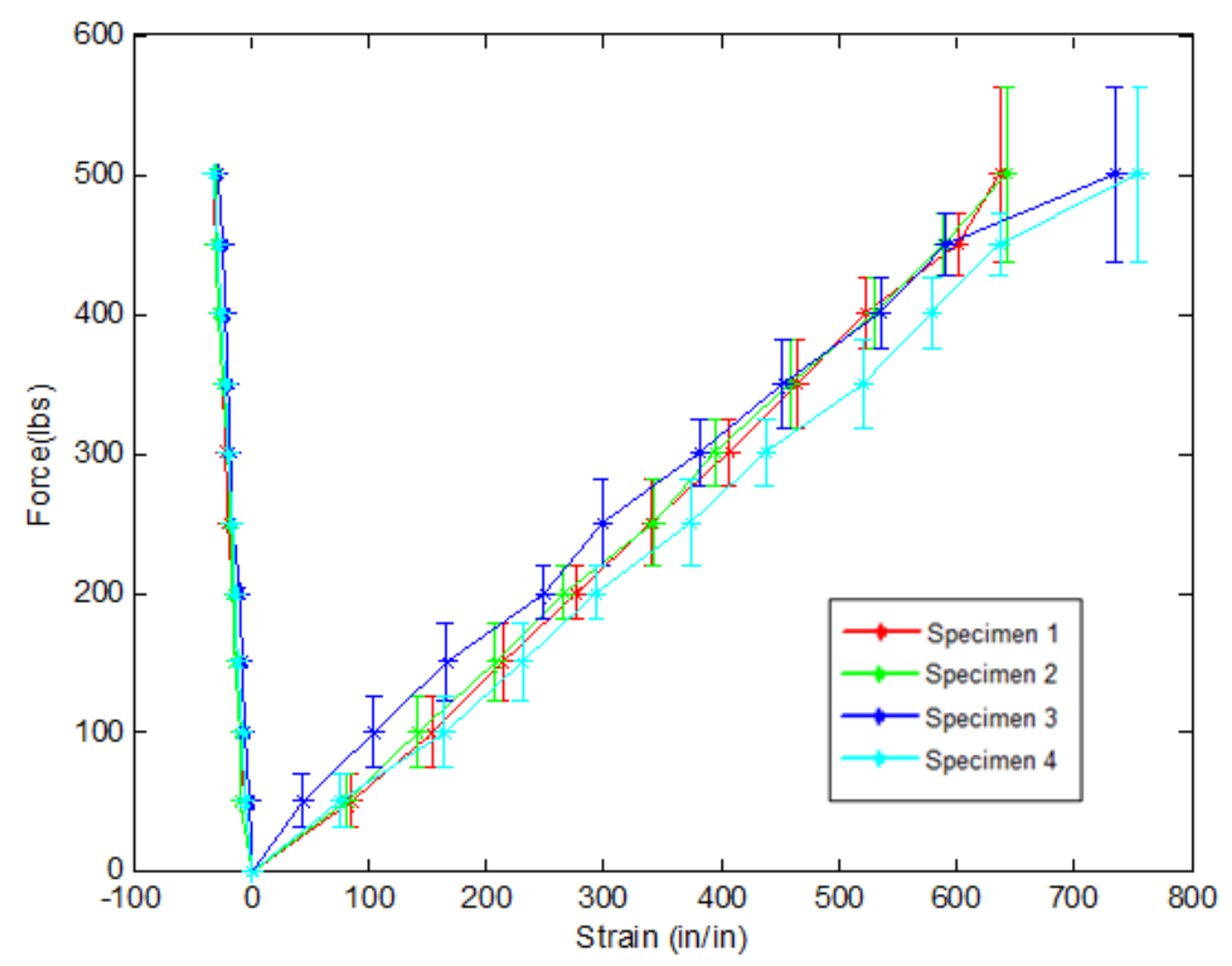

Figure 29: Data from longitudinal and transverse strain gages acquired from Poisson's ratio.

The Poisson's ratio of the carbon fiber composite plate had an average value of 0.051 with an error of $0.48 \%$ from the four specimens. Figure 29 represents the data from the transverse and longitudinal strain gages. Figure 30 shows the error bars of the data values for the transverse strain gages and longitudinal strain gages. 

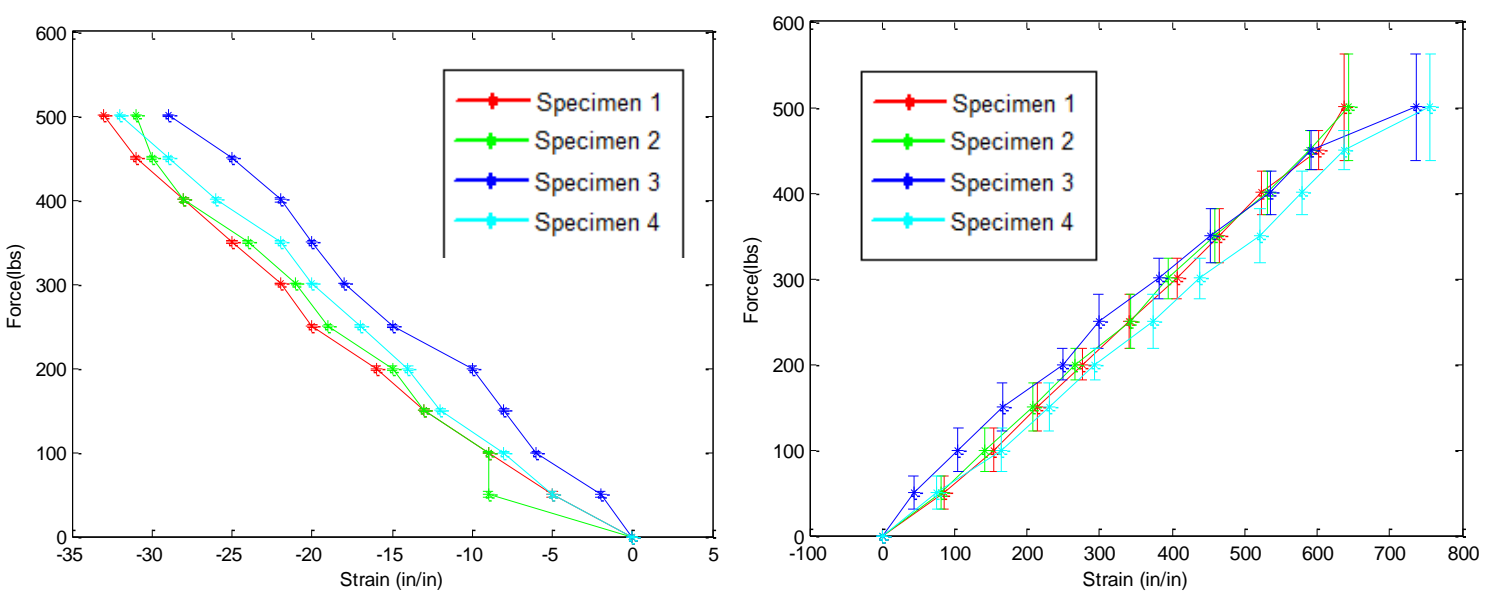

Figure 30: Transverse strain gage and longitudinal strain gage data with error bars for four specimen. 


\section{VIBRATIONAL RESULTS}

The main goal of the vibration test was to determine the frequency response of each isolator group and compare them to determine if a significant change in the vibration performance characteristics of each isolator group was apparent. The duration of each vibration test was programmed for one minute and the frequency ranged from 20 to 2000 Hz. Each isolator group was either vibrated in the flat frequency spectrum or high frequency spectrum. The tolerance of each vibration test was $\pm 3 \mathrm{~dB}$. The results showed the frequency responses of each isolator group in three axes for vibration tests with the lead mass and steel mass. The vibration tests with the $10 \mathrm{lbs}$ lead mass consisted of groups 1 through 6, which included isolator groups that were not outgassed and not cured, outgassed for 24 hours and cured, and outgassed for 36 hours and cured. The vibration tests with the $10 \mathrm{lbs}$ steel mass included groups 7 through 10 , which will be explained in section 6.3. However, prior to vibrating all of the isolator groups, a break-in process was necessary to ensure that the isolator groups had consistent frequency responses.

The break-in process began with choosing the accelerometer to use as the control and which ones to use for acquiring the frequency responses in the different axes. The initial stiffness of an isolator is usually very stiff and requires the break-in process to loosen the chemical bonds of the silicone damping material of the E22-02-40 isolators. Mainly, the break-in process helps to converge the stiffness of the damping material to a finite value. The calibrated accelerometer (T356A02) and non-calibrated accelerometers were vibrated next to each other in the flat frequency spectrum and their frequency responses 
were compared. Comparing the frequency responses of each accelerometer, as seen in Figure 31, helped ensure that any of the non-calibrated accelerometers could be used as a control by showing how accurate they were to the calibrated accelerometer.

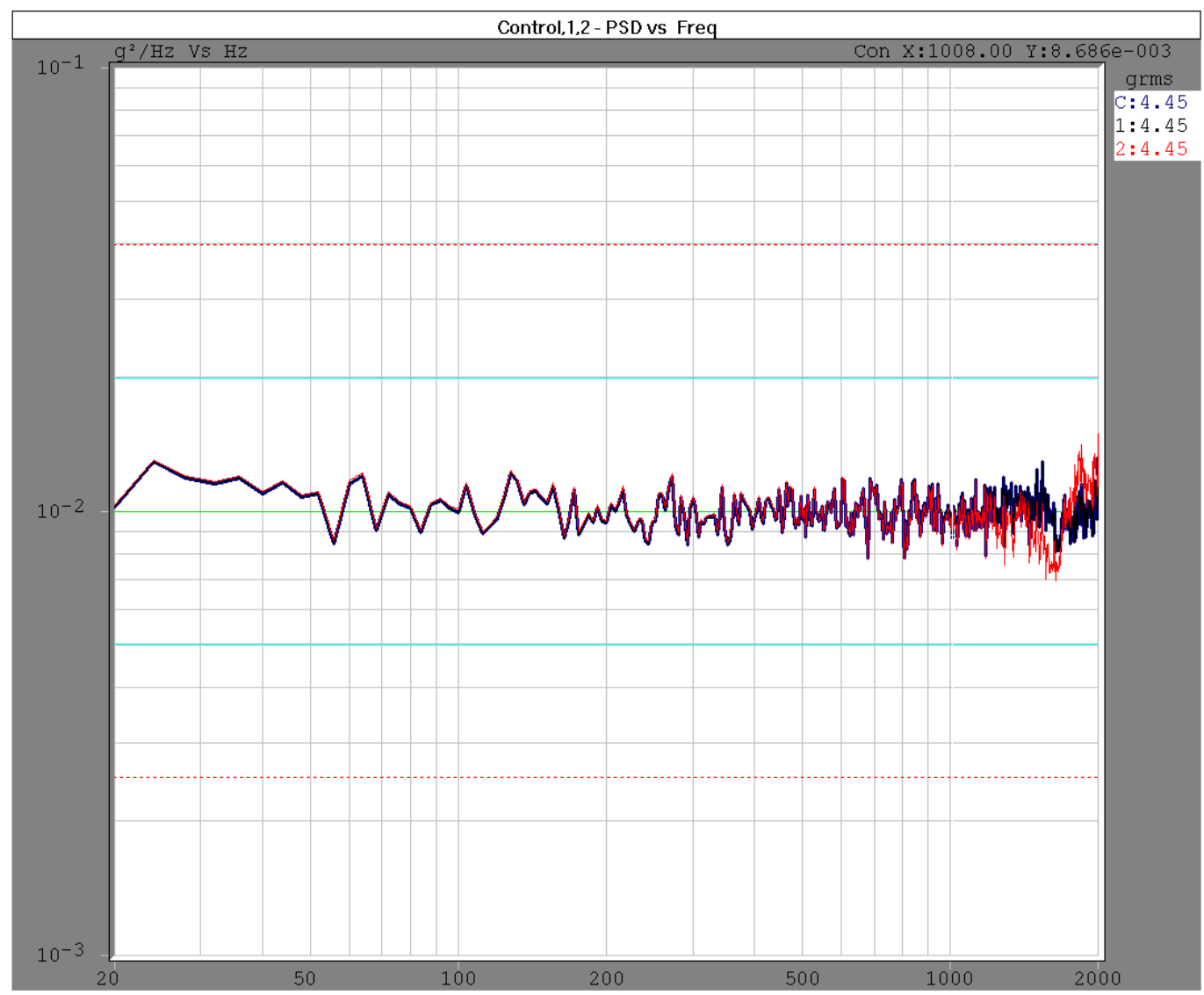

Figure 31: Two non-calibrated accelerometers vibrated next to calibrated accelerometer to compare deviation of accuracy in the flat frequency spectrum.

Figure 31 shows the non-calibrated accelerometers (represented by the blue and black lines) had very similar frequency response trend lines. The red line represented the frequency response of the calibrated accelerometer. Towards $2000 \mathrm{~Hz}$ the frequency responses of the calibrated accelerometer and non-calibrated accelerometer did not match and showed that the non calibrated accelerometers were slightly inaccurate. The calibrated accelerometer provided a definable degree of accuracy between the physical 
quantity being measured and the electrical signal generated by the sensor, which was necessary when analyzing data [14]. After the accelerometers were assigned, the break-in process for the accelerometers commenced.

The 20 isolators donated by Barry Controls were vibrated four at a time in the $\mathrm{z}$ direction to acquire the frequency responses of each isolator group. The frequency responses of all isolator groups were compared and determined if any had inconsistent trends. Figure 32 shows the comparison of the isolator groups in the flat frequency spectrum for the breakin process.

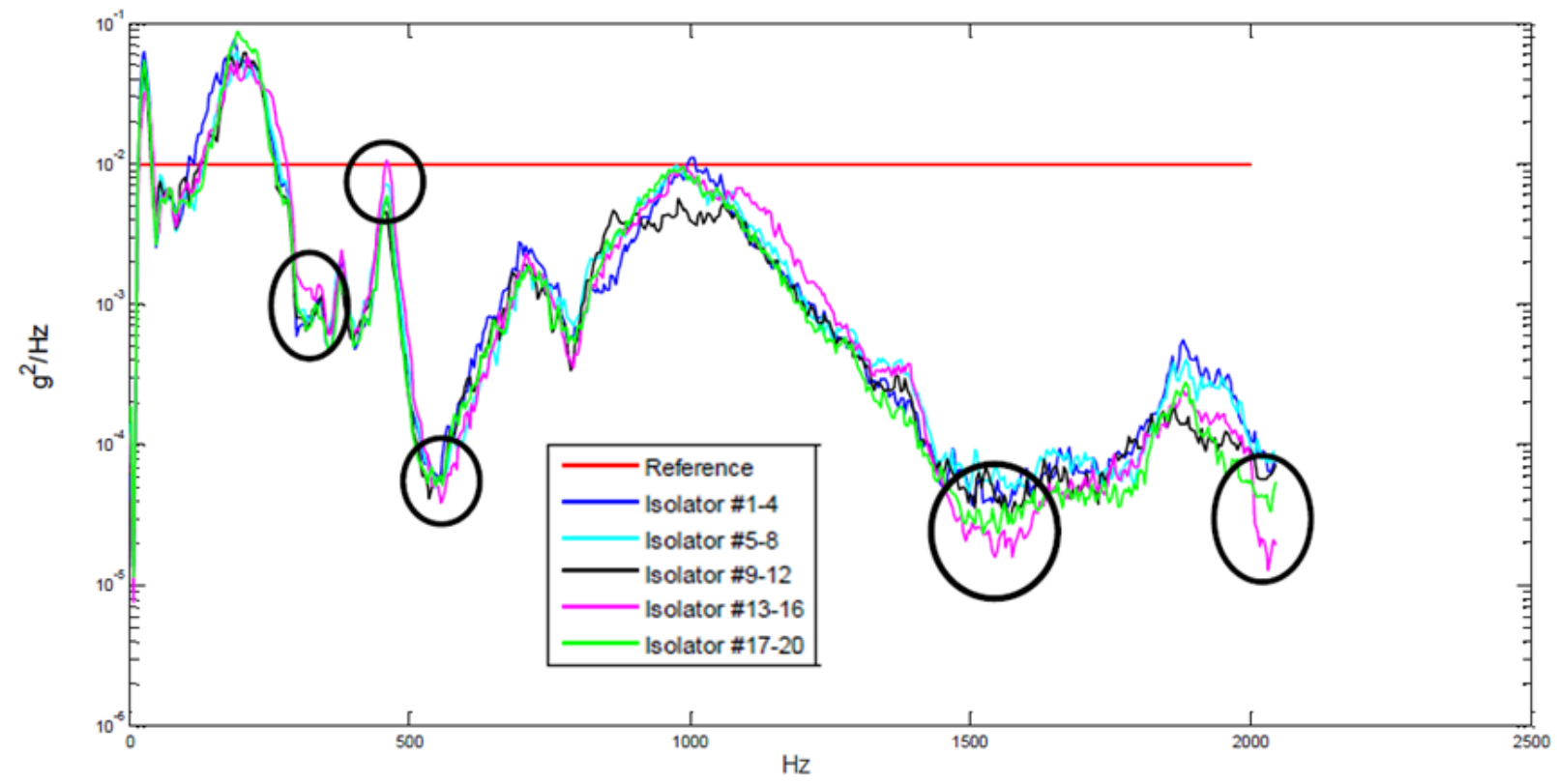

Figure 32: Log of the ASD vs. frequency responses of all the isolator groups for the break-in process in the flat frequency spectrum. 
Only one group (isolator numbers 13-16) had many inconsistencies in its frequency response and was ommitted from the experiment tests. The black circles in Figure 32 show the inconsistent areas of the omitted group. The group with isolators numbered 9 through 12 had one inconsistancy, but it was not considered an outlier. Therefore the group was kept and used in the experiments in order to provide more data. The legend of Figure 32 separates the 20 isolators into groups of four because they were mounted on the aluminum fixture, four at a time, and vibrated in the $\mathrm{z}$ direction in order to perform the break-in process. Also, to identify any inconsistencies in the frequency responses of each group of isolators. From Figure 32, the group with isolators 13 through 16 had a slightly different frequency response than compared to the rest of the groups. Therefore, the group with isolators 13 through 16 were not used in the remainder of the thesis. After the break-in process, the remaining isolators were separated into different groups, seen in Table 1 from section 1.4. The isolator groups 1 through 6 have been explained in section 1.4 and groups 7 through 10 will be be exlpained in section 6.3 .

\subsection{Vibrational results from 24 hour outgassed and cured isolator groups with comparisons}

The first spectrum test performed was in the flat frequency spectrum for group 1 and group 2. Both groups were vibrated in three axes with the setup procedure explained in section 3.3 of this report. Figure 33 displays the frequency responses of groups 1 and 2 in the $\mathrm{x}, \mathrm{y}$, and $\mathrm{z}$ directions. 


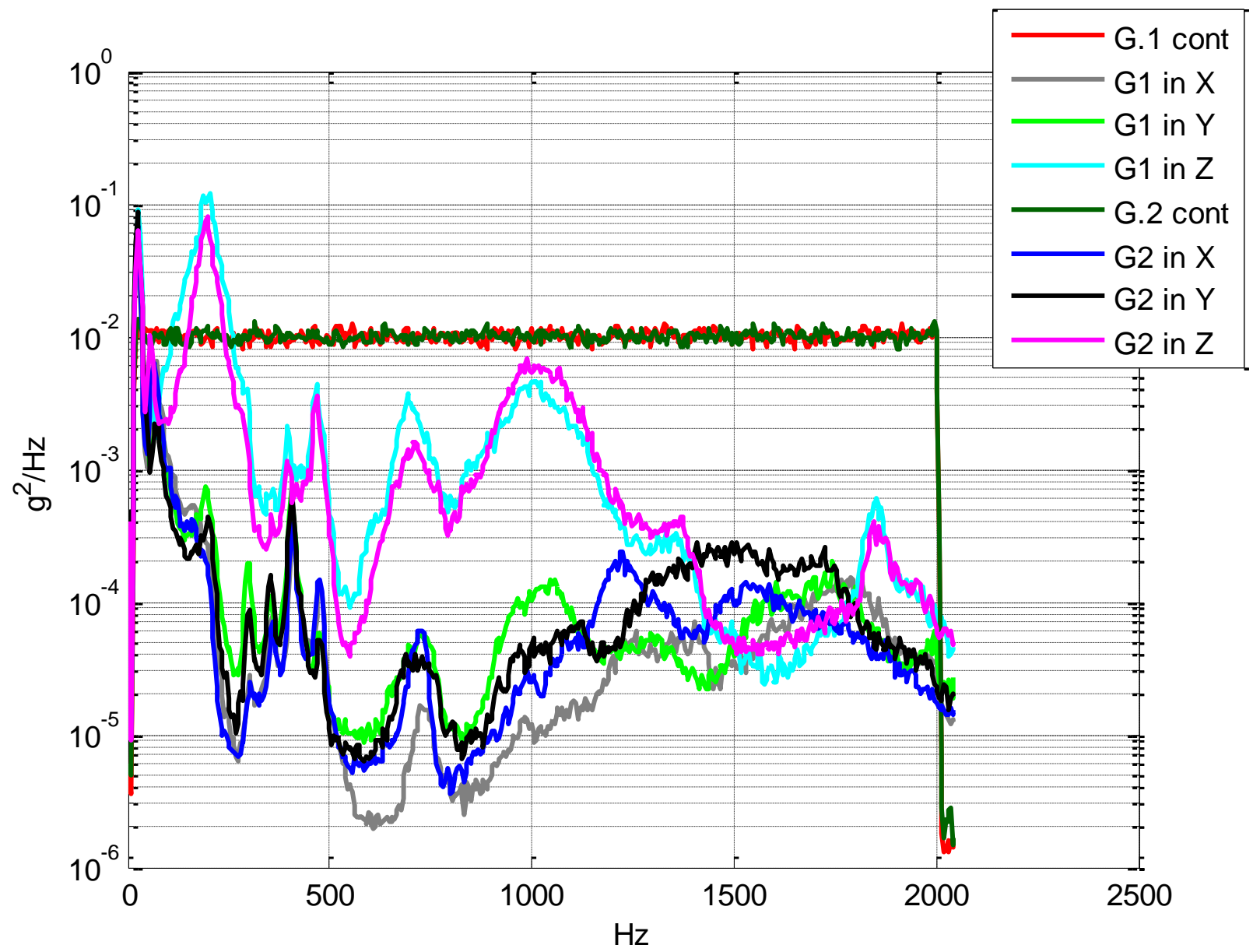

Figure 33: Comparison of the frequency response of each primary axis $(x, y$, and $z)$ between group 1 and group 2 in the flat frequency spectrum.

The broadband comparison between the two different groups in the flat frequency spectrum have similar trends. Both sets of data showed a great roll-off, while bracket modes were noticed in the higher frequency range. The amplitudes of the frequency responses for group 1 were slightly higher than group 2 overall. This trend may indicate a few changes have occurred to the vibrational performance of the isolators due to outgassing and baking, but the change is not very clear in the flat frequency spectrum. 
A close up of the first modes of the corresponding frequency responses for group 1 and group 2 may be seen in Figure 34. Based on the graph, the $\mathrm{x}$ and $\mathrm{y}$ directions from group 1 decreased in amplitude, but the frequency for the first mode of group 1 and group 2 in the $\mathrm{x}$ and $\mathrm{y}$ directions remained at $24 \mathrm{~Hz}$. The amplitude in the $\mathrm{z}$ direction of group 1 increased, but the frequency remained at $28 \mathrm{~Hz}$. The amplitude in the $\mathrm{z}$ direction was higher for group 1 than group 2. Both group 1 and 2 at the first mode did not change in frequency, but changed in amplitude.

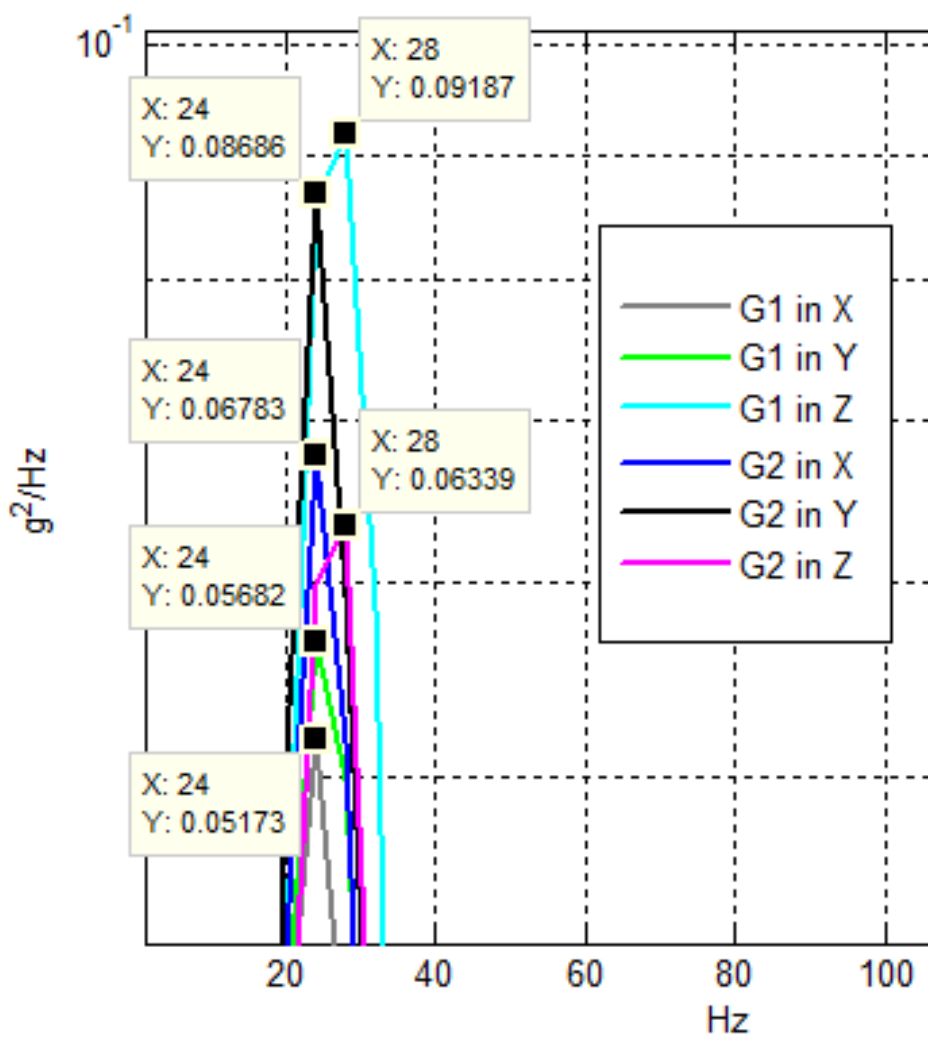

Figure 34: Close up of the first mode for groups 1 and 2. 
A comparison was made between group 3 and group 4 in the high frequency spectrum in order to observe the performance of the isolators with the added energy. Figure 35 shows the frequency response of groups 3 and 4 after shaking in the $\mathrm{x}, \mathrm{y}$, and $\mathrm{z}$ directions. The graph showed that the amplitude of group 3 slightly increased in the $\mathrm{z}$ direction, but not a great deal. A slightly noticeable change in the amplitude of the frequency responses for group 3 and 4 was observed due to the added energy in the higher frequency range. Most of the amplitudes of group 4 were higher than group 3 in the $\mathrm{x}$ and $\mathrm{y}$ directions throughout the frequency range. The change in amplitude and frequency might suggest that the vibrational performance of the isolators for group 3 was affected after outgassing for 24 hours and cured. The change was not very much because the frequency responses had similar trends. For example, the frequency response in the $\mathrm{z}$ direction for group 3 and 4 were almost the same, but most of the amplitudes of group 3 were slightly higher. 


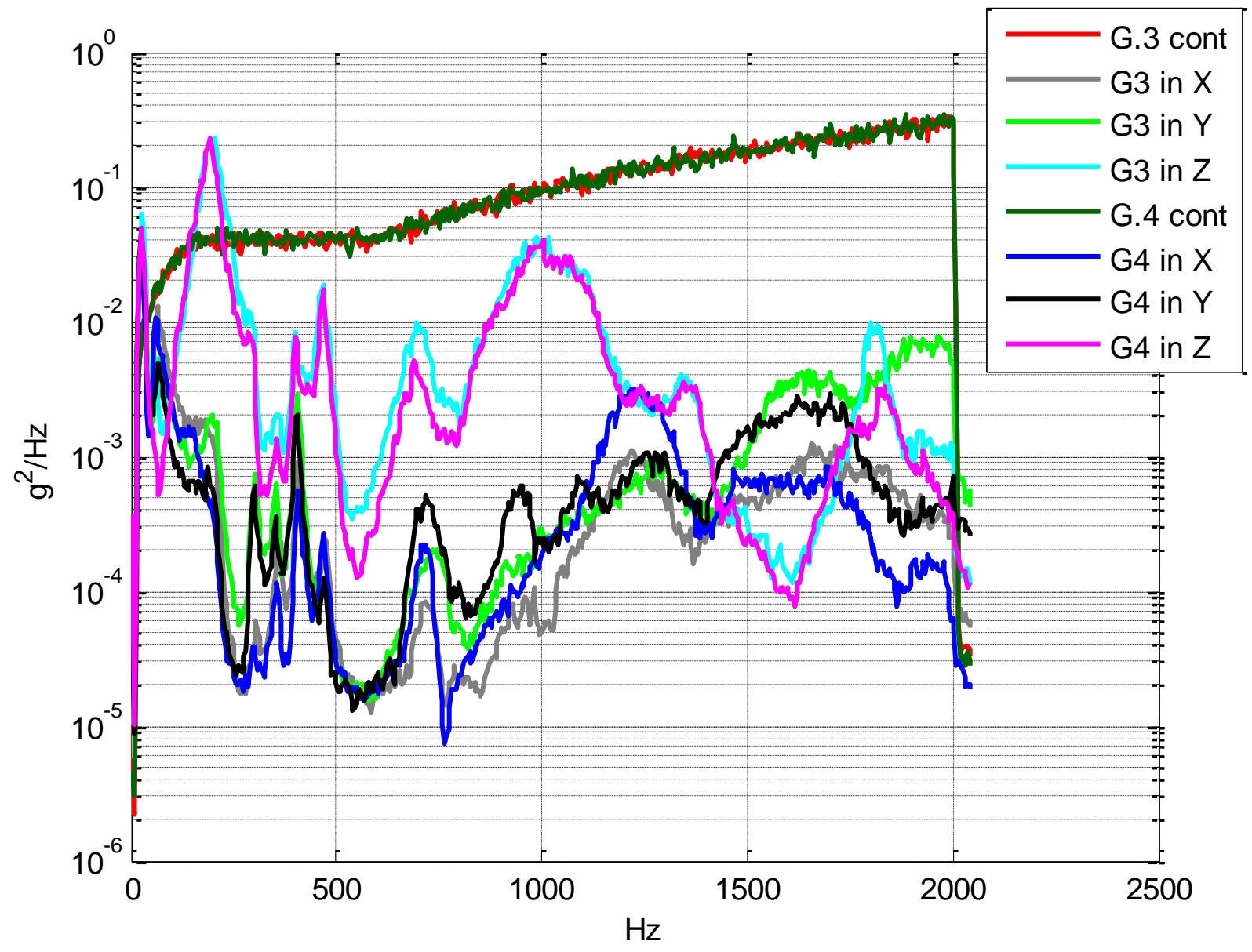

Figure 35: Comparison between group 3 and group 4 in the high frequency energy spectrum.

A zoomed view of the first frequency mode for group 3 and group 4 is shown in Figure 36. The frequency response in the $\mathrm{x}$ and $\mathrm{y}$ directions of group 3 decreased in amplitude, but the frequency remained at $24 \mathrm{~Hz}$. However the frequency of group 3 in the $\mathrm{z}$ direction increased to $28 \mathrm{~Hz}$ at an amplitude of $0.0621 \mathrm{~g}^{2} / \mathrm{Hz}$ and the $\mathrm{z}$ direction of group 4 remained at a frequency of $24 \mathrm{~Hz}$ and amplitude of $0.0493 \mathrm{~g}^{2} / \mathrm{Hz}$. 


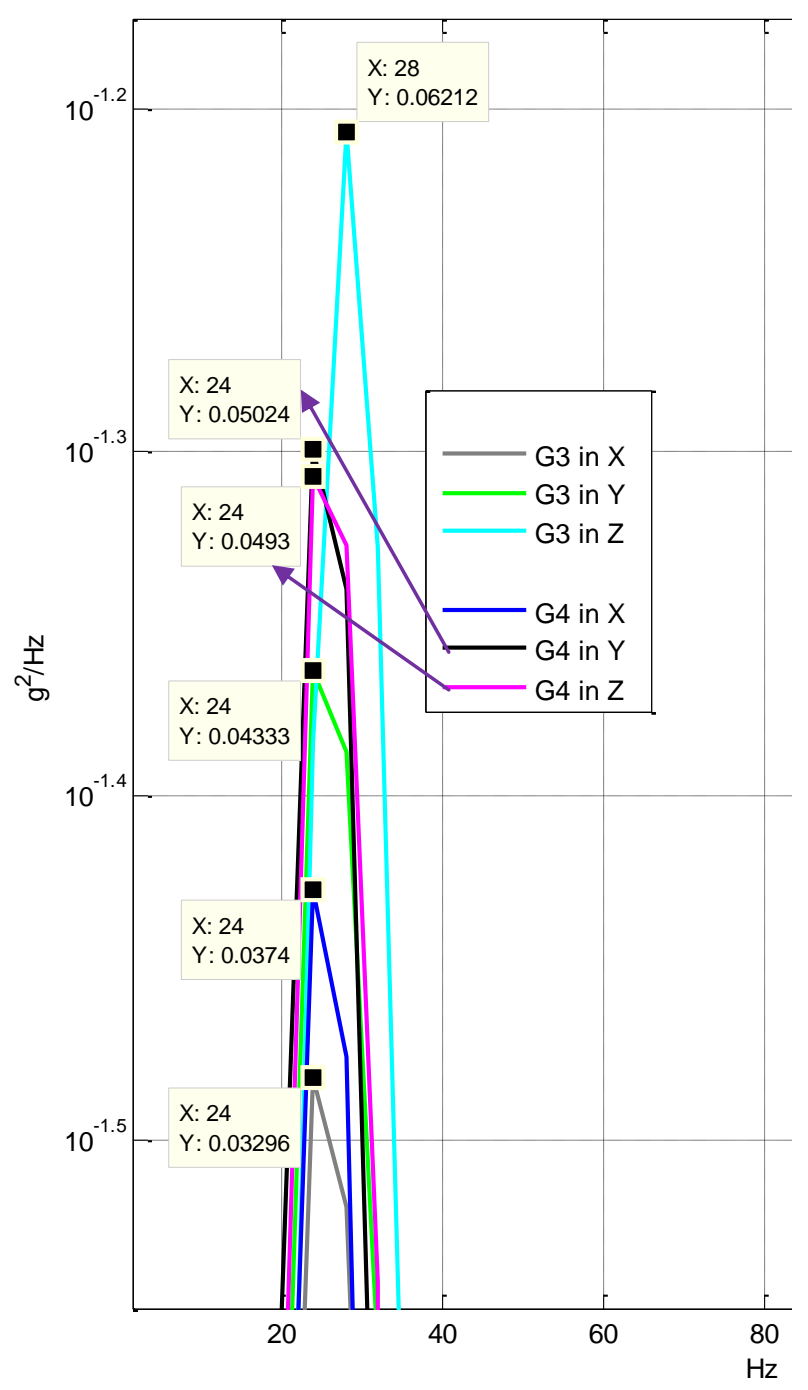

Figure 36: Close up of the first mode for groups 3 and 4 in the high frequency energy spectrum.

\subsection{Comparisons between 24 hours and 36 hours outgassing and bake-out tests}

Since there were two different outgassing times and cures for elastomeric isolators, two new groups of isolators were created, which included groups 5 and 6 . The curing temperatures and duration of outgassing are listed in Table 1, which follow a previous study performed by Barry Controls that made high damp silicone isolators grade A for 
outgassing. Given that group 2 and 4 have been outgassed using the 24 hour curing cycle, they could not be used for this next test. Therefore, group 1's isolators became groups 5 and 6, as explained in section 1.4 of this thesis. A comparison between the outgassed isolators of groups 5 and 6 is graphed in Figure 37. The legend indicates the frequency response with the corresponding primary axis that it was vibrated in for each group. For example, group 5 was vibrated in the $\mathrm{x}, \mathrm{y}$, and $\mathrm{z}$ directions and is labeled as G.5 in X for the frequency response in the $\mathrm{x}$ direction of group 5 and so on. These two groups were outgassed for 36 hours and cured at different temperatures to be turned into a presumed grade A for outgassing. Off-the-shelf, the isolators were considered grade C for outgassing, but now that group 5 and 6 were converted to a presumed grade A, the vibrational performance characteristics in the different spectra may be compared and observed. Overall, the frequencies at the bracket modes for group 6 increased in the three vibrated axes ( $\mathrm{x}, \mathrm{y}$, and $\mathrm{z})$, while the bracket frequencies for group 5 decreased. 


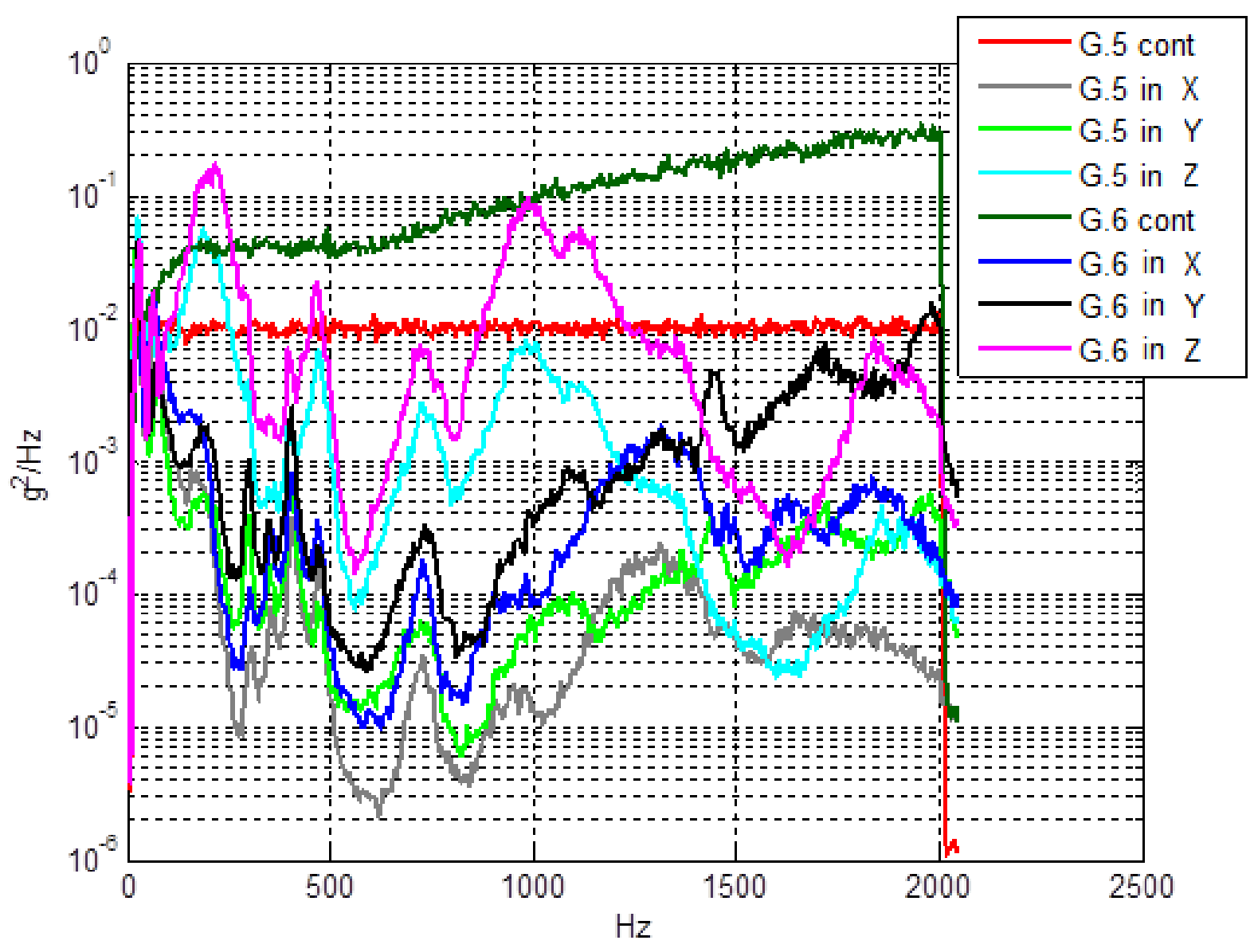

Figure 37: Comparison between groups 5 and 6 in order to see how the isolators performed in the different spectrums.

An additional comparison of group 5 was made with group 2 on the first mode of each group and may be seen in Figure 38. The amplitude for group 5 decreased, but the frequency increased when compared to group 2 (the non-outgassed and non-cured case). Figure 38 indicates the amplitude of the first mode in the $\mathrm{x}$ and $\mathrm{y}$ directions of group 5 decreased from group 2 in the same directions. The change implies that the vibrational performance of group 5 reduced due to its curing and bake-out cycle. 


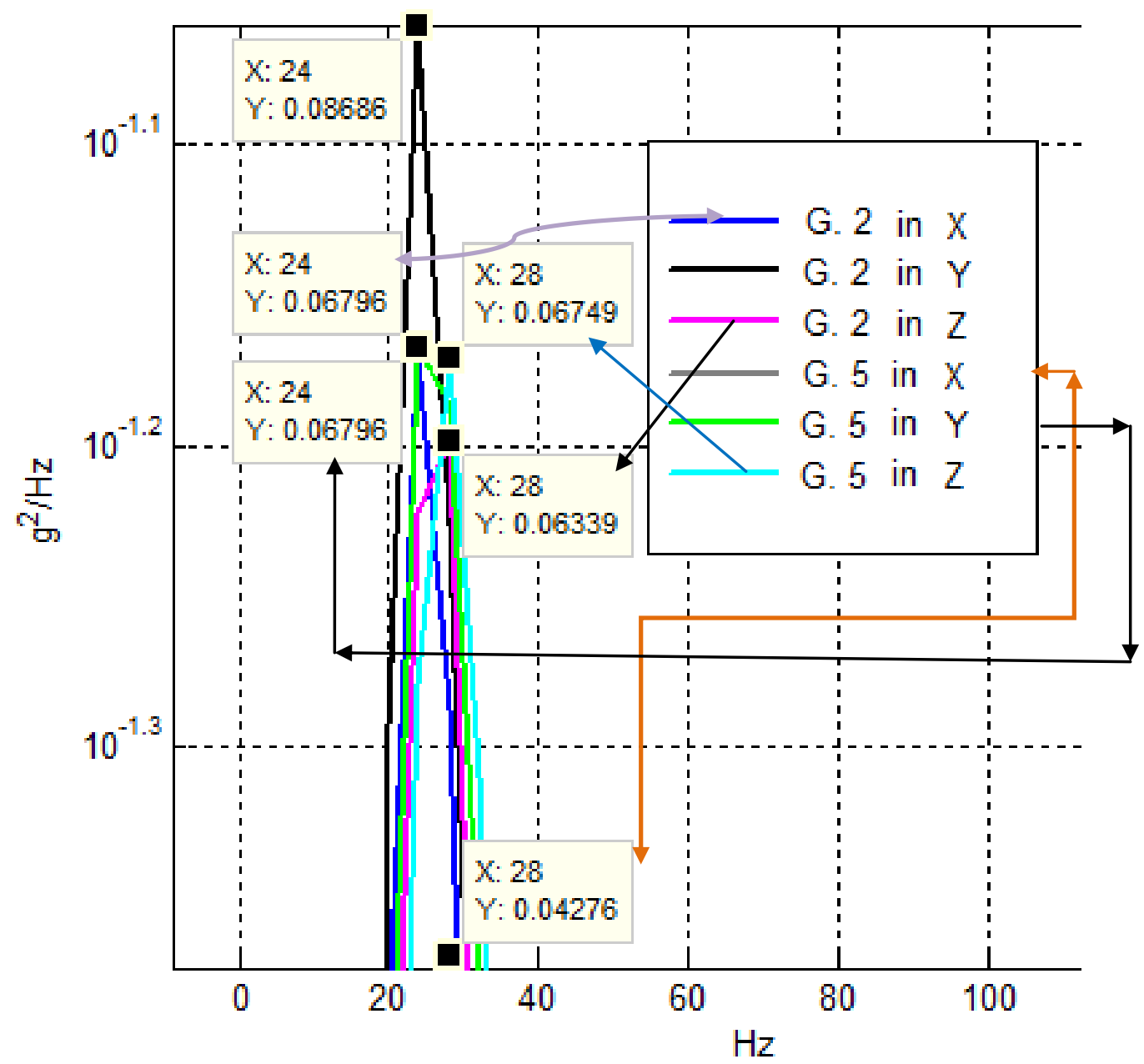

Figure 38: Comparison between group 2 and 5 in flat spectrum.

Another comparison of the first mode was made in the flat frequency spectrum for group 1,2 , and 5 because all three groups had different curing and outgassing conditions. In the $\mathrm{x}$ direction group 5 decreased in amplitude when compared to group 1, but its frequency increased when compared to group 1 and 2. In the y direction group 1, 2, and 5 had the same frequency in the first mode at $24 \mathrm{~Hz}$. The amplitude increased in the y direction for group 5 when compared to group 1 . In the $\mathrm{z}$ direction group 1 had the maximum amplitude followed by group 5, and lastly group 2 . The frequency in the $\mathrm{z}$ direction for 
groups 1, 2, and 5 remained at $28 \mathrm{~Hz}$. The data does not show a clear trend in the flat frequency spectrum and is hard to observe. Therefore, a more clear observation is made in the high frequency spectrum.

Groups 3, 4, and 6 were vibrated in the high frequency spectrum and compared to each other to observe any differences in their vibrational performance. Figure 39 compares the frequency response of the vibrated $\mathrm{x}, \mathrm{y}$, and $\mathrm{z}$ directions of groups 4 and 6 . The amplitudes of the frequency responses in all three axes were higher for group 6 than group 4 throughout the entire frequency range.

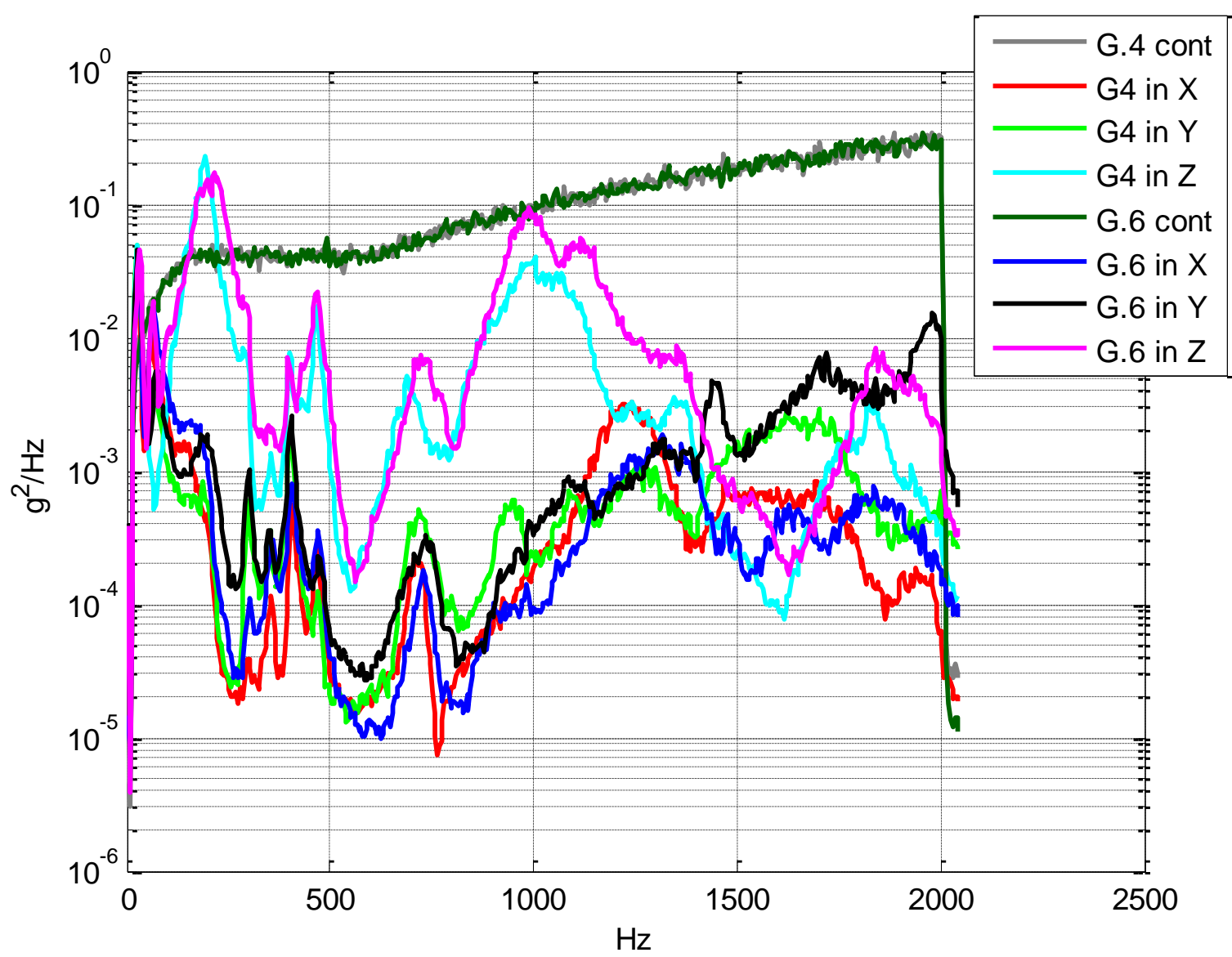

Figure 39: Comparison between group 4 and 6 in the high frequency energy spectrum. 
Comparing the first mode in the $\mathrm{x}$ and $\mathrm{y}$ directions, the amplitude and frequency were higher for group 6 than group 3. However, in the $\mathrm{z}$ direction group 6 had the highest first mode frequency at $32 \mathrm{~Hz}$, group 3 at $28 \mathrm{~Hz}$, and group 4 at $24 \mathrm{~Hz}$. Group 6 had the lowest first mode amplitude, followed by group 4, and group 3 with the largest amplitude of the three groups. The data proved that the dampening material of the isolators for group 6 got stiffer due to the higher frequency at the first mode, which is confirmed in section 7.2.

\subsection{Steel mass results for 36 hour outgas test}

An additional vibrational experiment was conducted in the same method as the previous groups, the only difference was the material of the $10 \mathrm{lb}$ mass. The material of the mass was steel instead of lead. This experiment was conducted in order to have more data to analyze and observe any differences. A total of four groups were conducted in the $\mathrm{x}, \mathrm{y}$, and $\mathrm{z}$ directions. Group 7 included isolators 9 through 12, which were outgassed for 36 hours and vibrated in the flat spectrum. Group 8 used the same isolators from group 7 and vibrated in the high frequency spectrum. Group 9 used isolators 17 through 20, previously group 4, and vibrated them in the flat frequency spectrum with the steel mass. Group 10 also utilized isolators 17 through 20, but were vibrated in the high frequency spectrum. Figure 40 shows groups 7 and 9 and their frequency responses. 


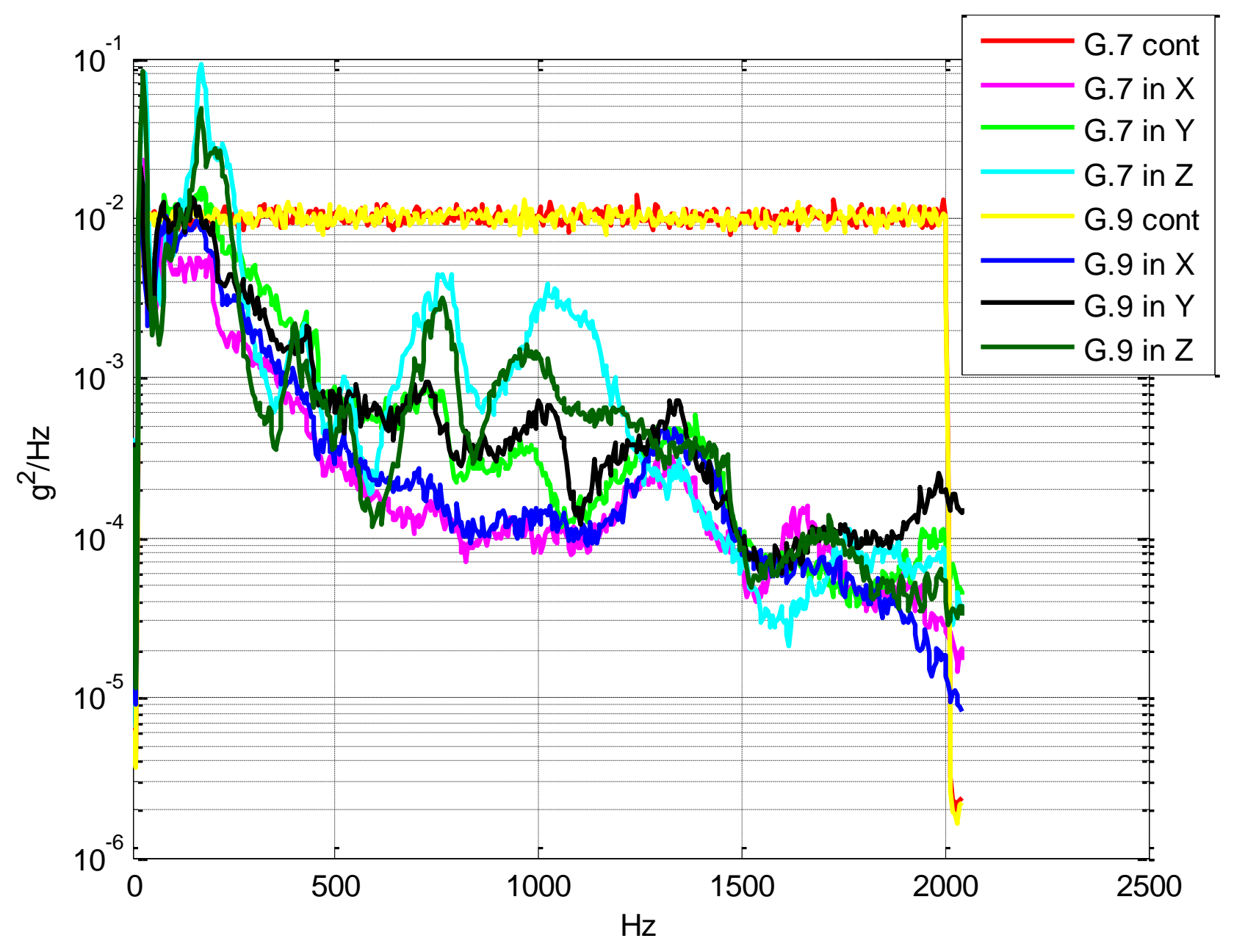

Figure 40: Comparison between group 7 and group 9 in the flat frequency spectrum.

The amplitudes of the frequency responses for groups 7 and 9 decreased after $1000 \mathrm{~Hz}$.

The amplitude of the $\mathrm{x}$ and $\mathrm{z}$ directions of group 7 were higher than group 9's after 1000 Hz. The amplitude in the y direction of group 7 was lower than the amplitude of group 9. This inconsistency is most likely due to noise.

The frequency responses of groups 8 and 10 are shown in Figure 41. The amplitudes of the frequency responses for group 8 in the $\mathrm{x}$ and $\mathrm{z}$ direction were higher than group 10 . 
The amplitude of group 10 was higher than group 8 in the y direction. The PSD values of group 8 and group 10 decreased after $1000 \mathrm{~Hz}$, but the amplitudes varied. For example, the frequency response in the vibrated $\mathrm{x}$ and $\mathrm{z}$ directions had higher amplitude values in group 8 than group 10. In the y direction, group 10 had higher amplitude values than group 8 throughout the entire frequency range. The roll-off after $1000 \mathrm{~Hz}$ showed that the isolators were performing because the amplitudes were lower towards the higher frequency range.

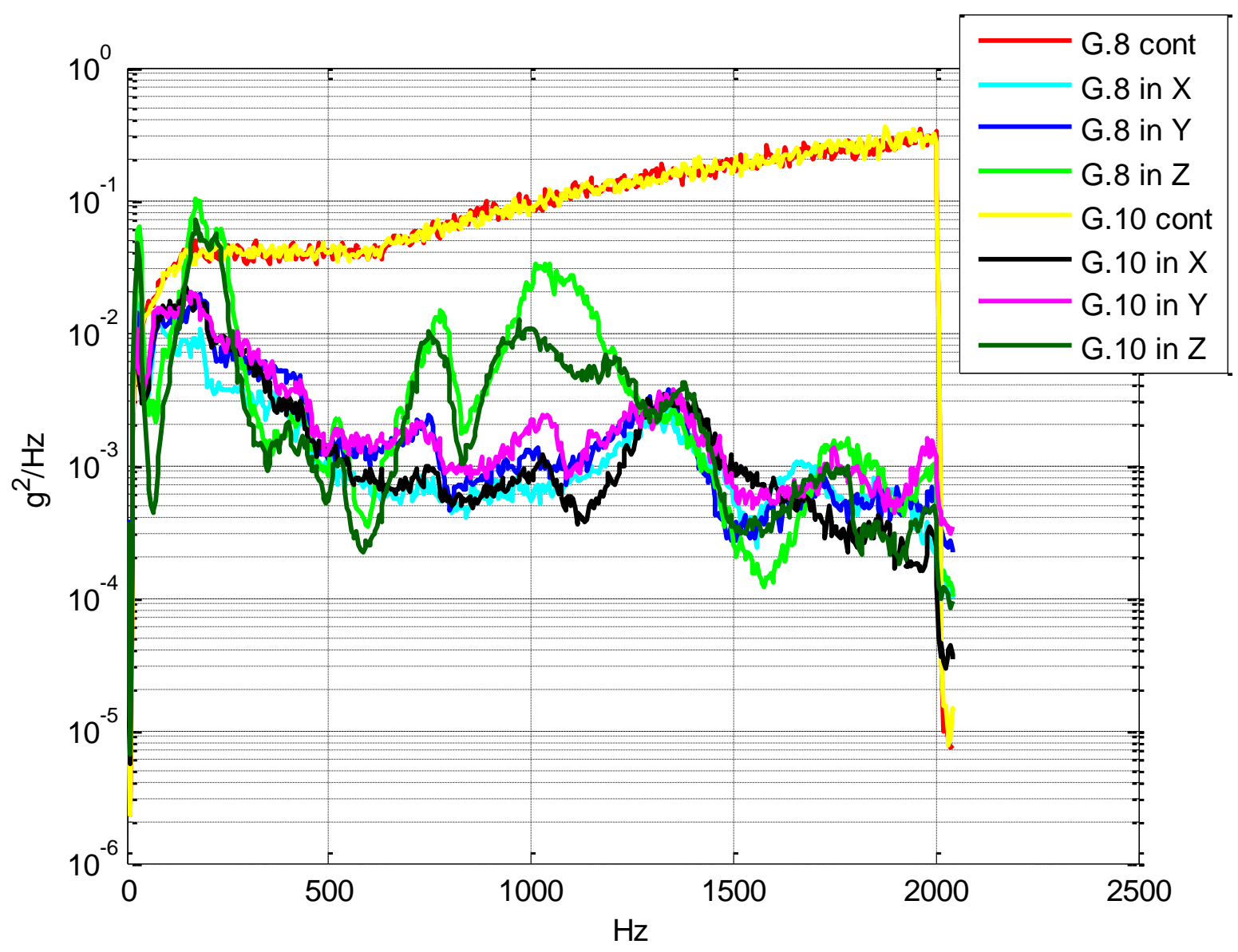

Figure 41: Comparison in the high frequency spectrum for group 8 and group 10. 
To acquire a better understanding of the frequency responses of each group, the GRMS values for groups 7 through 10 were listed in Table 3. The percent difference of the values on Table 3 can be seen in Table 5 .

Table 3: Comparison of GRMS values for group 7 through 10.

\begin{tabular}{|c|c|c|c|}
\hline & \multicolumn{3}{|c|}{ GRMS Values } \\
\hline Group \# & $\mathbf{X}$ & $\mathbf{Y}$ & $\mathbf{Z}$ \\
\hline $\mathbf{7}$ & 1.27 & 1.86 & 2.79 \\
\hline $\mathbf{8}$ & 1.9 & 2.31 & 4.13 \\
\hline $\mathbf{9}$ & 1.45 & 1.72 & 2.29 \\
\hline $\mathbf{1 0}$ & 2.28 & 2.48 & 3.28 \\
\hline
\end{tabular}

GRMS values in the $\mathrm{z}$ direction for all the groups in Table 3 had the highest values. The values in the $\mathrm{y}$ direction were the second highest and the values in the $\mathrm{x}$ direction had the lowest. The GRMS values of all the groups were lower than the input GRMS value of the high frequency spectrum of 15.37 and flat frequency spectrum of 4.48 . The experimental GRMS values were lower than the input GRMS values indicating the results were within tolerance for the vibrational tests. 


\section{SWELLING TEST PROCEDURE AND DISCUSSION}

\subsection{Swelling Test Procedure}

Once the isolators were vibrated and outgassed, the swelling test procedure was conducted. The swelling test determined the swelling capacity of a polymer by the amount of solvent material that could be absorbed. For this experimental swelling test, 12 samples of the silicone material were immersed in THF (Tetrahydrofuran) solvent for several days. THF is an organic compound that is colorless and smells similar to acetone. Since THF was absorbed by the silicone damping material, it was the chosen solvent. The isolators that were used for the swelling test included isolators numbered 17-20, 9-12, 1, 4, 5, and 8. The isolators 17-20 were not outgassed and not cured (will be referred as group A), 9-12 were outgassed for 36 hours and cured ( now labeled group C), and the last group of isolators were outgassed for 24 hours and cured ( now named group B). The isolators were previously used for the vibration tests. Once the vibration tests were conducted, the three different groups of isolators previously mentioned were taken apart and the silicone material was removed for each, as seen in Figure 42.

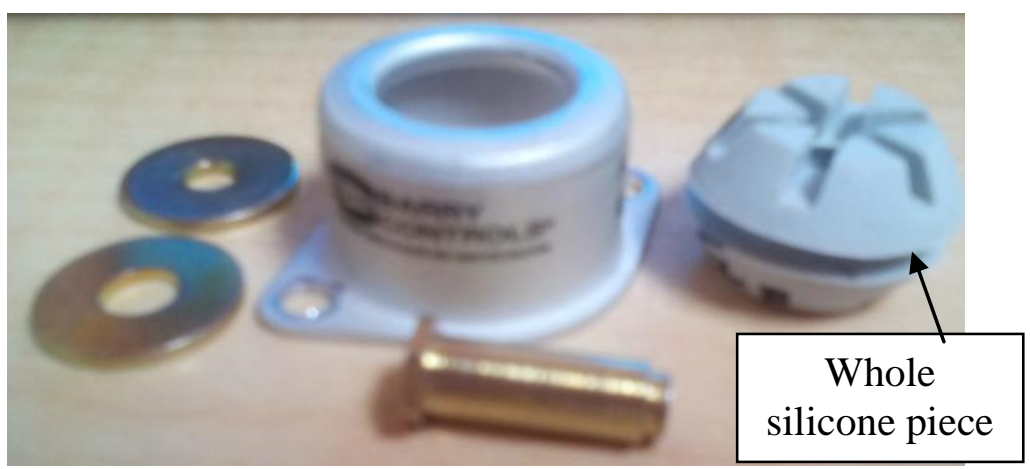

Figure 42: Individual parts of an E22-02-40 isolator. 
The silicone material of each isolator was evenly cut into 4 pieces, as seen in Figure 43 . The silicone damping material was cut with a razor blade and each piece was numbered.

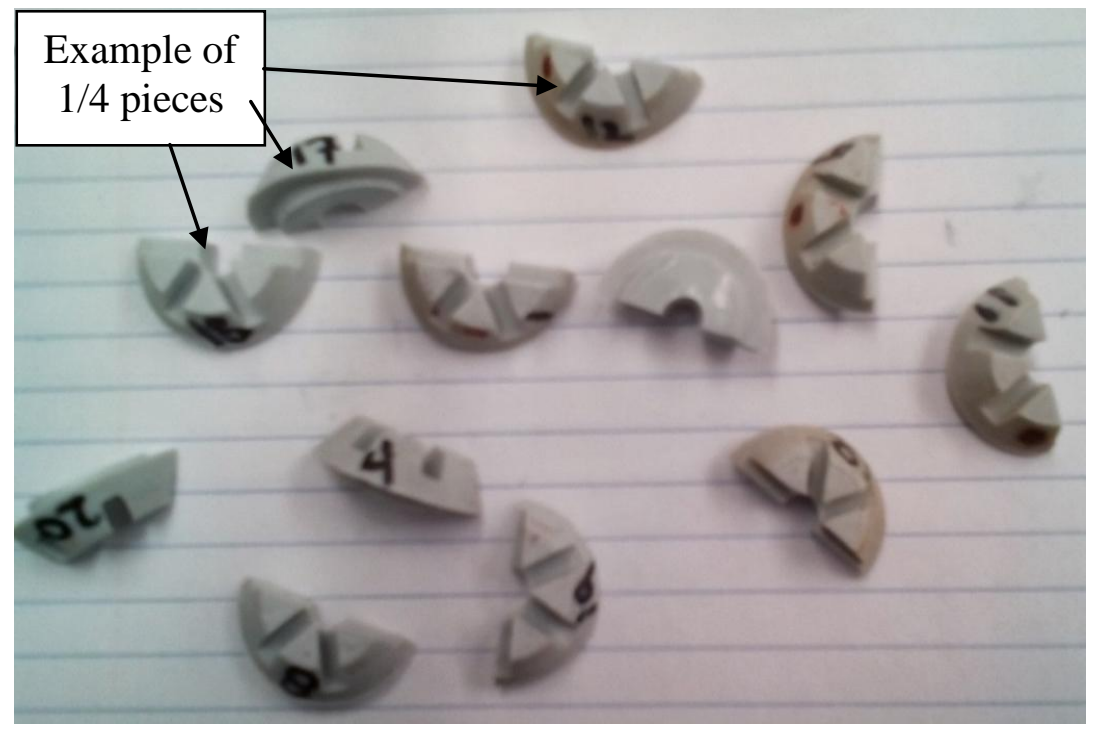

Figure 43: Representation of silicone material of the E22-02-40 isolators cut into 1/4 pieces.

Only $1 / 4$ of the silicone material was used for each isolator as part of the swelling test and placed inside a glass jar, as seen in Figure 44. Only $1 / 4$ of the silicone for each isolator was used because a whole silicone material would expand too much and could swell beyond the jar's limits. 


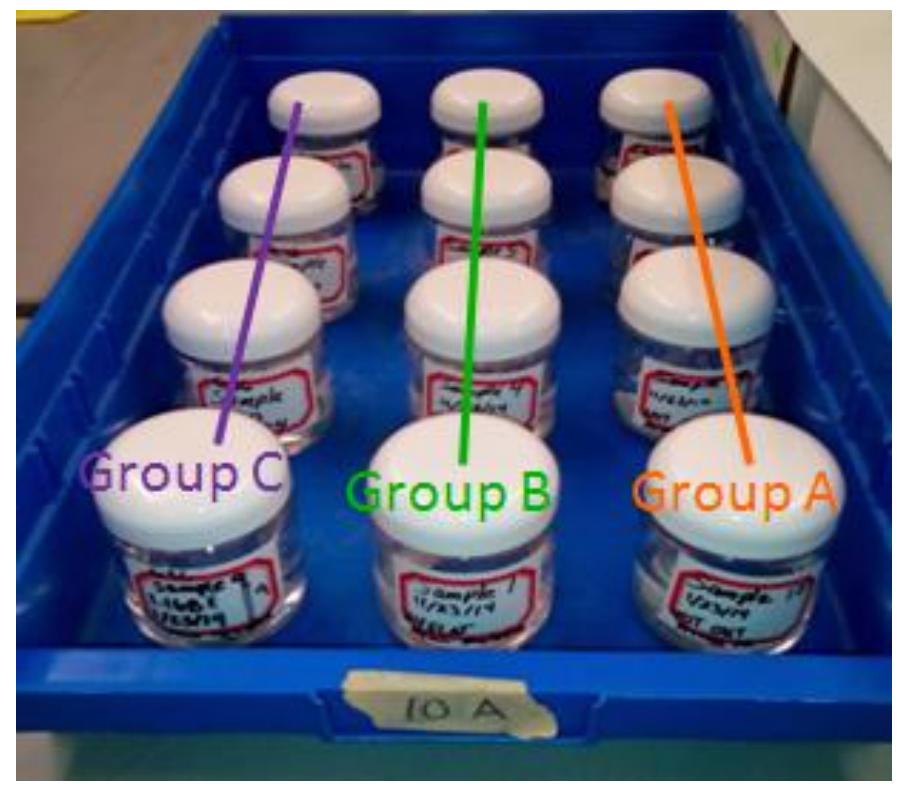

Figure 44: Twelve glass jars for different outgassing cases with silicone materials.

Sixty $\mathrm{ml}$ of THF was poured into each jar that housed the $1 / 4$ of the silicone material. A total of twelve jars were used and the silicone piece in each jar was weighed for several days. The pieces were weighed after 1 day, 3 days, 7 days, and 11 days. The 1/4 silicone pieces could have been weighed every day, but decided to weigh them in 2 through 4 day increments to allow the silicone material to fully absorb the THF solvent. The silicone pieces were taken out of their respective jars, dried with a paper towel, then weighed in a Sartorius Quintix 224-1S analytical laboratory balance, as seen in Figure 45. 


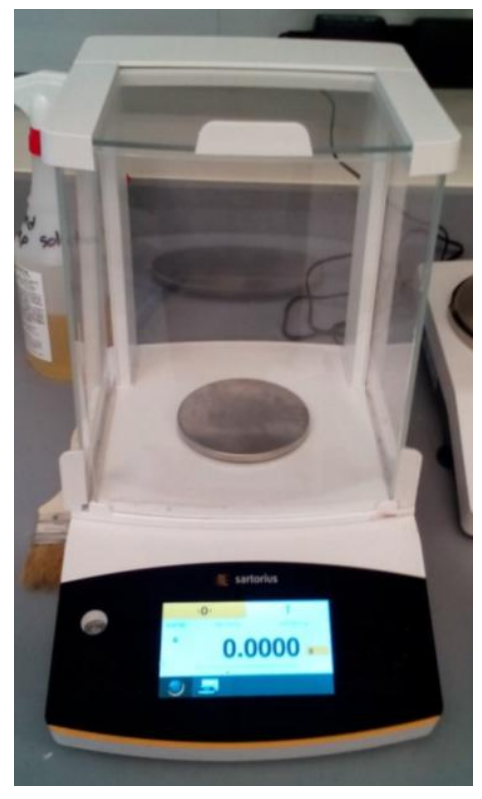

Figure 45: Sartorius high precision scale used to weight the silicone samples for swelling tests.

\subsection{Swelling Test Results}

The four samples of group A, group B, and group C were combined to make only three groups to analyze instead of twelve. The average mass values of the silicone pieces of each group are listed in Table 4, along with the standard deviation of the percent mass increase. The amount of solvent absorbed by the silicone damping material increased per day. There was a slight inconsistency in the mass weighed because the solvent evaporated once the material was exposed to air. Figure 46 plots the percent mass increase of each group for the different days measured along with error bars. Group B absorbed the most amount of THF solvent, which meant the silicone material became more elastic. Group C absorbed the least amount of solvent than the rest of the groups and the silicone material became stiffer due to the curing cycle of the isolators from group 5 and group 6 . A physical change happened to the silicone damping material because of the outgassing and temperature from the curing cycle of group 5. In general, the silicone material cured at a 
temperature of $180^{\circ} \mathrm{C}$, or higher changes the silicone material. The curing cycle of group 1 at a temperature of $125{ }^{\circ} \mathrm{C}$ for 24 hours showed that the silicone material was elastic and changed to stiff when it was cured at $204{ }^{\circ} \mathrm{C}$ for 24 hours (group 5's curing cycle). However, more studies should be made in the future to confirm this observation.

Table 4: Average mass values for the silicone material during the swelling test with the average percent mass increase standard deviation of each group.

\begin{tabular}{|c|c|c|c|c|}
\hline \multirow{2}{*}{ Group } & \multicolumn{4}{|c|}{ Increase in mass (\%) } \\
\cline { 2 - 5 } & Day 1 & Day 3 & Day 7 & Day11 \\
\hline A & $3.70 \pm 0.569$ & $4.39 \pm 7.12$ & $4.40 \pm 10.4$ & $4.33 \pm 5.40$ \\
\hline B & $3.48 \pm 4.48$ & $4.25 \pm 4.98$ & $4.14 \pm 10.4$ & $4.07 \pm 12.7$ \\
\hline C & $3.27 \pm 8.15$ & $3.96 \pm 7.16$ & $4.03 \pm 9.24$ & $3.94 \pm 9.77$ \\
\hline
\end{tabular}

The results of the swelling test verified that the vibration tests correlated with the physical change of the silicone damping material of each isolator group. For example, the swelling test showed that the silicone material of group $\mathrm{C}$ was the stiffest and matched the vibration results of group 6, which had the highest first frequency mode than the rest of the isolator groups. A material is stiffer when it absorbs less solvent because the crosslink density is higher and the chemical bonds are tighter. 


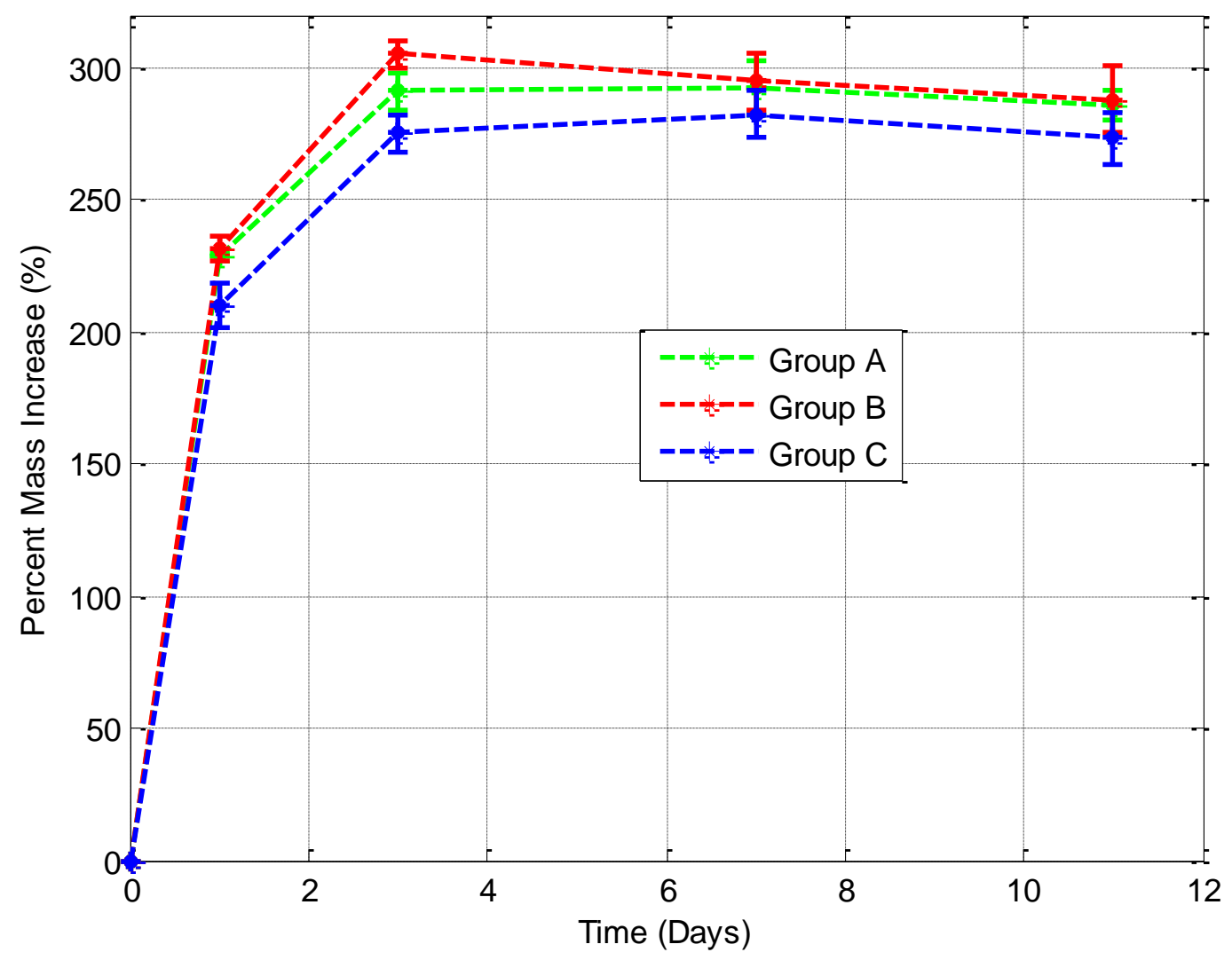

Figure 46: Percent mass increase of silicone material over time for 3 outgassing cases 


\section{NUMERICAL FINITE ELEMENT ANALYSIS}

The numerical analysis on the vibration system tested was aided by using the finite element analysis program, Abaqus/CAE. The carbon fiber composite plate was modeled as a 3D shell part, as seen in Figure 47. The dimensions of the plate modeled were 10 inches by 10 inches with a thickness of 0.107 inches. The experimental material properties of the carbon fiber composite plate that were acquired from the tensile test and Poisson's ratio test (refer to section 5.1) were inserted into the materials section of Abaqus/CAE.

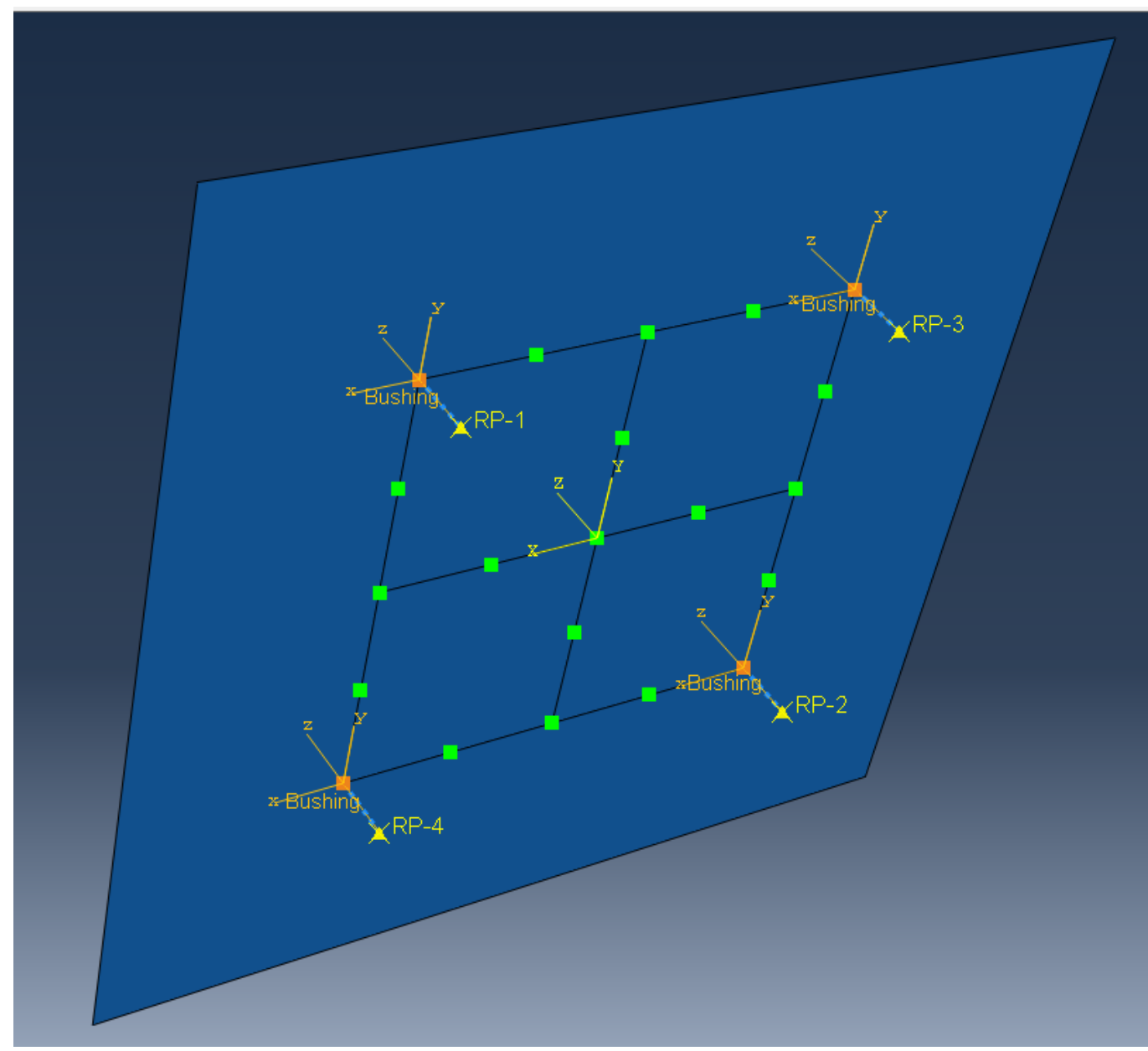

Figure 47: Boundary conditions of finite element analysis model. 
The section was assigned as a composite plate with 16 layers and their respective angle orientations. Under the assembly tab the part was designated as an independent mesh. The face of the modeled carbon fiber composite plate was partitioned in the location where the isolators interfaced with the plate. A total of four wire features under the assembly tab were placed on the corners of the square partition. A connector assignment was created for the wire features and a connector section was assigned (the assembled/complex type was bushing) to input the damping coefficient of 0.15 and stiffness of $263 \mathrm{lbs} / \mathrm{in}$ to represent the isolators. A distributed mass of $10 \mathrm{lbs}$ was inserted in the inertia engineering features under the assembly tab. Any value with a mass dimension was converted to an English unit of ( $\mathrm{lbm}-\mathrm{in}) / \mathrm{sec}^{2}$ because it is a default unit for Abaqus/CAE. The boundary conditions of the vibration setup are seen in Figure 48 .

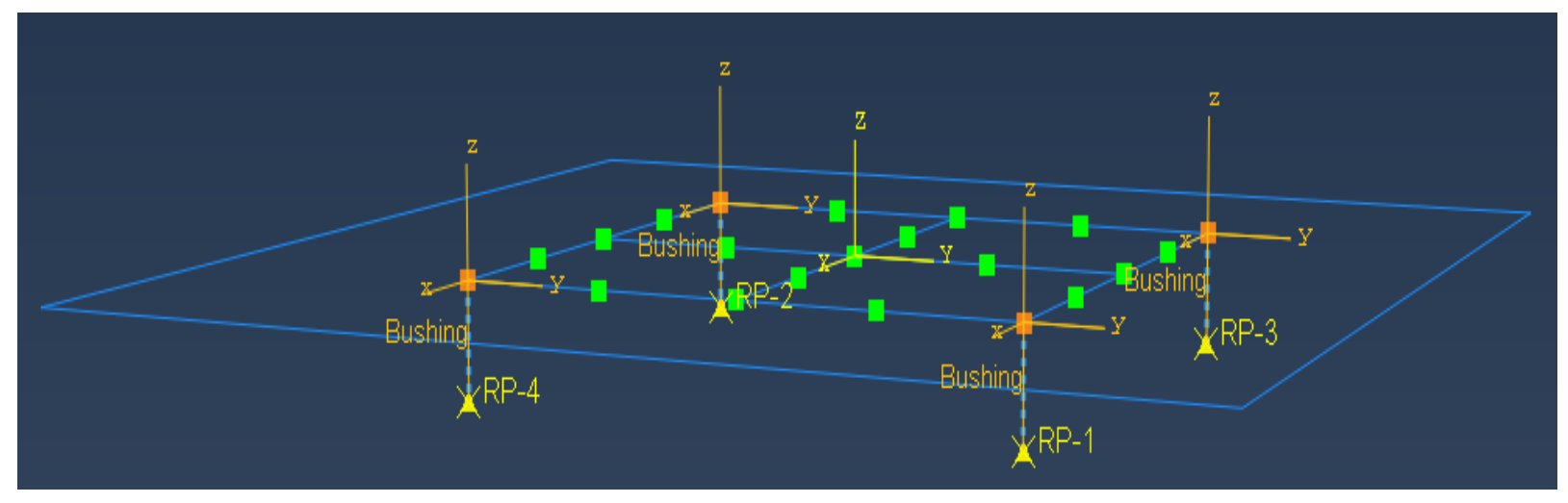

Figure 48: Side view of boundary conditions representing vibrational experiments.

The four wires were constrained on the ends, where the isolators were bolted on the aluminum plate. The yellow triangles on Figure 48 were fixed to the ground under the boundary conditions tab. Once the boundary conditions and mesh were created, a field output request was created to perform the modal analysis. Also, two states were created 
to perform the modal analysis. Afterwards, a job was created to perform the modal analysis. The results of the first mode are seen in Figure 49.

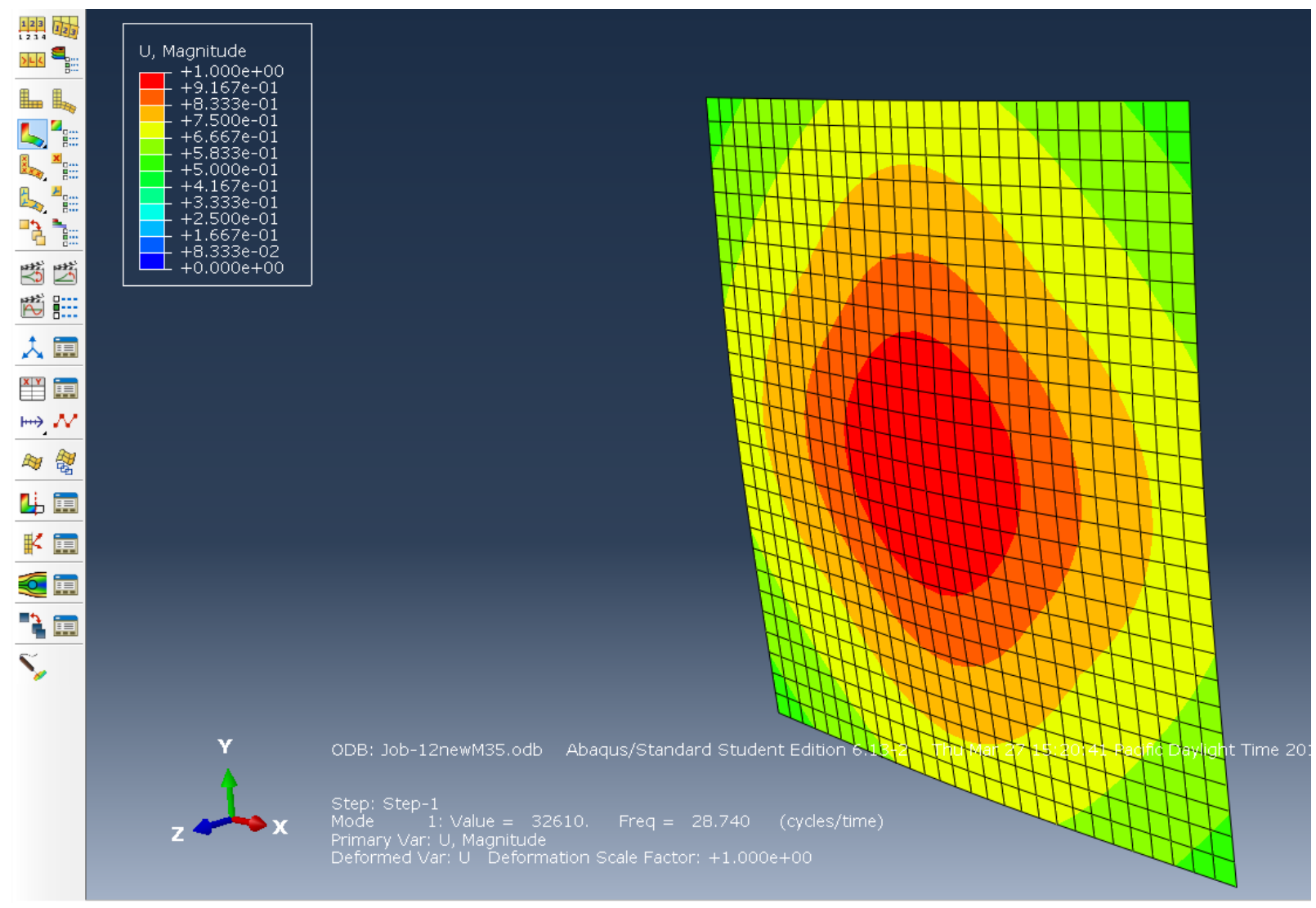

Figure 49: Numerical finite element analysis results of first mode and displacements.

The first frequency mode for the finite element analysis was at $28.74 \mathrm{~Hz}$. This mode was higher than the theoretical frequency of $27.4 \mathrm{~Hz}$. The magnitude was highest at the center, where the mass was applied. A second mode was modeled on Abaqus as seen in Figure 50. 


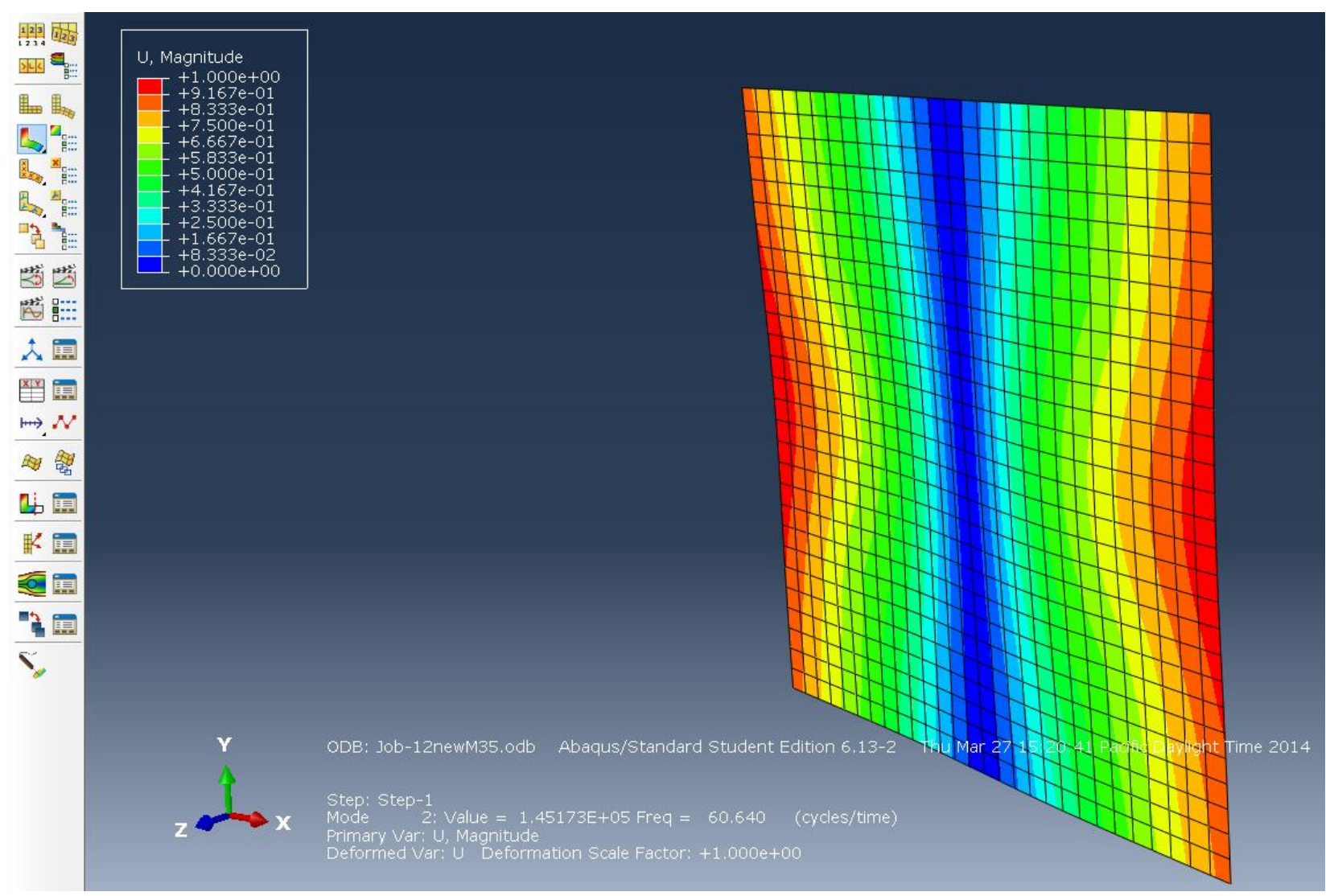

Figure 50: Numerical finite element analysis results of second mode and displacements.

The second mode for the numerical analysis resulted in $60.64 \mathrm{~Hz}$. The second mode was a bending mode and was slightly higher than the experimental results. The numerical results of the Abaqus model validated the experimental results.

A convergence test was performed in order to verify that the mesh chosen to determine the numerical results was accurate and reasonable. Figure 51 shows the convergence study of the numerical frequency results with the increased number of degrees of freedom. In the figure all the frequency values began converging after 1000 degrees of freedom. For the first mode the values fully converged after 1000 degrees of freedom. For the second frequency mode the values completely converged after 5000 degrees of 
freedom. Therefore, the frequency values used for the numerical results for the first and second modes were after 5000 degrees of freedom at a mesh seed of 0.35 for the mesh.

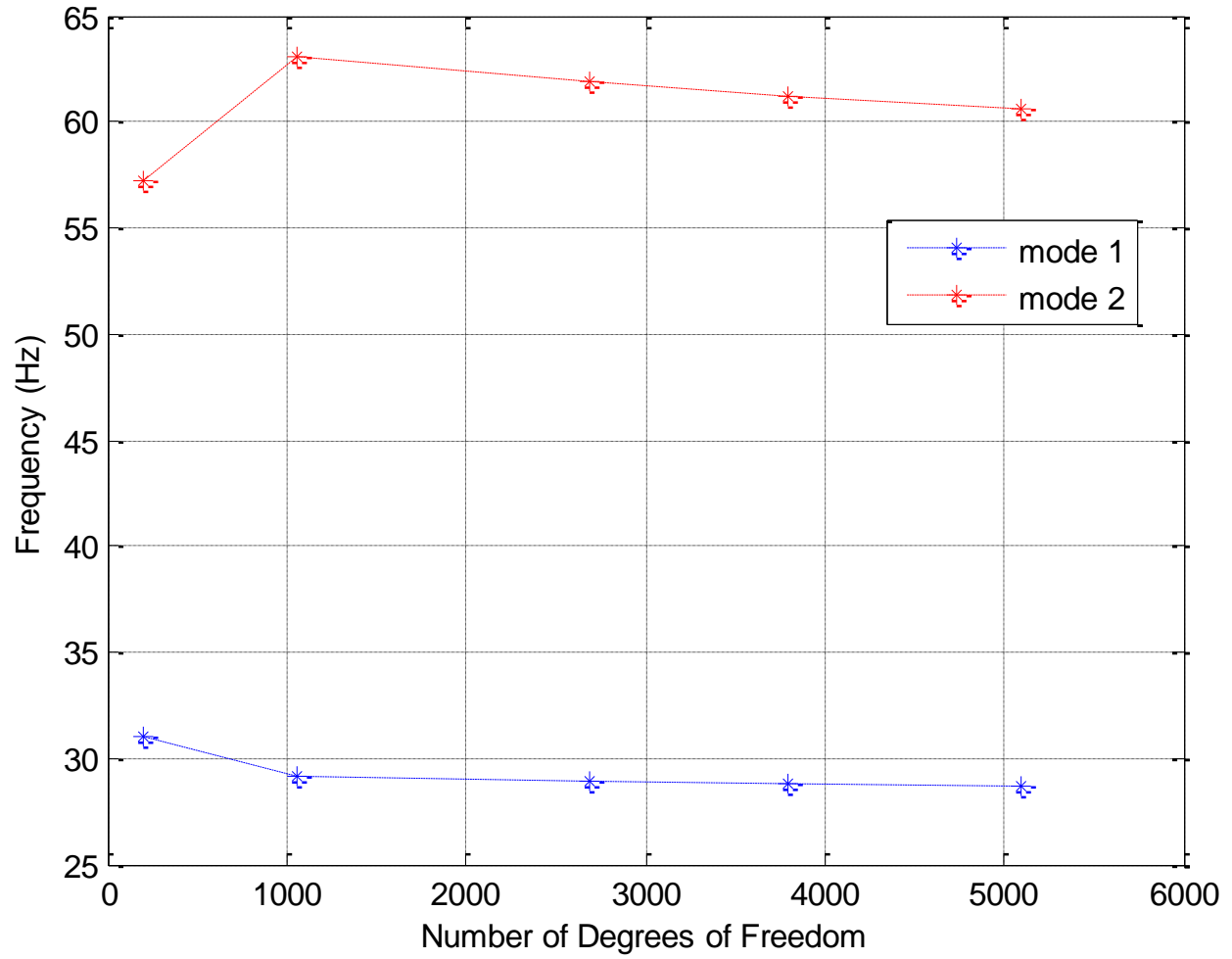

Figure 51: Convergence study of the number of degrees of freedom versus numerical frequency results. 


\section{COMPARISONS BETWEEN RESULTS}

\subsection{First and second frequency mode comparison of numerical and experimental results}

Some comparisons were made in order to understand the experimental results of the vibration tests. The first comparison was made on the first and second frequency modes. Figure 52 is a mode comparison between numerical and experimental results. The numerical results were verified because they were similar to the experimental results. The experimental results of the first frequency mode was $28 \mathrm{~Hz}$ and the numerical first frequency mode was $28.74 \mathrm{~Hz}$. In the second frequency mode the experimental frequency was $56 \mathrm{~Hz}$ and the numerical frequency was $60.6 \mathrm{~Hz}$. The numerical results were higher than the experimental results, which made sense because Abaqus/CAE over estimates the results. The primary reason for the over estimation is due to the model, boundary conditions, and number or elements used. 


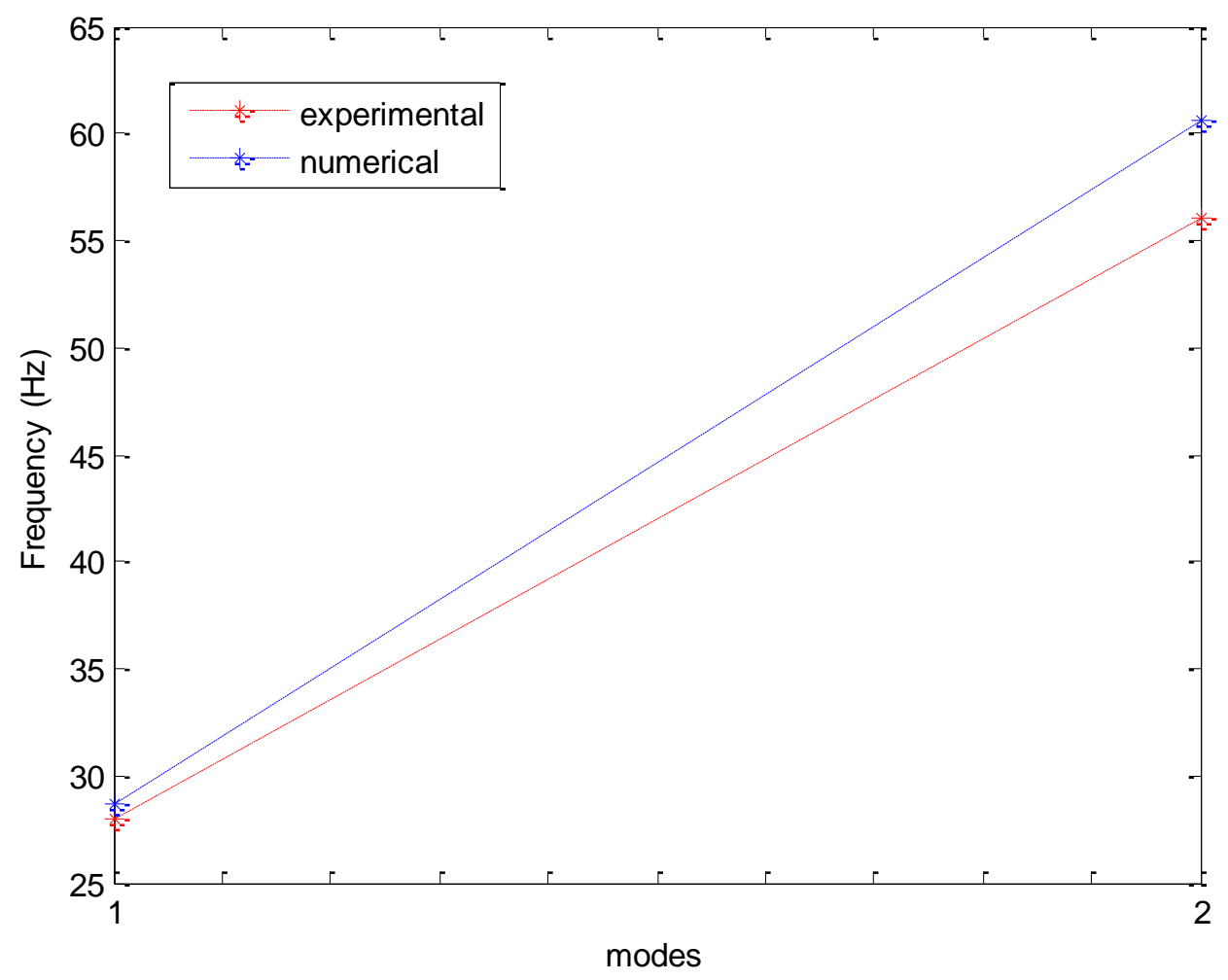

Figure 52: Comparison between numerical and experimental results of 1 st and second modes.

\subsection{A comparison in the high frequency spectrum for groups 3,4 , and 6}

The next comparison was made on the non-outgassed and not cured, 24 hour outgassed and cured, and 36 hour outgassed and cured experimental results in the high frequency spectrum. Figure 53 compared the previously mentioned groups in the high frequency spectrum. The vibrational experimental results in the flat spectrum were not compared because the frequency response trends were very similar. The results in the high energy frequency spectrum showed a better comparison between the different outgassed cases. Based on Figure 53 the 36 hour outgassed and cured case had the highest amplitude in its respective axis direction. 


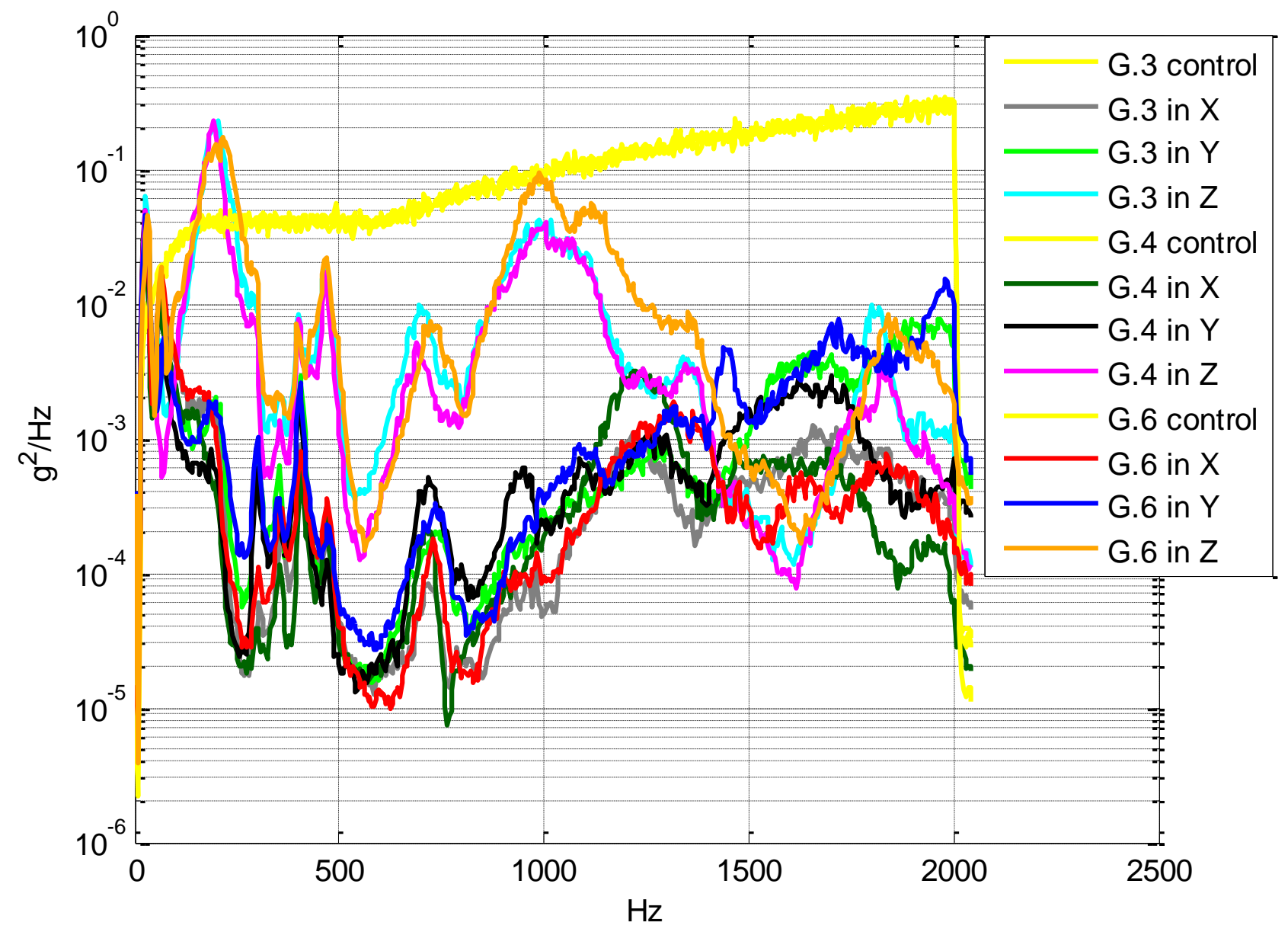

Figure 53: Comparison in the high frequency spectrum for groups 3, 4, and 6.

For example the frequency responses lowered after $1000 \mathrm{~Hz}$ in the y direction for the non-outgassed and non-cured case (bright green), the 24 hour and cured case (black), and the 36 hour and cured case (dark blue). However, the 36 hour outgassed and cured case had the highest amplitude for the y direction, then the non-outgassed and cured case had the second highest amplitude, followed by the 24 hour outgassed and cured case with the lowest amplitude. Recalling the swelling test made on all three cases, the 24 hour outgassed and cured case was the most ductile because it absorbed the most solvent and had a lower crosslink density because the chemical bonds were looser than the rest of the outgassing cases. 
Figure 54 is a simplified version of Figure 53 because it only focuses on one axis. The following figure compared the $\mathrm{z}$ directions of the three outgassing cases in the high frequency spectrum.

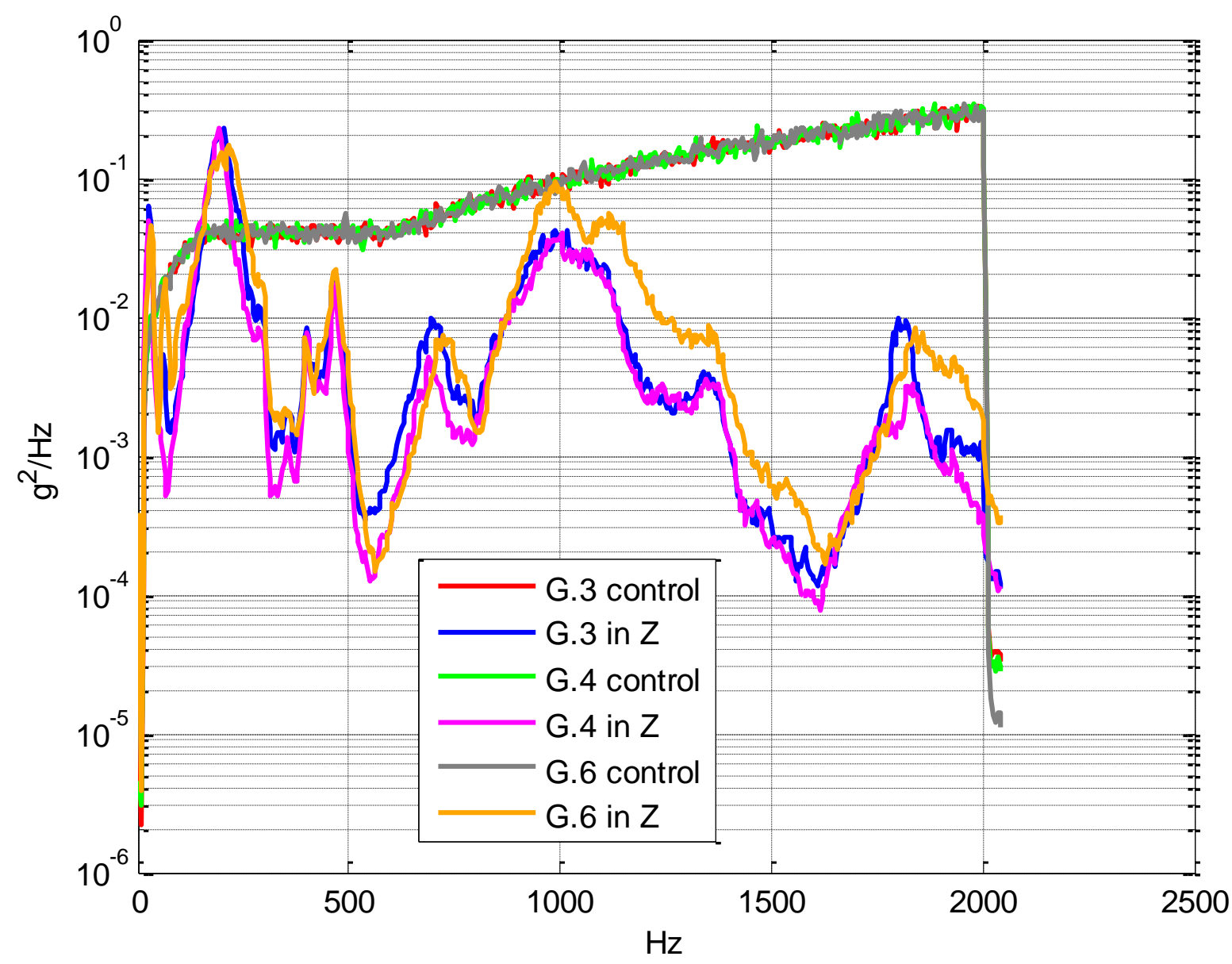

Figure 54: Comparison in $\mathrm{z}$ direction for group 3, 4, and 6.

After $1000 \mathrm{~Hz}$ the amplitude of group 6 was the highest. Group 3 had the lowest amplitudes throughout the high frequency spectrum because the silicone damping material became more elastic, as seen in the swelling test results. 


\subsection{A comparison between the experimental and input GRMS values for groups 1 through 10}

An additional comparison of the frequency responses for all the groups was made by calculating the GRMS values shown in Table 5. The percent difference is also shown on Table 5. The trend of the percent difference indicated how hard the isolators worked. For example, the higher the percent difference, the harder the isolator worked. The last column on Table 5 showed that the isolators vibrated in the flat frequency spectrum had smaller percent values. Whereas, the percent values vibrated in the high frequency spectrum where higher because of the added energy, which made the isolators work harder.

The GRMS values in the three axes were not the same for each group because the majority of the distributed load was applied in the $\mathrm{z}$ direction. The applied 10 pound mass not directly on top of the surface of the isolators (the mass was applied at the center of the composite plate); the center of the top surface of each isolator was half an inch away from the outer diameter of the mass. The diameter of the lead mass was 4.9 inches and the diameter of the steel mass was 5.0 inches. The displacement due to the mass was higher at the center of the stiff carbon fiber composite plate, which affected the distributed load on the top surface of the isolators. However, the primary reason for the difference in the GRMS values was attributed to the mass participation. The concept of mass participation is the amount of system mass participating in a particular mode, or the mass contribution in that mode [15]. Since the mass was applied in the $\mathrm{z}$ direction, the GRMS values were the highest in that direction. Also, the first frequency mode was the 
highest in the $\mathrm{z}$ direction, which indicated that the majority of the mass participation was in the $\mathrm{z}$ axis and in the first mode.

The non-outgassed isolator groups had the lowest GRMS values. The groups that had isolators outgassed for 36 hours and cured had the highest GRMS values. The input GRMS in the flat frequency spectrum was 4.49. Group 1, which was vibrated in the flat frequency spectrum, had all its GRMS values below the input GRMS value of 4.49. The experimental GRMS values were lower than the input, which meant that the isolators performed within tolerance.

Table 5: Experimental GRMS values of the frequency response in the three vibrated axes for each isolator group.

\begin{tabular}{|c|c|c|c|c|c|c|c|c|}
\hline \multirow[b]{2}{*}{$\begin{array}{c}\text { Group } \\
\#\end{array}$} & \multirow[b]{2}{*}{$\begin{array}{c}\text { Material } \\
\text { of } 10 \mathrm{lb} \\
\text { Mass }\end{array}$} & \multirow[b]{2}{*}{$\begin{array}{c}\text { Frequency } \\
\text { Spectrum } \\
\text { Input GRMS: } \\
\text { Flat }=4.49 \text {, } \\
\text { High }=15.37\end{array}$} & \multicolumn{6}{|c|}{ GRMS Values \& \% Difference } \\
\hline & & & $\mathbf{X}$ & $\begin{array}{c}\begin{array}{c}\% \text { Difference } \\
\text { from }\end{array} \\
\text { Corresponding } \\
\text { Spectra for X }\end{array}$ & $\mathbf{Y}$ & $\begin{array}{l}\% \text { Difference } \\
\text { from } \\
\text { Corresponding } \\
\text { Spectra for Y }\end{array}$ & $\mathbf{Z}$ & $\begin{array}{c}\% \text { Difference } \\
\text { from } \\
\text { Corresponding } \\
\text { Spectra for } \mathrm{Z}\end{array}$ \\
\hline 1 & Lead & Flat & 0.99 & 77.95 & 1.04 & 76.84 & 3.21 & 28.51 \\
\hline 2 & Lead & Flat & 1.08 & 75.95 & 1.16 & 74.16 & 2.55 & 43.21 \\
\hline 3 & Lead & High & 1.28 & 91.67 & 1.88 & 87.77 & 4.97 & 67.66 \\
\hline 4 & Lead & High & 1.31 & 91.48 & 1.43 & 90.70 & 4.52 & 70.59 \\
\hline 5 & Lead & Flat & 1.07 & 76.17 & 1.21 & 73.05 & 2.81 & 37.42 \\
\hline 6 & Lead & High & 1.36 & 91.15 & 2.09 & 86.40 & 5.86 & 61.87 \\
\hline 7 & Steel & Flat & 1.27 & 71.71 & 1.86 & 58.57 & 2.79 & 37.86 \\
\hline 8 & Steel & High & 1.9 & 87.64 & 2.31 & 84.97 & 4.13 & 73.13 \\
\hline 9 & Steel & Flat & 1.45 & 67.71 & 1.72 & 61.69 & 2.29 & 48.99 \\
\hline 10 & Steel & High & 2.28 & 85.17 & 2.48 & 83.86 & 3.28 & 78.66 \\
\hline
\end{tabular}

In addition, the input GRMS value in the high frequency spectrum was 15.37. All the groups that were vibrated in the high frequency spectrum were under the input value and proved to perform within tolerance. For example group 6 , which was vibrated in the high 
frequency spectrum, had all its GRMS values below the input GRMS of 15.37. All the experimental GRMS values from Table 5 were lower than the input GRMS values in the flat and high frequency spectra.

\subsection{Comparison of the in-line axes and cross axes in the vibrated $x, y$, and $z$ directions for group 4 in the high frequency spectrum}

Each group that was vibrated in $\mathrm{x}, \mathrm{y}$, and $\mathrm{z}$ orientations had an in-line axis in its vibrated orientation and cross axes. There were a total of ten groups and each was vibrated in three axes and for each in-line axis there were two cross axes. Therefore, for each group there were a total of nine data sets and a total of ninety data sets for all ten groups. Instead of showing ninety graphs, only a few were compared in order to provide a meaningful analysis of the data.

Group four was chosen to compare the cross axes of the vibrated $\mathrm{x}, \mathrm{y}$, and $\mathrm{z}$ directions because it provided the original vibrational performance characteristics of the E22-02-40 isolators in the high frequency spectrum. Figure 55 shows the frequency responses of the vibrated $\mathrm{x}$ axis with the cross axes in the $\mathrm{y}$ and $\mathrm{z}$ directions for the high frequency spectrum. The figure showed how the cross axes and the in-line $\mathrm{x}$ axis responded when vibrating in the $\mathrm{x}$-axis. At the first and second modes the $\mathrm{x}$ axis was dominant and had the highest amplitudes, which made sense because it was the primary vibrated axis. After the second frequency mode and before $1000 \mathrm{~Hz}$, the $\mathrm{z}$ cross axis was dominant. Towards $2000 \mathrm{~Hz}$ the amplitude of the frequency response of the y cross axis was the highest. 


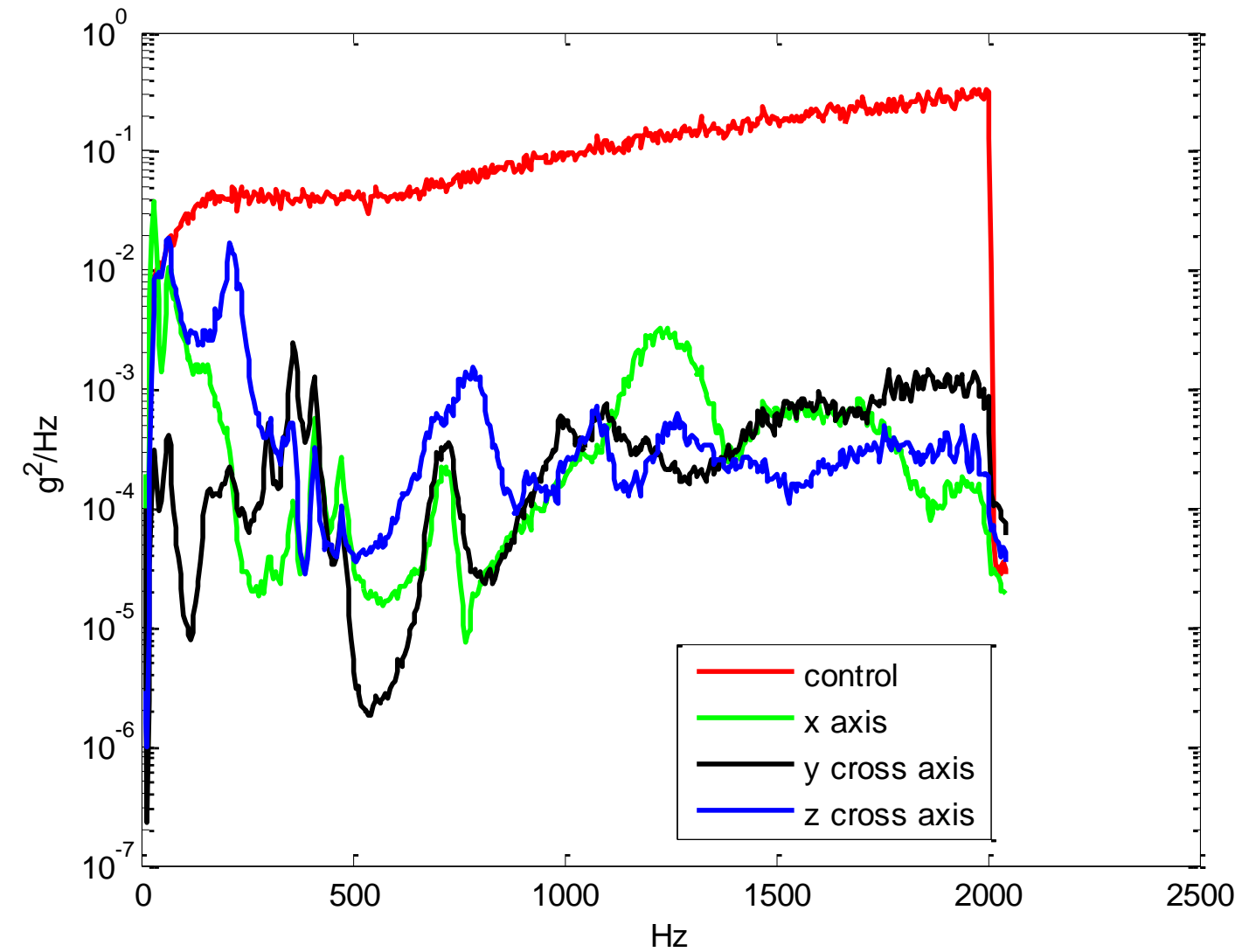

Figure 55: Frequency response of the $x$ axis and cross axes ( $y$ and $z$ ) for the vibrated $x$ direction of group 4.

Figure 56 shows the frequency response of each cross axes for the vibrated y axis of group 4. The y axis was dominant for the first two frequency modes, which was expected since the vibrated axis was in the y direction. The $\mathrm{z}$ cross axis proved to be dominant after the second frequency mode. The frequency response of the $\mathrm{x}$ cross axis had the lowest amplitudes throughout the frequency range. The frequency response of the y axis had the highest amplitudes towards the higher frequency range, followed by the $\mathrm{z}$ cross axis, and lastly the $\mathrm{x}$ cross axis. 


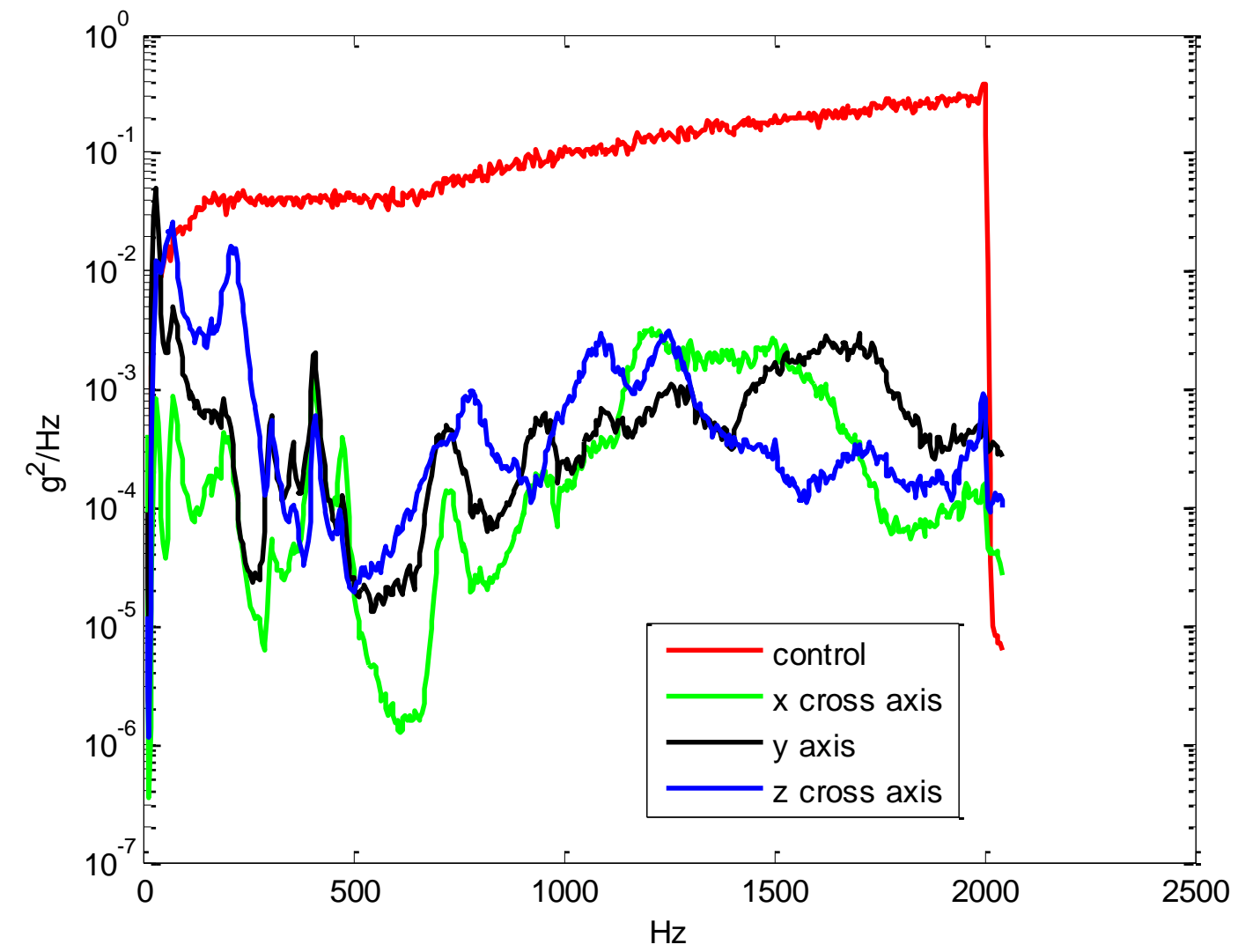

Figure 56: Frequency response of the $y$ axis and cross axes $(x$ and $z)$ in the vibrated $y$ direction of group 4.

Figure 57 shows the frequency responses of the y cross axis of the vibrated $\mathrm{z}$ direction. The $\mathrm{x}$ cross axis was missing in the figure because an accelerometer was not placed in the $\mathrm{x}$ direction. The $\mathrm{z}$ axis was dominant throughout the entire vibration test in the $\mathrm{z}$ direction, which proved that it was the dominant axis. The amplitude of the frequency response of the $\mathrm{z}$ axis was also higher than the y cross axis. However, towards $2000 \mathrm{~Hz}$ the amplitude of the frequency response of the y cross axis was higher. 


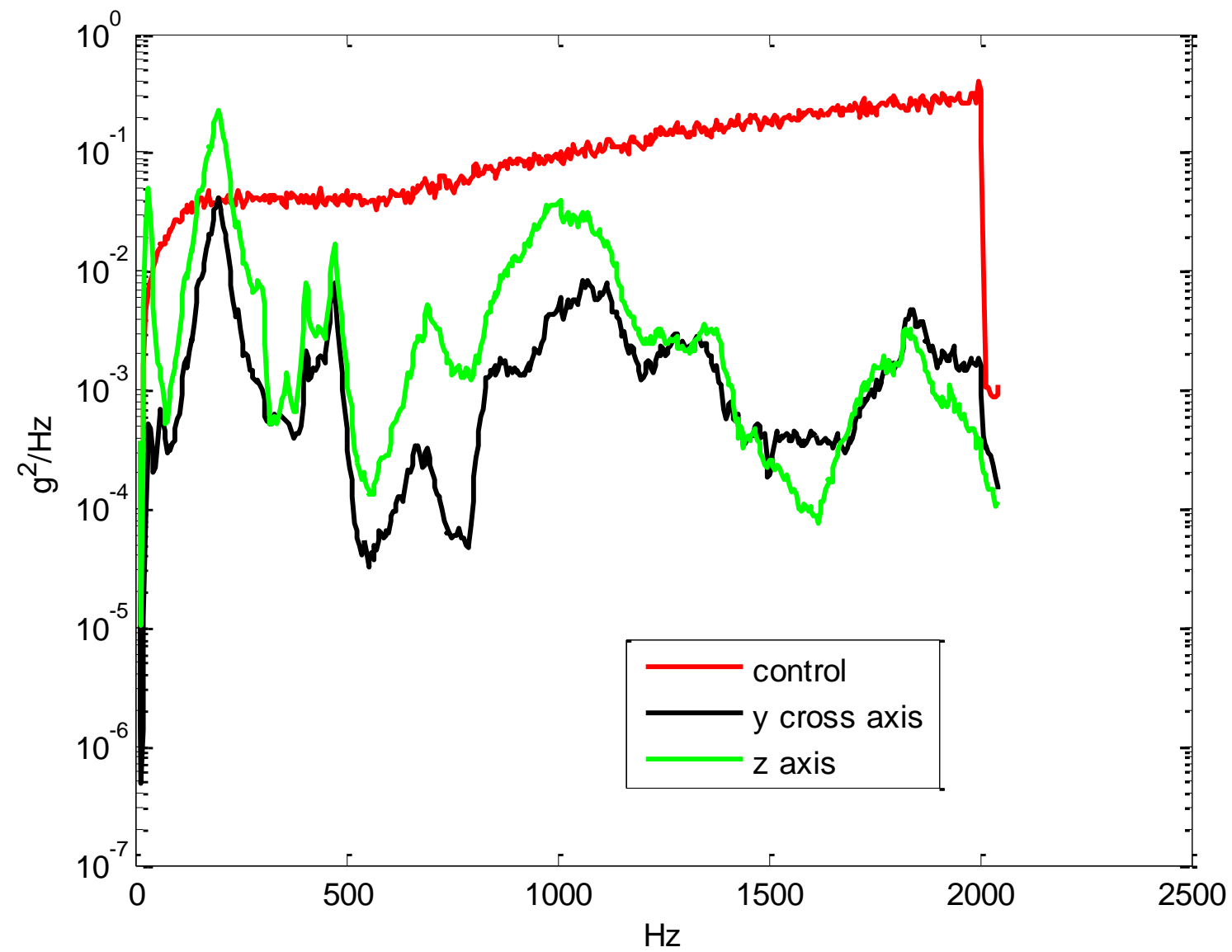

Figure 57: Frequency response of the vibrated $z$ direction and its y cross axis of group 4.

Additional comparisons were made after contrasting the frequency responses of the cross axes for each vibrated axis. Figure 58 evaluated all the $\mathrm{x}$ axes results from each vibrated axis of group 4. The frequency response of the $\mathrm{x}$ axis from the vibrated primary axes had a similar trend. However, the frequency response of the $\mathrm{x}$ axis from the vibrated $\mathrm{x}$ direction resulted with the highest amplitudes throughout the frequency range. At the first and second frequency modes the amplitude of the $\mathrm{x}$ axis of the vibrated $\mathrm{x}$ direction was higher than the $\mathrm{x}$ cross axis of the vibrated y direction. Some bracket frequency modes matched after the second frequency modes for the $\mathrm{x}$ axis from the vibrated $\mathrm{x}$ and $\mathrm{y}$ 
directions. The $\mathrm{x}$ cross axis of the vibrated $\mathrm{z}$ direction was missing from the graph because no accelerometer was placed in the corresponding direction.

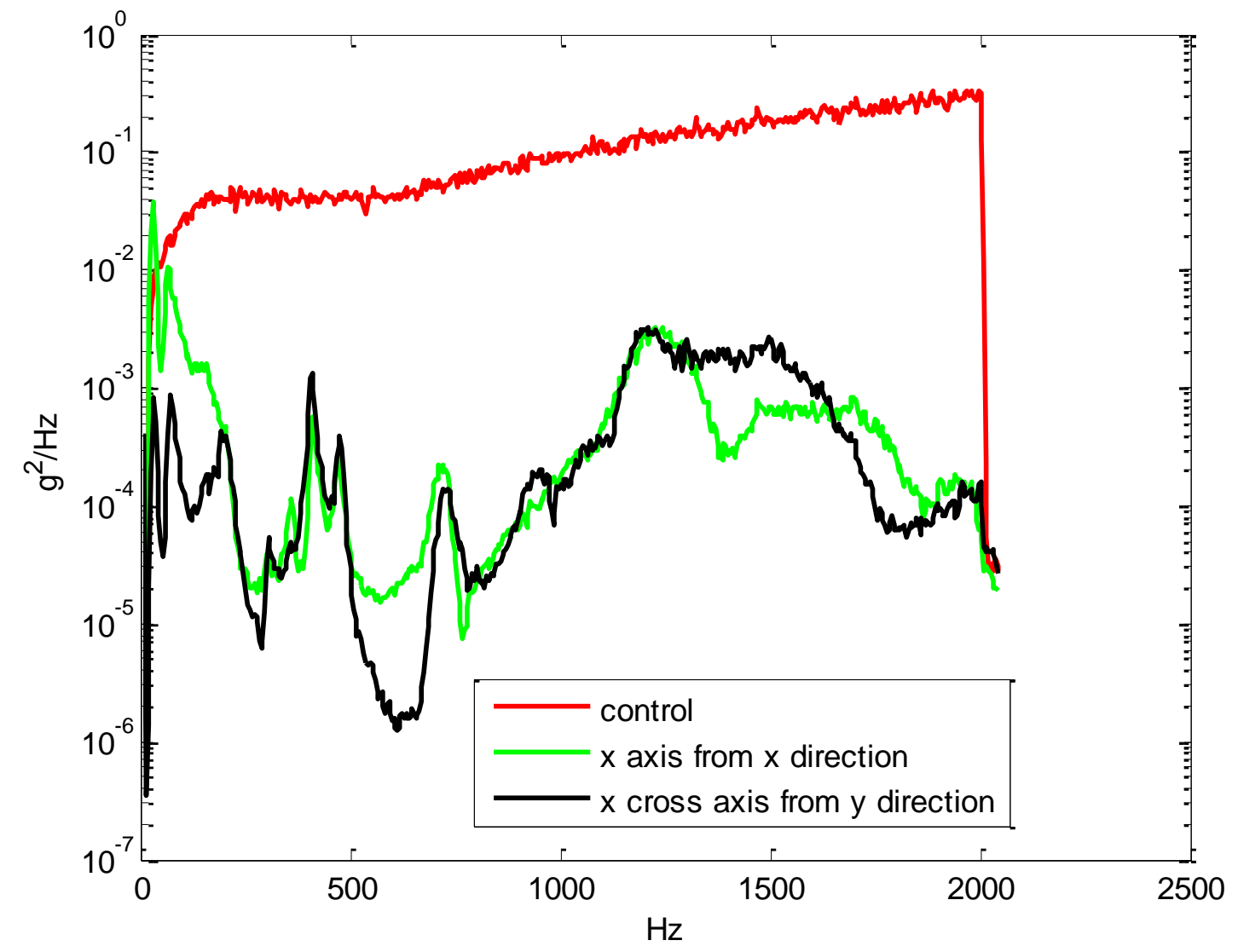

Figure 58: The $\mathrm{x}$ axis results from vibrating in the $\mathrm{x}$ and $\mathrm{y}$ directions for group 4 .

The y axis results from the three different tests were compared in Figure 59. As expected, the frequency response from vibrating in the y axis had the highest amplitudes at the first and second frequency modes. After the second frequency mode, the bracket modes of the $\mathrm{y}$ cross axis from the vibrated $\mathrm{z}$ direction had the higher amplitudes. 


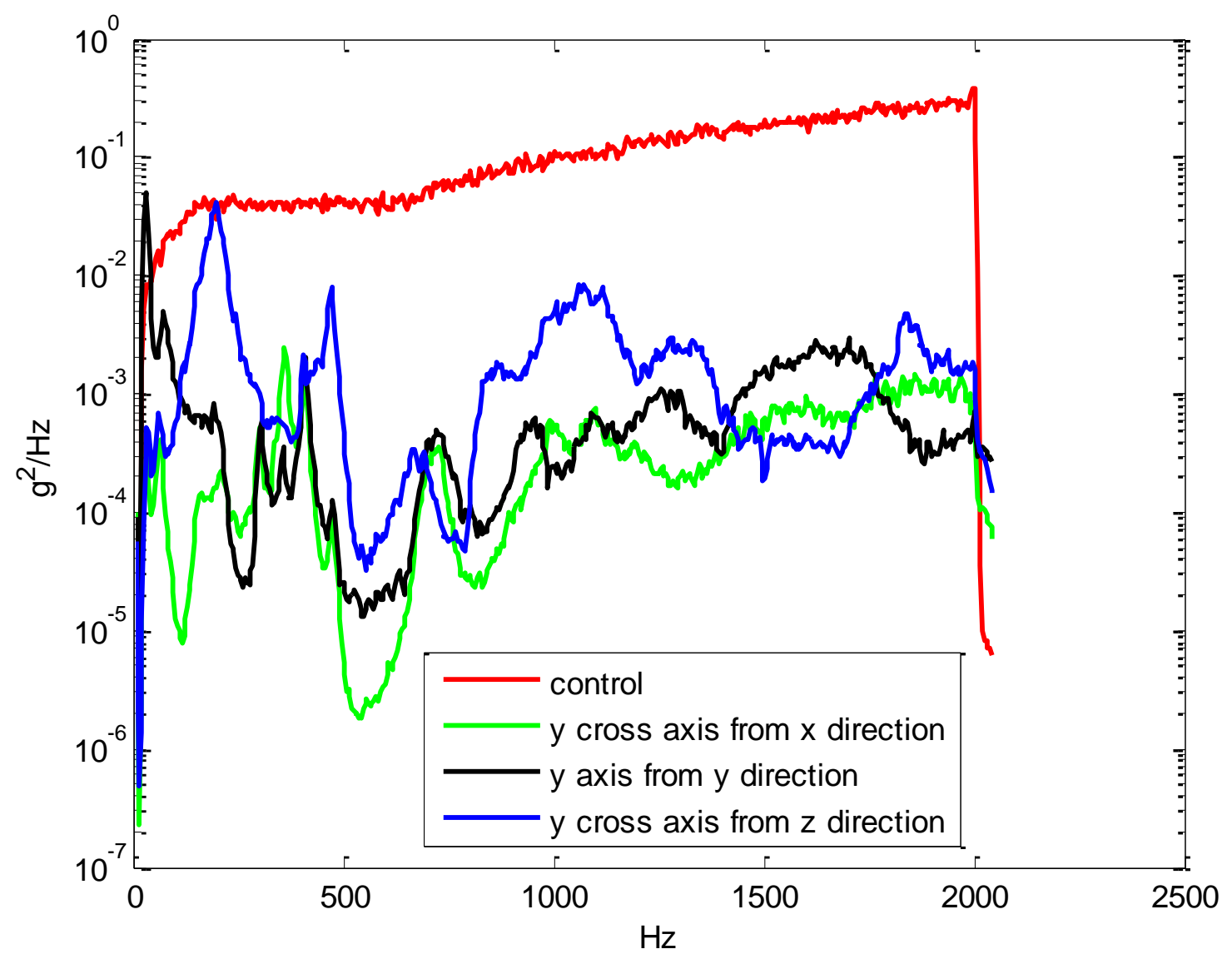

Figure 59: The $y$ axis results from vibrating in the $x, y$ and $z$ directions for group 4 .

Figure 60 contrasts the frequency responses of the $\mathrm{z}$ axis results when vibrating in all three axes. The dominant frequency response was during the in-line $\mathrm{z}$ axis test. The first and second frequency modes of the vibrated $\mathrm{z}$ direction were the highest. The $\mathrm{z}$ cross axes from the vibrated $\mathrm{x}$ and $\mathrm{y}$ directions matched several times throughout the frequency range. 


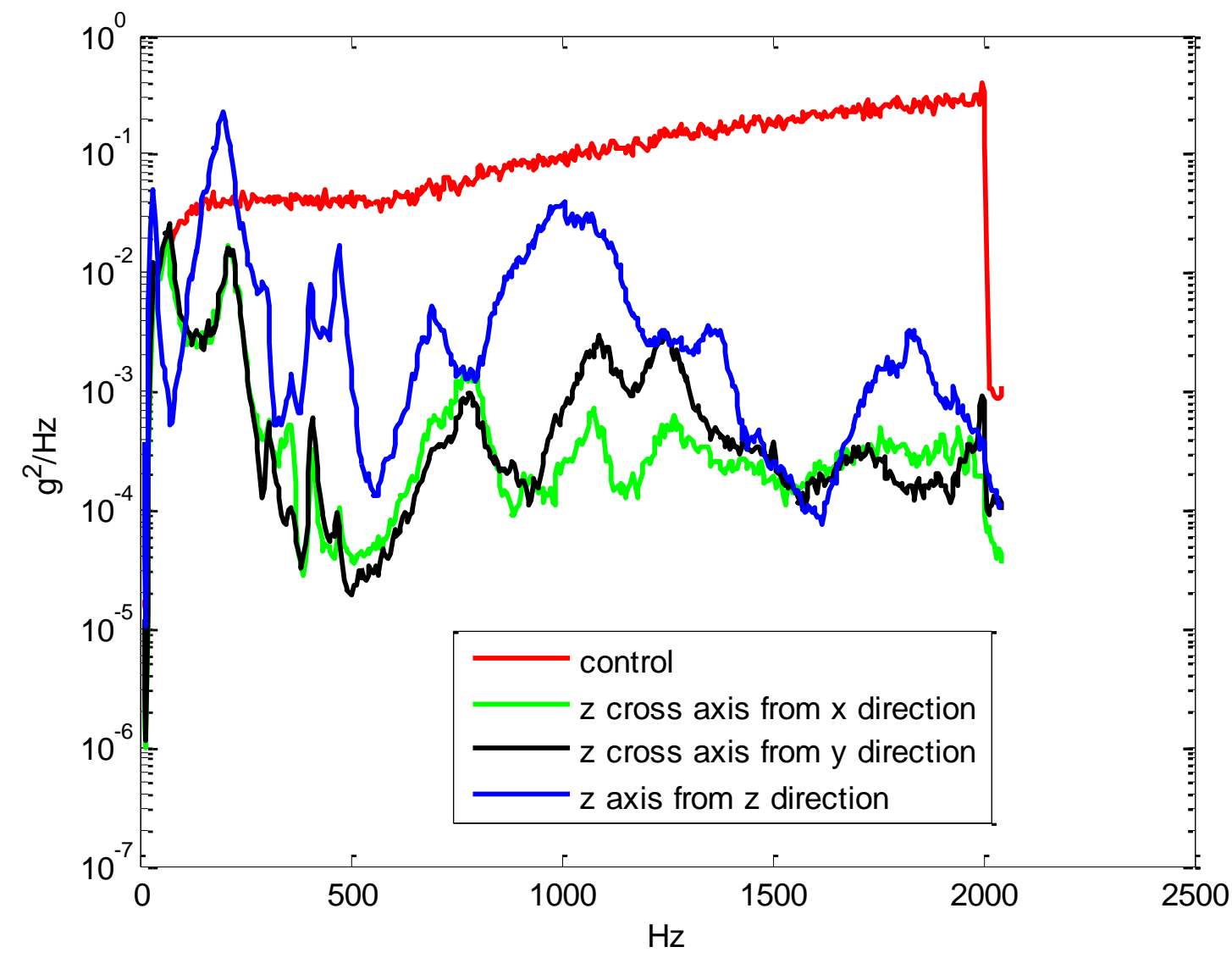

Figure 60: The $\mathrm{z}$ axis results from vibrating in the $\mathrm{x}, \mathrm{y}$ and $\mathrm{z}$ directions for group 4 .

Lastly, Figure 61 studied the worst case of Figures 58 through 60 in order to better understand the vibrational performance characteristics of isolators belonging to group 4 . Only the maximum amplitude values of the $\mathrm{x}$ cross axes and in-line axis from Figure 58 were combined to make one frequency response trend line. That trend line is represented as the green line in Figure 61. The same process from Figure 58 was applied to Figures 59 and 60. The maximum frequency response of the y cross axes and in-line axis were represented as the black frequency response trend line in Figure 61. 


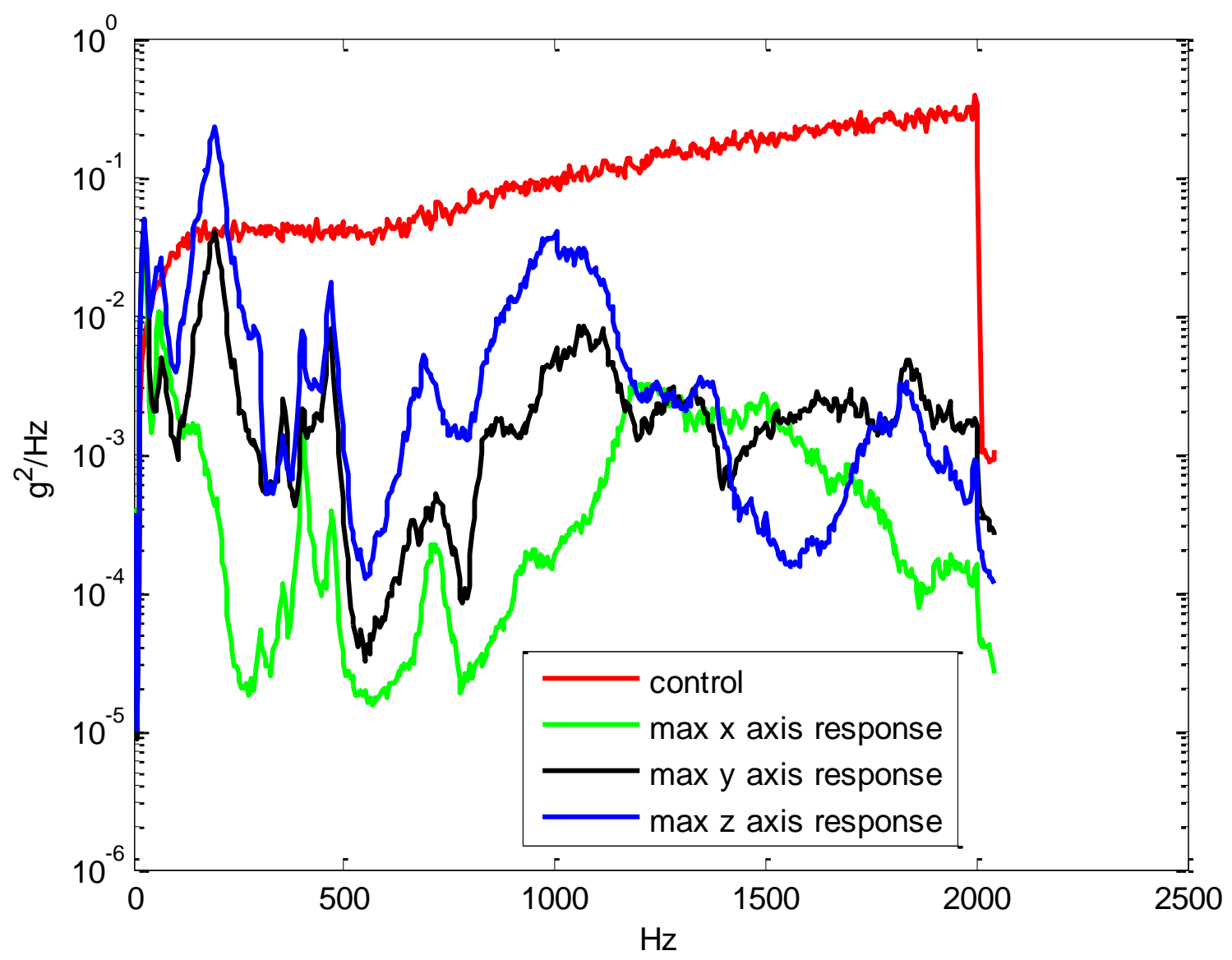

Figure 61: Maximum data results in the $x, y$, and $z$ axes responses of group 4.

The maximum amplitude values of the $\mathrm{z}$ axis were represented as the blue line in Figure 61. Based on Figure 61, the $\mathrm{z}$ axis response and $\mathrm{z}$ cross axes from Figure 60 had the highest PSD values, which meant that the $\mathrm{z}$ direction was the most affected during the vibration tests. The frequency response of the y axis had the second highest PSD values, followed by the frequency response of the $\mathrm{x}$ axis. 


\subsection{A comparison between the maximum frequency values of the cross axes for the vibrated $x, y$, and $z$ orientations belonging to group 3,4 , and 6}

The same process taken to create Figure 61 was used to make the following figures in order to compare the worst cases of each primary axis. For example Figure 62 compared the frequency response of the max PSD values for the $\mathrm{x}$ axis of groups 3,4 , and 6 . All three groups were vibrated in the high frequency spectrum, but were outgassed and cured at different temperatures and times. The comparison of the max PSD values for the $\mathrm{x}$ axis showed that group 6 had the highest amplitudes. This showed that the isolators of group 6 performed the worst. That meant that turning the isolators to grade A reduced their vibrational performance. The frequency responses of groups 3 and 4 were very similar and almost matched that it made hard to analyze which group performed better or worse.

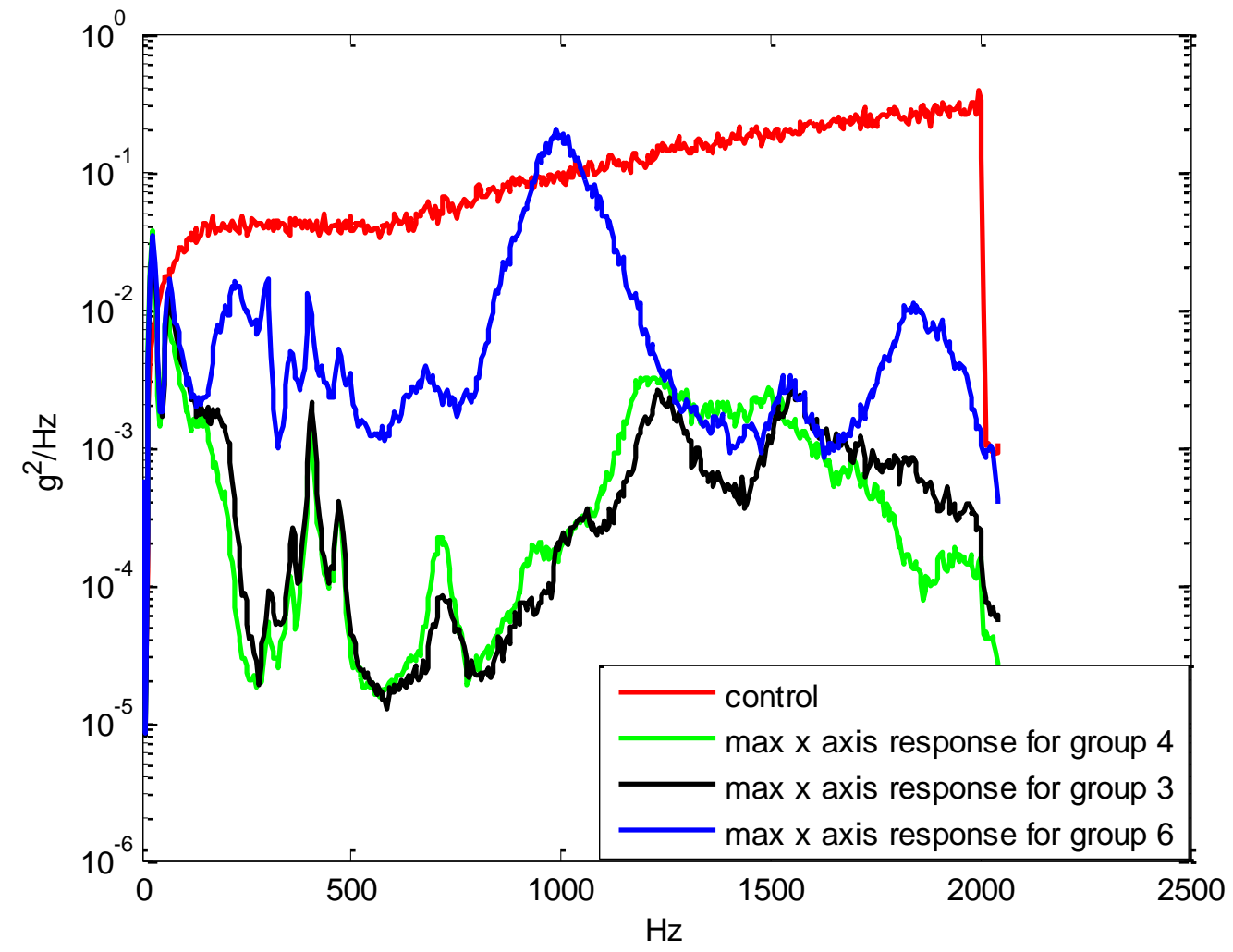

Figure 62: Maximum $x$ axis response of group 3, 4, and 6. 
The results of the maximum y axis response for groups 3, 4, and 6 were shown in Figure 63. In the first and second modes, group 6 had the highest PSD values. The amplitude of the frequency response for group 3 and 4 were very similar and difficult to analyze. Group 3 and 4 were dominating through the frequency range of the high frequency spectrum. However, group 3 had slightly higher amplitudes than group 4 for the max $y$ axis response. The results suggest that the frequency response of the max y axis response was higher for group 3 and the vibrational performance decreased the most out of the three groups.

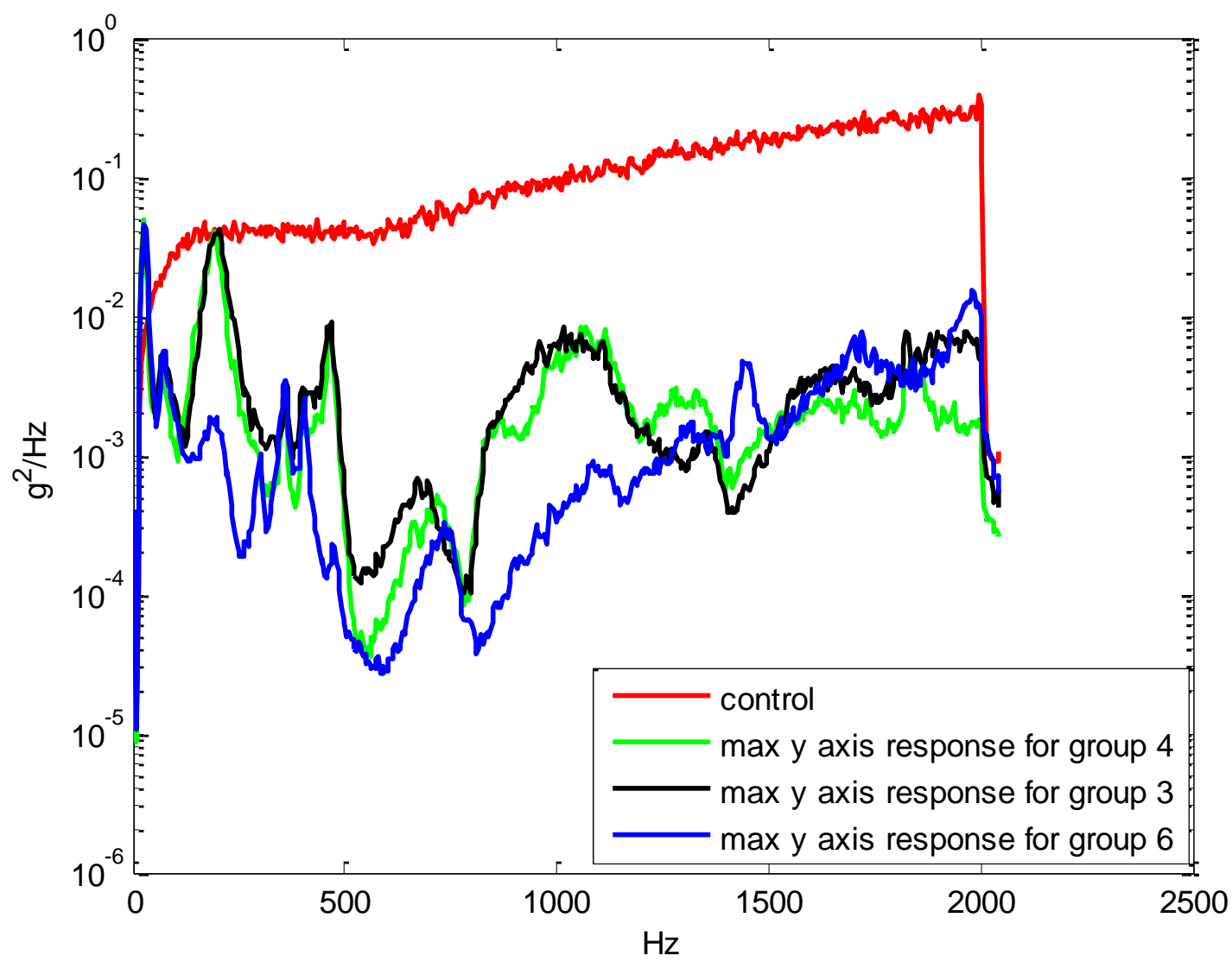

Figure 63: Maximum y axis response of group 3, 4, and 6.

Figure 64 demonstrated the last comparison made for the maximum $\mathrm{z}$ axis response for groups 3, 4, and 6. The frequency response of all three groups were very similar, but a 
slight difference in the amplitudes was apparent. For example, the PSD values of the frequency response belonging to group 6 were the highest. Group 3 had the second highest amplitudes, but the difference was not as apparent because group 3 and 4 had almost the same frequency responses.

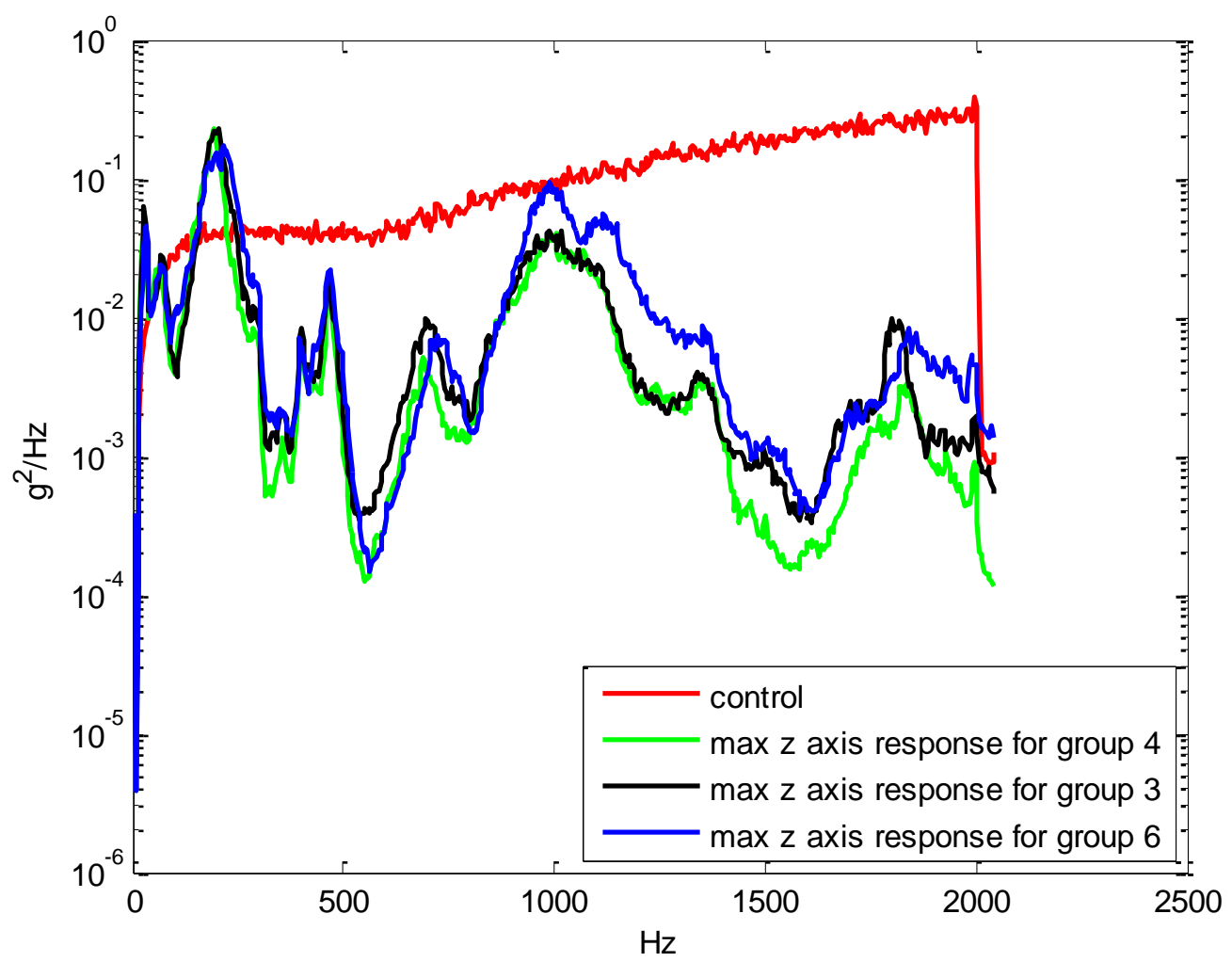

Figure 64: Maximum $\mathrm{z}$ axis response of group 3, 4, and 6.

Either way the maximum PSD values for the first and second frequency modes were from group 6. The data indicated that vibrational performance characteristics of group 6, which was outgassed for 36 hours and cured, had a reduction in its performance. The performance of group 3 and group 4 varied and were inconsistent. For the most part, the results demonstrated that the outgassed and cured isolators were affected and their vibrational performance decreased. 
A better comparison of the results from Figures 62 through 64 are seen in the following table. Table 6 lists the GRMS results of the maximum primary axes responses of group 3, 4, and 6. Group 6 had the highest GRMS values in the maximum $\mathrm{x}$ axis response and $\mathrm{z}$ axis response than the rest of the groups. However, group 6 had the lowest GRMS values for the maximum y axis response than the rest of the groups. Overall the results from Table 6 showed that group 6 had the highest GRMS values in the maximum $\mathrm{x}$ and $\mathrm{z}$ axes responses, while group 3 had the highest GRMS value in the maximum y axis response.

Table 6: Percent difference and GRMS of the maximum $x, y$, and $z$ axis response for groups $3,4, \& 6$.

\begin{tabular}{|c|c|c|c|c|c|c|c|c|}
\hline & & \multicolumn{5}{|c|}{ Maximum GRMS Values \& \% Difference } \\
\cline { 3 - 9 } & Group \\
$\#$ & $\begin{array}{c}\text { Material } \\
\text { of 10 lb } \\
\text { Mass }\end{array}$ & $\begin{array}{c}\text { Frequency } \\
\text { Spectrum } \\
\text { Input } \\
\text { GRMS: } \\
\text { High=15.37 }\end{array}$ & $\mathbf{X}$ & $\begin{array}{c}\text { \% Difference } \\
\text { from High } \\
\text { Frequency } \\
\text { Spectrum for } \\
\mathbf{X}\end{array}$ & $\mathbf{Y}$ & $\begin{array}{c}\text { \% Difference } \\
\text { from High } \\
\text { Frequency } \\
\text { Spectrum for } \\
\mathbf{Y}\end{array}$ & $\mathbf{Z}$ & $\begin{array}{c}\text { \% Difference } \\
\text { from High } \\
\text { Frequency } \\
\text { Spectrum for } \\
\mathbf{Z}\end{array}$ \\
\hline 3 & Lead & High & 1.43 & 90.696 & 2.79 & 81.848 & 5.07 & 67.014 \\
\hline 4 & Lead & High & 1.46 & 90.501 & 2.47 & 83.930 & 4.61 & 70.007 \\
\hline 6 & Lead & High & 5.72 & 62.785 & 2.11 & 86.272 & 5.92 & 61.483 \\
\hline
\end{tabular}

The results from the table show that the outgassed and cured groups had the highest GRMS values in the three primary axes indicating that the vibrational performance of the outgassed and cured groups decreased. 


\section{CONCLUSION}

There was an obvious difference in the frequency response and physical change in the silicone material of the isolator groups that were cured, outgassed, and vibrated in the different spectrums. For example groups 1, 3, 5, and 6 showed a great difference in amplitude and frequency when compared to the non-outgassed groups in the flat frequency spectrum and high frequency spectrum. The apparent change in the frequency and amplitudes for all isolator groups implied that the vibrational performance characteristics of the isolators changed with time exposure to different temperatures and pressure from outgassing. The frequency increased the most in the high frequency energy spectrum of the isolators outgassed for 36 hours and cured at $149^{\circ} \mathrm{C}$ and $204{ }^{\circ} \mathrm{C}$. Group 6, which was vibrated in the high frequency spectrum, showed the largest difference in the vibrational performance from group 4, which was not outgassed and not cured. For example, the first frequency mode in the $\mathrm{x}$ and $\mathrm{y}$ directions of group 6 increased by 16.7 $\%$ from group 4 . In the $\mathrm{z}$ direction the first frequency mode increased for group 6 by 33.3 $\%$ from group 4 . In the $\mathrm{x}$ direction, the second frequency mode of group 6 increased by $13 \%$ when compared to group 4 . Lastly, in the $y$ and $z$ directions the second frequency mode increased in group 6 by $6 \%$ from group 4 . The percent difference in the first and second modes proved there was a change in the vibrational performance of the E22-02-40 isolators after they were cured and outgassed. The vibrational results from section 6 showed that all the isolators performed how they should because the amplitudes were decreased towards the higher frequency range. 
Another beneficial study was the numerical finite element analysis made on the vibration tests to verify and compare the first and second frequency modes. The percent difference from the numerical analysis and experimental analysis for the first frequency mode was $2.57 \%$. For the second frequency mode, the percent difference of the numerical and experimental analysis was $7.59 \%$. The low percent differences between the numerical and experimental analyses helped verify the experimental results.

There was very little divergence in the flat frequency spectrum based on the results from the frequency responses and GRMS values; whereas the isolator groups that were vibrated in high frequency spectrum showed a higher variation throughout the frequency range in the frequency responses and GRMS values. The GRMS results further confirmed that the vibrational performance of the outgassed and cured isolator groups decreased. The group with the overall highest GRMS values was group 6. In general the higher the GRMS value, the worse that isolator performs. Also, when the maximum values of the GRMS were compared in Table 6, group 6 had the highest GRMS in the $x$ and $\mathrm{z}$ directions. In the y direction, group 3 had the highest GRMS value in Table 6. The results showed that the performance of the E22-02-40 isolators was affected when they were cured and outgassed. The reason for the reduction in the vibrational performance of the isolators was primarily accredited to the high curing temperature of $204{ }^{\circ} \mathrm{C}$, but will have to be explored and confirmed in the future.

The swelling test that was conducted on the silicone damping material confirmed the physical change due to the outgassing and curing cycle. The isolator groups that were not outgassed and not cured did not change and were the baseline for the other isolator groups. The swelling test showed that group B absorbed the most amount of THF solvent, 
which made the material ductile. In comparison, group $\mathrm{C}$ absorbed the least amount of THF solvent and became stiff. The results showed that the curing temperatures and pressure due to outgassing affected the change of the damping material of the E22-02-40 isolators.

\subsection{Future Work}

It would be beneficial to figure out how much the temperature and pressure from outgassing affected the silicone material of the E22-02-40 isolators of both outgassing cases. The results from the swelling test showed that the silicone damping material physically changed. Identifying how much contribution the temperature had on the physical change of the silicone material would be important to understanding how the isolators were affected by the curing cycle. A possible test would be to outgas four E2202-40 isolators for a total of 36 hours and cure them at $150{ }^{\circ} \mathrm{C}$. Then outgas four more isolators for 36 hours and cure them at $200{ }^{\circ} \mathrm{C}$. There should also be a group of four isolators that will not be outgassed and not cured in order to compare them to the other groups. A swelling test done on all three test groups would help verify the physical change of the silicone material.

In addition, a test should be done to test the outgassing level of the outgassing and curing cycle from group 1 ( 24 hour outgassing at $125{ }^{\circ} \mathrm{C}$ group) and group 6 (12 hour outgassing at $149{ }^{\circ} \mathrm{C}$ and 24 hour outgassing at $204{ }^{\circ} \mathrm{C}$ ). The swelling test showed that the material physically changed and the isolators from the 36 hour outgassing and curing cycle performed the worst. It would be important to see if the 24 hour outgassing and curing cycle was grade A because it affected the vibrational performance of the isolators 
less. If a test verified that the 24 outgassing cure was grade $\mathrm{A}$, then that cure would be better for the isolators because it would not only meet NASA's outgassing standards, but it would not affect the isolators' vibrational performance as much as the 36 hour cure. Afterwards, the isolators of the 24 hour outgassed cure and the 36 hour outgassed cure should be tested in the flat frequency spectrum and high frequency spectrum to test the vibrational performance of each outgassing and curing case. If this test proved that the 24 hour outgassing and bake-out cycle met NASA's standards, then more options for outgassing and curing would be available for the E22-02-40 isolators. 


\section{REFERENCES}

1. "E22-02-40 Series Isolator for Vibration and Shock Protection -- E22-03-40.” IHS Global Spec. 2014.< http://novibration.com/e21specs.htm >.

2. "Low Profile Mounts." Barry Controls. 2014. 2 Jan. 2014 <http://www.aektechnology.com/bcdi/loprofile/pdf/E\%20Series.pdf>.

3. Connolly, Christine. "Vibration Isolation Theory and Practice." Emerald Group Publishing Limited. Ed. Assembly Automation. Vol.29, 2009.

4. Johnson, Conor D., and Paul S. Wilke. "PROTECTING SATELLITES FROM THE DYNAMICS OF THE LAUNCH ENVIRONMENT." AIAA. n. page. Web. 28 Feb. 2014. <http://arc.aiaa.org/doi/pdf/10.2514/6.2003-6266>.

5. Fisher, Rich. "Silicone Outgassing."Barry Controls a unit of Applied Power. 22 May 1991.

6. Gallagher, R.H. "Buckling Strength of Structural Plates." H.P. Adam, R.R. Meyer, M.F. Card, W.J. Crichlow, and R.E. Hubka: Springfield, Virginia, National Technical Information Service. 1971. Web. 22 Oct. 2011. <http://ntrs.nasa.gov/archive/nasa/casi.ntrs.nasa.gov/19710023855_1971023855.pdf>

7. "Natural Frequency and Resonance."N.p., n.d. Web. 22 Oct 2011. <http://www.cs.wright.edu/ jslater/SDTCOutreachWebsite/nat_frequency.htm>.

8. "Random Vibration- An Overview." Barry Controls. 3 Jan. 2014. Hopkinton, MA.

9. MIL-STD-1540 C, 1994, “Test Requirements for launch, Upper-Stage, and Space Vehicles.” Military Standard. www.everyspec.com. 
10. Harris, C., Piersol, A., Harris Shock and Vibration Handbook, Fifth Edition, McGraw-Hill, 2002.

11. Marekich, . Passive Vbration Isolation. 2012. Graphic. Passvib1.svgWeb. 28 Feb 2014.

12. "Materials Design: Vibration Isolation and Damping, the Basics." ROGERS Corporation. N.p., 1 Jan. 2012. Web. 1 Apr. 2014. <Vibration-Isolation-andDamping-the-Basics-Color.pdf>.

13. Coladonato, Bob, Bill Case, Jaap Wijker, and Ryan Simmons. "FEMCI The Book." Calulating Grms (Root-Mean-Square Acceleration). NASA. Web. 28 Mar 2014. <http://femci.gsfc.nasa.gov/random/randomgrms.html>.

14. "Platinum Stock Products; Triaxial, general purpose, ceramic shear ICP Installation and Operating Manual." PCB Piezotronics Vibration Division. Manual Revison: B. Depew, NY : A PCB Group Company, 2002. Print.

15. Martinez, Jaime. "Understanding the Mass Participation Factor." Engineer JAU. WordPress, 11 May 2013. Web . <http://engineerjau.wordpress.com/2013/05/11/understanding-the-mass-participationfactor/comment-page-1/>. 


\section{APPENDIX}

The Appendix contains information regarding the Matlab code used for the analysis of certain tests results, some raw data, information regarding the triaxial accelerometer, and detailed dimensions of the aluminum plate. Since the raw data from the vibration tests contained over 500 data points each, it was not included in the Appendix.

\subsection{Appendix A: Matlab Code}

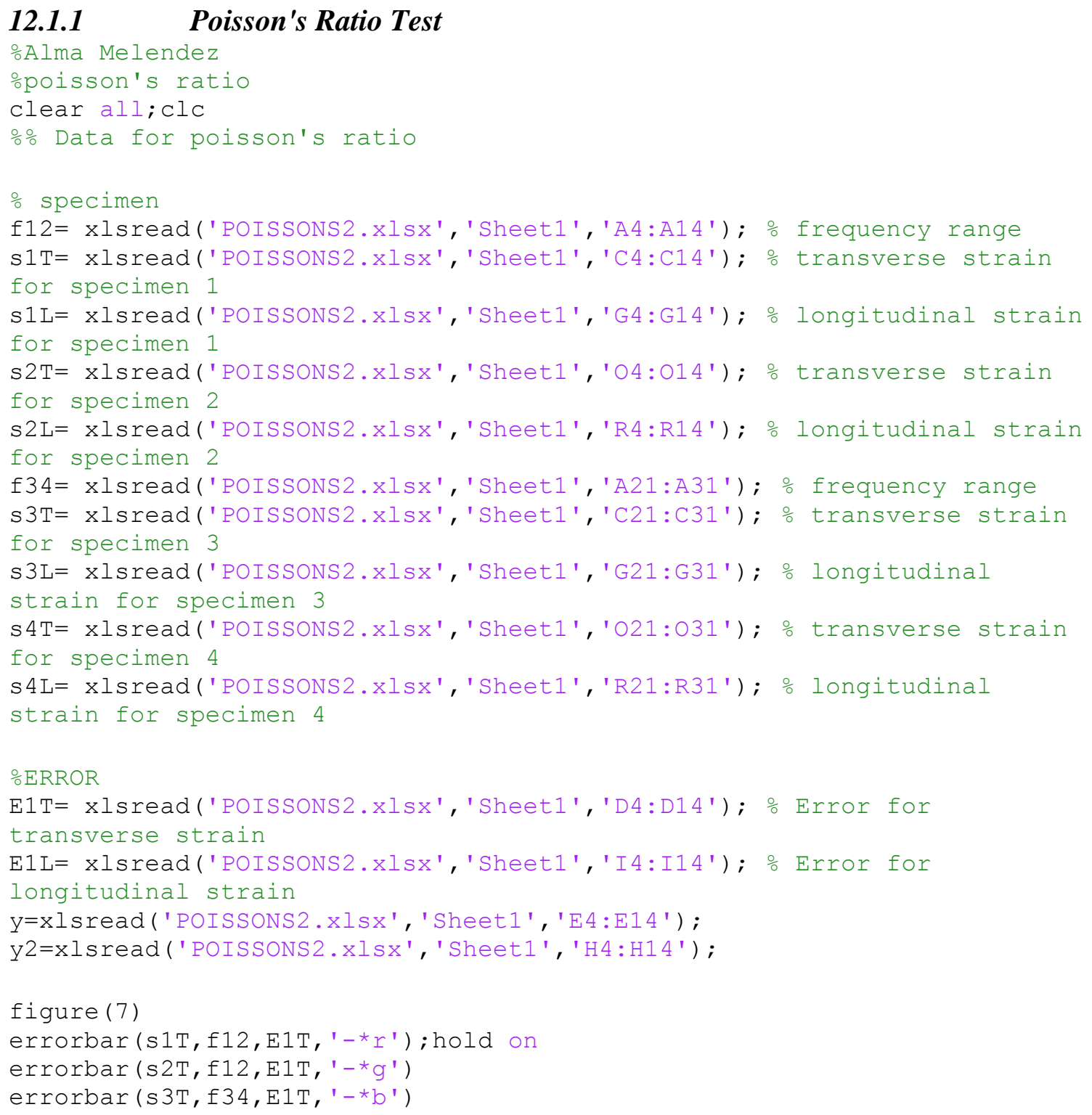




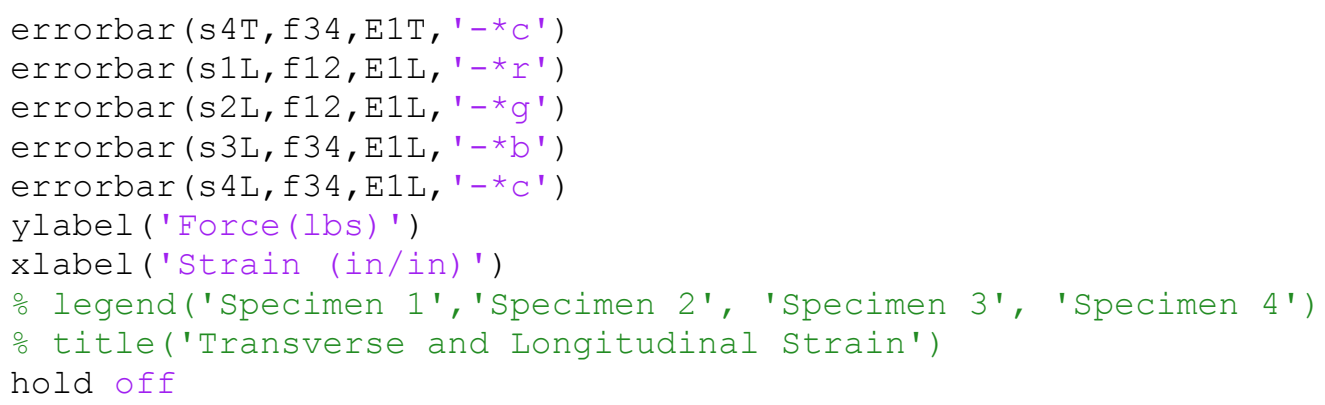

\subsubsection{Tensile Test}

\% TENSILE TEST SPECIMEN \%

\% This file includes data from tensile test on the Instron Machine.

o This file outputs graphs for comparing strain/stress curves and extension

\% versus load. These graphs help visualize the average data and will help

with acquiring material properties of the specimen/composite plate.

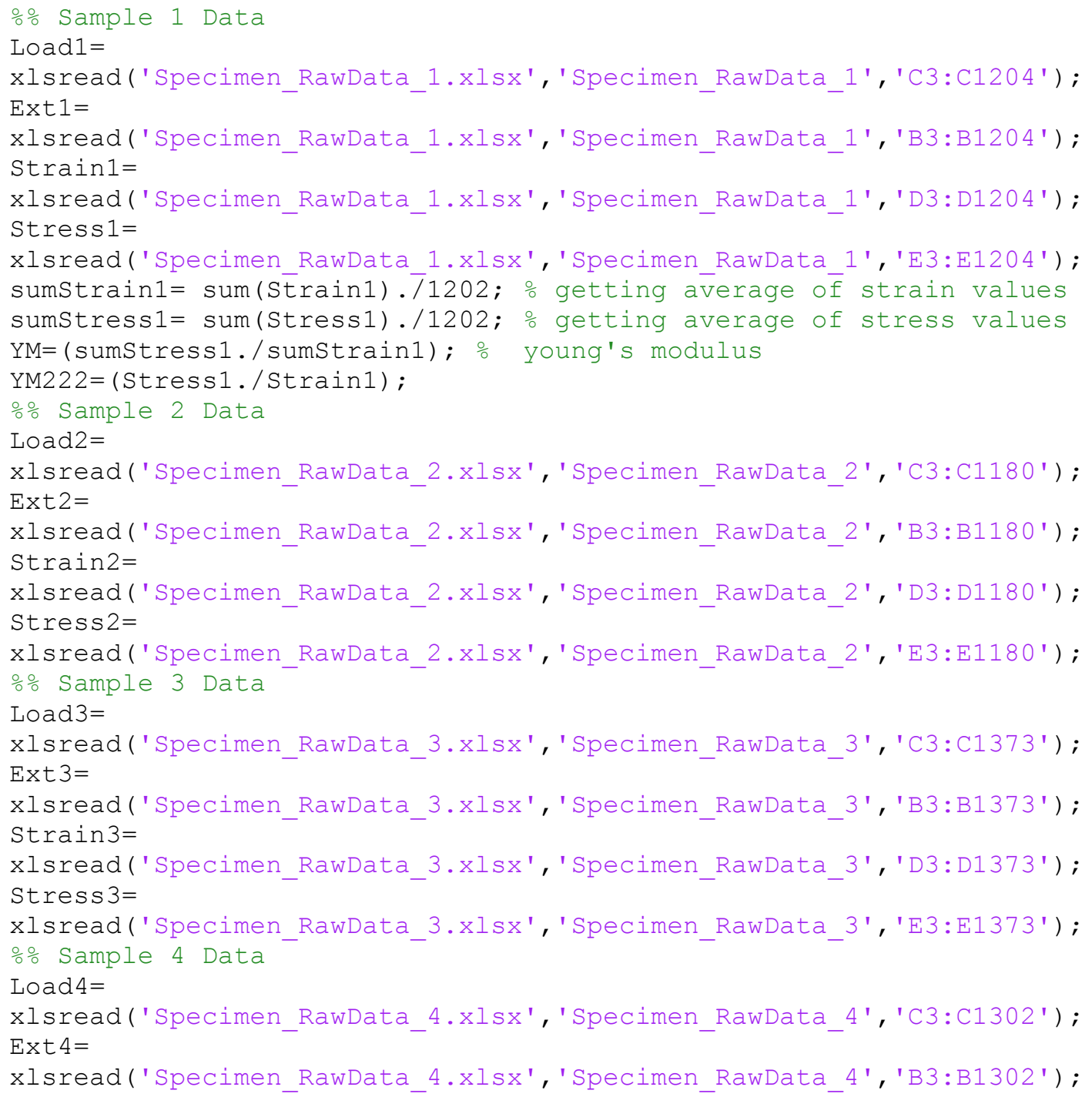




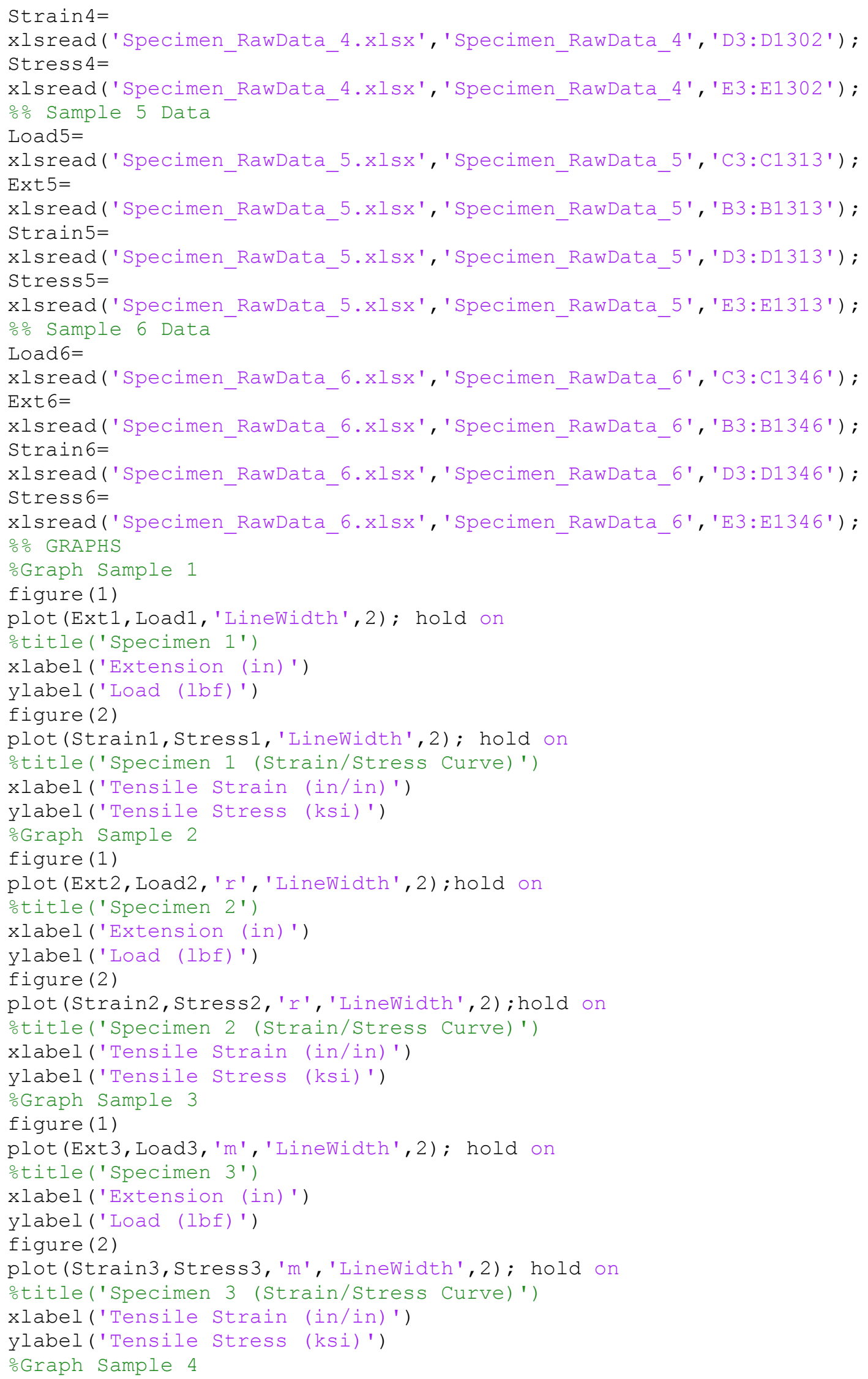




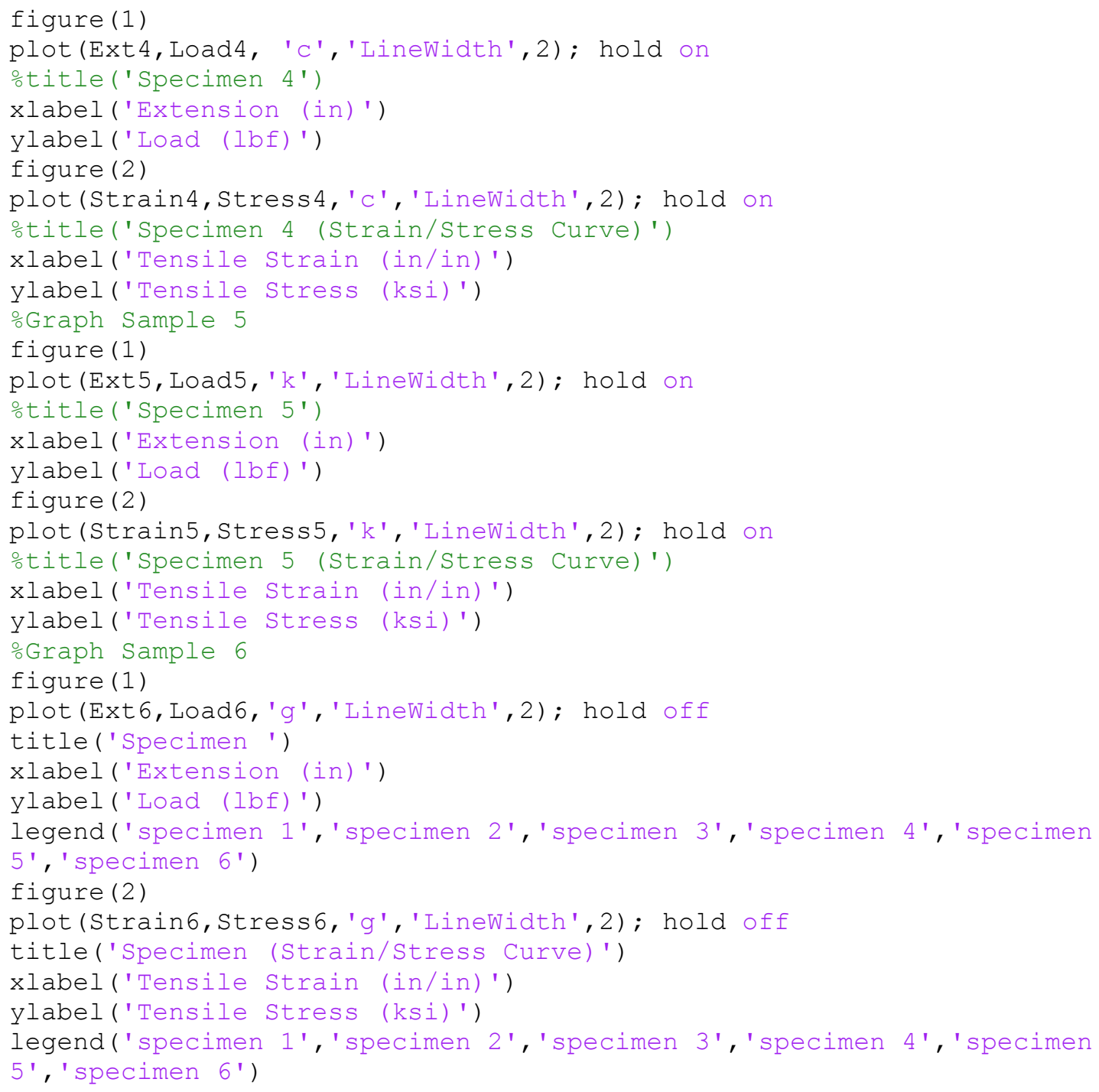

\subsubsection{Convergence Test}

\% Convergence Test

clear all; clc

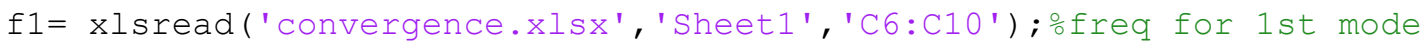
$\mathrm{f2}=\mathrm{xlsread}\left(\right.$ 'convergence.xlsx', 'Sheet1','D6:D10'); $\frac{\circ}{\mathrm{o}}$ freq for 2nd mode Num= xlsread ('convergence.xlsx',' Sheet1','B6:B10'); \%number of elements f11 = xlsread('convergence.xlsx','Sheet1','C24:C29'); with extra seed 
ylabel ('Frequency (Hz)' )

grid on

hold off

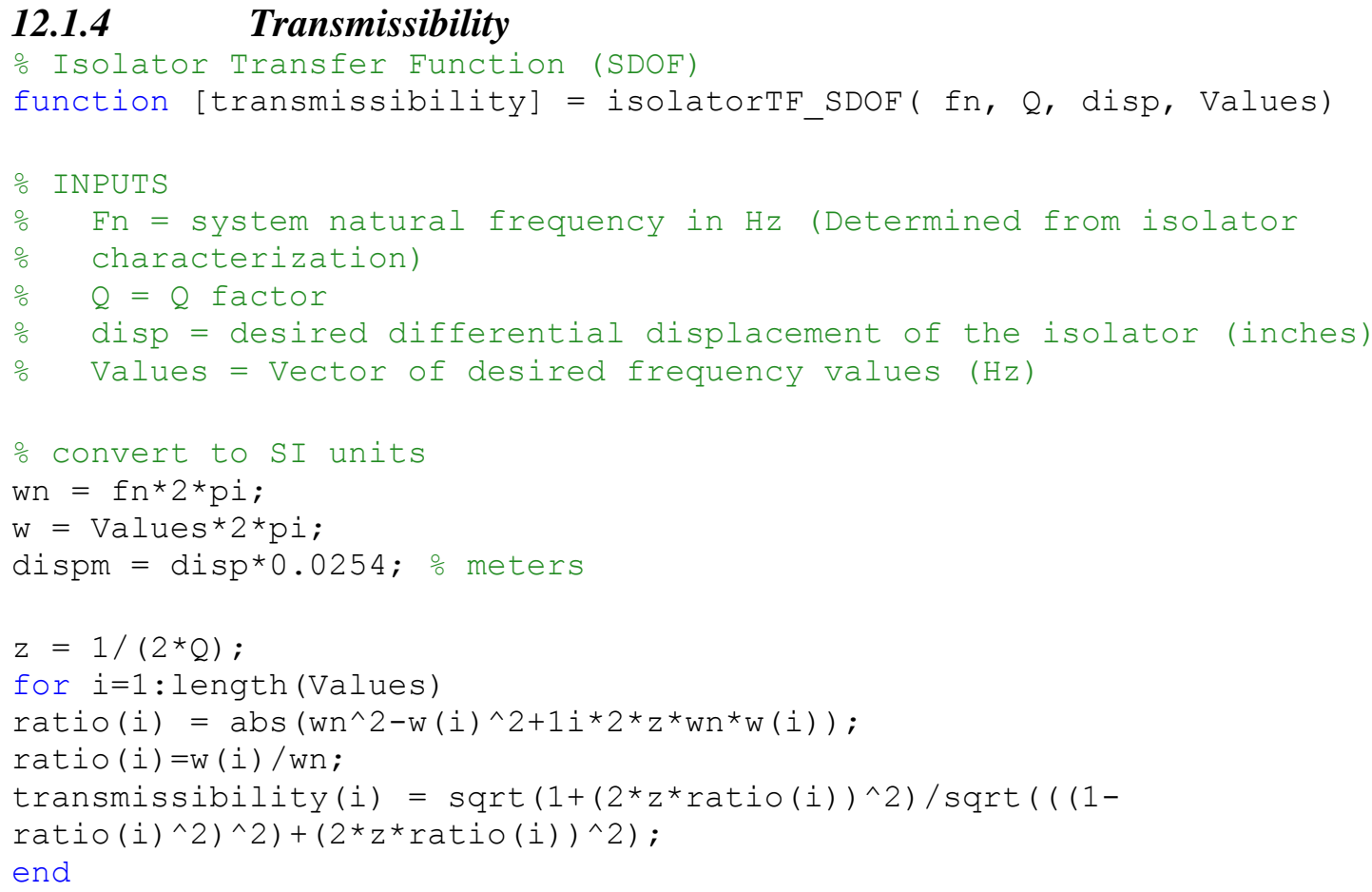

\subsubsection{Vibration Tests: Flat and High Frequency Spectrums}

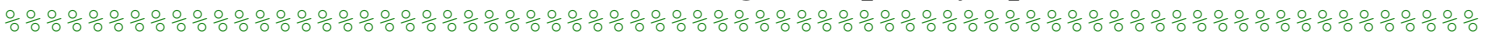

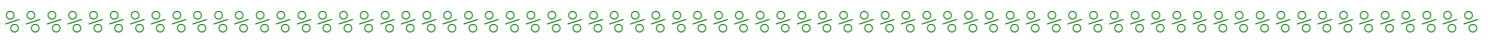

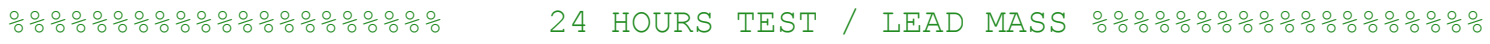
$\% \frac{0}{0} \%$ NOT OUTGASSSED AND OUTGASSED $\% \% \% \%$

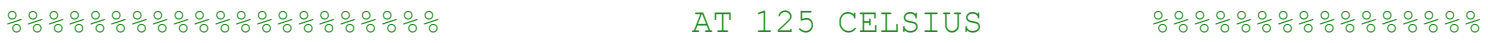

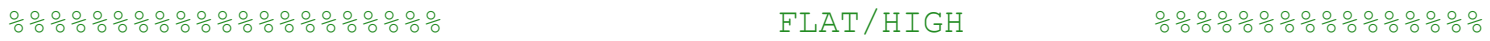

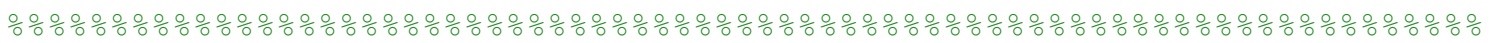
$\%$ Data for 1-4 in the $\mathrm{X}$ direction OUTGASSED LEAD MASS GROUP 1 $\mathrm{Hz} 14 \mathrm{X}=$

xlsread('Flat_yes_baseline_1_4_X_direction_out.xlsx', 'ALMA_FLAT', 'B33: B543'); $\frac{o}{0}$ frequency for $X$, out

$\mathrm{CH} 1$ - $\mathrm{X}=$

xls G543'); 으을

$\mathrm{CH} 2-4 \mathrm{X}=$

xlsread('Flat_yes_baseline_1_4_X_direction_out.xlsx', 'ALMA_FLAT', 'H33:

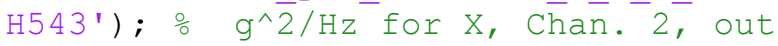

$\mathrm{CH} 34 \mathrm{X}=$

xls read('Flat_yes_baseline_1_4_X_direction_out.xlsx', 'ALMA_FLAT', 'I33:

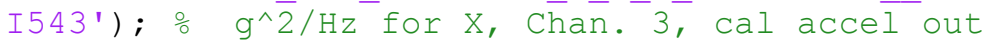

$\mathrm{CH} 4$ _ $4 \mathrm{X}=$

xlsread('Flat_yes_baseline_1_4_x_direction_out.xlsx', 'ALMA_FLAT', 'J33:

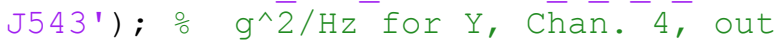

CONT $4 \mathrm{X}=$

xlsrēad('Flat_yes_baseline_1_4_x_direction_out.xlsx', 'ALMA_FLAT', 'D33: D543'); \% g^$^{\wedge} / \mathrm{Hz}$ for $\mathrm{X}$, Control, out 
응 Data for 1-4 in the Y direction OUTGASSED LEAD MASS

$\mathrm{Hz} 14 \mathrm{Y}=$

xlscread('Flat yes baseline 14 Y direction out.xlsx', 'ALMA FLAT', 'B33:

B543'); 들

$\mathrm{CH} 14 \mathrm{Y}=$

xlsread('Flat_yes_baseline_1_4_y_direction_out.xlsx', 'ALMA_FLAT', 'G33:

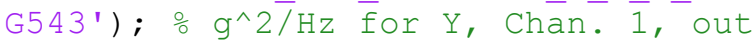

$\mathrm{CH} 24 \mathrm{Y}=$

xlscread('Flat yes baseline 14 Y direction out.xlsx', 'ALMA FLAT', 'H33:

H543'); $\frac{\circ}{\circ} \overline{2} / \mathrm{Hz}^{-}$for $\mathrm{Y}$, Chā̄.

$\mathrm{CH} 34 \mathrm{Y}=$

xlsread('Flat_yes_baseline_1_4_Y_direction_out.xlsx', 'ALMA_FLAT', 'I33:

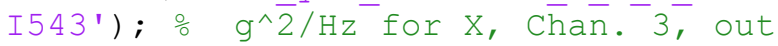

$\mathrm{CH} 4 \quad 4 \mathrm{Y}=$

xlscread('Flat yes baseline 14 Y direction out.xlsx', 'ALMA FLAT', 'J33:

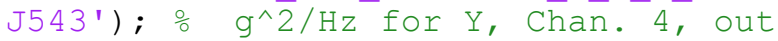

CONT $4 \mathrm{Y}=$

xlsrēad('Flat_yes_baseline_1_4_Y_direction_out.xlsx', 'ALMA_FLAT', 'D33:

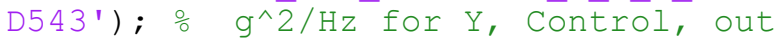

응 Data for 1-4 in the Z direction OUTGASSED LEAD MASS

$\mathrm{Hz} 14 \mathrm{Z}=$

xlšread('Flat_yes_baseline_1_4_z_direction_out.xlsx', 'ALMA_FLAT', 'B33: B543'); $\frac{o}{0}$ frequency for Y, out

$\mathrm{CH} 1$ _ $\mathrm{Z}=$

xlšread('Flat_yes baseline_1_4_Z_direction out.xlsx', 'ALMA_FLAT', 'G33: G543'); $\circ \mathrm{g}^{\wedge} 2 \overline{\mathrm{H}} \mathrm{Hz}$ for Z, Chān. $\overline{1}$, out

$\mathrm{CH} 2 \quad 4 \mathrm{Z}=$

xlsread('Flat_yes_baseline_1_4_z_direction_out.xlsx', 'ALMA_FLAT', 'H33:

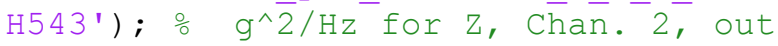

CH3 $4 \mathrm{Z}=$

xls read('Flat yes baseline 14 Z direction out.xlsx', 'ALMA FLAT', 'I33:

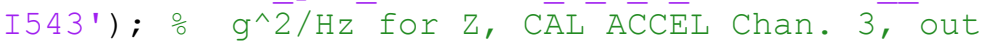

$\mathrm{CH} 4 \quad 4 \mathrm{Z}=$

xlsread('Flat_yes_baseline_1_4_z_direction_out.xlsx', 'ALMA_FLAT', 'J33:

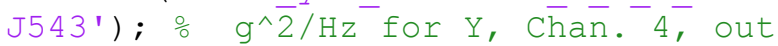

CONT $4 \mathrm{Z}=$

xlsrēad('Flat yes baseline 14 Z direction out.xlsx', 'ALMA FLAT', 'D33: D543'); $\frac{\circ}{\circ} \overline{2} / \mathrm{Hz}^{\prime}$ for $\mathrm{y}$, Contrōi, out

응 Data for 9-12 in the $\mathrm{X}$ direction NOT OUTGASSED LEAD MASS GROUP 2

Hz 9 - $12 \mathrm{X}=$

xlšread('FLAT_yes_baseline_9_12_X_direction_not.xlsx', 'ALMA_FLAT', 'B33: B543'); $\frac{\circ}{\circ}$ frequency for $\mathrm{X}$, ${ }^{\mathrm{NO}} \overline{\mathrm{T}} \mathrm{T}$ out

$\mathrm{CH} 19 \mathrm{12 \textrm {X }}=$

xlšreàd('FLAT_yes_baseline_9_12_x_direction_not.xlsx', 'ALMA_FLAT', 'G33:

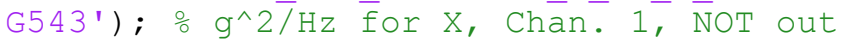

CH2 $9-12 \mathrm{X}=$

xls $\bar{r}$-äd('FLAT yes baseline 9 12 X direction_not.xlsx', 'ALMA_FLAT', 'H33:

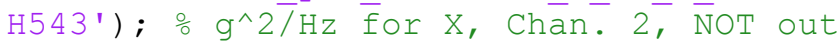

CH3_9_ $12 \mathrm{X}=$

xls $\bar{r}$ ād('FLAT_yes_baseline_9_12_X_direction_not.xlsx', 'ALMA_FLAT', 'I33:

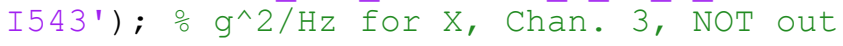


CH4_ 9 - $12 \mathrm{X}=$

xls $\bar{r}$ eàd('FLAT yes baseline 912 x direction not.xlsx', 'ALMA FLAT', 'J33: J543'); 으을

CONT $912 \mathrm{X}=$

xlsread('FLAT_yes_baseline_9_12_X_direction_not.xlsx', 'ALMA_FLAT', 'D33:

D543'); 으을

응 Data for 9-12 in the Y direction NOT OUTGASSED LEAD MASS

Hz 9 - $12 \mathrm{Y}=$

xlsčread('Flat yes baseline 912 Y direction not.xlsx', 'ALMA FLAT', 'B33: B543'); $\frac{\circ}{0}$ frequency for $Y, \overline{N O T} \overline{\text { out }}$

CH1_9_12Y=

xlsread('Flat_yes_baseline_9_12_y_direction_not.xlsx', 'ALMA_FLAT', 'G33: G543'); 으일

$\mathrm{CH} 29$ 12Y=

xls reād('Flat yes baseline 912 y direction not.xlsx', 'ALMA FLAT', 'H33: H543'); 으을

CH3_9_12Y=

xls

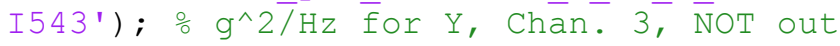

CH4_9_12Y=

xls reàd('Flat yes baseline 912 y direction not.xlsx', 'ALMA FLAT', 'J33:

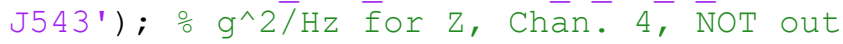

CONT_9_12Y=

xlsrēèd'('Flat_yes_baseline_9_12_Y_direction_not.xlsx', 'ALMA_FLAT', 'D33:

D543'); 으일

응 Data for 9-12 in the $\mathrm{Z}$ direction NOT OUTGASSED LEAD MASS

$\mathrm{Hz} 912 \mathrm{Z}=$

xls read('Flat yes baseline 9 12_Z direction not.xlsx', 'ALMA_FLAT', 'B33: B543'); $\frac{\circ}{\circ}$ frequency for $Z, \overline{N O T} \overline{\text { out }}$

$\mathrm{CH}_{1}{ }^{9}{ }_{-} 12 \mathrm{Z}=$

xls reād('Flat yes baseline 9 12_Z direction not.xlsx', 'ALMA_FLAT', 'G33: G543'); 으을

CH2_9_12Z=

xls H543'); 으을

CH3_ 9 - $12 \mathrm{Z}=$

xls $\bar{r}$ ād('Flat_yes_baseline_9_12_z_direction_not.xlsx', 'ALMA_FLAT', 'I33:

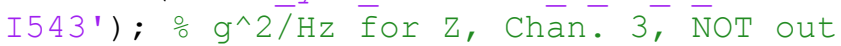

CH4 9 12Z=

xlscreàd('Flat_yes_baseline_9_12_Z_direction_not.xlsx', 'ALMA_FLAT', 'J33:

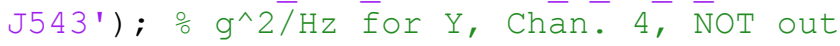

CONT_9_12z=

xlsrēeād'Flat_yes_baseline_9_12_z_direction_not.xlsx', 'ALMA_FLAT', 'D33: D543'); 으을

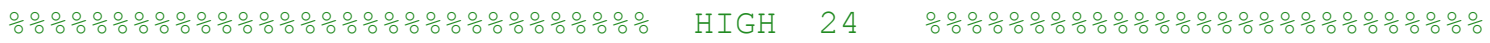

응 Data for HIGH 5-8 in X direction NOT OUTGASSED LEAD MASS GROUP 3

$\mathrm{Hz} 5$ _ $8 \mathrm{XH}=$

xlsread('HIGH_24_yes_baseline_5_8_x_direction_outgassed_leadl.xlsx', '2

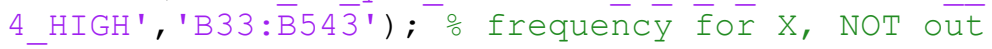


$\mathrm{CH}_{1}{ }_{-}{ }_{-} 8 \mathrm{XH}=$

xls reād('HIGH 24 yes baseline 58 x direction outgassed lead1.xlsx', '2 $4 \mathrm{HIGH}^{\prime}$, 'G33: $\overline{\mathrm{G}} 54 \overline{3}^{\prime}$ ) ; $\frac{\circ}{\circ} \mathrm{g}^{\wedge} 2 / \mathrm{Hz}$ for $\mathrm{X}$, Chan. 1, NoT out

$\mathrm{C} \overline{\mathrm{H}} 2 \quad 5 \quad 8 \times \mathrm{XH}=$

xlsread('HIGH_24_yes_baseline_5_8_x_direction_outgassed_leadl.xlsx', '2

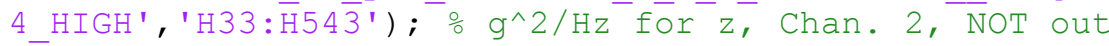

$\mathrm{CH} 3 \_$_ $8 \times \mathrm{H}=$

xlstreàd('HIGH 24 yes baseline 58 x direction outgassed lead1.xlsx', '2

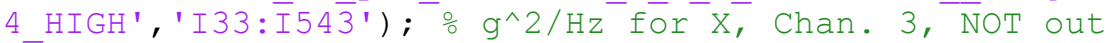

$\mathrm{C} \overline{\mathrm{H}} 4-5$ - $8 \mathrm{XH}=$

xlsreād'HIGH_24_yes_baseline_5_8_x_direction_outgassed_leadl.xlsx', '2

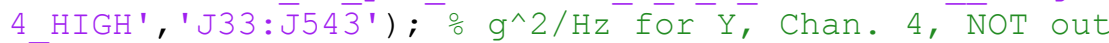

$\mathrm{CONT} 58 \mathrm{XH}=$

xlsrēead'('HIGH 24 yes baseline 5 _ x direction outgassed lead1.xlsx', '2

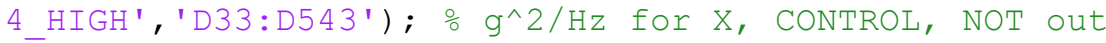

응 Data for HIGH 5-8 in the Y direction NOT OUTGASSED LEAD MASS

$\mathrm{Hz} 5$ _ $8 \mathrm{YH}=$

xlsread('HIGH_24_yes_baseline_5_8_y_direction_outgassed_leadl.xlsx', '2

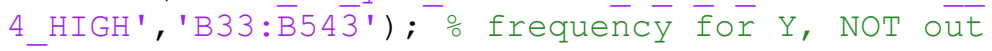

$\mathrm{C} \overline{\mathrm{H}} 1$ - 5 - $8 \mathrm{YH}=$

xls

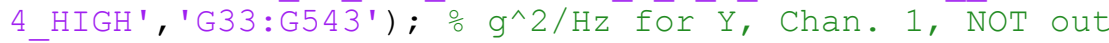

$\mathrm{C} \overline{\mathrm{H}} 2-5-8 \mathrm{YH}=$

xls

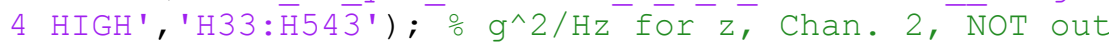

$\mathrm{C} \overline{\mathrm{H}} 3 \quad 5 \quad 8 \mathrm{YH}=$

xlsread('HIGH_24_yes_baseline_5_8_y_direction outgassed_lead1.xlsx', '2

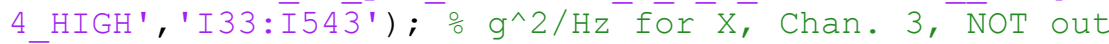

$\mathrm{CH} 4$ - 5 - $8 \mathrm{YH}=$

xls reād('HIGH 24 yes baseline 58 y direction outgassed leadl.xlsx', '2

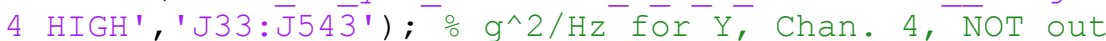

CONT 5 \&YH=

xlsrēèd('HIGH_24_yes_baseline_5_8_y_direction_outgassed_lead1.xlsx', '2

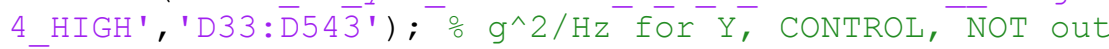

응 Data for HIGH 5-8 in the z direction NOT OUTGASSED LEAD MASS

$\mathrm{Hz} 5$ \& $8 \mathrm{H}=$

xlstead('HIGH 24 yes baseline 5 z d direction outgassed lead1.xlsx', '2

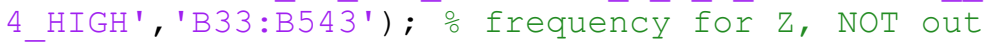

$\mathrm{C} \overline{\mathrm{H}} 1$ _ $8 \mathrm{ZH}=$

xlsreàd('HIGH 24 yes baseline 5 8 z direction outgassed lead1.xlsx', '2

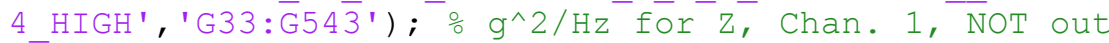

$\mathrm{C} \overline{\mathrm{H}} 2 \quad 5 \quad 8 \mathrm{ZH}=$

xlstreàd('HIGH 24 yes baseline 5 z direction outgassed leadl.xlsx', '2

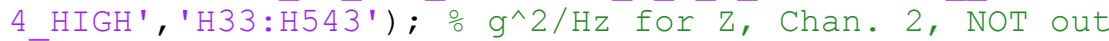

$\mathrm{C} \overline{\mathrm{H}} 3 \_5 \_\mathrm{ZH}=$

xls

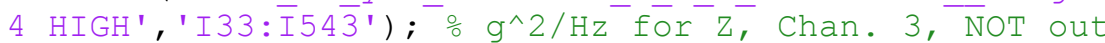

$\mathrm{CH} 4-5$ - $\mathrm{ZH}=$

xlsread('HIGH_24_yes_baseline_5_8_z_direction_outgassed_lead1.xlsx', '2

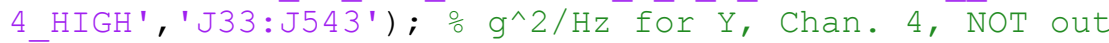

CONT_5_8ZH=

xlsrēēd ('HIGH_24_yes_baseline_5_8_z_direction_outgassed_leadl.xlsx', '2

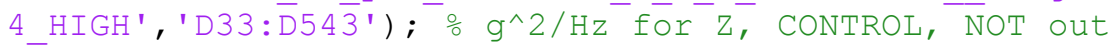


응 Data for HIGH 17-20 in $\mathrm{x}$ direction NOT OUTGASSED LEAD MASS GROUP 4 $\mathrm{Hz} 17$ 20XH=

xlsrēad('HIGH 24 yes_baseline_17_20_x_direction_not_outgassed_lead1.xls

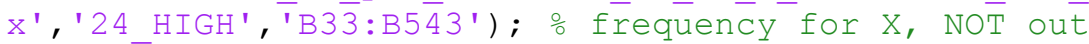

$\mathrm{CH} 117-20 \mathrm{xH}=$

xls $\bar{r}$ ead ('HIGH_24_yes_baseline_17_20_x_direction_not_outgassed_lead1.xls

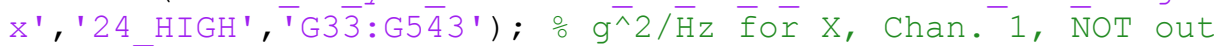

$\mathrm{CH} 217-20 \mathrm{xH}=$

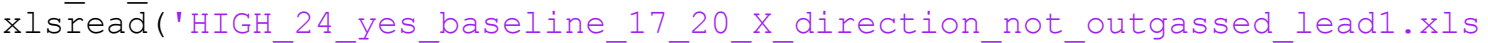

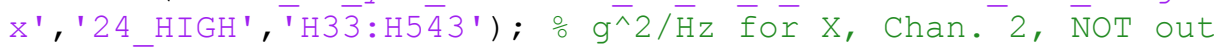

CH3_17-20XH=

xls $\bar{r}$ ead ('HIGH_24_yes_baseline_17_20_x_direction_not_outgassed_lead1.xls

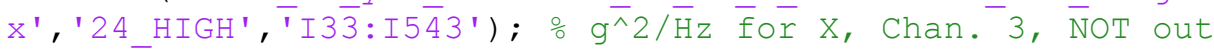

$\mathrm{CH} 41720 \mathrm{XH}=$

xls $\bar{r}$ a $\bar{d}(' H I G H$ _24_yes_baseline_17_20_x_direction_not_outgassed_lead1.xls

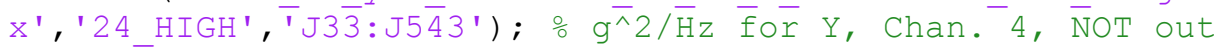

CONT_1 $1 \overline{7} 20 \times \mathrm{XH}=$

xlsrēed'('HIGH_24_yes_baseline_17_20_x_direction_not_outgassed_lead1.xls

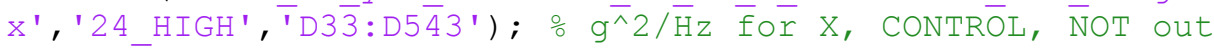

응 Data for HIGH 17-20 in the Y direction NOT OUTGASSED LEAD MASS $\mathrm{Hz} 17$ 20YH=

xlsréad('HIGH_24_yes_baseline_17_20_Y_direction_not_outgassed_lead1.xls

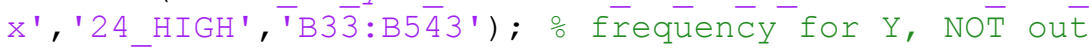

$\mathrm{CH} 1{ }^{-} \mathrm{-} 2 \mathrm{YH}=$

xls $\bar{r}$ ead̄'('HIGH 24 yes baseline 1720 Y direction not outgassed lead1.xls

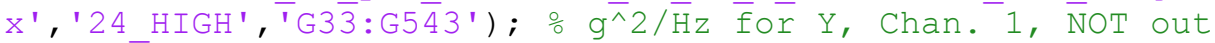

CH2_17_2OYH=

xls $\bar{r}$ ead ('HIGH_24_yes_baseline_17_20_y_direction_not_outgassed_lead1.xls

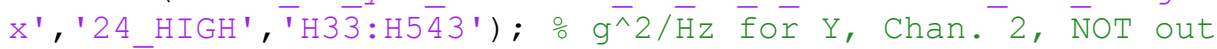

CH3 $17^{-} 20 \mathrm{YH}=$

xls $\bar{r}$ ead ('HIGH_24_yes_baseline 17_20 y direction not outgassed lead1.xls

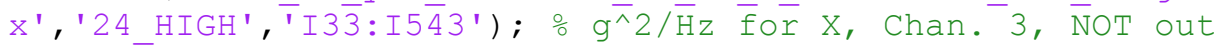

$\mathrm{CH} 417-20 \mathrm{YH}=$

xls $\bar{r}$ ead ('HIGH_24_yes_baseline_17_20_Y_direction_not_outgassed_lead1.xls

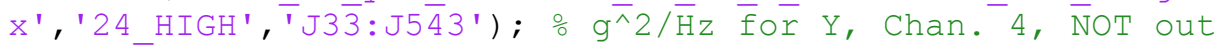
CONT_1 $\overline{7} 20 \mathrm{YH}=$

xlsrēad'('HIGH 24 yes baseline 1720 y direction not outgassed lead1.xls

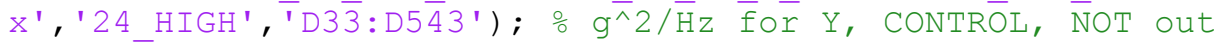

응 Datā for HIGH 17-20 in the z direction NOT OUTGASSED LEAD MASS

$\mathrm{Hz} 17$ _20 $\mathrm{ZH}=$

xlsrēed('HIGH 24 yes baseline 17_20_z direction not outgassed_lead1.xls

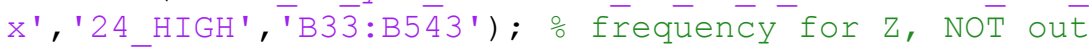

$\mathrm{CH} 17^{-} 20 \mathrm{ZH}=$

xlsread'('HIGH_24_yes_baseline_17_20_z_direction_not_outgassed_lead1.xls

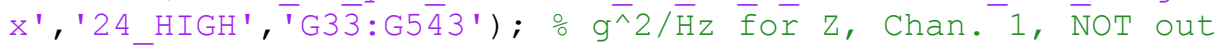

$\mathrm{CH} 217-20 \mathrm{ZH}=$

xls $\bar{r}$ a d' ('HIGH 24 yes baseline 17 20 Z direction not outgassed_lead1.xls

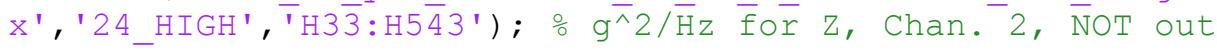

CH3 17 20ZH=

xlsread'('HIGH_24_yes_baseline_17_20_z_direction_not_outgassed_leadl.xls

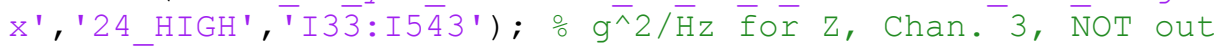

CH4 17 $20 \mathrm{ZH}=$

xls $\bar{r}$ ead ('HIGH 24 yes baseline 17_20_z direction not outgassed_lead1.xls

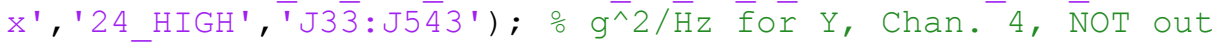


CONT_17_20ZH=

xlsrēed'̄'HIGH 24 yes baseline 1720 Z direction not outgassed lead1.xls

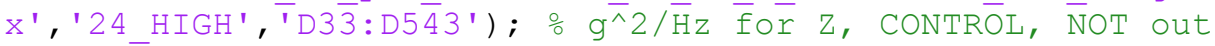

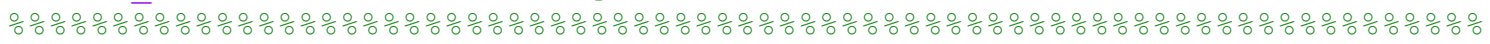
응응응

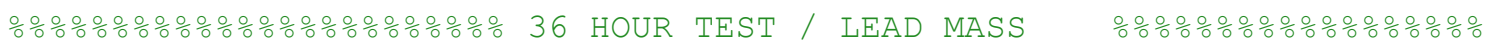
$\% \% \frac{0}{0} \% \% \frac{0}{0} \% \% \% \% \%$ 응 $\frac{0}{0} \% \frac{0}{0} \% \circ \%$

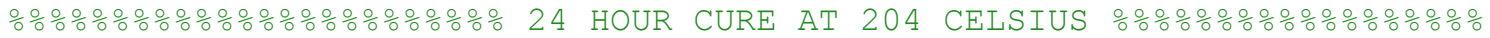

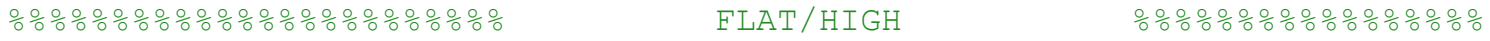

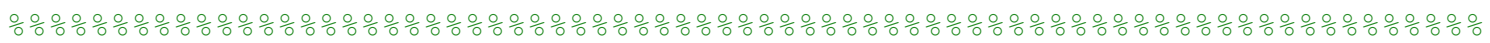
응 Data FLAT 9-12 in the $\mathrm{X}$ direction 36 HOUR OUTGASSED LEAD MASS GROUP 5

Hz9_12X36=

xls

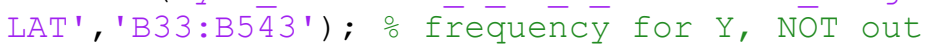

CH1_9_12X36=

xlstreād('yes baseline 912 x direction outgassed 36hr leadl.xlsx', '36 F

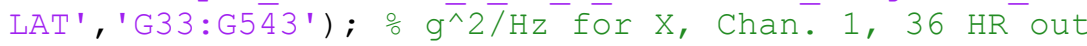

$\mathrm{CH} 2912 \times 36=$

xlsreād('yes_baseline_9_12_X_direction_outgassed_36hr_lead1.xlsx', '36_F

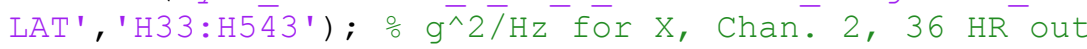

CH3_9_12 $126=$

xlstreād('yes baseline 912 X direction outgassed 36hr leadl.xlsx', '36 F

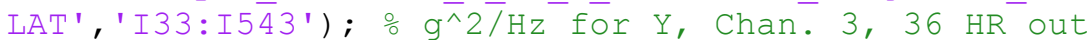

CH4 9 - $12 \times 36=$

xlsreād('yes_baseline_9_12_X_direction_outgassed_36hr_lead1.xlsx', '36_F LAT', 'J33: J5 $\overline{4} 3$ '); $\frac{\circ}{\bar{\wedge}} 2 \overline{7} \mathrm{~Hz}^{-}$for $\mathrm{X}, \mathrm{Chan}-4,36 \mathrm{HR}$ out

CONT_9_12X36=

xlsrēèd'('yes_baseline_9_12_X_direction_outgassed_36hr_leadl.xlsx', '36_F

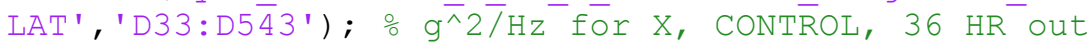

응 Data for FLAT 9-12 in the Y direction 36 HOUR OUTGASSED LEAD MASS Hz9_12Y36=

xlsread('yes_baseline_9_12_Y_direction_outgassed_36hr_lead1.xlsx', '36_F

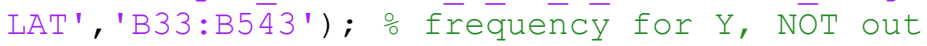

CH1_9_12Y36=

xls

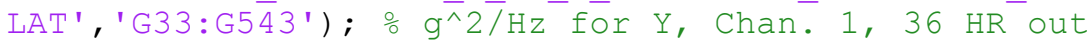

CH2_9_12Y36=

xlsreād('yes_baseline_9_12_y_direction_outgassed_36hr_lead1.xlsx', '36_F

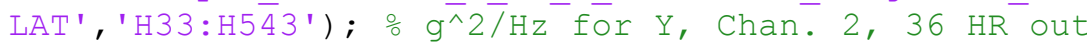

CH3 9 12Y36=

xls $\bar{r}$ ād('yes_baseline_9_12_y_direction_outgassed_36hr_leadl.xlsx', '36 F

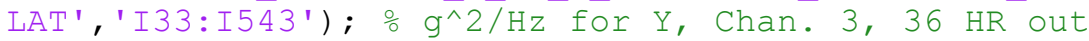

CH4 9 - $12 \mathrm{Y} 36=$

xls

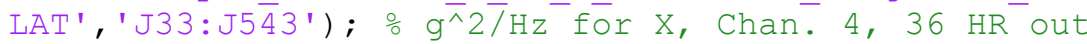

CONT_9_12Y36=

xlsrēēd'yes_baseline_9_12_y_direction_outgassed_36hr_lead1.xlsx', '36_F

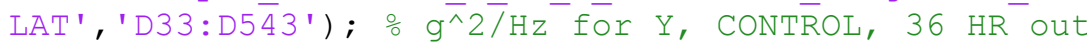

응 Data for FLAT 9-12 in the Z direction 36 HOUR OUTGASSED LEAD MASS 
Hz9_12Z36=

xls $\bar{r}$ ead('yes_baseline_9_12_z_direction_outgassed_36hr_lead1.xlsx', '36 F

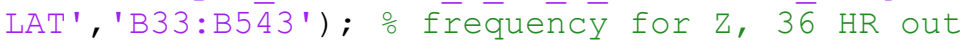

$\mathrm{CH} 19$ 12Z36=

xlsread('yes_baseline_9_12_z_direction_outgassed_36hr_lead1.xlsx', '36_F

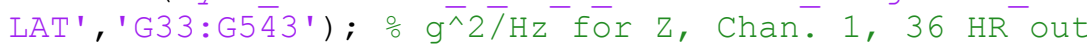

CH2_9_12 $236=$

xls

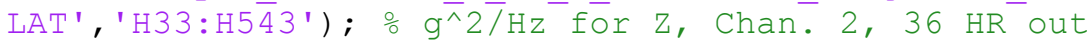

CH3_9_12Z36=

xlsreād('yes_baseline_9_12_Z_direction_outgassed_36hr_lead1.xlsx', '36_F

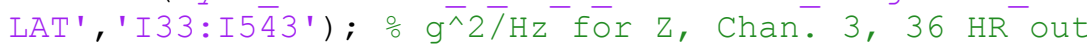

$\mathrm{CH} 4 \mathrm{P} 12 \mathrm{Z3} 6=$

xlsreàd('yes_baseline_9_12_Z_direction_outgassed_36hr_leadl.xlsx', '36_F LAT', 'J33: J5s $\left.\overline{4} 3^{\prime}\right)$; $\circ \mathrm{g}^{\wedge} 2 \overline{\mathrm{H} z}$ for $\mathrm{X}$, Chan. 4, $36 \mathrm{HR}$ out

CONT_9_12Z36=

xlsreāèd'yes_baseline_9_12_Z_direction_outgassed_36hr_leadl.xlsx', '36_F

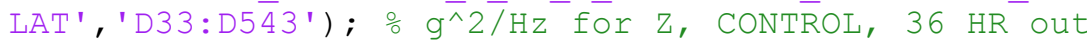

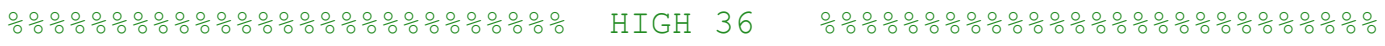

GROUP 6

응 Data for HIGH 9-12 in the $\mathrm{X}$ direction 36 HOUR OUTGASSED LEAD MASS

Hz 9 12X36L=

xls

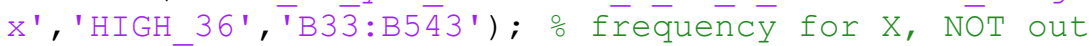

CH1_9_12 $\bar{X} 36 \mathrm{~L}=$

xls

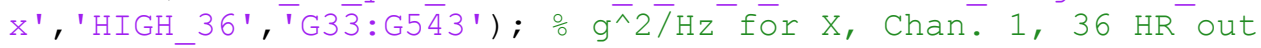

CH2_9_12 ${ }^{2} 36 \mathrm{~L}=$

xls reād('HIGH 36 yes baseline 912 X direction outgassed 36hr lead1.xls

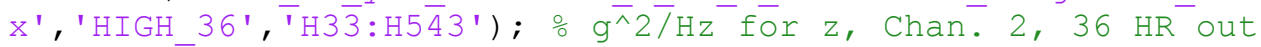

CH3_ $912 \overline{\times} 36 \mathrm{~L}=$

xlsread('HIGH_36_yes_baseline_9_12_x_direction_outgassed_36hr_leadl.xls

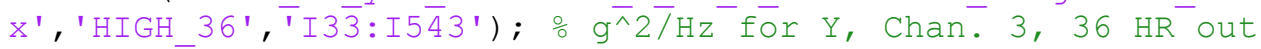

CH4_ 9 - $12 \overline{\mathrm{X}} 36 \mathrm{~L}=$

xls

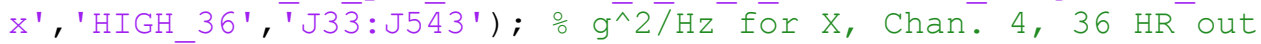

CONT_9_1 $\overline{2} \times 36 \mathrm{~L}=$

xlsreād('HIGH_36_yes_baseline_9_12_x_direction_outgassed_36hr_lead1.xls

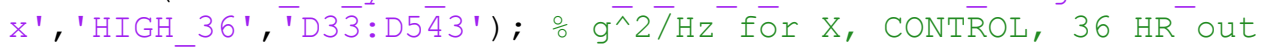

응 Data for HIGH 9-12 in the Y direction 36 HOUR OUTGASSED LEAD MASS

Hz 9 12Y36L=

xlstread('HIGH 36 yes baseline 9 12 y direction outgassed 36hr_lead1.xls

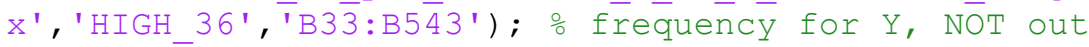

$\mathrm{CH} 1$ __ $12 \overline{\mathrm{Y}} 36 \mathrm{~L}=$

xlsread('HIGH_36_yes_baseline_9_12_y_direction_outgassed_36hr_lead1.xls

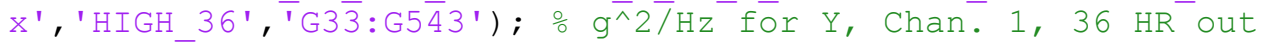
CH2_9_12 $\bar{Y} 36 \mathrm{~L}=$

xlsread('HIGH_36_yes_baseline_9_12_y_direction_outgassed_36hr_lead1.xls

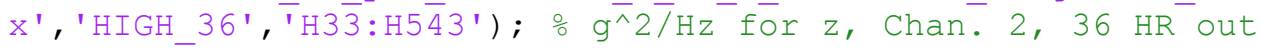

CH3_ 9 - $12 \overline{\mathrm{Y}} 36 \mathrm{~L}=$

xls $\bar{r}$ ād('HIGH_36_yes_baseline_9_12_y_direction_outgassed_36hr_lead1.xls

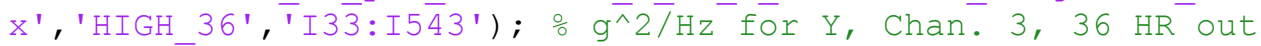


CH4_9_12Y36L=

xls reād('HIGH 36 yes baseline 912 y direction outgassed 36 hr leadl.xls

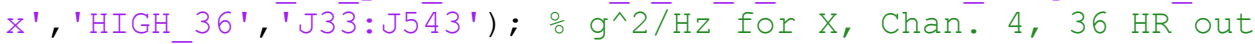

CONT $91 \overline{2} \mathrm{Y} 36 \mathrm{~L}=$

xlsread ('HIGH_36_yes_baseline_9_12_y_direction_outgassed_36hr_lead1.xls

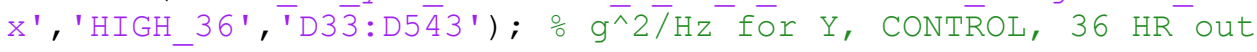

응 Data for HIGH $9-12$ in the $\mathrm{z}$ direction 36 HOUR OUTGASSED LEAD MASS

Hz 9 - $12 \mathrm{Z3} 6 \mathrm{~L}=$

xlstread('HIGH 36 yes baseline 912 Z direction outgassed 36hr_lead1.xls

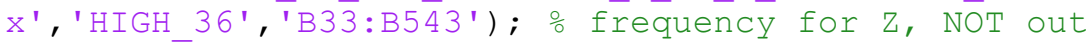

CH1_9_12 $\overline{\mathrm{Z}} 36 \mathrm{~L}=$

xlsreād('HIGH_36_yes_baseline_9_12_z_direction_outgassed_36hr_leadl.xls

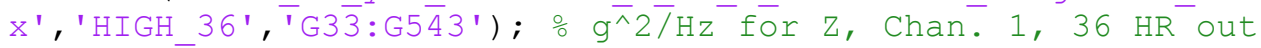

$\mathrm{CH} 2$ - $92 \overline{\mathrm{Z}} 36 \mathrm{~L}=$

xlsread('HIGH_36 yes_baseline 9_12_Z_direction_outgassed_36hr_lead1.xls

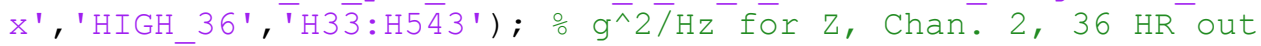

CH3_9_12 $\overline{\mathrm{Z}} 36 \mathrm{~L}=$

xlsreàd('HIGH_36_yes_baseline_9_12_z_direction_outgassed_36hr_lead1.xls

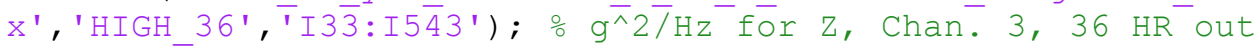

CH4_9_12Z36L=

xlstreàd('HIGH 36 yes baseline 912 Z direction outgassed 36hr_lead1.xls

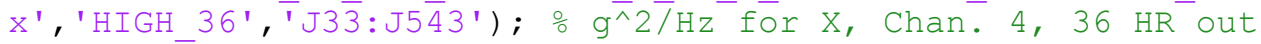

CONT $91 \overline{2} \mathrm{Z} 36 \mathrm{~L}=$

xlsrēeād('HIGH_36_yes_baseline_9_12_z_direction_outgassed_36hr_lead1.xls

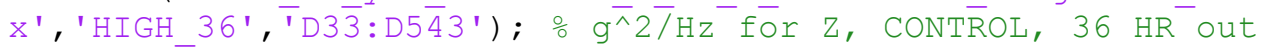

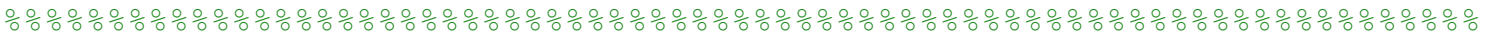

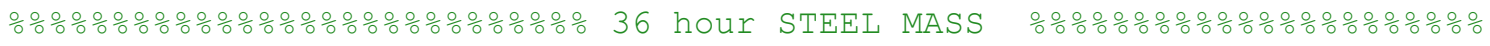

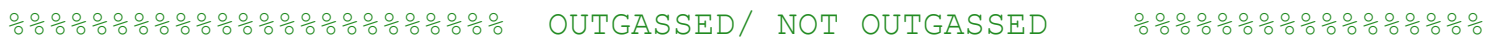

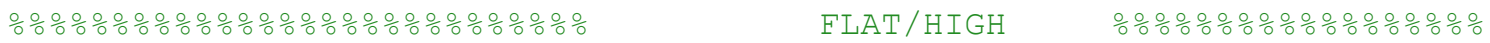

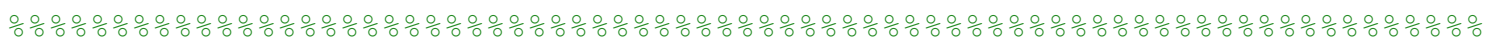

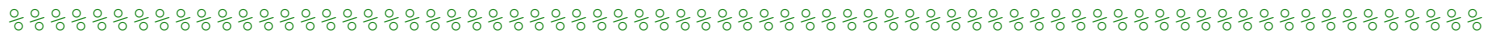

응 Data for 9-12 in the $\mathrm{X}$ direction 36 HOUR OUTGASSED STEEL MASS

Hz $912 \times 36$ STEEL=

xlsread('yes_baseline_9_12_x_direction_outgassed_36hr_steel1.xlsx', '36_ FLAT_STEEL',' 'B33:B543'); 을

CH1_ ${ }^{\prime} \_12 \times 36$ STEEL=

xls $\bar{r}$-äd('yess baseline_9_12 x direction outgassed_36hr_steel1.xlsx','36

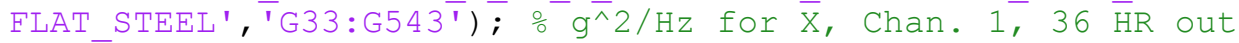

CH2_ ${ }^{-} \_12 \times 36$ STEEL $=$

xls $\bar{r}$ ād('yess_baseline_9_12_x_direction_outgassed_36hr_steel1.xlsx', '36 FLAT_STEEL', 'H33:H543') ; $\mathrm{g}^{\wedge} 2 / \mathrm{Hz}$ for $\overline{\mathrm{X}}$, Chan. 2, $36 \overline{\mathrm{HR}}$ out CH3 $\overline{9} 12 \times 36$ STEEL=

xlsreād('yess_baseline_9_12_x_direction_outgassed_36hr_steel1.xlsx', '36

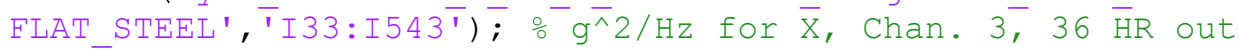

CH4_ $\overline{9}$ - $12 \times 36$ STEEL=

xlsread('yes_baseline_9_12_x_direction_outgassed_36hr_steel1.xlsx', '36

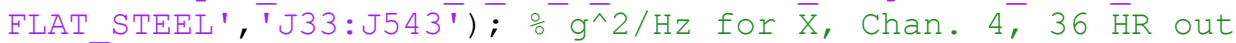
CONT_9_12X36_STEEL=

xlsréād('yes_baseline_9_12_x_direction_outgassed_36hr_steel1.xlsx', '36

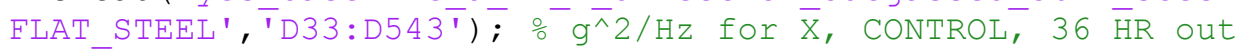

응 Data for 9-12 in the Y direction 36 HOUR OUTGASSED STEEL MASS 
Hz9_12Y36_STEEL=

xlšread('Ȳes baseline 912 Y direction outgassed 36hr steel1.xlsx', '36 FLAT STEEL', 'B33:B543'); 응 fequency for $Y, 36$ HR out

$\mathrm{CH} 1 \overline{9} 12 \mathrm{Y} 36$ STEEL=

xlsread('yes_baseline_9_12_Y_direction_outgassed_36hr_steel1.xlsx','36

FLAT STEEL', 'G33:G543') ; $\% \mathrm{~g}^{\wedge} 2 / \mathrm{Hz}$ for $\bar{Y}$, Chan. 1, $36 \overline{\mathrm{HR}}$ out

CH2_ $\overline{9}$ - 12 Y 36 STEEL=

xls $\bar{r}$-äd('yes baseline 9_12 Y direction outgassed 36hr steel1.xlsx', '36 FLAT STEEL', 'H33:H543') ; $\mathrm{g}^{\wedge} 2 / \mathrm{Hz}$ for $\bar{Y}$, Chan. 2, $36 \overline{\mathrm{HR}}$ out

CH3_ ${ }^{9} \_12 Y 36 \_$STEEL $=$

xlsreād('yess_baseline_9_12_Y_direction_outgassed_36hr_steel1.xlsx', '36 _ FLAT STEEL',' 'I33:I543') ; $\mathrm{g}^{\wedge} 2 / \mathrm{Hz}$ for $\bar{Y}$, Chan. 3, $36 \overline{\mathrm{HR}}$ out

CH4 $\overline{9} 12$ Y36 STEEL=

xlsread('yes baseline 912 Y direction outgassed 36hr steel1.xlsx','36 FLAT_STEEL', 'J33:J543') ; $\mathrm{g}^{\wedge} 2 / \mathrm{Hz}$ for $\bar{Y}$, Chan. 4, $36 \overline{\mathrm{HR}}$ out

CONT_9_12Y36_STEEL=

xlsrēēd ('yes_baseline_9_12_Y_direction_outgassed_36hr_steel1.xlsx', '36 FLAT_STEEL',' 'D33:D543') ; $\frac{\circ}{\circ} \mathrm{g}^{\wedge} / \mathrm{Hz}$ for $\bar{Y}, \mathrm{CONTROL}, 36 \overline{\mathrm{HR}}$ out

응 Data for 9-12 in the Z direction 36 HOUR OUTGASSED STEEL MASS

Hz 9 12Z36 STEEL=

xlscread('yes baseline 912 Z direction outgassed 36hr steel1.xlsx', '36 FLAT_STEEL',' 'B33:B543'); 을 $\bar{r}$ '

CH1_ $\overline{9}$ 12Z36_STEEL=

xls $\bar{r}$ àd('yess_baseline_9_12_z_direction_outgassed_36hr_steel1.xlsx','36 FLAT STEEL', 'G33:G543') ; $\mathrm{g}^{\wedge} 2 / \mathrm{Hz}$ for $\bar{Y}$, Chan. 1, $36 \overline{\mathrm{HR}}$ out

CH2 $\overline{9} 12 \mathrm{Z3} 6$ STEEL=

xlsread('yes_baseline_9_12_Z_direction_outgassed_36hr_steel1.xlsx','36

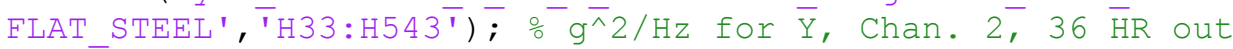

CH3 $\overline{9} 12 \mathrm{Z3} 6$ STEEL=

xls $\bar{r}$-äd('yes baseline_9_12_z_direction outgassed 36hr steel1.xlsx','36

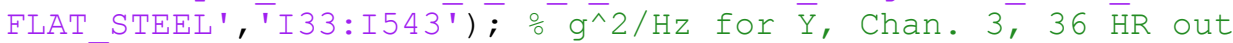

CH4 $\overline{9} 12 \mathrm{Z36}$ STEEL=

xls $r$ ead('yes baseline 9_12_z direction outgassed_36hr_steel1.xlsx','36

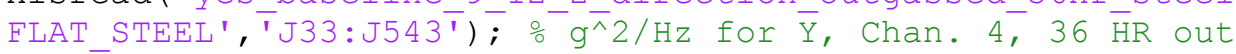

CONT_9_12Z36_STEEL=

xlsrēād'yes_baseline_9_12_z_direction outgassed_36hr_steel1.xlsx','36 FLAT_STEEL','D33:D543'); $\frac{\circ}{\circ} \mathrm{g}^{\wedge} 2 / \mathrm{Hz}$ for $\bar{Y}, \mathrm{CONTROL}, 36 \overline{\mathrm{HR}}$ out

응 Data for 17-20 in the $\mathrm{X}$ direction 36 HOUR OUTGASSED STEEL MASS

Hz17_20X36_STEEL=

xlsréad('yess baseline_17_20_x_direction_not outgassed 36hr steel1.xlsx'

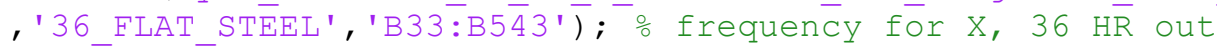

CH1 $\overline{1} 720 \bar{X} 36$ STEEL=

xls $\bar{r}$ ad̄ ('yes baseline 1720 X direction not outgassed 36hr steel1.xlsx'

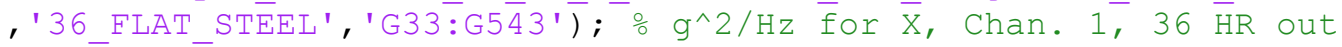

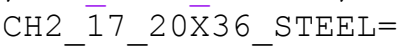

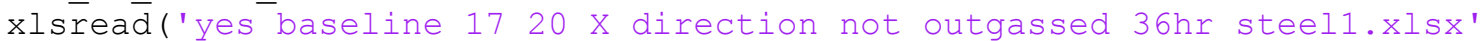

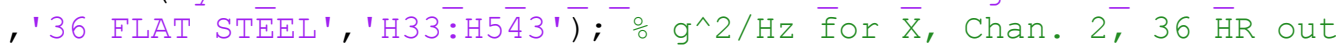
CH3 $\overline{1} 7$ 20र्X36_STEEL=

xls

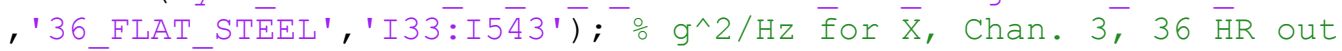

CH4_ī 17 _ $20 \times 36$ STEEL=

xls $\bar{r}$ ead ('yes_baseline_17_20_x_direction_not_outgassed_36hr_steel1.xlsx'

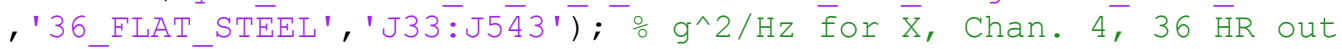


CONT_17_20X36_STEEL=

xlsréad' 'yes baseline 1720 X direction not outgassed 36hr steel1.xlsx'

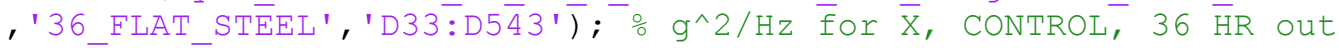

응 Data for 17-20 in the Y direction 36 HOUR OUTGASSED STEEL MASS Hz17_20Y36_STEEL=

xlsrēad('yes baseline 1720 Y direction not outgassed 36hr steel1.xlsx'

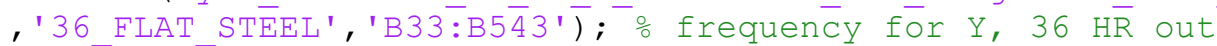

CH1_-17_20Ȳ36_STEEL=

xls $\bar{r}$ ead ('yes_baseline_17_20_y_direction_not_outgassed_36hr_steel1.xlsx'

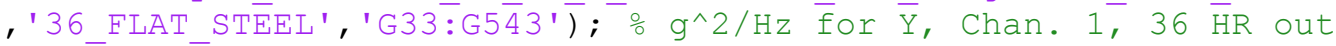
CH2 $\overline{1} 720 \bar{Y} 36$ STEEL=

xls $\bar{r}$ ead ('yes_baseline_17_20_y_direction_not_outgassed_36hr_steel1.xlsx'

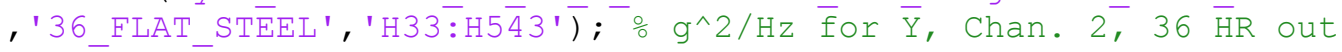

CH3 $\overline{1} 7$ 20 $\bar{Y} 36$ STEEL=

xls $\bar{r}$ ead ('yes baseline 1720 Y direction not outgassed 36hr steel1.xlsx'

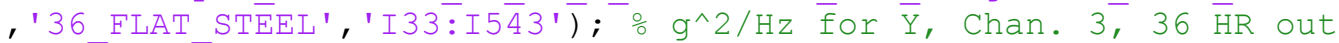
CH4 17 20Y 36 STEEL=

xls $\bar{r}$ add ('yes_baseline_17_20_Y_direction_not_outgassed_36hr_steel1.xlsx'

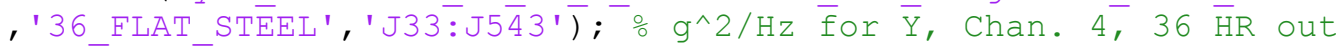
CONT_17_20Y36_STEEL=

xlsréad('yes baseline 1720 y direction not outgassed 36hr steel1.xlsx'

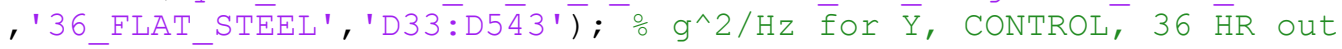

응 Data for 17-20 in the Z direction 36 HOUR OUTGASSED STEEL MASS Hz17_20Z36_STEEL=

xlsrēad('yes_baseline_17_20_z_direction_not_outgassed_36hr_steel1.xlsx'

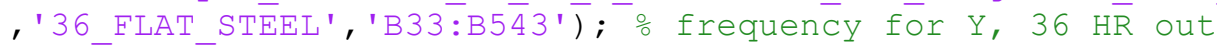

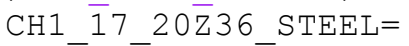

xls $\bar{r}$ ead ('yes baseline_1720 Z direction not outgassed_36hr_steel1.xlsx' ,'36 FLAT STEEL', 'G33:G543'); \% $\mathrm{g}^{\wedge} 2 / \mathrm{Hz}$ for $\bar{Y}$, Chan. 1, $36 \overline{\mathrm{HR}}$ out

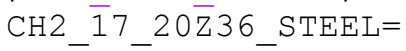

xls $\bar{r}$ ead ('yes baseline 1720 Z direction not outgassed 36hr steel1.xlsx'

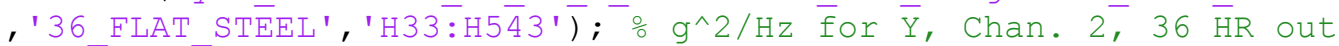

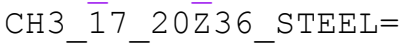

xls $\bar{r}$ ead ('yes baseline_1720_z_direction_not_outgassed_36hr_steel1.xlsx'

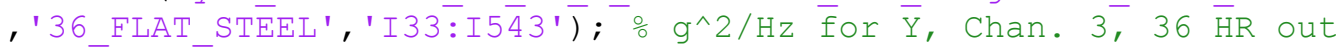

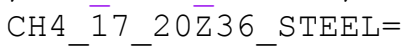

xls $\bar{r}$ ead ('yes_baseline_17_20_z_direction_not_outgassed_36hr_steel1.xlsx'

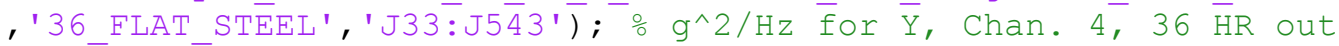
$\mathrm{CONT}^{-} 172 \overline{0} \mathrm{Z} 36$ STEEL=

xlsrēead'yes_baseline_17_20_z_direction_not_outgassed_36hr_steel1.xlsx'

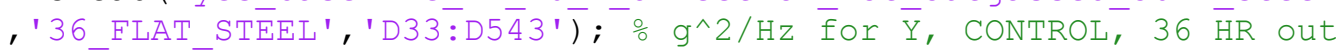

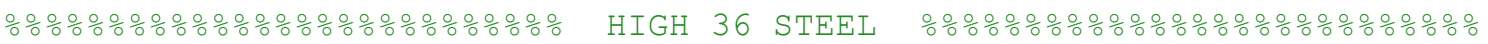

응 Data for 9-12 in the $\mathrm{X}$ direction 36 HOUR OUTGASSED STEEL MASS

$\mathrm{Hz} 9$ _ $12 \times 36$ SH=

xls $\bar{r}$ ead(' $\bar{H} I G H 36$ STEEL yes baseline 9 12_x direction_outgassed 36hr_ste

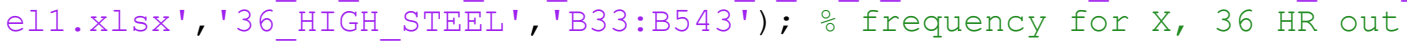
CH1_9_12X36_s $\overline{\mathrm{H}}=$

xls $\bar{r}$-àd('HI $\bar{G} H$ _36_STEEL_yes_baseline_9_12_X_direction_outgassed_36hr_ste

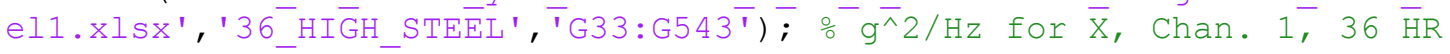
out 


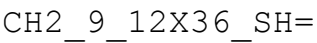

xls $\bar{r}$-äd('HI ĞH 36 STEEL yes baseline 912 X direction outgassed 36 hr ste

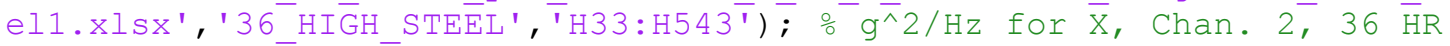

out

CH3_9_12X36_SH=

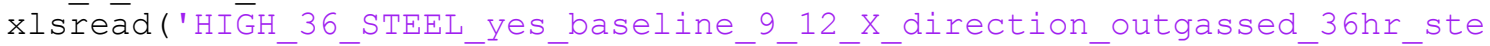

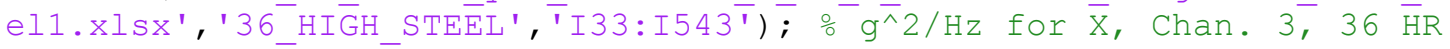

out

CH4 $912 \times 36 \quad \mathrm{SH}=$

xls $\bar{r}$ ād('HI $\bar{G} H$ _36_STEEL_yes_baseline_9_12_X_direction_outgassed_36hr_ste

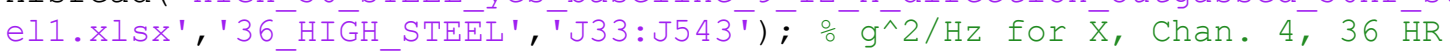

out

CONT $912 \times 36 \mathrm{SH}=$

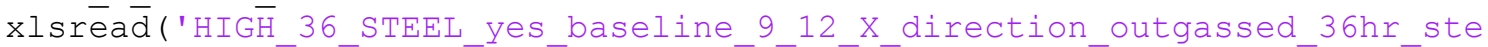

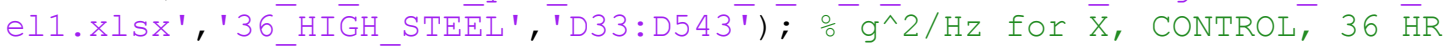
out

응 Data for 9-12 in the y direction 36 HOUR OUTGASSED STEEL MASS $\mathrm{Hz} 9$ _12Y36_SH=

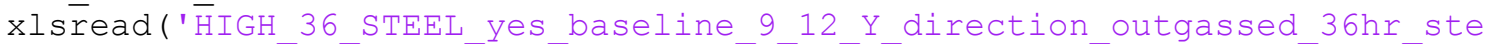

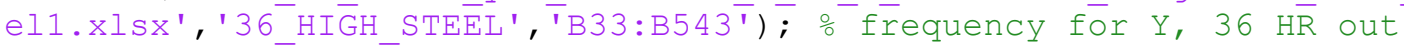
$\mathrm{CH} 1912 \mathrm{Y} 36 \mathrm{~S} \overline{\mathrm{H}}=$

xlsread('HIG $\bar{G}$ _36_STEEL_yes_baseline_9_12_Y_direction_outgassed_36hr_ste

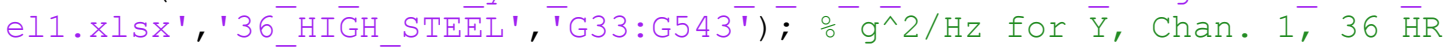
out

$\mathrm{CH} 2912 \mathrm{Y} 36 \mathrm{SH}=$

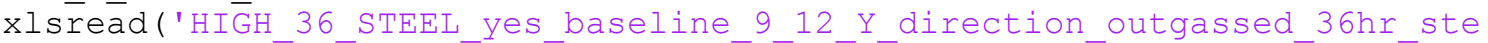

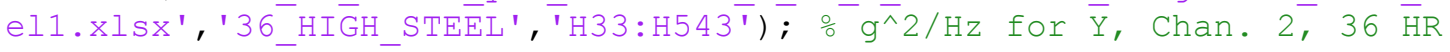
out

CH3_9_12Y36_SH=

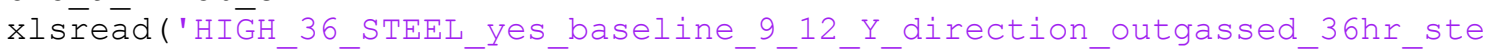

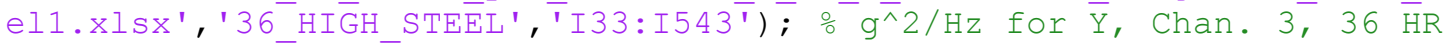

out

CH4_9_12Y36_SH=

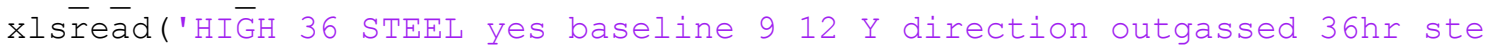

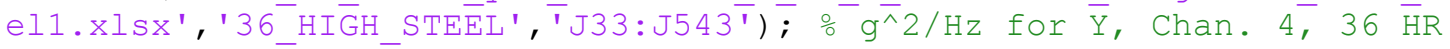
out

CONT 912 Y36 $\mathrm{SH}=$

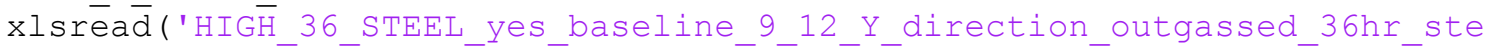

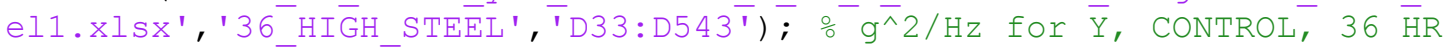
out

응 Data for 9-12 in the Z direction 36 HOUR OUTGASSED STEEL MASS

$\mathrm{Hz} 912 \mathrm{Z3} 6 \mathrm{SH}=$

xls $\bar{r}$ ead('

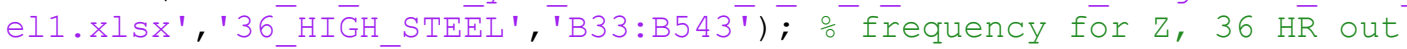

$\mathrm{CH} 1{ }_{-}{ }_{1} 12 \mathrm{Z3} 6 \_\mathrm{S} \overline{\mathrm{H}}=$

xls

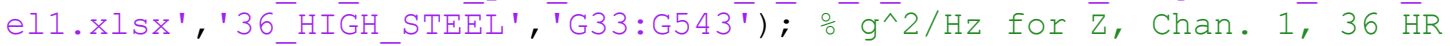

out

CH2_9_12Z36_SH=

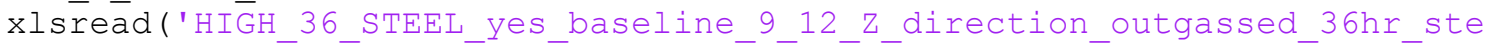

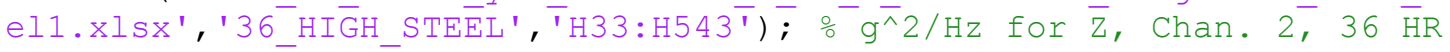
out

CH3_9_12Z36_SH=

xlsread('HIGH_36_STEEL_yes_baseline_9_12_z_direction_outgassed_36hr_ste

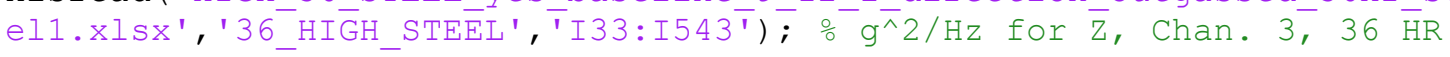
out 
$\mathrm{CH} 4$ 9_12Z36_SH=

xls $\bar{r}$-äd('HI ĞH 36 STEEL yes baseline 912 Z direction outgassed 36 hr ste

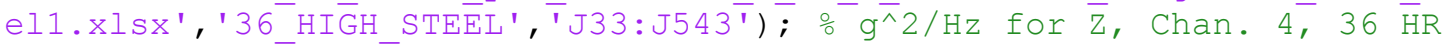

out

CONT_9_12Z36_SH=

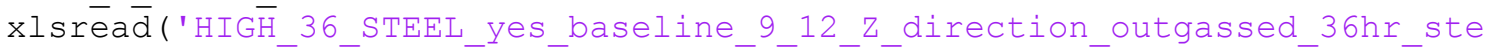

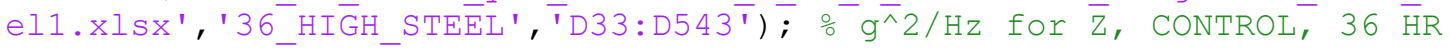
out

응 Data for 17-20 HIGH in the $\mathrm{X}$ direction 36 HOUR NOT OUTGASSED STEEL MASS

Hz17_20X36_SH=

xlsréad('HİGH 36 STEEL yes baseline 17 20 x direction not outgassed $36 \mathrm{~h}$

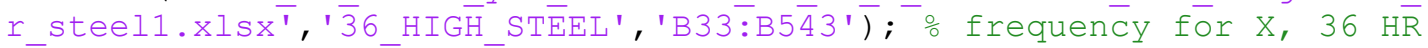

out

$\mathrm{CH} 11720 \times 36 \mathrm{SH}=$

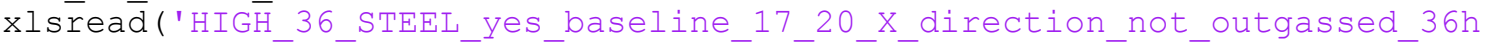

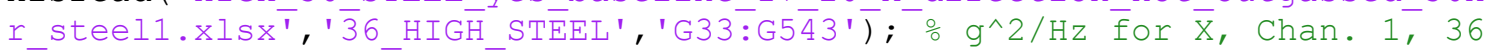
HR out

$\mathrm{CH} 21720 \times 36 \mathrm{SH}=$

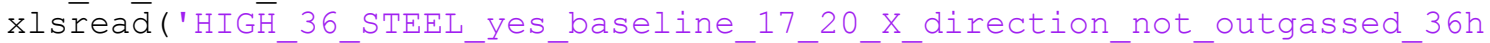

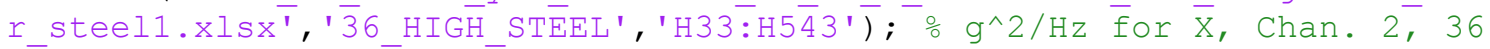
HR out

CH3_17_20X36_SH=

xls $\bar{r}$ ea $\bar{d}(' H I G \bar{H} 36$ STEEL yes baseline_17 20 x direction not outgassed $36 \mathrm{~h}$

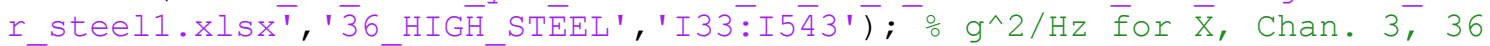
HR out

CH4 $1720 \times 36 \mathrm{SH}=$

xls $\bar{r} e a \bar{d}\left(' H I G \bar{H} \_36\right.$ STEEL_yes_baseline_17_20_x_direction_not_outgassed_36h

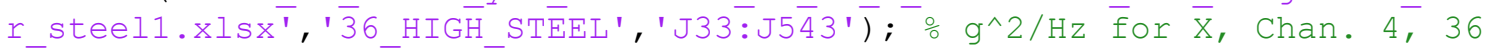
$\mathrm{H} \overline{\mathrm{R}}$ out

CONT_17_20X36_SH=

xlsrēad'('HIGH_36_STEEL_yes_baseline_17_20_x_direction_not_outgassed_36h

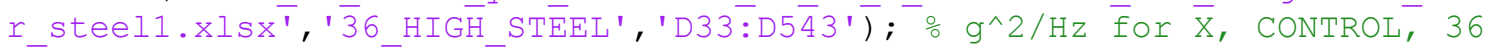
$\mathrm{H} \overline{\mathrm{R}}$ out

응 Data for 17-20 HIGH in the Y direction 36 HOUR NOT OUTGASSED STEEL MASS

$\mathrm{Hz} 1720 \mathrm{Y} 36 \mathrm{SH}=$

xlsrēad('HİGH_36_STEEL_yes_baseline_17_20_Y_direction_not_outgassed_36h

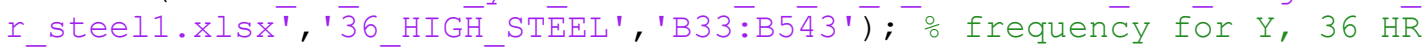
out

CH1_17_20Y36 SH=

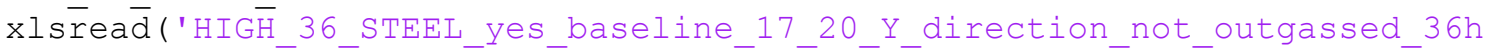

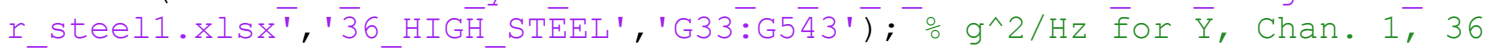
HR out

CH2_17_20Y36_SH=

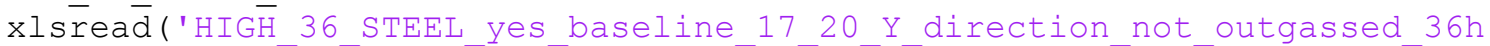

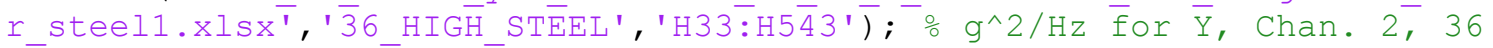
HR out

CH3 $1720 \mathrm{Y}_{3} 6 \mathrm{SH}=$

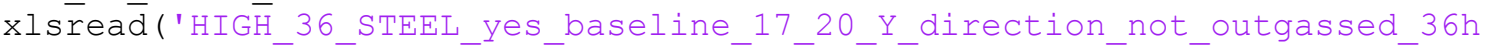

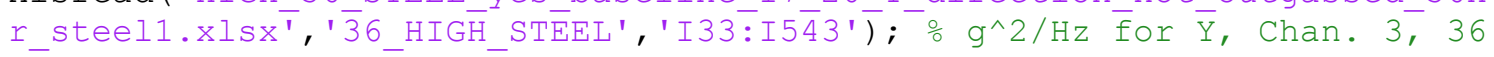
HR out

CH4_17_20Y36 SH=

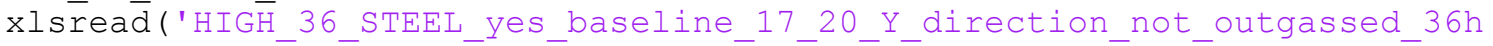


r_steel1.xlsx','36_HIGH_STEEL','J33:J543'); \% 9^2/Hz for y, Chan. 4, 36 HR out

CONT_17_20Y36_SH=

xlsrēed'('HIGH 36 STEEL yes baseline 17 20 Y direction not outgassed 36h

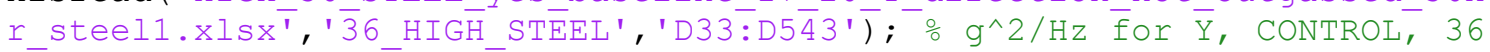
$\mathrm{H} \overline{\mathrm{R}}$ out

\% Data for 17-20 HIGH in the Z direction 36 HOUR NOT OUTGASSED STEEL MASS

$\mathrm{Hz} 1720 \mathrm{Z} 36 \mathrm{SH}=$

xlsrēad('HİGH_36_STEEL_YES_REAL_baseline_17_20_z_direction_not_outgasse

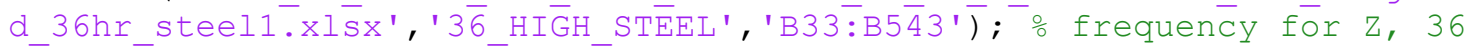

HE out

$\mathrm{CH} 1$ 17_20Z36_SH=

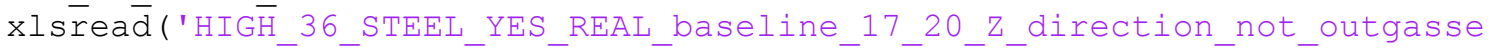

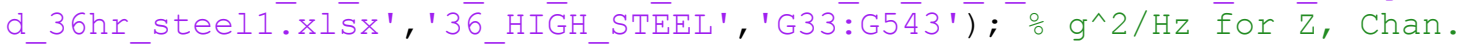

$1,36 \overline{\mathrm{HR}}$ out

CH2_17_20Z36_SH=

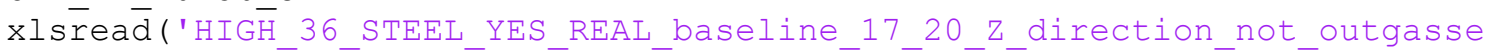

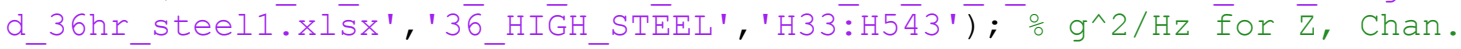

$2,36 \overline{H R}$ out

CH3 $1720 \mathrm{Z3} 6 \mathrm{SH}=$

xlsread'('HIGH_36_STEEL_YES_REAL_baseline_17_20_z_direction_not_outgasse

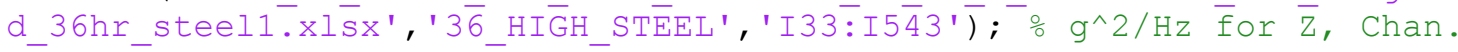

$3,36 \overline{\mathrm{HR}}$ out

CH4_17_20Z36 SH=

xls $\bar{r}$ ead ('HIGH_36_STEEL_YES_REAL_baseline_17_20_Z_direction_not_outgasse

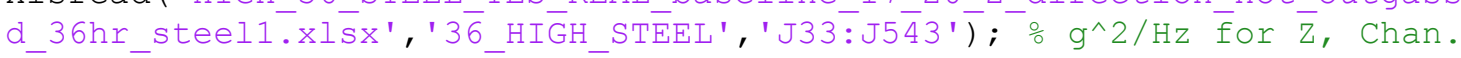

$4,36 \overline{\mathrm{HR}}$ out

CONT_17_20Z36_SH=

xlsrēed' 'HIGH_36_STEEL_YES_REAL_baseline_17_20_z_direction_not_outgasse

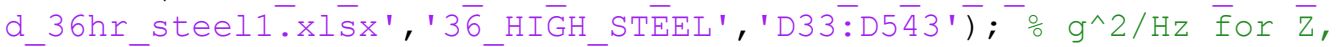

CONTROL', 36 HR out

응 PLOTS OF THE FREQUENCY RESPONSE FOR ALL GROUPS

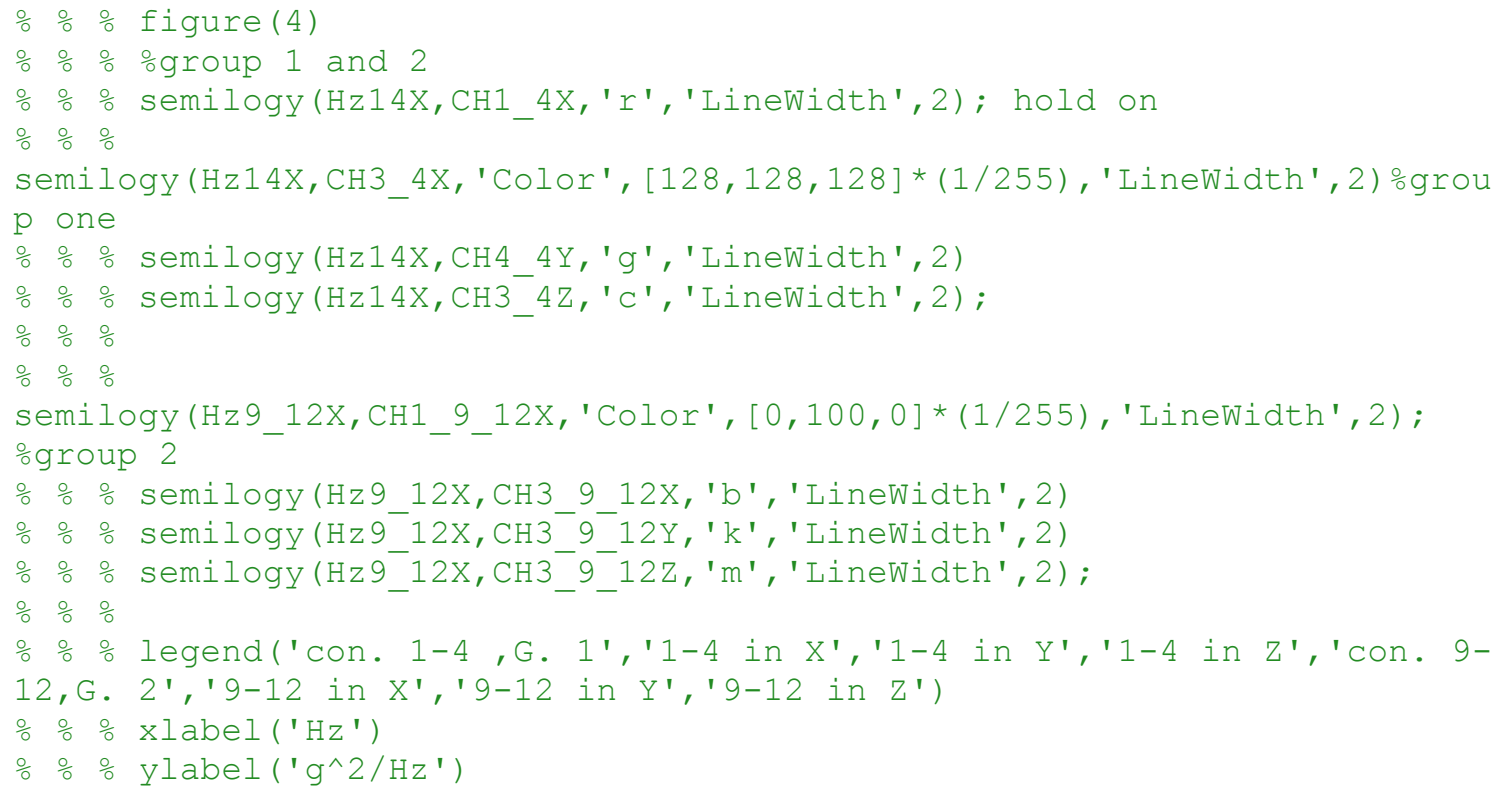




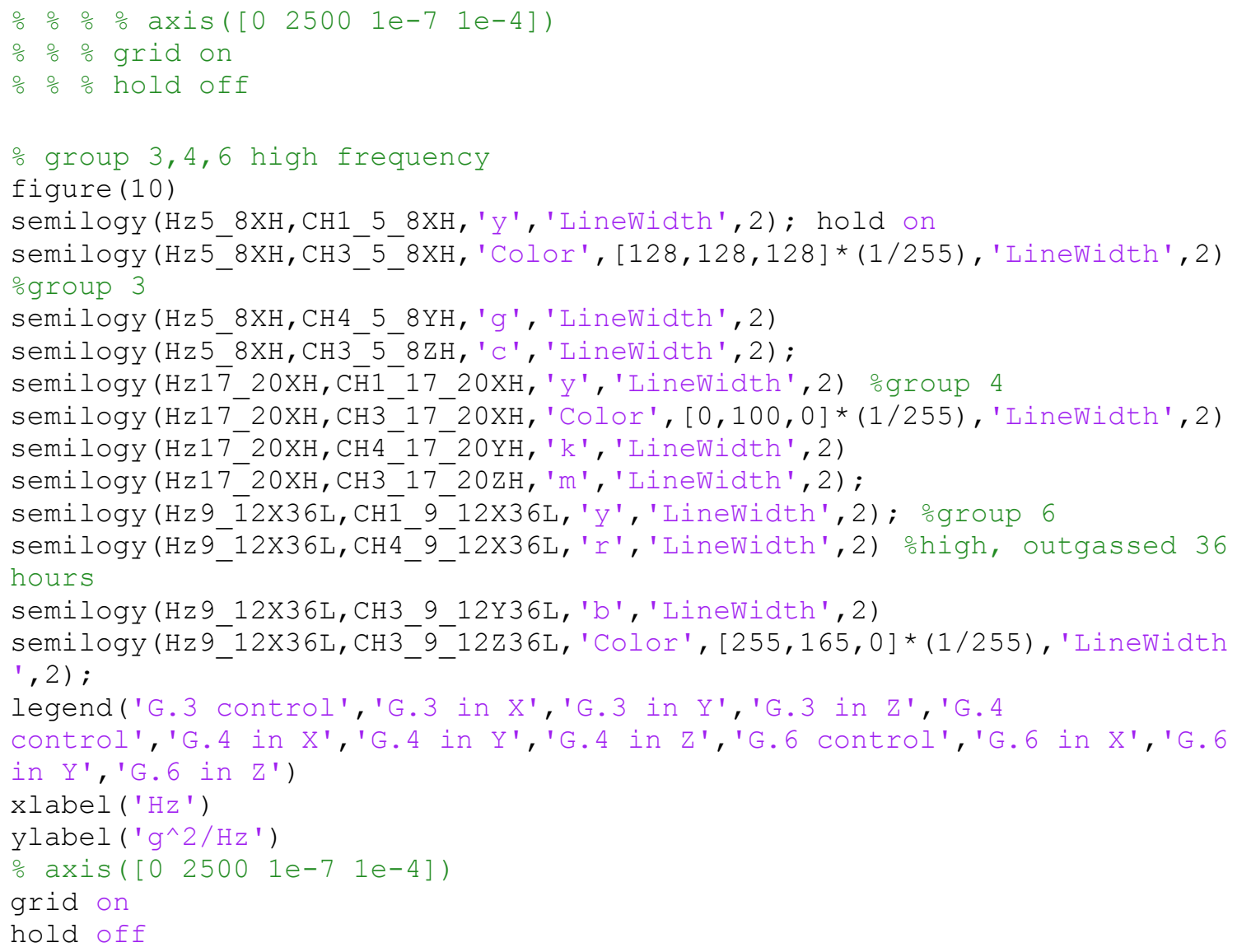

\subsubsection{GRMS Results and Comparisons}

Function

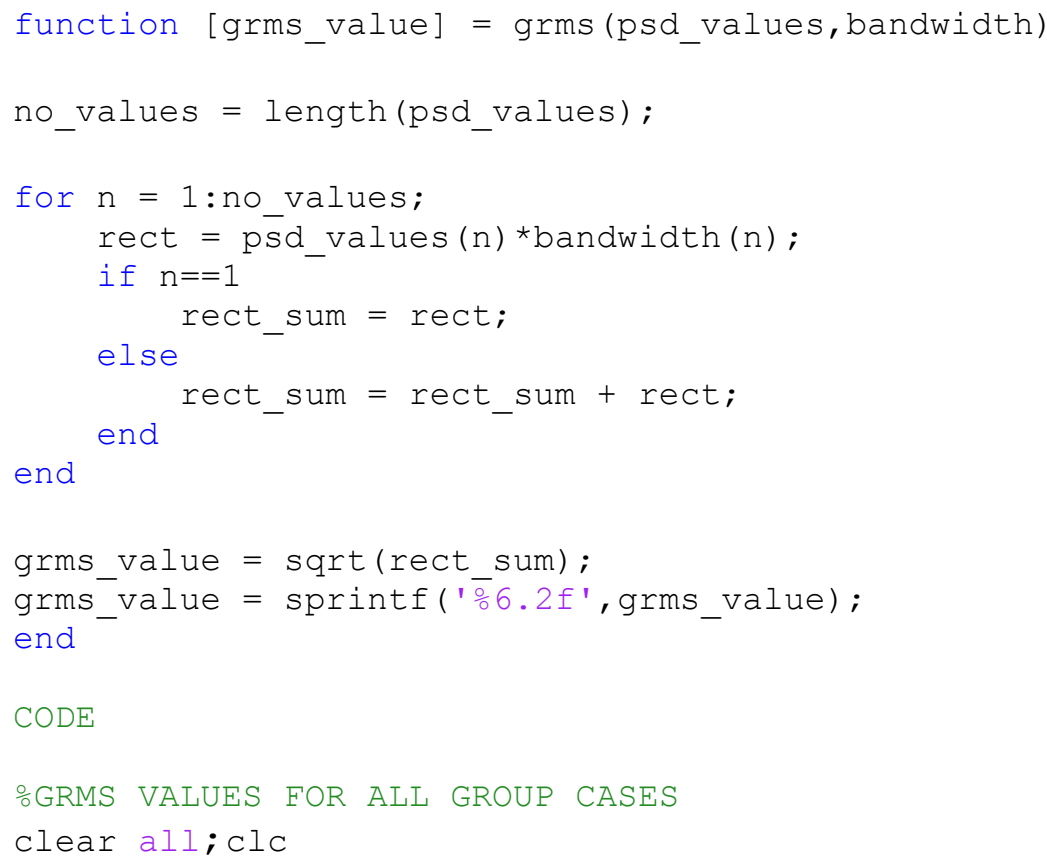




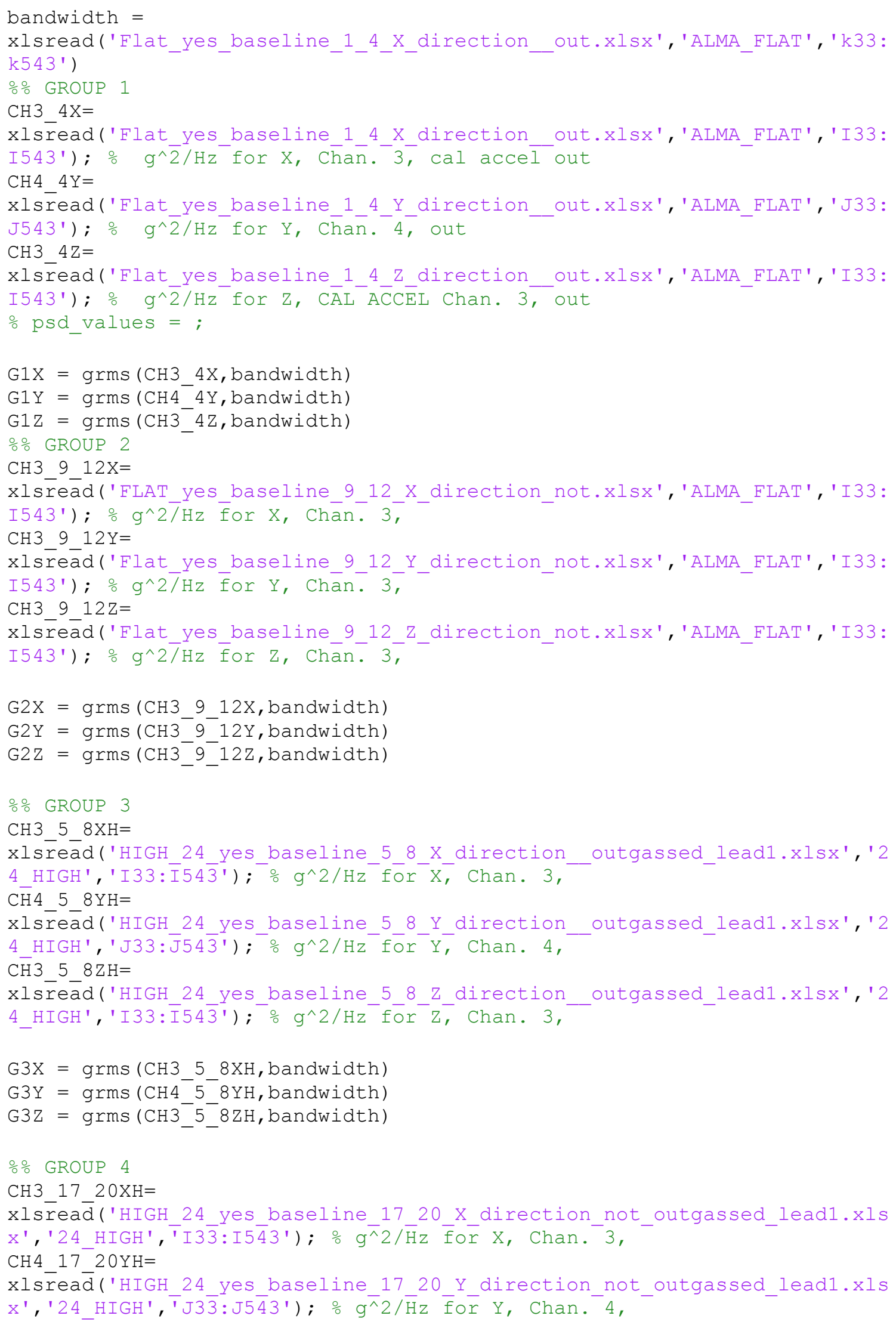


CH3 $1720 \mathrm{ZH}=$

xls $\bar{r}$ ead̄'('HIGH 24 yes baseline 1720 Z direction not outgassed lead1.xls

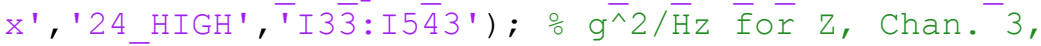

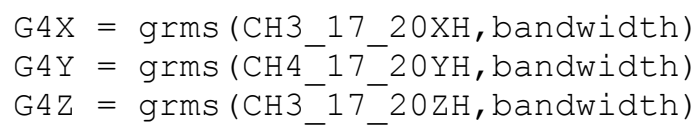

응 GROUP 5

CH4 9 - $12 \times 36=$

xls

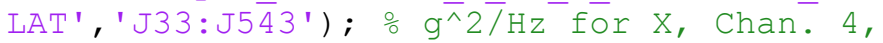

CH3_9_12Y36=

xlsreād('yes_baseline_9_12_y_direction_outgassed_36hr_lead1.xlsx', '36_F

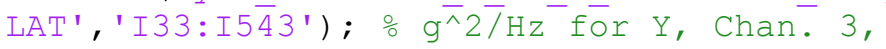

CH3_9_12Z36=

xls $\bar{r}$-äd('yes baseline 912 Z direction outgassed 36hr_leadl.xlsx', '36 F

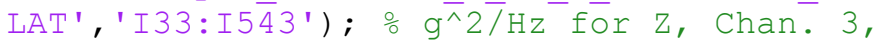

$\mathrm{G} 5 \mathrm{X}=\operatorname{grms}(\mathrm{CH} 4 \quad 9$ 12X36, bandwidth)

$\mathrm{G} 5 \mathrm{Y}=\operatorname{grms}\left(\mathrm{CH} 3{ }^{-}{ }^{-} 12 \mathrm{Y} 36, \mathrm{bandwidth}\right)$

$\mathrm{G} 5 \mathrm{Z}=\operatorname{grms}\left(\mathrm{CH}^{-}{ }^{-}{ }^{-}-12 \mathrm{z} 36, \mathrm{bandwidth}\right)$

응 GROUP 6

CH4_9_12X36L=

xls reād('HIGH 36 yes baseline 912 X direction outgassed 36hr lead1.xls

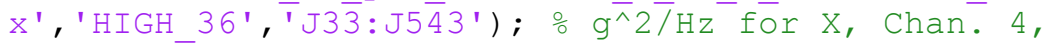

CH3_9_12 $\bar{Y} 36 \mathrm{~L}=$

xlsread('HIGH_36_yes_baseline_9_12_y_direction_outgassed_36hr_lead1.xls

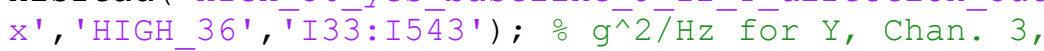

CH3_9_12 $\overline{\mathrm{Z}} 36 \mathrm{~L}=$

xls

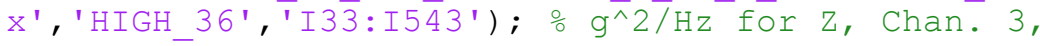

$\mathrm{G} 6 \mathrm{X}=\operatorname{grms}(\mathrm{CH} 4$ _ $12 \mathrm{X} 36 \mathrm{~L}, \mathrm{bandwidth})$

$\mathrm{G} 6 \mathrm{Y}=\operatorname{grms}\left(\mathrm{CH}^{-}{ }^{-}\right.$- $12 \mathrm{Y} 36 \mathrm{~L}$, bandwidth $)$

$\mathrm{G} 6 \mathrm{Z}=\operatorname{grms}\left(\mathrm{CH}^{-}{ }^{-}{ }^{-}{ }_{-} 12 \mathrm{z} 36 \mathrm{~L}, \mathrm{bandwidth}\right)$

응응

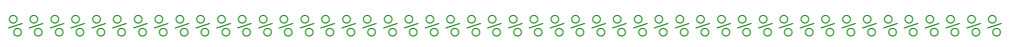

응 응 $\frac{0}{0} \%$

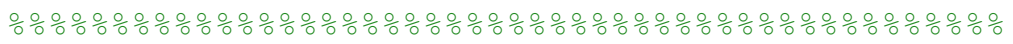

응 GROUP 7

CH4_9_12X36_STEEL=

xls $\bar{r}$-äd('yess_baseline_9_12_x_direction_outgassed_36hr_steel1.xlsx','36 FLAT STEEL', 'J33:J543') ; $\frac{\circ}{-} \mathrm{g}^{\wedge} 2 / \mathrm{Hz}$ for $\overline{\mathrm{X}}$, Chan. 4, CH3 $\overline{9} 12$ Y3 6 STEEL=

xls $\bar{r}$ ād('yess_baseline_9_12_Y_direction_outgassed_36hr_steel1.xlsx', '36

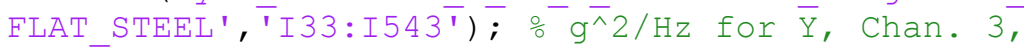
CH3_ $\overline{9}+12 \mathrm{Z3} 6$ STEEL $=$

xls $\bar{r}$ àd('yes_baseline_9_12_z_direction_outgassed_36hr_steel1.xlsx', '36

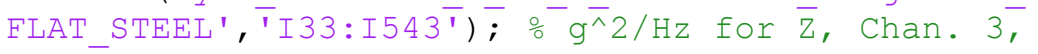

$\mathrm{G} 7 \mathrm{X}=\mathrm{grms}\left(\mathrm{CH} 4{ }_{-}{ }_{-} 12 \mathrm{X} 36\right.$ STEEL, bandwidth $)$ 
G7Y $=\operatorname{grms}($ CH3 912 Y36 STEEL, bandwidth $)$

$\mathrm{G} 7 \mathrm{Z}=\operatorname{grms}\left(\mathrm{CH}^{-}{ }^{-}{ }^{-} 12 \mathrm{Z} 36^{-} \mathrm{STEEL}, \mathrm{bandwidth}\right)$

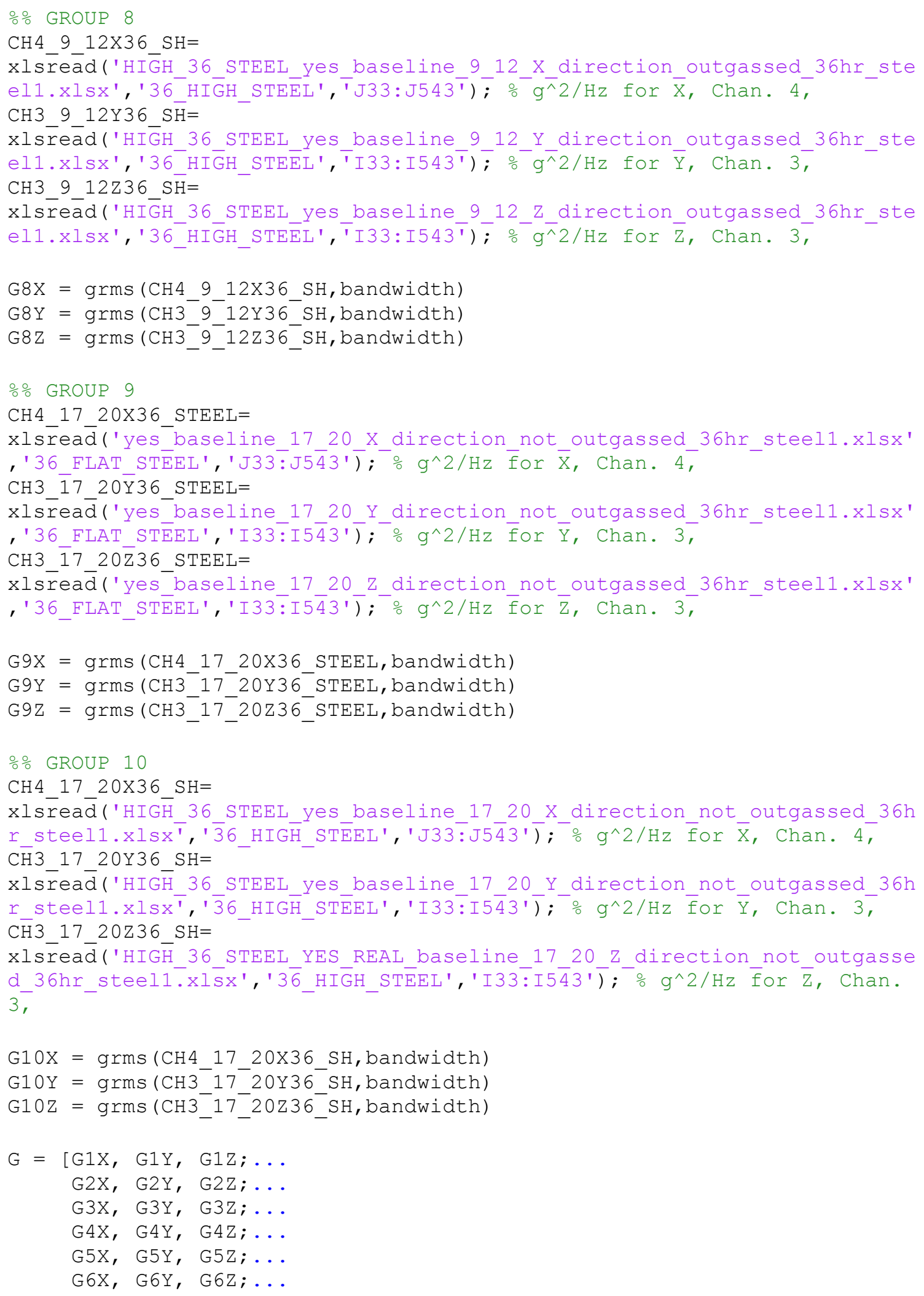




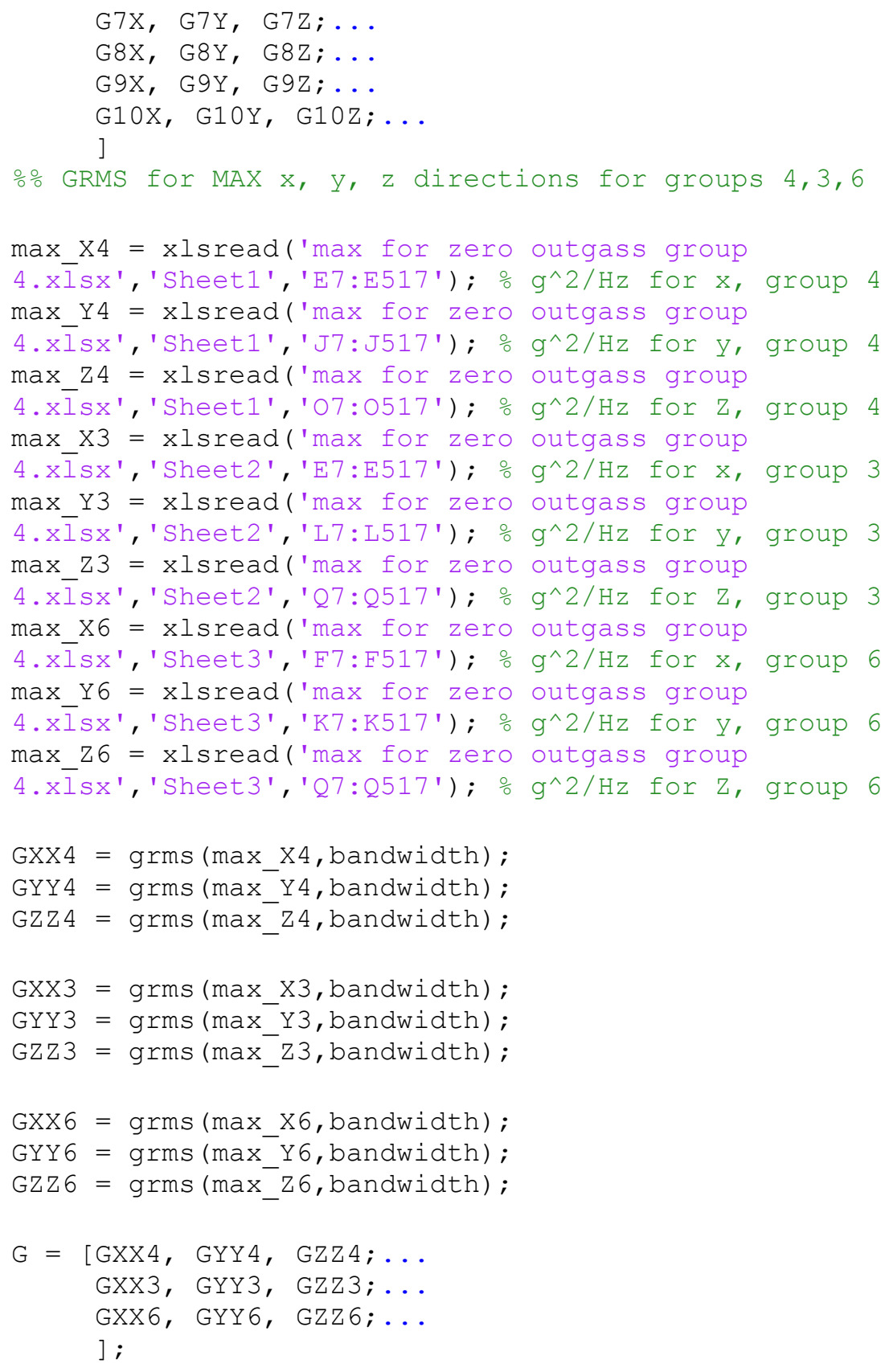

\subsubsection{Swelling Test}

\% Plot of \% mass increase over a period of time.

\% comparing 24 hour outgassed and cured, 36 hour outgassed and cured,

\% and not outgassed and not cured silicone material isolators.

clear all; clc;

\% PLOT OF MASS INCREASE \% OVER TIME

plot average masso increase over time with standard deviations midev = xlsread('MassInc.xlsx', 'Sheet2', 'M25:M36'); NEVIATION \% mass increase not $1=[0 ; \operatorname{midev}(1,1) ; \operatorname{midev}(4,1) ; \operatorname{midev}(7,1) ; \operatorname{midev}(10,1)]$; 


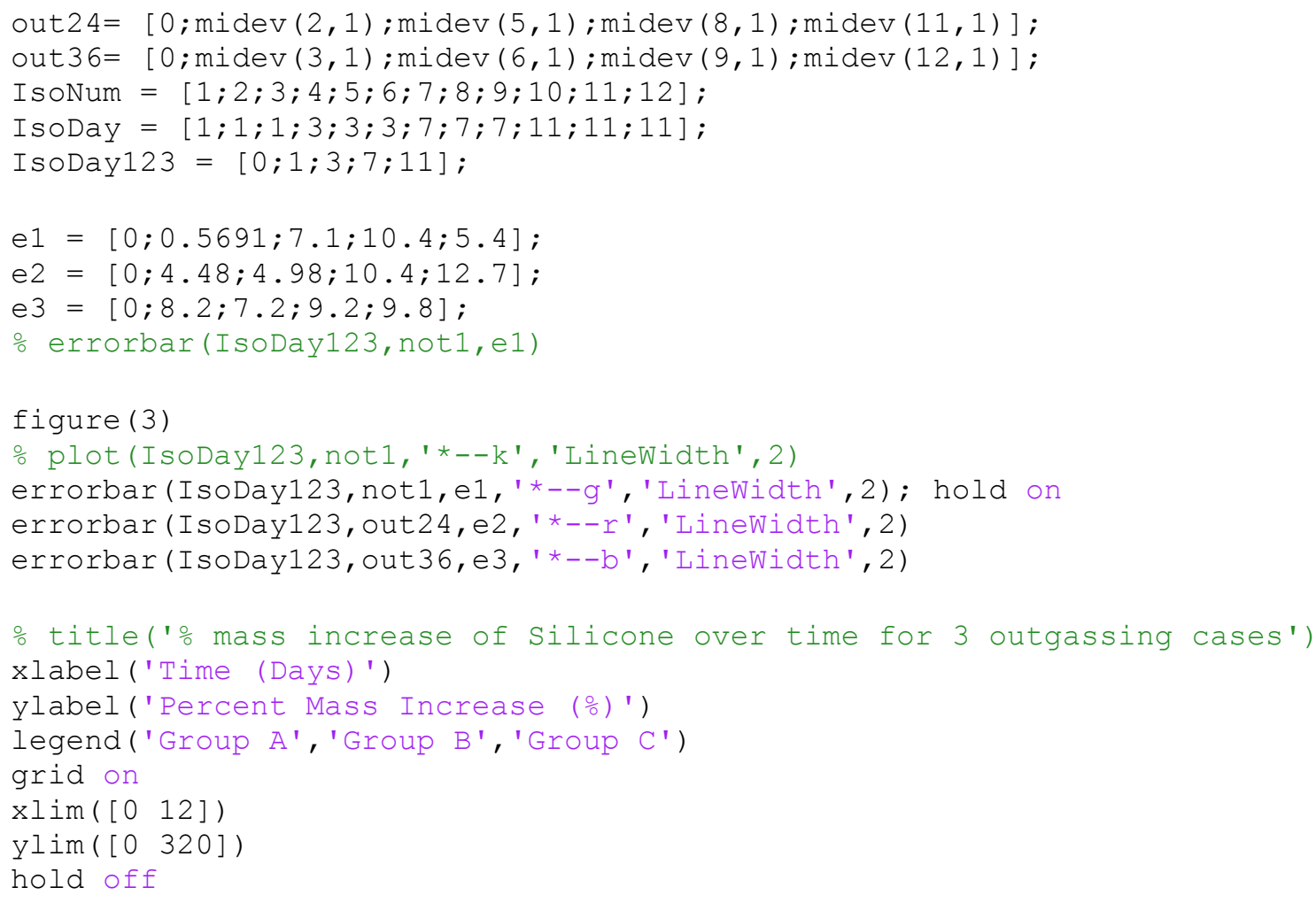


12.2 Appendix B: AutoCAD
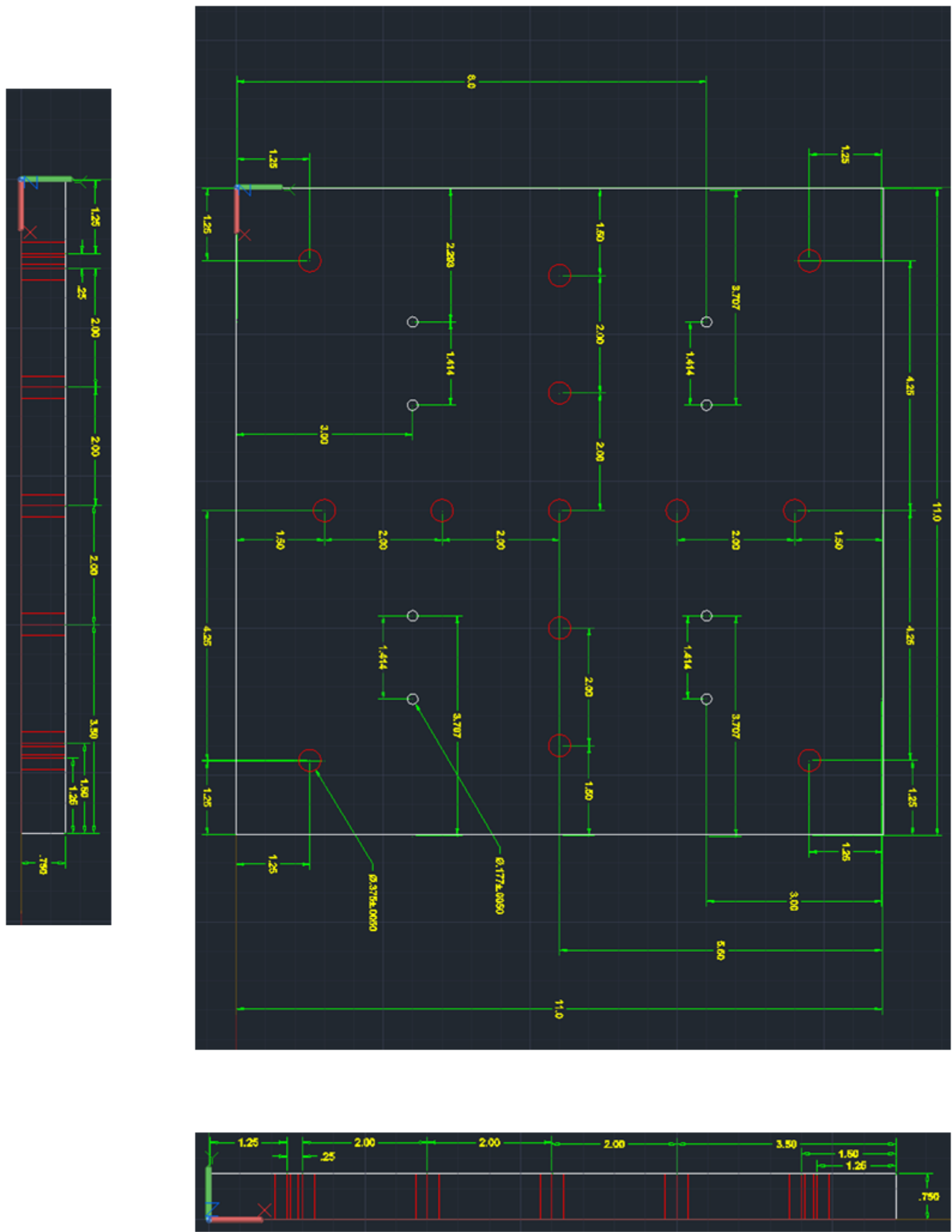


\subsection{Appendix C: Triaxial accelerometer information and calibration certification [14]}

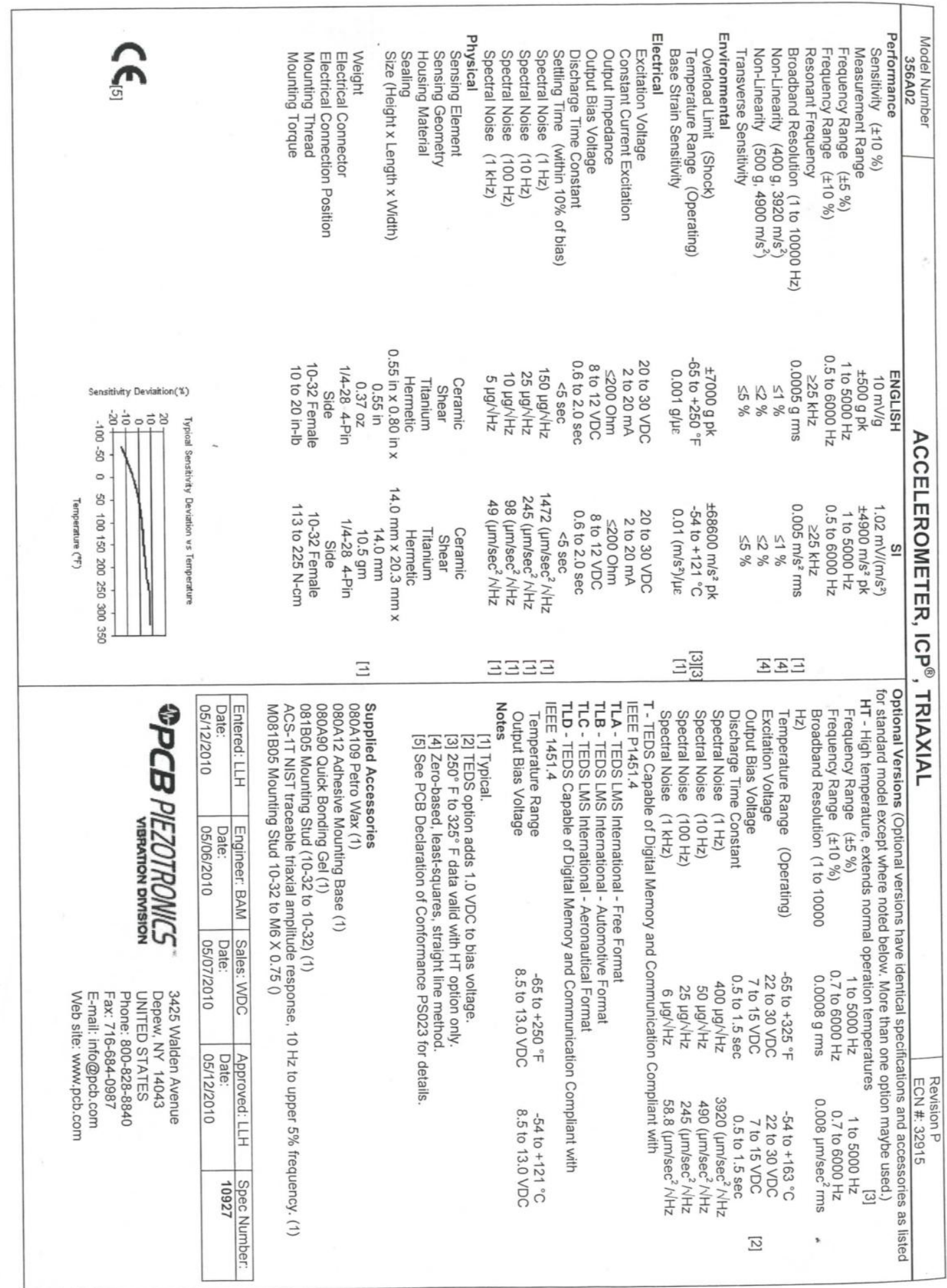




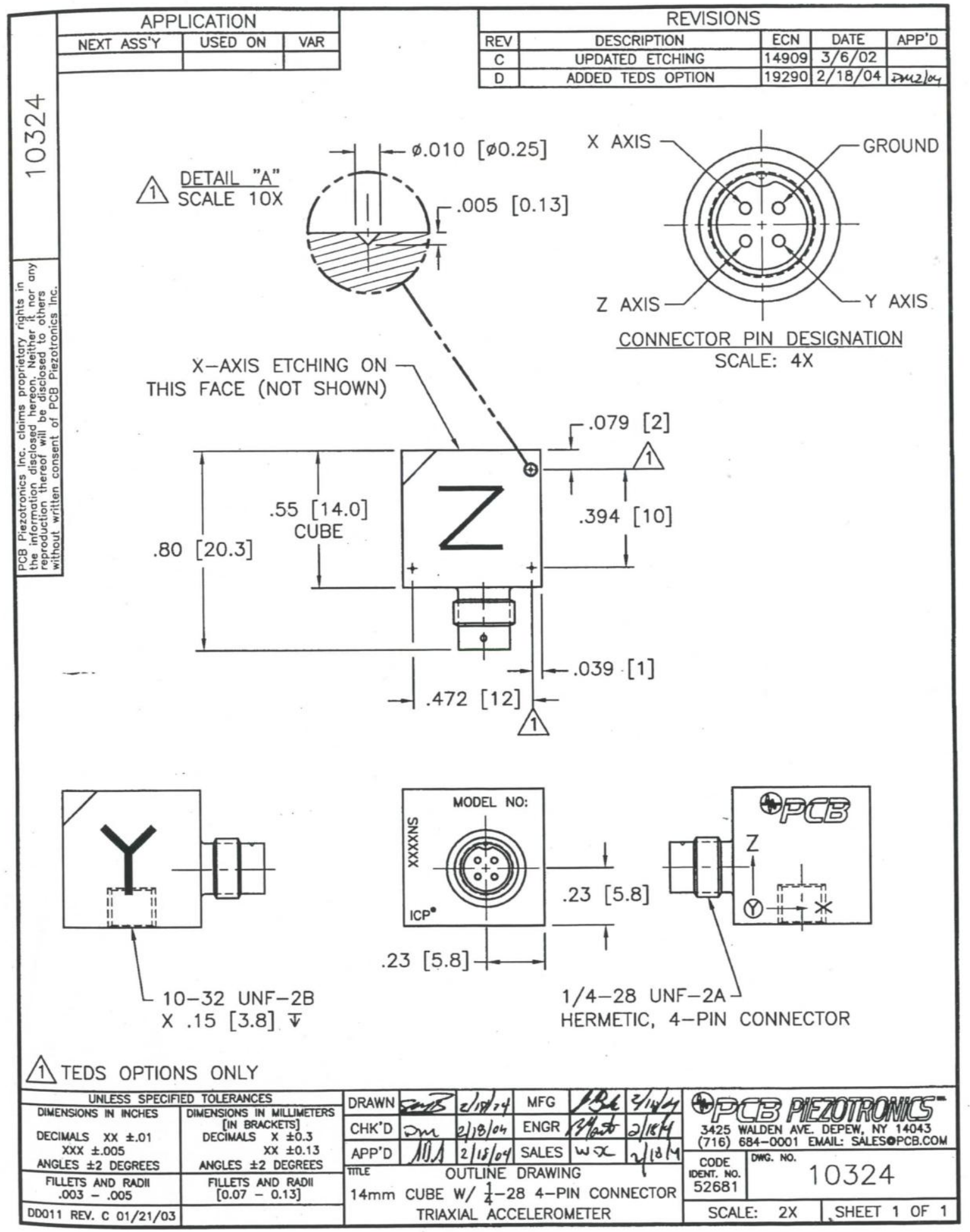




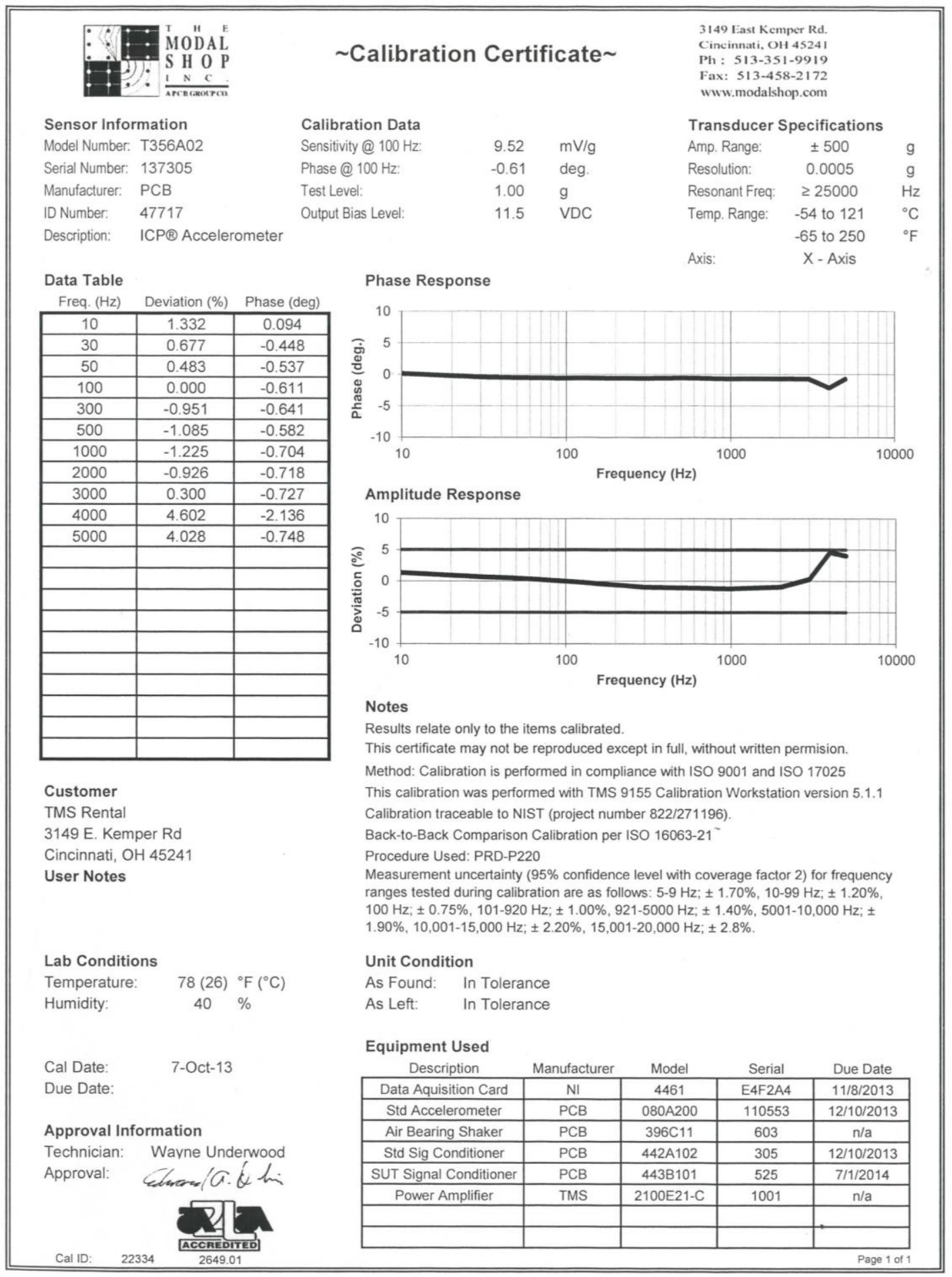




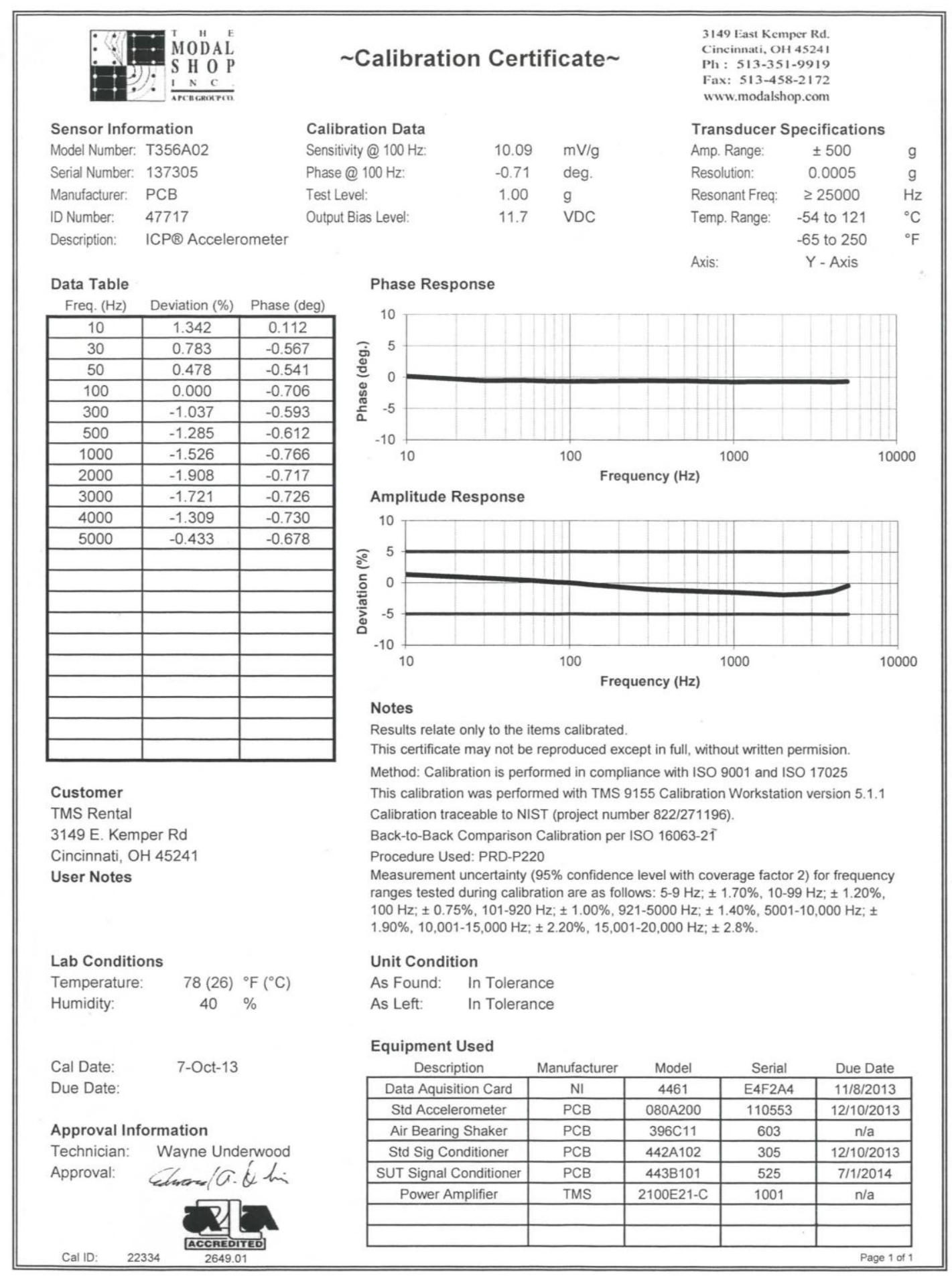




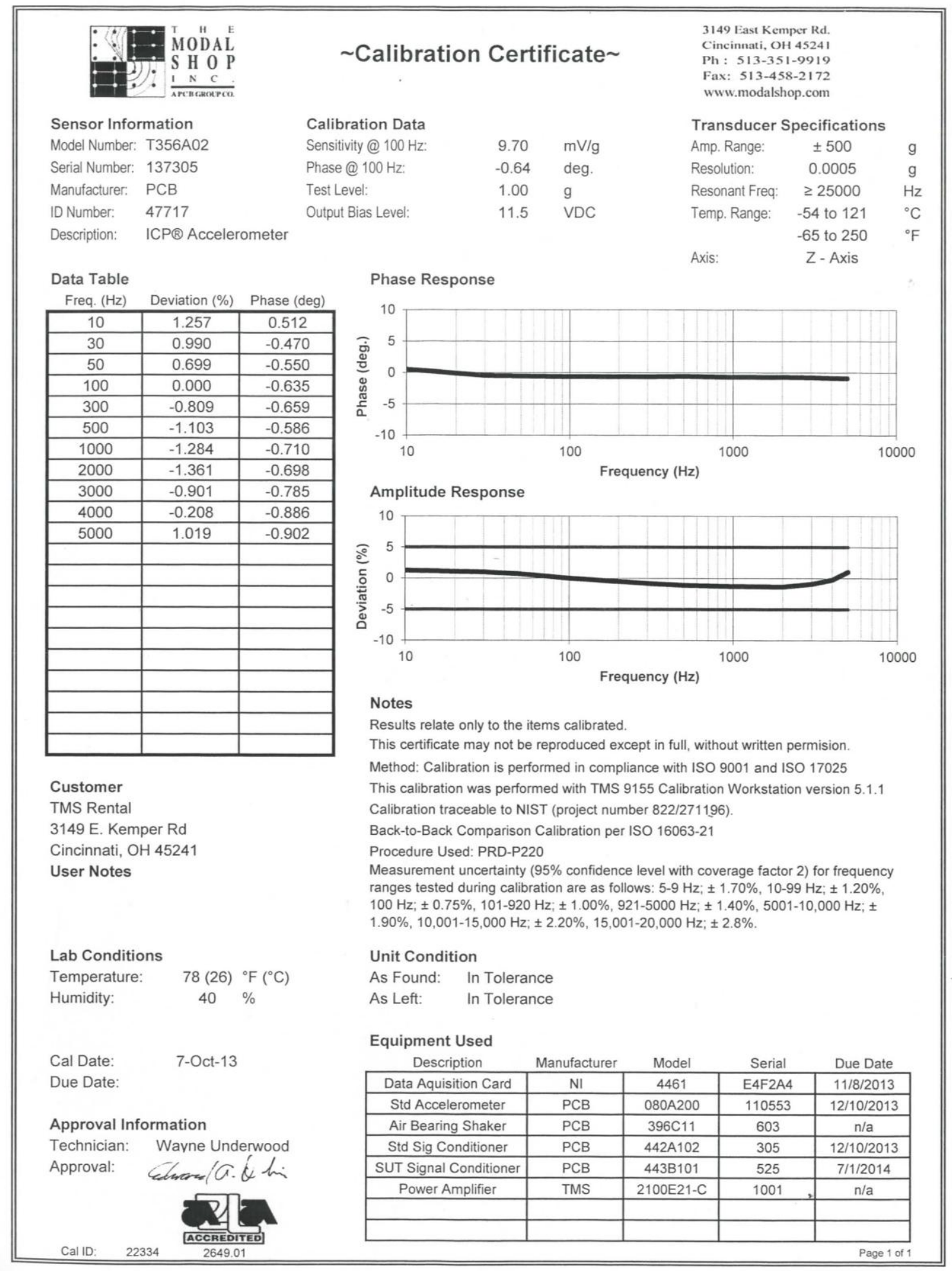




\subsection{Appendix D: Raw Data}

\subsubsection{Tensile tests}

\begin{tabular}{|l|c|c|c|c|}
\hline & Specimen label & $\begin{array}{c}\text { Maximum Load } \\
(\mathrm{lbf})\end{array}$ & $\begin{array}{c}\text { Maximum Tensile } \\
\text { stress } \\
(\mathrm{ksi})\end{array}$ & $\begin{array}{c}\text { Extension at } \\
\text { Maximum Load } \\
\text { (in) }\end{array}$ \\
\hline 1 & t2_tension & 6550.95516 & 59.44066 & 0.09028 \\
\hline 3 & t3_tensile & 6159.89424 & 55.89233 & 0.08864 \\
\hline 4 & t4_tensile & 6372.91661 & 57.28980 & 0.10460 \\
\hline 5 & t5_tensile & 6671.96745 & 61.10980 & 0.09793 \\
\hline 6 & t7_tensile & 6053.23030 & 56.50043 & 0.09175 \\
\hline Mean & & 6354.88067 & 57.12766 & 0.10229 \\
\hline $\begin{array}{l}\text { Standard } \\
\text { Deviation }\end{array}$ & & 6360.64074 & 57.89345 & 0.09591 \\
\hline $\begin{array}{l}\text { Coefficient } \\
\text { of Variation }\end{array}$ & & 231.57207 & 1.98164 & 0.00667 \\
\hline $\begin{array}{l}\text { Mean + 1 } \\
\text { SD }\end{array}$ & & 3.64070 & 3.42291 & 6.94975 \\
\hline Mean - 1 SD & & 6592.21281 & 59.87509 & 0.10258 \\
\hline & & 6129.06867 & 55.91180 & 0.08925 \\
\hline
\end{tabular}

\begin{tabular}{|l|c|c|c|c|}
\hline & \multicolumn{1}{|c|}{$\begin{array}{c}\text { Modulus } \\
\text { (Automatic } \\
\text { Young's }\end{array}$} & $\begin{array}{c}\text { Length } \\
\text { (in) }\end{array}$ & $\begin{array}{c}\text { Thickness } \\
\text { (in) }\end{array}$ & $\begin{array}{c}\text { Width } \\
\text { (in) }\end{array}$ \\
\hline 1 & 7005.82749 & 10.00000 & 0.10700 & 1.03000 \\
\hline 2 & 7070.23554 & 10.00000 & 0.10700 & 1.03000 \\
\hline 3 & 6870.86804 & 10.00000 & 0.10800 & 1.03000 \\
\hline 4 & 7141.68557 & 10.00000 & 0.10600 & 1.03000 \\
\hline 5 & 6915.21945 & 10.00000 & 0.10800 & 0.99200 \\
\hline 6 & 6892.40711 & 10.00000 & 0.10800 & 1.03000 \\
\hline Mean & 6982.70720 & 10.00000 & 0.10733 & 1.02367 \\
\hline $\begin{array}{l}\text { Standard } \\
\text { Deviation }\end{array}$ & 108.33889 & 0.00000 & 0.00082 & 0.01551 \\
\hline $\begin{array}{l}\text { Coefficient } \\
\text { of }\end{array}$ & 1.55153 & 0.00000 & 0.76071 & 1.51548 \\
\hline Variation & & & & 1.03918 \\
\hline $\begin{array}{l}\text { Mean + 1 } \\
\text { SD }\end{array}$ & 7091.04609 & 10.00000 & 0.10815 & 1.00815 \\
\hline $\begin{array}{l}\text { Mean - 1 } \\
\text { SD }\end{array}$ & 6874.36830 & 10.00000 & 0.10652 & \\
\hline
\end{tabular}




\begin{tabular}{|r|c|c|c|}
\hline & $\begin{array}{c}\text { Area } \\
\text { (in^2) }\end{array}$ & $\begin{array}{c}\text { Tensile stress at } \\
\text { Maximum Load } \\
(\mathrm{ksi})\end{array}$ & $\begin{array}{c}\text { Tensile strain at } \\
\text { Maximum Load } \\
\text { (in/in) }\end{array}$ \\
\hline 1 & 0.11021 & 59.44066 & 0.00902 \\
\hline 2 & 0.11021 & 55.89233 & 0.00886 \\
\hline 3 & 0.11124 & 57.28980 & 0.01046 \\
\hline 4 & 0.10918 & 61.10980 & 0.00979 \\
\hline 5 & 0.10714 & 56.50043 & 0.00918 \\
\hline 6 & 0.11124 & 57.12766 & 0.01022 \\
\hline Mean & 0.10987 & 57.89345 & 0.00959 \\
\hline $\begin{array}{l}\text { Standard } \\
\text { Deviation }\end{array}$ & 0.00155 & 1.98164 & 0.00067 \\
\hline $\begin{array}{l}\text { Coefficient } \\
\text { of Variation }\end{array}$ & 1.40626 & 3.42291 & 6.95719 \\
\hline $\begin{array}{l}\text { Mean + 1 } \\
\text { SD }\end{array}$ & 0.11141 & 59.87509 & 0.01026 \\
\hline Mean - 1 SD & 0.10832 & 55.91180 & 0.00892 \\
\hline
\end{tabular}

\subsection{Appendix E: Curing Cycle for Carbon Fiber Composite Plates}

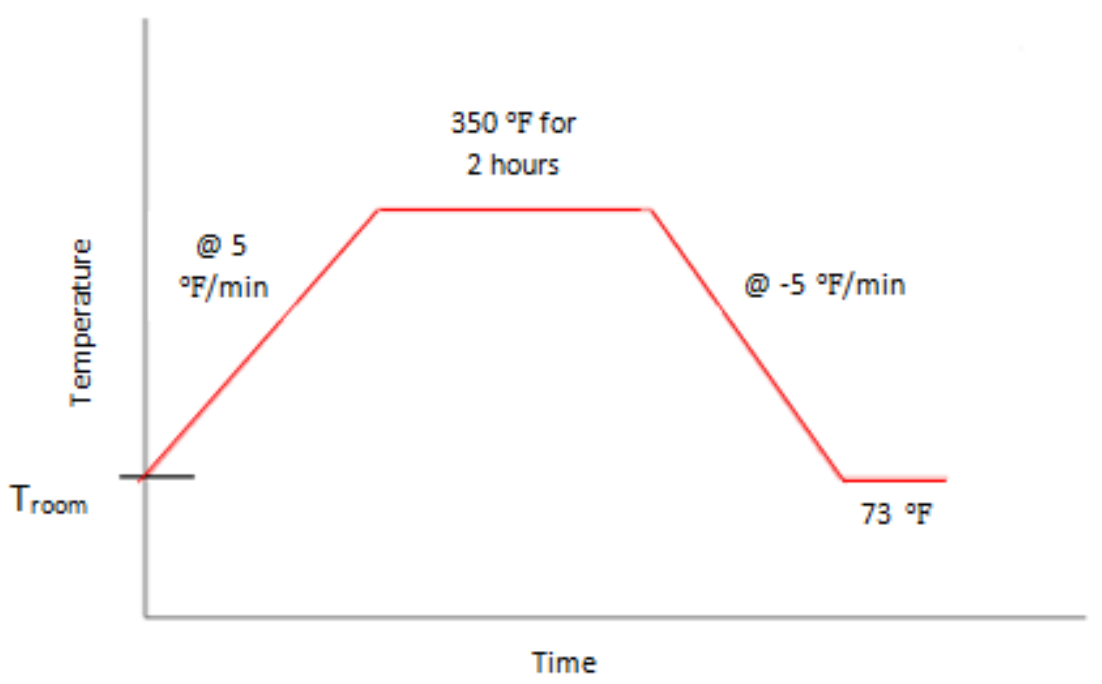

Image provided by Hexcel for the T3001K5H/M74 bidirectional woven carbon fiber. 